Marietta Jass

\title{
Erfolgskontrolle des Abwasserabgabengesetzes
}

Ein Konzept zur Erfassung der Gesetzeswirkungen verbunden mit einer empirischen Untersuchung in der Papierindustrie 
Marietta Jass

\section{Erfolgskontrolle des Abwasserabgabengesetzes}

Das Abwasserabgabengesetz regelt die erste Emissionsabgabe mit Anreizfunktion in der Bundesrepublik Deutschland. Trotz der intensiven umweltpolitischen Diskussion über Emissionsabgaben wurden bislang nur Untersuchungen vorgestellt, die die Wirkungsweise der Abwasserabgabe vor Beginn der Abgabepflicht erfassen. Es wird deshalb ein Konzept der Erfolgskontrolle entwickelt, mit dem die Zielerreichungen festgestellt, exogene Einflußgrößen sowie der Gesetzesvollzug berücksichtigt und Ursache-WirkungsZusammenhänge durchleuchtet werden. Eine empirische Untersuchung ermittelt die Gesetzeswirkungen in der Papierindustrie.

Marietta Jass, geboren 1960 in Göttingen, studierte von 1979 bis 1984 Betriebswirtschaftslehre an der Georg-August-Universität in Göttingen; Diplomexamen 1984. Von 1984 bis 1985 Ergänzungsstudium an der Technischen Hochschule Darmstadt, Schwerpunkt Papierfabrikation. Anschließend Promotionsstudium an der Technischen Hochschule Darmstadt in Volkswirtschaftslehre, Fachgebiet Finanzwissenschaft; 1989 Promotion. 
Erfolgskontrolle des Abwasserabgabengesetzes Ein Konzept zur Erfassung der Gesetzeswirkungen verbunden mit einer empirischen Untersuchung in der Papierindustrie 


\section{Sozialökonomische Schriften}

Herausgegeben von Bert Rürup

Band1

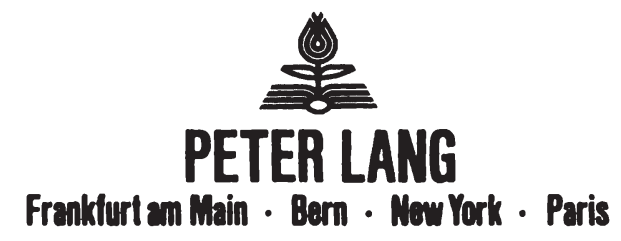

Marietta Jass-Teichmann - 978-3-631-75034-6 


\section{Marietta Jass}

\section{Erfolgskontrolle des Abwasserabgabengesetzes}

Ein Konzept zur Erfassung der Gesetzeswirkungen verbunden mit einer empirischen Untersuchung in der Papierindustrie

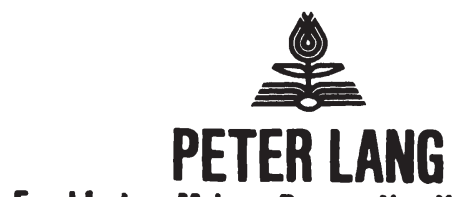

Franklurt an Main - Bern - Now York - Paris 
CIP-Titelaufnahme der Deutschen Bibliothek

Jass, Marietta:

Erfolgskontrolle des Abwasserabgabengesetzes : ein Konzept zur Erfassung der Gesetzeswirkungen verbunden mit einer empirischen Untersuchung in der Papierindustrie / Marietta Jass.

- Frankfurt am Main ; Bern ; New York ; Paris : Lang, 1990

(Sozialōkonomische Schriften ; Bd. 1)

Zugl.: Darmstadt, Techn. Hochschule., Diss., 1989

ISBN 3-631-42561-9

NE: GT

Open Access: The online version of this publication is published on www.peterlang.com and www.econstor.eu under the international Creative Commons License CC-BY 4.0. Learn more on how you can use and share this work: http://creativecommons. org/licenses/by/4.0.

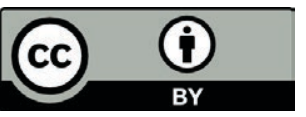

This book is available Open Access thanks to the kind support of ZBW - Leibniz-Informationszentrum Wirtschaft.

\author{
D 17 \\ ISSN 0172-1747 \\ ISBN 3-631-42561-9 \\ ISBN 978-3-631-75385-9 (eBook) \\ (c) Verlag Peter Lang GmbH, Frankfurt am Main 1990 \\ Alle Rechte vorbehalten.
}

Das Werk einschließlich aller seiner Teile ist urheberrechtlich geschützt. Jede Verwertung außerhalb der engen Grenzen des Urheberrechtsgesetzes ist ohne Zustimmung des Verlages unzulăssig und strafbar. Das gilt insbesondere fur Vervielfältigungen, Übersetzungen, Mikroverfilmungen und die Einspeicherung und Verarbeitung in elektronischen Systemen. 
Die aktuelle Diskussion dokumentiert die Bestrebungen, Steuern und Abgaben als Instrumente der Umweltpolitik einzusetzen. Denn über eine nichtfiskalische Instrumentalisierung von Zwangsabgaben soll eine Internalisierung von bislang "externen Kosten" bewirkt und auch gegebenenfalls eine vermeidungsorientierte Verhaltensänderung der Emittenten von Umweltbelastungen erreicht werden; derartige Abgaben entsprechen mithin dem Verursacherprinzip als einem der wichtigsten Leitprinzipien der deutschen Umweltpolitik.

Gerade vor dem Hintergrund dieser dringend $z u$ rationalisierenden Auseinandersetzung über Möglichkeiten und Probleme von Okosteuern und Okoabgaben ist es $z u$ begrüßen, daß von Frau Jass der "Prototyp" derartiger Emissionsabgaben, die bereits 1976 erlassene Abwasserabgabe, einer fundierten Evaluierung unterzogen wird. Während die "Signalwirkungen" dieses Gesetzes bereits Ende der 70er Jahre untersucht worden sind, fehlt bislang eine Erfolgskontrolle in Bezug auf die "realen" Effekte; dieses Wissensdefizit hat Frau Jass deutlich verringert.

In bemerkenswerter Manier werden von ihr die folgenden - nur auf den ersten Blick "simplen" - Fragen beantwortet:

1. Konnten die mit dem Abwasserabgabengesetz angestrebten Ziele erreicht werden?

2. Inwieweit sind die festgestellten Zielerreichungsgrade auf Wirkungen des Abwasserabgabengesetzes und nicht auf andere Wirkungsursachen, insbesondere auf die Auflagen, die nach wie vor das Wasserrecht dominieren, zurückzuführen?

3. Verhalten sich die Adressaten der Emissionsabgaben gemäB den Annahmen der umweltökonomischen Theorie bzw. erfüllen die Abgaben die ihr zugeschriebene steuerungsfunktion? 
Mittels eines empirisch fundierten before-and-after-Vergleichs 1974 bis 1985 belegt die Verfasserin mit einer imponierenden Fülle von

- ökonomischen

- ökologischen und

- technischen

Einzelergebnissen, daß "die Abwasserabgabe als anreizpolitisches Instrument ... die Erfüllung der Auflagen beschleunigt und ihre Einhaltung nachhaltig unterstützt hat, im Bereich der Restverschmutzung als Ursache für Emissionsverminderungen jedoch in den Hintergrund tritt."

Es ist dieser Arbeit $z u$ wünschen und für die Verfasserin $z u$ hoffen, daß diese gleichermaßen ökonomisch wie ingenieurwissenschaftlich kompetente Analyse nicht nur von einer Wissenschaftlerin für Wissenschaftler bzw. deren Bücherschränke geschrieben wurde, sondern die ihr gebührende Berücksichtigung in der umwelt- und finanzpolitischen Diskussion findet.

Prof. Dr. Bert Rürup August 1989 
INHALTSVERZEICHNIS

Seite

Verzeichnis der Tabellen .................... VI

Verzeichnis der Abbildungen .................. VIII

Verzeichnis der Abkürzungen $\ldots \ldots \ldots \ldots \ldots \ldots \ldots \ldots \ldots \ldots$ x

\section{Einleitung}

1. Problemstellung ........................ 1

2. Gang der Untersuchung $\ldots \ldots \ldots \ldots \ldots \ldots \ldots \ldots \ldots \ldots \ldots$

Teil A: DAS ABWASSERABGABENGESETZ ALS INSTRUMENT ZUR ERHALTUNG UND VERBESSERUNG DER WASSERQUALITAT IN DER BUNDESREPUBLIK DEUTSCHLAND

1. Umweltökonomischer Hintergrund der Abwasserabgabe

1.1 Das Verursacherprinzip als umweltökonomische

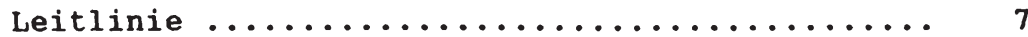

1.2 Probleme einer Anwendung des Verursacherprinzips 11

1.3 Auflagen versus Abgaben - der "klassische" Effizienzvergleich oder: Die Abwasserabgabe als ökonomischer Hebel der Gewässergütepolitik ..... 22

1.4 Weitere Ansätze zur Beurteilung von Auflagen und Abgaben ........................ 34

2. Rechtliche Grundlagen des Abwasserabgabensystems

2.1 Das Wasserrecht in der Bundesrepublik Deutschland 38

2.2 Das Wasserhaushaltsgesetz unter besonderer Berücksichtigung des $\$ 7$ a wHG ............. 40

2.3 struktur des Abwasserabgabengesetzes ......... 44

2.4 Die technische Ausgestaltung des Abwasserabgabensystems

2.4.1 Die instrumentelle Verknüpfung von Wasserhaushalts- und Abwasserabgabengesetz .... 48

2.4.2 Die Ausführungsgesetze der Länder als Vollzugsinstrumente .............. 49 
3. Finanzwirtschaftliche Würdigung der Abwasserabgabe

3.1 Beschreibung des Abgabetatbestandes anhand

"steuer"systematischer Merkmale ............

3.2 Die Abwasserabgabe im System der öffentlichen Abgaben ................................ 55

4. Intendierte Wirkungsweise des Abwasserabgabengesetzes

5. Das Abwasserabgabengesetz im Lichte von Effizienz-

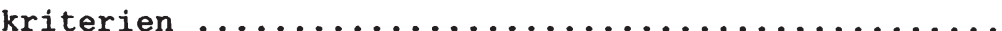

Teil B: ANALYTISCHE GRUNDLAGEN EINER ERFOLGSKONTROLLE DES ABWASSERABGABENGESETZES

1. Theoretische Grundlagen der Evaluation

1.1 Entwicklungslinien der Evaluation .......... 75

1.2 Die zentralen Aufgabenstellungen ............ 78

1.3 Inhaltliche Bedeutung der Erfolgskontrolle .... 80

1.4 Beschreibung der einzelnen Kontrollschritte .... 87

1.5 Methodische Durchführung ............... 90

2. Das Abwasserabgabengesetz als Evaluationsgegenstand

2.1 Die aktuelle Diskussion ........................... 94

2.2 Das Spektrum möglicher Evaluationsansätze zum Abwasserabgabengesetz ..................... 98

2.3 Eingrenzung des Untersuchungsbereichs ........ 105

2.4 Aufbau der durchzuführenden Erfolgskontrolle ... 110 
TEIL C: DARSTELLUNG EINER ERFOLGSKONTROLLE DES ABWASSERABGABENGESETZES

1. Identifizierung des relevanten Wirkungsfeldes

1.1 Bestimmung der abhängigen und unabhängigen Variablen

1.1.1 Ziel- und Programmstruktur als Angelpunkt der Erfolgskontrolle ............. 111

1.1 .2 Exogene Einflußgrößen ............. 120

1.2 Entwicklung einer Zielerreichungskontrolle

1.2.1 Stellenwert und Aufbau der Zielerreichungskontrolle ................. 124

1.2.2 Voraussetzungen der Indikatorenbildung und Zielmessung

1.2.2.1 Operationalität der Zielinhalte 125 1.2.2.2 Diskussion der Zielbeziehungen . 130

1.2.3 Indikatorenauswahl .............. 133

1.2.4 Messung der Zielerreichungen ........ 143

1.3 Entwicklung einer Vollzugskontrolle

1.3.1 Inhaltliche Abgrenzung ............ 145

1.3.2 Kategorialer Bezugsrahmen .......... 146

1.3.3 Für die Wirkungskontrolle relevante Implementationsergebnisse .......... 148

1.3.4 Entwurf einer Bestandsaufnahme der wasser- und abgaberechtlichen Rahmenbedingungen ................... 150

1.4. Entwicklung einer Bedingungskontrolle

1.4.1 Inhaltliche Abgrenzung ........... 152

1.4.2 Bestimmung der zu kontrollierenden exogenen Einflußgrößen ............ 153 
2. Lösung des Kausalitätsproblems: Entwicklung einer Wirkungskontrolle

2.1 Vorgehensweise ....................... 155

2.2 Konzeptualisierung der zu untersuchenden Wirkungszusammenhänge

2.2.1 Hypothesen über die "Gesamtwirkungen" des Abwasserabgabengesetzes ............. 156

2.2.2 Hypothesen über die Wirkungen einzelner

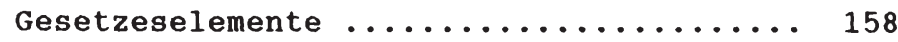

2.2.3 Operationalisierung der Hypothesen ..... 162

2.2.4 Methodenwah1 .................. 169

TEIL D: SEKTORALE ANALYSE DER AUSWIRKUNGEN DES ABWASSERABGABENGESETZES

1. Hinweise zum Verfahren

1.1 Anlage der Untersuchung ................ 171

1.2 Anzahl und struktur der untersuchten Papier-

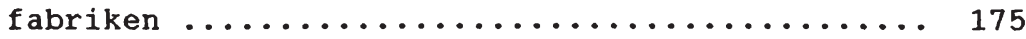

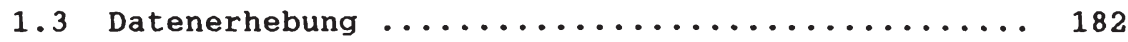

1.4 Auswertung der Daten $\ldots \ldots \ldots \ldots \ldots \ldots \ldots \ldots \ldots \ldots$

2. Bestandsaufnahme der wasser- und abgaberechtlichen Situation der untersuchten Papierfabriken

2.1 Genehmigungspraxis, weitere Bestimmungsgrößen der Abgabenhöhe und behördliche oberwachung bei der Versuchsgruppe ..................... 185

2.2 Genehmigungspraxis und behördliche Uberwachung bei der Kontrollgruppe .................. 193

2.3 Unterschiede in den Rahmenbedingungen und Konsequenzen für die Erfolgskontrolle des Abwasserabgabengesetzes ..................... 196 
3. Okologische Wirkungen

3.1 Verminderung der Emissionen ............... 199

3.2 Verwirklichung der ökologischen Teilziele

3.2.1 Bau von Abwasserreinigungsanlagen ..... 207

3.2.2 Verbesserung der Abwasserreinigungstechnik 212

3.2.3 Einsatz abwasserarmer/-loser Produktions-

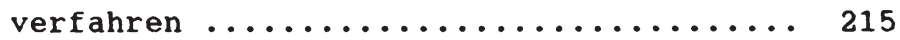

3.2.4 Sparsamere Verwendung abwasserintensiver

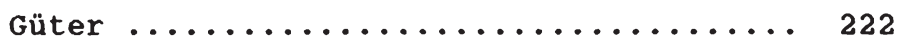

3.2.5 Beschleunigte Anwendung der allgemein anerkannten Regeln der Technik ........ 224

3.2.6 Einhaltung der Auflagen ............ 227

3.3 Die Emissionsentwicklung während der Abgabejahre 229

3.4 Exkurs: Anfall und Verbleib der Rückstände aus der Abwasserbehandlung ................ 236

4. Okonomische Wirkungen

4.1 Allokative Effekte

4.1.1 Gültigkeit der abgabentheoretischen Wirkungshypothese ................ 239

4.1.2 statische Allokationswirkungen ........ 248

4.2 Distributive Effekte

4.2.1 Gerechtere Verteilung der Kostenlast .... 251

4.2.2 Exkurs: Internationale Wettbewerbs-

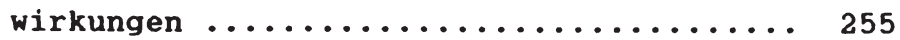

4.2.3 Vermeidung sprunghafter Nachfrage nach Abwasserreinigungsanlagen ......... 256

Ergebnisse, Konsequenzen und Ausblick ............ 260

Literaturverzeichnis ..................... 271

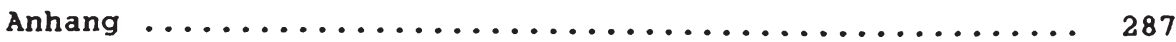


VERZEICHNIS DER TABELLEN

Seite

Tab. 1: Merkmale "steuer"systematischer Art zur Beschreibung von finanzwirtschaftichen Regelungen mit umweltschützenden Zielen .........

Tab. 2: Synopse sozialwissenschaftlicher Methoden .....

Tab. 3: Mögliche Evaluationsansätze zum Abwasser-

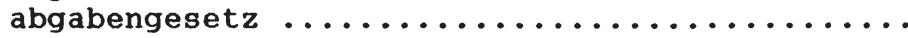

Tab. 4: Exogene Einflußgrößen auf das Emissionsverhalten gewerblicher Direkteinleiter ...........

Tab. 5: Indikatorenkatalog für die Messung der Zielerreichungen des Abwasserabgabengesetzes bei

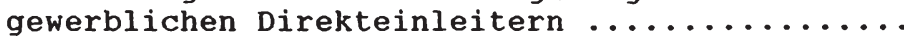

Tab. 6: Informationskatalog zum wasser- und abgabe-

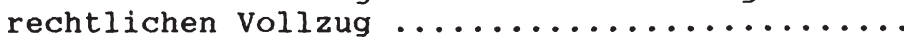

Tab. 7: Anzahl der untersuchten deutschen Werke pro

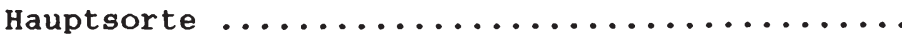

Tab. 8: Anzahl der untersuchten deutschen Werke je Produktgruppe nach den Mindestanforderungen ...

Tab. 9: Anzahl der schweizerischen Werke pro Hauptsorte 181

Tab. 10: Anzahl der untersuchten schweizerischen Werke

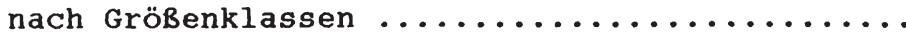

Tab. 11: Verteilung der schweizerischen werke auf die

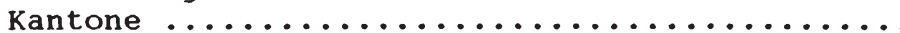

Tab. 12: Jahre der Festlegung der Grenzwerte bei den

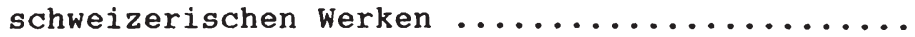

Tab. 13: Entwicklung der entgoltenen Schadfrachten (und der Jahresproduktionen) von 1981 bis 1985 bei

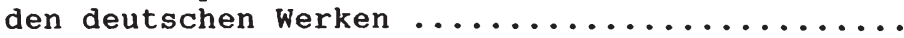

Tab. 14: Homogenisierte durchschnittliche Kosten pro vermiedener Schadeinheit und realisierte Wirkungsgrade von Reinigungsanlagen deutscher Werke (1985)

Tab. 15: Nicht homogenisierte durchschnittliche Kosten pro vermiedener schadeinheit und realisierte Wirkungsgrade von Reinigungsanlagen deutscher

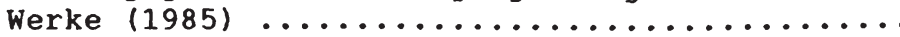


Tab. 16: Realisierte und zur Einhaltung der Uberwachungswerte erforderliche Wirkungsgrade von Reinigungsanlagen deutscher Werke (1985) ..... 245

Tab. 17: Realisierte und zur Einhaltung der Uberwachungswerte erforderliche Wirkungsgrade bei Einleitern, deren Bescheide 1985 bereits umgestellt waren .......................... 249

Tab. 18: Jahre der Planung, des Baubeginns und der Inbetriebnahme von Reinigungsstufen bei den deutschen Werken .................... 257 
Abb. 1: Berücksichtigung unterschiedlicher Grenzkosten der Abwasserreinigung ................. 32

Abb. 2: Ziel- und Programmstruktur der Gewässergüte-

Abb. 3: Ziel- und Programmstruktur der Gewässergütepolitik, Teil II: das Abwasserabgabengesetz ... 118

Abb. 4: Mögliche Kausalitäten zwischen Wirkungen des Abwasserabgabengesetzes und seinen Gesetzeselementen

Abb. 5: Papierproduktion in der Bundesrepublik nach

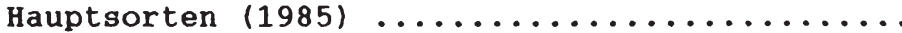

Abb. 6: Papierproduktion in der deutschen stichprobe nach Hauptsorten (1985)

Abb. 7: Anzahl der untersuchten deutschen Werke nach

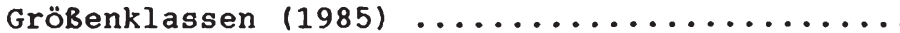

Abb. 8: Verteilung der untersuchten Werke auf die Bundesländer ......................... 186

Abb. 9: Jahre der Bescheidumstellung bei den deutschen

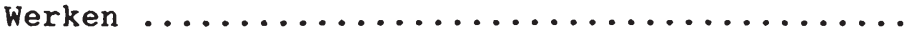

Abb. 10: Durchschnittliche Anzahl der behördlichen Kontrolien pro Jahr bei den deutschen Werken ..

Abb. 11: Emittierte Schadfrachten (produktbezogen) in den Jahren 1974 und 1985 ................ 201

Abb. 12: Das Verhältnis von eingeleiteten zu erlaubten Schadeinheiten bei den deutschen Werken (1985)

Abb. 13: Eingeleitete und erlaubte Schadfrachten (produktbezogen) bei vergleichbaren deutschen

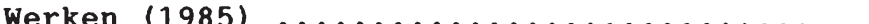

Abb. 14: Paarvergleich eingeleiteter und erlaubter BSBs-

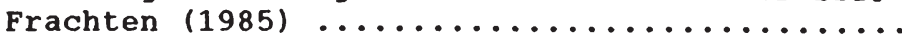

Abb. 15: Angewandte Reinigungsverfahren bei den deutschen werken ................... 208

Abb. 16: Angewandte Arten der biologischen Reinigung bei

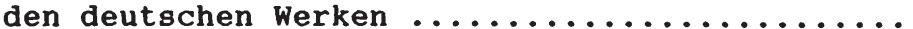

Abb. 17: Angewandte Reinigungsverfahren bei den schweizerischen Werken ..................... 
Abb. 18: $\mathrm{BSB}$-Abbau von biologischen Reinigungsanlagen deutscher Werke $(1985) \ldots \ldots \ldots \ldots \ldots \ldots \ldots \ldots$

Abb. 19: CSB-Abbau von biologischen Reinigungsanlagen

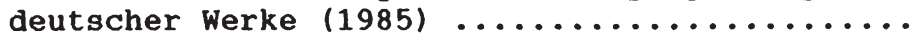

Abb. 20: Prozentuale Senkung des spezifischen Abwasseranfalls von 1974 bis 1985 bei den deutschen

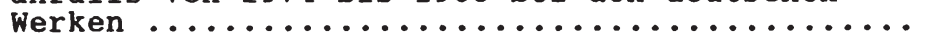

Abb. 21: Prozentuale Veränderung der Produktionsmenge und der produktbezogenen Schadfrachten (SE gemäB Abgabenerhebung) über die Abgabejahre bei den deutschen Werken..$\ldots \ldots \ldots \ldots \ldots \ldots \ldots \ldots$

Abb. 22: Zusammenhang zwischen der prozentualen Veränderung von Produktionsmenge und produktbezogenen Schadfrachten (SE gemäß Abgabenerhebung) bei

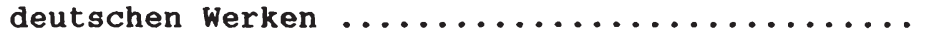

Abb. 23: Zusammenhang zwischen der prozentualen Veränderung von Produktionsmenge und produktbezogenen Schadfrachten (SE bei eingeleiteter Jahresschmutzwassermenge) bei deutschen Werken ......

Abb. 24: Prozentuale Veränderung der Produktionsmege und der eingeleiteten BSBs-Frachten (produktbezogen) bei schweizerischen Werken von 1981

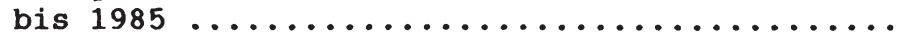

Abb. 25: Verbleib der mechanischen/mechanisch-chemischen Faserschlämme bei den deutschen Werken .. 238

Abb. 26: Verbleib des biologischen Uberschußschlamms

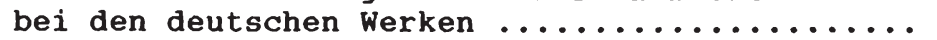

Abb. 27: Durchschnittliche Kosten pro vermiedener Schadeinheit bei den deutschen Werken (1985) ......

Abb. 28: Homogenisierte Abwasserreinigungskosten und Anzahl der vermiedenen schadeinheiten bei den

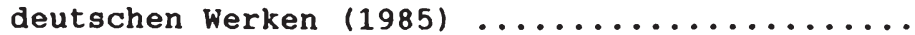

Abb. 29: Auf den Umsatz bezogene Abwasserkosten von Werken, die auf der Produktseite im Wettbewerb

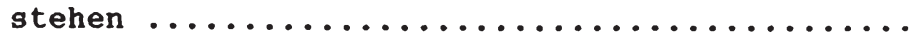

Abb. 30: Jahre der Inbetriebnahme neuer Anlagen und (nicht homogenisierte) Kosten pro vermiedener

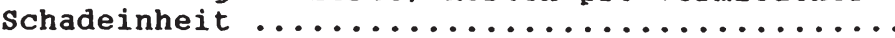


VERZEICHNIS DER ABKURZUNGEN

$\begin{array}{ll}\text { a.a.R.d.T. } & \begin{array}{l}\text { allgemein anerkannte Regeln der Technik } \\ \text { AbWAG }\end{array} \\ \text { AO } & \begin{array}{l}\text { Abwasserabgabengesetz } \\ \text { AS }\end{array} \\ \text { BGBI. } & \text { Bundesgesetzblatt } \\ \text { BSB. } & \text { Biochemischer Sauerstoffbedarf } \\ \text { CSB } & \text { Chemischer Sauerstoffbedarf } \\ \text { FS } & \text { Feststoffe } \\ \text { GMBl. } & \text { Gemeinsames Ministerialblatt } \\ \text { HAbWAG } & \text { Hessisches Abwasserabgabengesetz } \\ \text { HWG } & \text { Hessisches Wassergesetz } \\ \text { SE } & \text { Schadeinheit } \\ \text { StGB } & \text { Strafgesetzbuch } \\ \text { VDP } & \text { Verband Deutscher Papierfabriken } \\ \text { WHG } & \text { Wasserhaushaltsgesetz }\end{array}$




\section{Einleitung}

\section{Problemstellung}

Angesichts der Umweltsituation und alarmierender Prognosen sollte es außer Diskussion stehen, daß ein massiver Handlungsbedarf zur Abwehr einer fortschreitenden Zerstörung der natürlichen Lebensgrundlagen besteht. Bereits vor etwa 25 Jahren kam man zu der úberzeugung, daß der staat vermehrt Steuerungsfunktionen wahrzunehmen habe, die der Abwehr und Beseitigung von Umweltschädigungen dienen. Damals setzte der Prozeß des Umdenkens ein, in dem von der Vorstellung, die Umwelt sei ein freies, d.h. unbegrenzt und unentgeltlich zur Verfügung stehendes Gut, Abschied genommen wurde. Die Bundesregierung erklärte 1971 Umweltpolitik zu einer eigenständigen öffentlichen Aufgabe von gleicher Bedeutung wie Bildungspolitik, sozialer, innerer und äußerer sicherheit und hat seitdem eine Reihe umweltpolitischer Maßnahmen ergriffen. Gleichzeitig mit diesen Maßnahmen entfachte sich eine breite Diskussion über die Vorteilhaftigkeit verschiedener umweltpolitischer Instrumente, die in Anbetracht der sich weiter zuspitzenden Umweltproblematik bis heute unvermindert anhält.

Ausgehend von der uberlegung, daß Umweltverschmutzung ein Allokationsproblem darstellt, wurde und wird in dieser umweltökonomischen Diskussion immer wieder hervorgehoben, daß Abgaben, insbesondere wenn sie auf Emissionen erhoben werden, besonders geeignet seien, die Umweltverschmutzer (Verursacher) in ihren Allokationsentscheidungen zu beeinflussen ${ }^{2}$.

1 Das Umweltprogramm der Bundesregierung (ohne Hrsg.), 3. Aufl., stuttgart, Köln, Berlin, Mainz 1973, s. 6.'

2 Es sollen also in erster Linie Verhaltensänderungen bewirkt werden, während die fiskalische Funktion einer Abgabe ganz oder teilweise in den Hintergrund tritt. Man bezeichnet sie deshalb auch als Lenkungsabgaben. Vgi. Hansmeyer, K.H.: Abgaben und steuerliche Instrumente der Umweltpolitik - Wirkungsweise, Erfahrungen, Möglichkeiten, in: Zeitschrift für Umweltpolitik \& Umweltrecht, 9. Jg. (1987), Heft 3, S. 252 . 
Die solchen Abgaben zugesprochene Wirksamkeit basiert auf der Annahme, daB ein Verursacher, wird ihm eine derartige Abgabe auferlegt, solange bestrebt ist, seine Emissionen zu verringern, wie die Grenzkosten der Vermeidungsmaßnahmen niedriger als der Abgabesatz pro Emissionseinheit sind. Wird die Abgabe auch für die Restemission erhoben, bietet sie zudem einen finanziellen Anreiz zu weitergehenden Vermeidungsmaßnahmen, weshalb ihr - im Gegensatz zum klassischen Auflageninstrumentarium - die Fähigkeit zugeschrieben wird, den umweltfreundichen technischen Fortschritt nachhaltig zu fördern.

Diese und weitere "Qualitäten" einer Emissionsabgabe veranlabten die Bundesregierung dazu, bei der Reformierung des Wasserrechts nicht nur die bestehenden Auflagen zu verschärfen, sondern mit der Einführung der Abwasserabgabe einen "Meilenstein" in der deutschen Umweltpolitik zu setzen. 1976 wurde das Abwasserabgabengesetz, das die Erhebung einer Abgabe für das Einleiten von Abwasser in Gewässer regelt . erlassen.

Wenngleich die Einführung einer Emissionsabgabe mit Anreizfunktion seitdem auch in anderen Bereichen erwogen wird ${ }^{1}$, konnte sie bisher nur in der Abwasserabgabe realisiert werden. Diese Einmaligkeit auf der einen und die grundsätzliche Attraktivität einer Emissionsabgabe als ökonomischem Hebel der Umweltpolitik auf der anderen Seite machen dann auch das Interesse an der Wirkungsweise des Abwasserabgabengesetzes aus. Hinzu kommt der mangelhafte Konsens über die Ausgestaltung des Gesetzes, der vor allem darauf zurückzuführen ist, daß die Befürchtungen der abgabepflichtigen Verursacherseite hinsichtlich der Tragbarkeit von finanziellen Belastungen, die mit dem zunächst vorgeschlagenen Abgabesatz verbunden gewesen wären, in hohem Maße die Ausgestaltung des Gesetzes bestimmten. So wurde der Abgabesatz, vom Sachverständigenrat für Umweltfragen einstmals mit

1 Diskutiert wurden in letzter Zeit u.a. eine Schwefelabgabe, stickstoffabgabe und eine Emissionsabgabe auf Verbrennungsvorgänge. 
80 DM veranschlagt, auf 40 DM gesenkt und in dieser Höhe auch erst im Jahr 1986 erreicht, da eine Abgabestaffelung die Abgabepflicht 1981 zunächst mit 12 DM pro Schadeinheit beginnen und die Abgabesätze bis 1986 dann ansteigen ließ. Diese und weitere "verschmutzerfreundliche" Regelungen brachten dem Gesetz die wenig schmeichelhafte Bezeichung "Verschmutzerschutzgesetz" ein, wobei einige Kritiker sogar soweit gingen, ihm jegliche ökologische Wirksamkeit abzusprechen.

Das Abwasserabgabengesetz ist jedoch, obwohl es die typischen Merkmale einer KompromiBlösung trägt, wesentlich besser als sein ürsprünglicher Ruf. So konnten die Wirkungsuntersuchungen, die im Auftrag des Umweltbundesamtes am Finanzwissenschaftlichen Institut $z u$ Köln durchgeführt wurden ${ }^{1}$ und nicht zuletzt der Versachlichung der Diskussion dienen sollten, erstaunlich hohe signaleffekte, also Wirkungen vor Beginn der Abgabepflicht, konstatieren. Die Wirkungsforschung zum Abwasserabgabengesetz erweist sich allerdings trotz dieser studien als nicht ausreichend: Es liegen bislang keine Untersuchungen vor, die auch die zweite Wirkungsphase des Abwasserabgabengesetzes durchleuchten, obwohl der in der Theorie unterstellte Wirkungsmechanismus der Abgabe und auch die Wirkungen spezieller und gerade strittiger Gesetzeselemente erst nach 1981 erfaßt werden können. Dieses Evaluationsdefizit ist umso gravierender, als die Reaktionen, mit denen die Verursacher auf eine Emissionsabgabe antworten, bislang kaum bekannt sind. Daß die "realen" Anpassungsprozesse letztlich bei einer vielzahl von umweltpolitischen Instrumenten noch weitgehend im Dunkeln liegen, läBt sich darauf zurückführen, daß Umweltpolitik noch nicht allzu lange betrieben wird und die Erfahrungen bzw. Analysen entsprechend

1 Vgl. u.a. Hoffmann, V., Ewringmann, D.: Auswirkungen des Abwasserabgabengesetzes auf Investitionsplanung und abwicklung in Unternehmen, Gemeinden und Abwasserverbänden, Köln 1977; Ewringmann, D., Kibat, K., Schafhausen, F.J.: Die Abwasserabgabe als Investitionsanreiz. Auswirkungen des 87 a WHG und des Abwasserabgabengesetzes auf Investitionsplanung und -abwicklung industrieller und kommunaler Direkteinleiter, Berlin 1980. 
gering sind ${ }^{1}$. Gerade im Hinblick auf die Effizienz zukünftiger umweltpolitischer steuerungsmaßnahmen sind Kenntnisse über die Wirkungsmechanismen der einzelnen Instrumente jedoch unabdingbar. Es ist daher das Ziel dieser Arbeit, am Beispiel der Abwasserabgabe als dem deutschen Paradebeispiel einer Emissionsabgabe einen Beitrag zur Behebung dieses allgemeinen Evaluationsdefizits zu leisten.

Im Spannungsfeld zwischen dem Abwasserabgabengesetz mit seinen spezifischen Konstruktionsmerkmalen einerseits und der "reinen" Abgabentheorie andererseits ergeben sich für die vorliegende Arbeit folgende zentrale Fragestellungen:

1. Konnten die mit dem Abwasserabgabengesetz angestrebten Ziele erreicht werden?

2. Inwieweit sind die festgestellten Zielerreichungsgrade auf Wirkungen des Abwassserabgabengesetzes und nicht auf andere Wirkungsursachen, insbesondere auf die Auflagen, die nach wie vor das Wasserrecht dominieren, zurückzuführen?

3. Verhalten sich die Adressaten der Emissionsabgabe gemäß den Annahmen der umweltökonomischen Theorie, erfüllt also das Instrument die steuerungsfunktion, die man ihm allgemein zuschreibt?

\section{Gang der Untersuchung}

Zur Beantwortung dieser Fragen werden zunächst in Teil A der Arbeit die umweltökonomischen, rechtlichen und finanzwirtschaftichen Grundlagen der Abwasserabgabe sowie die erwarteten Gesetzeswirkungen dargestellt. Anschießend werden in Teil B neben den theoretischen Grundlagen der Evaluation die Möglichkeiten einer Erfolgskontrolle des Abwasserabgaben-

1 Vgl. Siebert, $H_{.}:$Neuere Entwicklungen in der ökonomischen Analyse des Umweltschutzes, in: Möller, H., Osterkamp, R., Schneider, $W$. (Hrsg.), Umweltökonomik. Beiträge zur Theorie und Politik, Königstein/Ts., 1982, S. 280. 
gesetzes vorgestellt und der Evaluationsansatz dieser Arbeit eingegrenzt.

Eine Erfolgskontrolle, die auch die Wirkungen der Abwasserabgabe während der Abgabejahre erfaßt, ist bislang nicht vorgestellt worden. Es ist deshalb ein Schwerpunkt dieser Arbeit, in Teil $\mathrm{C}$ ein derartiges Konzept der Erfolgskontrolle zu entwickeln. Dieses Konzept hat Indikatoren zur Messung der Zielerreichungen zur Verfügung zu stellen und Einflußgrößen, die neben der Abwasserabgabe zu kontrollieren sind, festzulegen. Bevor Hypothesen über Ursache-Wirkungs-Beziehungen entwickelt und operationalisiert werden, ist außerdem $z u$ bestimmen, welche Informationen über den Vollzug der wasserund abgaberechtlichen Regelwerke für die Wirkungsuntersuchungen benötigt werden.

Auf diesem Konzept aufbauend schließt sich in Teil D eine empirische Untersuchung über die Wirkungsweise des Abwasserabgabengesetzes an. Die Datenerhebung erfolgt innerhalb der Papierindustrie als einer der Adressatengruppen des Abwasserabgabengesetzes. Für die Durchführung der Erfolgskontrolle bei papier-, karton- und pappeerzeugenden Unternehmen sprechen mehrere Aspekte:

- Die Papierherstellung ist ein typisches Beispiel für den bedeutenden Einsatz von Wasser als Produktionsfaktor. Wenngleich es an Versuchen, eine "trockene" Papiertechnologie zu entwickeln, nicht mangelte, werden die Nutzung von Frischwasser und die Ableitung von Abwasser auch weiterhin unentbehrlich sein'.

- Weiterhin sind rund $60 \%$ der Papierfabriken unmittelbare Adressaten des Abwasserabgabengesetzes, weil sie ihre Abwässer selbst reinigen und direkt in den Vorfluter

1 Vgl. Göttsching, L.: Innerbetriebliche Vermeidungsmaßnahmen und Abwasserreinigung in der Papierindustrie, in: Wochenblatt für Papierfabrikation, 107. Jg. (1979), Heft 10 , S. 359 . 
einleiten ${ }^{1}$. Dieser Prozentsatz liegt weit über dem Anteil von Direkteinleitern in der gesamten Industrie, der bei $20 \%$ anzusiedeln ist. Insofern ist insbesondere dieser Industriezweig vom Abwasserabgabengesetz direkt angesprochen.

- Die Papierindustrie ist der einzige Industriezweig, für den - zusammen mit der (vorgeschalteten) Zellstoffindustrie - im Auftrag des Bundesminister des Innern eine ex-ante-Analyse der Auswirkungen des Abwasserabgabengesetzes durchgeführt wurde, als sich das Gesetz noch in der Planungsphase befand ${ }^{2}$. Diese Untersuchung bezog sich allerdings auf den ersten Gesetzesentwurf zur Erhebung einer Abwasserabgabe, der nicht zuletzt aufgrund des Gutachtens noch in wesentlichen Punkten umgestaltet wurde.

1 Vgl. Jacobs, G.: Wasser und Abwasser in der Papierindustrie. Umweltorientierte Anforderungen, Leistungen und Probleme, in: Verband Deutscher Papierfabriken (Hrsg.). Umweltschutz in der Papierindustrie, Schriftenreihe Nr. 5/P, 1981, S. 18 .

2 Vgl. Rincke, G., Göttsching, L., Irmer, H., Dalpke, H.-L.: Gutachten über einzel- und volkswirtschaftliche Auswirkungen des geplanten Abwasserabgabengesetzes auf die Papier- und Zellstoffindustrie, Darmstadt 1985. 
TEIL A: DAS ABWASSERABGABENGESETZ ALS INSTRUMENT ZUR ERHALTUNG UND VERBESSERUNG DER WASSERQUALITAT IN DER BUNDESREPUBLIK DEUTSCHLAND

\section{Umweltökonomischer Hintergrund der Abwasserabgabe}

\subsection{Das Verursacherprinzip als umweltpolitische Leitlinie}

Nicht nur der zum Teil bedrohliche Zustand der Gewässer, sondern die Verschmutzung des gesamten Lebensraumes, worin sich die Umweltschutzdefizite der fünfiger und sechziger Jahre widerspiegelten, veranlaßten die Bundesregierung 1971, erstmalig ein Umweltprogramm vorzulegen. In diesem definierte sie Umweltpolitik als

"die Gesamtheit aller Maßnahmen, die notwendig sind,

- um dem Menschen eine Umwelt zu sichern, wie er sie für seine Gesundheit und für ein menschenwürdiges Dasein braucht,

- um Boden, Luft und Wasser, Pflanzen- und Tierwelt vor nachteiligen wirkungen menschlicher Eingriffe zu schützen und

- um Schäden oder Nachteile aus menschlichen Eingriffen $\mathrm{zu}$ beseitigen." 1

Das umweltpolitische Globalziel "Erhaltung und Verbesserung der Umweltqualität"z spezifizierte die Bundesregierung für die Wasserwirtschaft derart,

"den Wasserhaushalt so $\mathrm{zu}$ ordnen, das

- das ökologische Gleichgewicht der Gewässer bewahrt oder wiederhergestellt wird;

1 Vgl. Das Umweltprogramm .... a.a.o., s. 15.

2 Rat von Sachverständigen für Umweltfragen: Umweltgutachten 1974, stuttgart, Mainz 1974, s. 9. 
- die einwandfreie Wasserversorgung der Bevölkerung und der Wirtschaft gesichert ist, gleichzeitig aber auch

- alle anderen Wassernutzungen, die dem Gemeinwohl dienen, auf lange Frist möglich bleiben."1

Diese allgemeinen und wenig operationalen Ziele wurden durch die Maxime der Gewässergütepolitik, in allen Gewässern die Gewässergüte $\mathrm{II}^{2} \mathrm{zu}$ erhalten bzw. bis $1985 \mathrm{zu}$ erreichen, präzisiert ${ }^{3}$. Damit wurde ein bundesweiter Immissionsstandard festgelegt4.

1 Das Umweltprogramm ..., a.a.0., s. 103.

2 Um den biologischen Zustand eines Gewässers qualifizieren zu können, wurde das saprobiensystem entwickelt, das die (biologische) Gewässergüte in vier Klassen einteilt: Güteklasse I: keine oder nur geringe Verunreinigung, hoher Sauerstoffgehalt;

Güteklasse II: mäßige Verunreinigung, relativ hoher Sauerstoffgehalt;

Güteklasse III: starke Verunreinigung, niedriger Sauerstoffgehalt;

Güteklasse IV: übermäßige Verunreinigung, sehr geringer Sauerstoffgehalt.

Zu ausführlichen Erläuterungen des Saprobiensystems vgl. Ländergemeinschaft Wasser (LAWA) (Hrsg.): Die Gewässergütekarte der Bundesrepublik Deutschland, München 1985, S. $6 \mathrm{ff}$.

3 Vgl. Das Umweltprogramm ..., a.a.0., s. 110.

4 Es handelt sich bei diesem angestrebten Immissionsstandard um ein Minimalziel, da die Länder an die Qualität einzelner Gewässer höhere Anforderungen stellen können. Der Verzicht auf eine offizielle regionale Differenzierung der Gewässergüte, wie sie z.B. in den USA, Belgien und Frankreich vorgenommen wurde, bedeutet zwar das Abwenden von einer optimalen Gewässergütepolitik, trägt jedoch den fehlenden Daten und administrativen Voraussetzungen für eine regionale Differenzierung Rechnung. Der Verzicht wurde deshalb als "pragmatische KompromiBlösung" (Rat von Sachverständigen für Umweltfragen: Die Abwasserabgabe: wassergütewirtschaftliche und gesamtökonomische Wirkungen, 2. Sondergutachten, stuttgart, Mainz 1974, S. 6), wenn auch nur als "vorübergehende Ausnahme", gewertet - und bis zum heutigen Tag aufrecht erhalten. Zur regionalen Differenzierung vgl. Rincke, $G_{.}$: Anwendbarkeit des Verursacherprinzips am Beispiel der Wassergütewirtschaft, in: Bullinger, M., Rincke, G., Oberhauser, A., Schmidt, $R$. $-B$. , Das Verursacherprinzip und seine Instrumente, Berlin 1974, S. $115 \mathrm{ff}$. 
Als wesentliches instrumentelles Ziel im Rahmen der Sanierung und Nutzung der Umwelt forderte die Bundesregierung die grundsätzliche Anwendung des Verursacherprinzips, das mit der Fortschreibung des Umweltprogramms 1976 um das Vorsorgeund Kooperationsprinzip ergänzt wurde ${ }^{1}$.

Das Verursacherprinzip besagt, daß derjenige die Kosten einer Umweltbelastung $\mathrm{zu}$ tragen hat, der für ihre Entstehung verantwortlich ist. Es steht damit im Gegensatz zum Gemeinlastprinzip, nach dem die Kosten, die durch die Umweltbelastungen entstanden sind, von den öffentlichen Haushalten, also vom steuerzahler, getragen werden.

Das Verursacherprinzip ist nicht neu. Es baut auf der bereits von Pigou im Rahmen der Wohlfahrtsökonomie aufgestellten These auf, daß die Existenz externer Effekte eine Diskrepanz zwischen privaten und gesellschaftlichen Kosten bedingt, weswegen eine optimale Faktorallokation nicht mehr gegeben ist. Auf die Gewässerverschmutzung bezogen bedeutet dies folgendes :

steht Wasser unentgeltlich und zudem unbegrenzt zur Verfügung, wie es Anfang der siebziger Jahre noch häufig der Fall war und weshalb wasser in volkswirtschaftlichen Lehrbüchern gern als Prototyp eines freien Gutes aufgeführt wurde, kann seine "Ubernutzung"2 die Folge sein. Sie wird durch die Trittbrettfahrer-Position der Abwassereinleiter - in der Regel ist nicht der Einleiter selbst, sondern sein Unterlieger von den Immissionswirkungen der Emissionen betroffen begünstigt.

Da sich die Kosten für den Produktionsfaktor Wasser nicht als "private" Kosten bei den Wirtschaftssubjekten niederschlagen, sondern der Allgemeinheit angelastet werden

1 Vgl. Umweltbericht '76. Fortschreibung des Umweltprogramms der Bundesregierung vom 14. Juli 1976. Mit einer Einführung von Werner Maihofer (ohne Hrsg.), stuttgart, Berlin, Köln, Mainz 1976, S. 26 ff.

2 Siebert, H.: Analyse der Instrumente der Umweltpolitik, Göttingen 1976, s. 7 . 
- diesen Sachverhalt bezeichnet man als negativen externen Effekt -, differieren die privaten und gesellschaftlichen ${ }^{1}$ Kosten in Höhe der sogenannten sozialen Zusatzkosten. Die einhergehende Verzerrung der Produktions-, Preis- und Konsumstruktur führt zu einer Fehlallokation der Produktionsfaktoren, auf die die zunehmende Verschmutzung der Gewässer zum Teil zurückzuführen ist² .

Ziel des Verursacherprinzips ist es nun, derartige Entwicklungen durch die Internalisierung der externen Kosten $z u$ korrigieren.

So einfach das Konzept, jeder stehe für die Schäden ein, die er verursacht hat, zunächst klingen mag, so wenig greifbar und mithin problematisch ist es in seiner Anwendung.

Das Verursacherprinzip gilt als ein wesentlicher Grundsatz der Umweltpolitik und wird als solcher wohl auch deswegen immer wieder hervorgehoben, weil die Aktivierung der wirtschaftlichen Selbststeuerungskräfte des Marktes über die Internalisierung der Kosten "als Beweis für die prinzipielle Vereinbarkeit von Marktwirtschaft und effektivem Umweltschutz gesehen wird."3 Gerade wegen dieser Grundsatzfunktion besteht jedoch die Gefahr, daß das Verursacherprinzip als "allgemeiner Alibibegriff" verwendet wird, "unter den alle speziellen steuerungsabsichten und Einzelmaßnahmen gefaßt

1 Als gesellschaftliche Kosten bezeichnet man die summe aus den privaten und den der Gesellschaft durch externe Effekte entstehenden Kosten.

2 Die steigende Verschmutzung resultiert auch aus dem primär wachstumsbedingten Wassermehrbedarf von Industrie, Landwirtschaft und Bevölkerung.

3 Kloepfer, M.: Umweltschutz durch Abgaben, in: Die öffentliche Verwaltung, 28. Jg. (1975), Heft 17, S. 594; vgl, auch Rehbinder, E.: Politische und rechtliche Probleme des Verursacherprinzips, Berlin 1973, S. 29; Bonus, H.: Instrumente einer ökologieverträglichen Wirtschaftspolitik, in: Binswanger, H.-Ch., Bonus, H., Timmermann, M.: Wirtschaft und Umwelt - Möglichkeiten einer ökologieverträglichen Wirtschaftspolitik, stuttgart, Berlin, Köln, Mainz 1981, s. 114. 
werden können."1 Auch muß hervorgehoben werden, daß das Verursacherprinzip aufgrund seines instrumentalen Charakters erst dann wirksam werden kann, wenn umweltpolitische Ziele formuliert und z.B. in Umweltstandards, wie oben am Beispiel der Gewässergütepolitik ansatzweise aufgezeigt, umgesetzt worden sind ${ }^{2}$. Eine Verbesserung der Umweltqualität auf der Grundlage des Verursacherprinzips bedarf also zunächst eines politischen Entscheidungsprozesses ${ }^{3}$.

\subsection{Probleme einer Anwendung des Verursacherprinzips}

Im folgenden sollen einige der Probleme, mit denen die Anwendung des Verursacherprinzips behaftet ist, aufgezeigt werden. Die Ausführungen konzentrieren sich auf die drei Fragen:

- Was ist eine Umweltbelastung?

- Wer ist der Verursacher?

- Welches ist der Preis für die Umweltbelastung?

Rechtliche und verteilungspolitische Aspekte sowie gesamtwirtschaftliche Auswirkungen des Verursacherprinzips werden also nicht betrachtet4.

1 Vgl. Rat von Sachverständigen für Umweltfragen: Umweltgutachten 1978, stuttgart, Mainz 1978, S. 523.

2 Bonus weist darauf hin, daB Normen zu einer Verlagerung des Pareto-Optimums und damit zu einer Veränderung der sozialen Zusatzkosten führen. Vgl. Bonus, H.: Eine Lanze für den "Wasserpfennig". Wider die Vulgärform des Verursacherprinzips, in: Wirtschaftsdienst, 66. Jg. (1986), Heft 9, s. 627.

3 Vgl. Rehbinder, E.: Politische und rechtliche Probleme ..., a.a.0., s. 28 f.; Bonus, H.: Instrumente ..., a.a.0., S. 121; Kloepfer, M.: Umweltschutz..., a.a.O., S. 594.

- Ausführungen zu diesen Punkten finden sich u.a. bei Bullinger, M.: Rechtsfragen des Verursacherprinzips beim Umweltschutz, in: Bullinger, M., Rincke, G., Oberhauser, A., Schmidt, R.-B., Das Verursacherprinzip und seine Instrumente, Berlin 1974, S. $69 \mathrm{ff.;}$ im gleichen Band: 
"Umweltbelastungen" können häufig als Wirkungen von Schadstoffen umschrieben werden. Der Sachverständigenrat für Umweltfragen definiert Schadstoffe als solche in der Umwelt vorkommenden stoffe, "die das Potential haben, auf den Menschen, auf andere Lebewesen, auf Okosysteme oder auch auf Sachgüter schädlich zu wirken."1 Unmittelbare sowie langfristige schädigungen können grundsätzlich durch die Toxizität einer einzelnen Substanz oder durch Wechselwirkungen verschiedener stoffe miteinander verursacht werden. Selbst ungiftige bzw. ökologisch unbedenkliche substanzen können sich zu solchen verbinden, die eine schädigung im oben genannten Sinn hervorrufen. Als weitere EinfluBfaktoren können die Resorbierbarkeit im organismus, die biologische Halbwertzeit und die Langlebigkeit angeführt werden. Zur Beurteilung des Schadstoffcharakters einer chemischen Verbindung sind aber vor allem Kenntnisse über die Abhängigkeit des Wirkungsspektrums von der Konzentration erforder$1 \mathrm{ich}{ }^{2}$.

Die Klassifikation einer Substanz als Schadstoff bzw. ihre ökologische Bewertung unterliegt einem Wandel über die Zeit. Sie ist abhängig vom jeweiligen stand der Wissenschaft, womit auch und gerade die verfügbaren Meßmethoden angesprochen sind. Entsprechend den zu verzeichnenden Fortschritten wird die Anzahl der stoffe, welche als schädlich einzustufen

Oberhauser, A.: Gesamtwirtschaftliche wirkungen der Anwendung des Verursacherprinzips, S. 51 ff.; MaierRigaud, G.: Umweltpolitik in der offenen Gesellschaft, Opladen 1988; Merck, P.: Verteilungswirkungen einer effizienten Umweltpolitik, Berlin 1988; Töpfer, $K$.: Umweltschutz im Spannungsfeld zur Wirtschaftspolitik, in: Duwendag, D., Siebert, H. (Hrsg.), Politik und Macht, Stuttgart 1980, S. $433 \mathrm{ff}$, Rehbinder, E.: Politische und rechtliche Probleme ...., a.a.O.; Wicke, L.: Umweltökonomie. Eine praxisorientierte Einführung, München 1982.

1 Rat von Sachverständigen für Umweltfragen: Umweltgutachten 1978, a.a.0., s. 18 .

2 Vgl. ebenda, S. 18 ff.; Göttsching, L., Hamm, U., Putz, H. -J.: Altpapier-Studie über Marktanalyse und SchadstoffPfade, Darmstadt 1986 , S. 89. 
sind - und damit Gegenstand umweltpolitischer Maßnahmen werden können - ständig größer.

Der Begriff des Verursachers suggeriert eine Kausalitätsbetrachtung, bei der im Rahmen eines Schuld-und-Sühne-Schemas der "Schuldige" einer Umweltbelastung ermittelt wird. Eine solche Untersuchung käme dem Verursacherprinzip nahe, wie es im juristischen Sinn, insbesondere in der polizeirechtlichen störerhaftung, verstanden wird. Im Rahmen der umweltökonomischen Theorie hat das Verursacherprinzip jedoch keinen ethischen oder rechtsnormativen Gehalt ${ }^{1}$. Es ist ein Kostenzurechnungsprinzip, mit dem steuernd in den Verursachungsprozeß eingegriffen werden soll. Für die Identifikation des Verursachers ist deshalb nicht der Entstehungsort einer Umweltbelastung, also die Verursachung im naturwissenschaftlichen sinn, sondern die wirtschaftliche Verursachung entscheidend" ${ }^{2}$. Folgerichtig ist Verursacher jeder, "der für den Eintritt von Umweltbelastungen eine Bedingung setzt."3

Als Verursacher von Umweltbelastungen werden in der Literatur überwiegend sowohl die Hersteller von Gütern und Dienstleistungen als auch jeder Bürger, zum einen in seiner Funktion als Verbraucher, zum anderen als Nutzer von Umweltgütern, qualifiziert4. Zu den Verursachern zählen außerdem staatliche stellen, sofern sie Umweltgüter in Anspruch nehmen' .

1 Vgl. Hartkopf, G., Bohne, E.: Umweltpolitik, Bd. 1, Opladen 1983, S. 111.

2 Vgl. u.a.Bonus, H.: Instrumente .... a.a.0., S. 114; Kade, G.: Okonomische und gesellschaftspolitische Aspekte des Umweltschutzes, in: Glagow, M. (Hrsg.), Umweltgefährdung und Gesellschaftssystem, München 1972, s. 135 f.

3 Hartkopf, G., Bohne, E.: Umweltpolitik ..., a.a.o., S. 111, bezugnehmend auf den Bundesminister des Innern (Hrsg.): Das Verursacherprinzip, Möglichkeiten und Empfehlungen zur Durchsetzung, Umweltbrief Nr. 1, Bonn 1973, S. 6 .

- Stellvertretend für viele vgl. Rehbinder, E.: Politische und rechtliche Probleme .... a.a.0., S. 29; vgl. auch Das Umwel tprogramm ..., a.a.o., s. 32 .

- Vgl. Hartkopf, G., Bohne, E.: Umweltpolitik ..., a.a.o., S. 111 . 
Von dieser Auffassung, nach der Verursacherketten die ökonomische Verantwortung tragen, weicht Bonus ab, der allein die Verbraucher für die Verursachung verantwortlich macht. "Alle Wirtschaftstätigkeit ist ja keineswegs selbstzweck; sondern sie ist immer am Endverbrauch orientiert. Wer also ein bestimmtes Gut verbraucht, hat die ganze Kette in Bewegung gebracht, in deren Verlauf die diversen Umweltbelastungen entstanden sind." 1

Maier-Rigaud sieht dagegen den stat als den alleinigen Verursacher produktionsbedingter Umweltbelastungen. Er argumentiert, daß weder der Einzelne noch das gesamte privatwirtschaftliche system als Verursacher identifiziert werden kann, weil die Wirtschaft als Ganzes betrachtet nicht die Freiheit hat, ineffizient $z$ arbeiten ${ }^{2}$. Hingegen setzt der staat die Rahmenbedingungen für das Marktverhalten. Er ist darüber hinaus nicht nur "Veranstalter von strategien zur Internalisierung produktionsrelevanter externer Effekte", sondern ist selbst - und dies vor allem auf freiwilliger Basis - "auf vielfältige Weise Generator und Katalysator (im chemischen sinne des Wortes) externer Effekte."3

Eine ganz andere - grundsätzlichere - Uberlegung zu der Frage, wer der Verursacher externer Effekte ist, leitet sich aus der Nutzungskonkurrenz des Gutes Umwelt ab. Begreift man externe Effekte als Knappheitsfolgen, so ist deren Verursacher nicht ein einziger, "sondern es ist der Exzess von Ansprüchen, der Knappheit erst entstehen läßt"4. Bei der Entstehung von Umweltbelastungen wirken - im wirtschaftlichen Sinn - "Schädigende" und "Geschädigte" in symmetrischer Weise

1 Bonus, H.: Instrumente ..., a.a.0., S. $87 \mathrm{f}$. und $114 \mathrm{f}$.

2 Vgl. Maier-Rigaud, G.: Umweltpolitik ..., a.a.o., S. $80 \mathrm{ff}$.

3 Ebenda, S. 86. Als Beispiel nennt Maier-Rigaud u.a. die Energiepolitik. Nimmt der stromverbrauch zu, schafft der staat die Voraussetzungen für weitere Verbrauchssteigerungen und damit auch für weitere Umweltbelastungen. Vgl. ebenda, s. 87.

4 Bonus, H.: Eine Lanze ..., a.a.0., s. 452 . 
zusammen; externe Effekte sind mithin reziproker Natur ${ }^{1}$. Welche der genannten "Parteien" als Verursacher deklariert wird, "ist nicht eine Prinzipienfrage, sondern eine Frage politischer Klugheit."2

Das Verursacherprinzip gibt auch bei der Betrachtung von Verursacherketten keine Hinweise, wo die Verantwortlichen für die Umweltbelastung zu suchen sind. Es besagt lediglich, daB im Rahmen des gesamtgesellschaftlichen systems die Verantwortlichkeit für eine bestimmte Umweltbelastung auf ein Subsystem eingegrenzt werden kann ${ }^{3}$. An welches Glied der Verursacherkette sich die umweltpolitischen Maßnahmen zu richten haben, ist eine politische Entscheidung. Diese sollte von Gesichtspunkten wie der ökonomischen und der ökologischen Effizienz, des Verwaltungsaufwandes und der politischen Durchsetzbarkeit geleitet sein .

Nicht minder problematisch als die Identifizierung des Verursachers ist die Bestimmung des Preises für die Umweltbelastung. Pigou schlug vor, die Produktion der Güter in Höhe der von ihnen verursachten sozialen Zusatzkosten ("Schadenskosten") zu besteuern". Die Realisierung des Verurgacherprin-

1 Diese Erkenntnis geht auf Coase zurück. Vgl. Coase, R.H.: The Problem of Social Cost, in: The Journal of Law and Economics, Vol. 3 (1960), s. 1 ff.

2 Bonus, $H_{.}:$Don Quichotte, Sancho Pansa und der Wasserpfennig, in: Wirtschaftsdienst, 66. Jg. (1986), Heft, 12 , S. 626. Zur praktischen Anwendung dieser Betrachtungsweise vgl. die Kontroverse bzgl. des Wasserpfennigs zwischen Bonus auf der einen und Scheele/Schmitt sowie Brösse auf der anderen Seite im Wirtschaftsdienst während der Jahre 1986 und 1987.

3 Vgl. Rehbinder, E.: Politische und rechtliche Probleme ..., a.a.o., s. 33 .

- Vgl. u.a. ebenda, S. 34; Hartkopf, G., Bohne, E.: Umweltpolitik .... a.a.0., S. 111; ähnlich auch Bea, F.X.: Die Verteilung der Lasten des Umweltschutzes nach dem Verursacherprinzip, in: Wirtschaftswissenschaftliches studium, 2. Jg. (1973), S. 454 .

- Vgl. Pigou, A.C.: The Economics of Welfare, Reprint der 4. Auflage von 1932, London 1952, S. $224 \mathrm{f}$. 
zips in dieser idealtypischen Form - man schreibt ihr die größte Allokationseffizienz aller Internalisierungsmaßnahmen $\mathrm{zu}^{1}$ - erscheint jedoch aufgrund der Komplexität externer Effekte im Umweltbereich als nicht möglich². So stehen beispielsweise im Bereich der Wasserwirtschaft in der Regel einem bzw. mehreren Abwasserproduzenten (synergistische Effekte!) eine Vielzahl von Betroffenen gegenüber, was die Erfassung, Quantifizierung und Zurechnung der Schadenskosten höchst problematisch macht. Gegen die Zurechnung von Schadenskosten spricht außerdem, daß der Preis für eine Umweltbelastung auch durch das Verhalten und die Anpassungsmöglichkeiten der Geschädigten beeinflußt wird. So steigen die mit einer Emission verbundenen Schäden beispielsweise, wenn in dem belasteten Gebiet Wohnsiedlungen errichtet werden ${ }^{3}$.

Daneben ist es ein für die Umweltökonomie grundsätzliches Problem, daß die Wertschätzung, die die Menschen der Umwelt entgegenbringen, von der Theorie nur angenommen und nicht

1 Endres weist allerdings darauf hin, daß selbst die Pigousteuer zwar die Marginal-, aber nicht immer die Totalbedingungen für eine optimale Allokation erfüllt, weil im Falle eines konstanten steuersatzes und steigender (sinkender) sozialer Grenzzusatzkosten langfristig zu viele (wenige) Verursacher zum Austritt aus dem Markt gezwungen werden. Vgl. Endres, A.: Umwelt- und Ressourcenökonomie, Darmstadt 1985, S. 28 f., bezugnehmend auf Burrows, P.: Pigouvian Taxes, Polluter Subsidies, Regulation, and the size of a Polluting Industry, in: Canadian Journal of Economics, Vol. 12 (1979), S. 494 ff.

2 Vgl. Fischer, H.P.: Die Finanzierung des Umweltschutzes im Rahmen einer rationalen Umweltpolitik, Frankfurt, Bern, Las Vegas 1978, S. 316; Hansmeyer, K.H.: Die Abwasserabgabe als Versuch einer Anwendung des Verursacherprinzips, in: Issing, $O$. (Hrsg.), Okonomische Probleme der Umweltschutzpolitik, Berlin 1976, s. 71; Nowotny, E.: Wirtschaftspolitik und Umweltschutz, Freiburg i.Br. 1974, S. $67 \mathrm{ff}$.

3 Vgl. Jürgensen, H.: Das Verursacherprinzip im Umweltschutz, in: Volkswirtschaftliche Korrespondenz der AdolfWeber-stiftung, 11. Jg. (1972), Nr. 6, 0.S., bezugnehmend auf Coase, R.H.: The Problem ..., a.a.o., s. 1 ff. 
analytisch ermittelt werden kann'. Folglich läBt sich auch der Preis des Gutes Umwelt nicht feststellen.

Eine andere Internalisierungsstrategie entwarf Coase. Er unterbreitete den Vorschlag, Verursacher und Geschädigte auf dem Verhandlungswege über das Niveau des externen Effektes sowie die Höhe der Ausgleichszahlungen bestimmen zu lassen ${ }^{2}$. Gilt z.B. die "Verursacherregel", so entrichtet der Verursacher Kompensationszahlungen an die Geschädigten in Höhe der ausgehandelten Schadensansprüche. Der Verursacher wird dadurch angeregt, Vermeidungsmaßnahmen zu ergreifen. Dieser verhandlungstheoretische Ansatz scheitert jedoch zum einen an der Höhe der Transaktionskosten (Informationskosten, Kosten der Organisation einer Verhandlungspartei und Kontrollkosten) ${ }^{3}$, die mit der Komplexität externer Effekte, wie sie im Umweltbereich vorliegt, zunehmen, zum anderen am Charakter der Umwelt als öffentlichem Gut. So betreffen Veränderungen der Umweltqualität viele Menschen, was z.B. Freifahrerverhalten auf der Seite der NutznieBer bedingt. Auch sind für ökonomische Transaktionen, wie Coase sie vorschlägt, Eigentumsrechte Voraussetzung, die aber gerade bei der Umwelt als einem öffentlichen Gut nicht vorliegen’.

1 Vgl. Maier-Rigaud, G.: Umweltpolitik ..., a.a.0., s. 66 .

2 Vgl. Coase, R.H.: The Problem of Social Cost, Journal of Law and Economics, Vol. 3, 1960, S. 1 ff.

3 Vgl. u.a. Bender, D.: Makroökonomik des Umweltschutzes, Göttingen 1976, S. 38 ff.; Siebert, H.: Haftung ex post versus Anreize ex ante: Einige Gedanken zur Umweltpolitik bei Unsicherheit, Konstanz 1987, S. 11.

4 Vgl. Cansier, D.: Offentliche Finanzen im Dienst der Umweltpolitik. Neuere theoretische Ansätze, in: schmidt, $K$. (Hrsg.), offentliche Finanzen und Umweltpolitik I, Schriften des Vereins für Socialpolitik, Gesellschaft für Wirtschafts- und Sozialwissenschaften, Neue Folge Bd. $176 / I$, Berlin 1988, S. 12 .

- Vgl. ebenda; Scheele, M., Schmitt, G.: Der "Wasserpfennig": Richtungsweisender Ansatz oder Donquichoterie?, in: wirtschaftsdienst, 66. Jg. (1986), Heft 11, S. 570 ff. 
Wenngleich beide Internalisierungsstrategien in ihrer reinen Form nicht anwendbar sind, so gaben sie doch Impulse für pragmatischere Konzepte zur Verwirklichung des Verursacherprinzips. So stand Pigou Pate bei der uberlegung, die Verursacher zwar nicht mit den schadenskosten, dafür aber mit den jeweiligen Vermeidungskosten der Umweltschädigungen $z u$ belasten. Dieser Ansatz hat sogar den Vorteil, daB er im Gegensatz zur Pigou'schen Lösung, die eine ex-post-Internalisierung impliziert, den präventiven Umweltschutz ermöglicht.

Geht man nun von der bisher im wesentlichen statischen zu der dynamischen Betrachtung einer Anwendung des Verursacherprinzips über, so ist "rückwirkend" zunächst die Problematik der Altlasten zu untersuchen².

Gemäß dem "Umwelt-Lexikon" der "Katalyse-Umweltgruppe" werden unter Altlasten ehemalige Deponien, die unbekannte Giftstoffe enthalten und Bodenflächen, die z.B. durch ehemalige Industriebetriebe verseucht wurden, verstanden ${ }^{3}$. In der Bodenschutzkonzeption der Bundesregierung werden weitere Vorgänge genannt, die zu einer Kontamination des Bodens, des Grund- und Oberflächenwassers führen können. Verwiesen wird beispielsweise auf Korrosion von Leitungssystemen, defekte Abwasserkanäle, abgelagerte Kampfstoffe, unsachgemäße Lagerung wassergefährdender stoffe sowie Rückstände von Pflanzenschutzmitteln aus der Landwirtschaft .

1 Vgl. Fischer, H.P.: Die Finanzierung ..., a.a.o., S. $318 \mathrm{f}$.

2 Bemerkenswert ist, daB die Altlastenproblematik trotz ihres erheblichen Umfangs und ihrer Dringlichkeit in der umweltökonomischen Literatur bislang höchstens am Rande erwähnt wird. Auch im Umweltgutachten 1988 haben die Altlasten eher "ergänzende" Bedeutung, so daß für die nachfolgenden Ausführungen in erster Linie juristische Literatur rekurriert werden muBte.

3 Vgl. Katalyse-Umweltgruppe (Hrsg.): Umweltlexikon, Köln 1985, S. 19 .

4 Deutscher Bundestag 10. Wahlperiode: Drucksache 10/2977 vom 7.3.1985, S. $27 \mathrm{f}$. 
Die Problematik der Anwendung des Verursacherprinzips auf die Altlastenbewältigung faßt Diederichsen wie folgt zusammen: In fast allen Fällen ist ein großer Teil der Verursacher nicht mehr zu ermitteln, "weil die Betriebe bankrott gegangen sind bzw. ihre Produktion eingestellt haben oder weil die Herkunft der Schadstoffe nicht mehr festgestellt werden kann. Schließlich kommt hinzu, daß in hohem Maße die öffentliche Hand durch vorschnell erteilte Genehmigungen und mangelhafte Kontrollen der Abfallbeseitigung für die Entstehung und das AusmaB der Altlasten mit verantwortlich ist. Für die Genese des Altlastenproblems ist kennzeichnend die Mischung aus verantwortungsbemühter Kommunalpolitik und Unternehmensgestaltung mit kurzsichtiger Problemverdrängung, mangelhafter personeller Ausstattung der Behörden und schnödestem Verbrechertum." 1

Vor diesem Hintergrund und unter der Berücksichtigung, daB der gegenwärtige Wohlstand nicht zuletzt auf dieser unzulässigen Inanspruchnahme der Umwelt, deren Aufnahme- und Abbaufähigkeit überschätzt worden ist, beruht, folgert Diederichsen, daß das Altlastenproblem grundsätzlich auf der Basis des Gemeinlast- und nicht auf der des Verursacherprinzips zu lösen sei². Auch werde durch das Gemeinlastprinzip im Rahmen der Altlastenbewältigung umweltschädigendes Verhalten nicht gefördert ${ }^{3}$.

1 Diederichsen, $U_{.}$: Die Verantwortlichkeit für Altlasten im Zivilrecht, in: Breuer, R., Kloepfer, M., Marburger, $P$., Schröder, M. (Hrsg.), Altlasten und Umweltrecht. Trierer Kolloquium zum Umwelt- und Technikrecht vom 20. - 22 . November 1985, Düsseldorf 1986, S. 118 f; ähnlich Koch, $H .-J .:$ Altlasten - Eine umweltpolitische Herausforderung, in: Brandt, E. (Hrsg.), Altlasten: Untersuchung, Sanierung, Finanzierung, Taunusstein 1988, S. 15.

2 Vgl. Diederichsen, U.: Die Verantwortlichkeit ..., a.a.o., S. 119; ähnlich auch Hartkopf, G., Bohne, E.: Umweltpolitik ..., a.a.0., s. 111 .

3 Diederichsen, U.: Die Verantwortlichkeit .... a.a.o., S. 119, bezugnehmend auf Bälder, . $_{-}-H_{\text {.: }}$ Recht der Abfallwirtschaft, Bielefeld 1979, S. 213 und $221 \mathrm{f}$. Die Anwendung des Gemeinlastprinzips ließe sich auch insofern - zumindest teilweise - rechtfertigen, als einer der 
Hingegen vertritt Koch die Meinung, daB das Verursacherprinzip, soweit dies möglich ist, auch auf die Altlastenproblematik angewendet werden sollte. "Es ist $z$ u hoffen, daß Politiker die umweltpolitische Herausforderung erkennen, die darin liegt, das Verursacherprinzip auch gegen wirtschaftich starken Widerstand durchzusetzen."1 Würde so verfahren, bestünden allerdings etwa die gleichen probleme, die in der statischen Betrachtung für die Anwendung des Verursacherprinzips erläutert wurden.

Die zukünftigen Auwirkungen von Umweltschäden, welche in der Gegenwart verursacht werden, sind weiterer Bestandteil einer dynamischen Betrachtung. Siebert bemerkt treffend, daß Umweltbelastungen im statischen Allokationsproblem am Ende einer Periode "verschwinden"z. Da schadstoffe jedoch über die Zeit akkumulieren können, erbt die nachfolgende Generation einen "Schadstoffpool". Derzeit verursachte Umweltbelastungen beeinträchtigen also die zukünftige Qualität des Gutes Umwelt. Unter diesem Gesichtspunkt müßten sich in den sozialen Zusatzkosten auch die Langfristeffekte der schadstoffe niederschlagen ${ }^{3}$. Diese wären auf der Grundlage einer intertemporalen Kosten-Nutzen-Analyse zu ermitteln ${ }^{4}$. Die Bewertung von Umweltbelastungen wird damit noch schwieriger - und noch umstrittener.

Hauptverursacher der Altlasten die Haushalte sind. "Es gibt nichts Giftigeres als eine Hausmülldeponie, weil diese eine unübersehbare Vielzahl chemischer substanzen enthält, während alle Sondermülldeponien in der Regel eingrenzbare Abfälle haben." Lersner, $H_{\text {. }} v_{\text {. , als Teil- }}$ nehmer in der Podiumsdiskussion: Rechtspolitische Lösungen

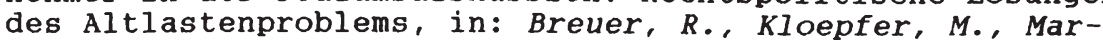
burger, P., Schröder, M. (Hrsg.), Altlasten und Umweltrecht. Trierer Kolloquium zum Umwelt- und Technikrecht vom 20. - 22. November 1985, Düsseldorf 1986, S. 191.

1 Koch, H.-J.: Altlasten ..., a.a.O., s. 15.

2 Siebert, H.: Die Umwelt in der ökonomischen Theorie, Konstanz 1987, S. 23.

3 Fraglich ist, inwieweit diese im Einzelfall ermittelt werden können.

4 Vgl. ebenda, S. 24 und 27. 
Es kann resümmierend festgehalten werden, daß die Anwendung des Verursacherprinzips mit Identifikations-, Zurechnungsund Bewertungsproblemen behaftet ist und zudem höchst unterschiedlich ausgelegt werden kann. Darüber hinaus werden dynamische Aspekte des Schadensentstehung und-vermeidung bisher weitgehend vernachlässigt.

Andererseits ist die idealtypische Anwendung des Verursacherprinzips von vornherein nicht möglich. "Die isolierte Betrachtung einzelner Externalitäten führt geradewegs zur Illusion der Identifizierbarkeit von Verursachern und zur Zuweisung von Verantwortung."1 Es können zwar einzelne externe Effekte internalisiert werden, sie tauchen jedoch an anderer stelle - in anderer Form - wieder auf. "Externe Effekte sind aber nicht nur unvermeidbar, sie sind geradezu konstitutiv für das Marktsystem und die Gesellschaft überhaupt. Die vollständige Internalisierung aller Externalitäten ist eine theoretische Absurdität. Sie würde vollkommene Information auch über die zukunft voraussetzen und eine welt ohne Risiko bedeuten." 2

Wenn aber die Anwendung des Verursacherprinzips die aufgezeigte Problematik beinhaltet, stellt sich zurecht die Frage, ob es als umweltpolitischer Grundsatz bezeichnet werden kann ${ }^{3}$. Vielmehr sollte von dem Bemühen, verursachungsorientierte Instrumente $z u$ entwickeln und zur Erhaltung und Verbesserung der Umweltqualität anzuwenden, gesprochen werden.

1 Maier-Rigaud, G.: Umweltpolitik ..., a.a.o., s. 80 .

2 Ebenda, S. 78 .

3 Vgl. dazu auch Jürgensen, H.: Das Verursacherprinzip ..., a.a.o. 
1.3 Auflagen versus Abgaben - der "klassische" Effizienzvergleich oder: Die Abwasserabgabe als ökonomischer Hebel der Gewässerqütepolitik

Im Rahmen einer verursachungsorientierten Umweltpolitik stehen dem staat "in seiner klassischen Rolle als gesamtwirtschaftlichem Reparaturbetrieb"1 zwei grundlegende Instrumente zur Imitation marktwirtschaftlicher Allokationsmechanismen zur Verfügung ${ }^{2}$ :

1. Ordnungsrechtliche Instrumente (Auflagenlösungen)

- Gebote

- Verbote

- Standards (Produkt- und Emissionsstandards) und

2. Okonomische Anreizinstrumente

- Abgabenlösungen (Emissionsabgaben, Produktmengenabgaben, Abgaben auf Produktionsfaktoren)

- Kompensationsregelungen und

- Emissionszertifikate ${ }^{3}$.

1 Praml, R.: Emissionsabgaben als Instrument des Umweltrechts, in: Jarre, J. (Hrsg.), Umweltrecht in der Bundesrepublik Deutschland. Erfolge, Probleme, Perspektiven, Loccumer Protokolle, Bd. 18, Rehburg-Loccum 1984, S . 86.

2 Siebert weist darauf hin, daß auch mit Haftungsregelungen die Verwirklichung des Verursacherprinzips angestrebt wird. Vgl. Siebert, H.: Umweltschäden als problem der Unsicherheitsbewältigung: Prävention und Risikoallokation, Konstanz 1986, S. $18 \mathrm{ff}$. Vgl, auch Rat von Sachverständigen für Umweltfragen: Umweltgutachten 1987, stuttgart, Mainz 1987, S. 70; ähnlich Schottelius, D.J.: Das Verursacherprinzip. Irrungen, Wirrungen, in: Privatautonomie, Eigentum und Verantwortung. Festgabe für Hermann Weitnauer zum 70. Geburtstag, Berlin 1980, s. 403; Wicke, L.: Umweltökonomie ..., a.a.0., s. 80 .

3 Die endogene Ausgestaltung von ordnungsrechtlichen Instrumenten und ökonomischen Anreizinstrumenten wird im folgenden Abschnitt nur soweit beschrieben, als es zum Verständnis des Untersuchungsrahmens dieser Arbeit notwendig ist. Die einzelnen Varianten der beiden Instrumente wurden in der Literatur intensiv erörtert. Vgl. u.a. Bonus, H.: Marktwirtschaftliche Konzepte im Umweltschutz, stuttgart 1984, S. 21 ff.; Endres, A.: Umwelt-und Ressourcenökonomie, a.a.O., s. 23 ff.; Fischer, H.P.: Die 
Bei Auflagenlösungen findet die Kostenzurechnung über die Vermeidungskosten, die aufzuwenden sind, um die Ge-, Verbote und/oder standards einzuhalten, statt. Die ökonomischen Instrumente dagegen dienen als pekuniärer Anreiz, Umweltverschmutzungen $\mathrm{zu}$ vermeiden. Da sie "eine erwerbswirtschaftliche Motivation des Menschen unterstellen und versuchen, über ökonomische Anreize bzw. die Erhebung eines Preises für die Nutzung des Gutes Umwelt Verhaltensänderungen zu bewirken"1, werden sie auch als indirekte Instrumente bezeichnet. Im Gegensatz dazu versteht man das Auflageninstrumentarium als direkte staatliche Kontrolle, weil es auf administrativen Eingriffen beruht und damit unmittelbar verhaltenslenkend wirkt2. "Pointiert man den Ansatz der direkten Kontrollen, so handelt es sich um die 'Politik des individuellen Schornsteins', bei der sich eine staatliche Instanz etwa auf der Grundlage eines Emissionskatasters um jede einzelne Emissionsquelle kümmert und sie einer prüfung unterwirft." 3

Finanzierung .... a.a.0, 1978, S. 319 ff.; Hartkopf, G., Bohne, E.: Umweltpolitik .... a.a.O., S. $185 \mathrm{ff.;}$ Kabelitz, K.R., Köhler, A.: Abgaben als Instrument der Umweltschutzpolitik, Köln 1977; dies.: Auflagen als Instrument der Umweltpolitik, Köln 1978; Osterkamp, $R$.: Emissionsstandards und Emissionssteuern als alternative Instrumente der Umweltschutzpolitik. Ein theoretischer Vergleich, München 1984; Pethig, R.: Umweltökonomische Allokation und Emissionssteuern, Tübingen 1979; Siebert, H.: Analyse ..., a.a.O.; Wicke, L.: Umweltökonomie. Fine praxisorientierte Einführung, München 1982, S. 91 ff.; Zimmermann, H.: Typen ökonomischer Anreizinstrumente in der Umweltpolitik, in: Schneider, G., Sprenger, R.U. (Hrsg.), Mehr Umweltschutz für weniger Geld - Einsatzmöglichkeiten und Erfolgschancen ökonomischer Anreizsysteme in der Umweltpolitik, München 1984, S. $225 \mathrm{ff}$.

1 Rat von Sachverständigen für Umweltfragen: Umweltgutachten 1987 , a.a.O., S. 67 .

2 Vgl.u.a.Kabelitz,K.R., Köhler, A.: Abgaben ..., a.a.o., s. 11 .

3 Siebert, H.: Instrumente der Umweltpolitik. Die ökonomische Perspektive, in: Möller, H., Osterkamp, R., Schneider, W. (Hrsg.), Umweltökonomik. Beiträge zur Theorie und Politik, Königstein/Ts. 1982, S. 285. 
Das eingangs erwähnte novellierte Wasserhaushaltsgesetz ist ein Auflagengesetz, während das Abwasserabgabengesetz, wie aus dem Namen ersichtlich, eine Emissionsabgabe regelt.

Die grundsätzliche Einführung der Abwasserabgabe resultierte aus der Diskussion über die Vorteilhaftigkeit von Abgaben gegenüber den damals praktizierten Auflagenlösungen bei der Erfüllung von Effizienzkriterien. Dieser "klassische", in der Literatur vielfach vorgenommene Vergleich soll im folgenden beschrieben werden.

Zur Durchsetzung der wasserwirtschaftlichen Ziele hatte der Rat von Sachverständigen für Umweltfragen sowohl ökologische als auch ökonomische Effizienz - spezifiziert als die "gesamtwirtschaftlich möglichst günstige Mittelverwendung"1 der zu ergreifenden Maßnahmen gefordert².

Im Wettbewerb um die beste Erfüllung dieses Anspruchs standen die Auflagenlösung in Form eines Emissionsstandards und die Abgabenlösung in Form einer Emissionsabgabe.

Als Emissionsstandards bezeichnet man gesetzlich vorgeschriebene Höchstgrenzen für die schadstoffemission ${ }^{3}$. Man kann sie im Sinne bestimmter Qualitätsnormen auch als Verbot, diese Normen zu überschreiten, interpretieren. Ziel des Emissionsstandards ist die Durchsetzung des technischen standes,

1 Rat von Sachverständigen für Umweltfragen: Die Abwasserabgabe .... a.a.0., s. 1. Neben diesen allokativen Effekten werden in den weiteren Teilen der vorliegenden Arbeit auch distributive Wirkungen zur ökonomischen Effizienz gezählt.

2 Weitere Kriterien zur Beurteilung umweltpolitischer Instrumente sind das Kriterium der abdministrativen Praktikabilität und das Kriterium der politischen Durchsetzbarkeit. Ausführliche Erläuterungen dazu vgl. Sprenger, $R_{-}-U_{.}$: Kriterien zur Beurteilung umweltpolitischer Instrumente aus der Sicht wissenschaftlicher Politikberatung, in: Schneider, G., Sprenger, R. $-U$. (Hrsg.): Mehr Umweltschutz für weniger Geld - Einsatzmöglichkeiten und Erfolgschancen ökonomischer Anreizsysteme in der Umweltpolitik, München 1984, S. $60 \mathrm{ff}$.

3 Vgl. Fischer, H.P.: Die Finanzierung ..., a.a.o., s. 327 ff. 
wodurch zur Realisierung der Immissionsstandards beigetragen werden soll.

Die Emissionsabgabe kann folgendermaßen ausgerichtet $\operatorname{sein}^{1}$ :

1. Sie internalisiert die Vermeidungskosten (Emissionsreduktionskosten), die zur Erreichung der Immissionsstandards notwendig sind. In diesem Fall könnte man sie als ordnungssteuer zur Einhaltung der Auflagen bezeichnen ${ }^{2}$.

2. Sie internalisiert die Vermeidungskosten und besteuert zudem die mit Einhaltung des Immissionsstandards verbleibenden schäden.

3. Sie internalisiert die Vermeidungskosten und belastet den Emittenten für die Restverschmutzung mit einer Gebühr, die als Knappheitspreis ${ }^{3}$ in einer Höhe anzusetzen wäre, daß durch die entsprechenden Vermeidungsmaßnahmen die gewünschte Umweltentlastung herbeigeführt wird.

Der Unterschied zwischen der zweiten und dritten Variante besteht darin, daß bei letzterer für jegliche Schadstoffemission, bei der zweiten Version nur für diejenige Menge, die noch einen Schaden verursacht, eine Gebühr erhoben wird.

Da die erste Variante gegenüber den Emissionsstandards keine nennenswerten Vorteile bietet und die zweite wegen der notwendigen Schadensbewertung und -zurechnung Probleme

1 Vgl. ebenda, S. 355 ff.; Oberhauser, A.: Abgrenzung des Verursacherprinzips und seine Einordnung in die Umweltpolitik, in: Bullinger, M., Rincke, G., Oberhauser, A., Schmidt, R. - B.. Das Verursacherprinzip und seine Instrumente, Berlin 1974, S. 45.

2 Idealerweise wird hier davon ausgegangen, daß die Emissionsstandards so gewählt sind, das ihre Einhaltung zur Erreichung des Immissionsstandards führt.

3 Vgl. ebenda, S. 42 . 
bereitet, wurde die Abwasserabgabe als eine "Restverschmutzungsabgabe" konzipiert².

Für diese Abgabenvariante ist es üblich, die Höhe des Abgabesatzes nach den unter dem stichwort "Preis-standardAnsatz" bekannt gewordenen Implikationen zu ermitteln. Dabei wird der Knappheitspreis so gewählt, daß ein vorher - mehr oder weniger willkürlich - bestimmtes Umweltqualitätsziel (Immissionsstandard, in der Gewässergütepolitik die Gewässergüte II) erreichbar erscheint. Anders ausgedrückt: Der Abgabesatz wird in Höhe der marginalen Vermeidungskosten angesetzt, die durchschnittlich bei den Verursachern für denjenigen Reinigungsgrad anfallen, der zur Erreichung des Umweltstandards erforderlich ist ${ }^{2}$. Es ist dies der abgabentheoretische Internalisierungsansatz, auf den sich die nachfolgende Argumentation für und wider die Effizienz der Emissionsabgabe - im Vergleich zum Emissionsstandard bezieht.

1 Diese Entscheidung stieß in der politischen Diskussion bei einigen Bundesländern (sowie bei vielen Emittenten) auf Unverständnis und wurde entsprechend attackiert. Die Substitution der Restverschmutzungsabgabe durch die mit dem Verursacherprinzip viel weniger kompatible - weil eine Freigrenze enthaltende - erste Abgabenlösung wurde insbesondere von den Ländern Schleswig-Holstein, Niedersachsen und Bayern gefordert. Sie gingen schlieblich sogar soweit, einen eigenen Gesetzesentwurf mit konkreten Anderungen des Abwasserabgabengesetzes vorzulegen, fast vier Jahre nach seinem ErlaB und knapp acht Monate, bevor es zur Anwendung kommen sollte. Entgegen der bis dahin geforderten Abgabenfreiheit für den Fall der Einhaltung der Emissionsstandards wurde eine "Zwitterlösung" zwischen der ersten und dritten Abgabenvariante (sowie eine Reihe weiterer Gesetzesänderungen) vorgeschlagen, von der Bundesregierung jedoch abgelehnt. Vgl. den Gesetzesentwurf des Bundesrates zur Anderung des Abwasserabgabengesetzes mit der stellungnahme der Bundesregierung, Deutscher Bundestag 8. Wahlperiode, Drucksache 8/4311 vom 25.6.1980.

2 Eine ausführliche Darstellung findet sich u.a. bei Baumol/Oates, die den Preis-Standard-Ansatz entwickelt haben. Vgl. Baumol, W.J., Oates, W.E.: Die Anwendung von Standards und Preisen zum Schutz der Umwelt, in: Siebert, H. (Hrsg.), Umwelt und wirtschaftliche Entwicklung, Darmstadt 1979, S. 169 ff. 


\section{Okologische Effizienz}

Wird eine Abgabe für die Restverschmutzung erhoben, so versucht ein kostenminimierend handelnder Emittent, die Restverschmutzung so weit einzuschränken, daß die marginalen Vermeidungskosten noch niedriger als der Abgabesatz pro Schadeinheit sind. Die Besteuerung der Restverschmutzung stellt einen ständigen, im Verhältnis zu Auflagen ungleich größeren Anreiz dar, über diesen Reinigungsgrad hinaus Emissionsvermeidungsmaßnahmen vorzunehmen ${ }^{1}$. Dies hat zum einen eine geringere Schadstoffemission zur Folge, zum anderen forciert der finanzielle Anreiz nachhaltig den umwelttechnischen Fortschritt und seine Anwendung beim Emittenten.

Im Gegensatz dazu unterstellt man Auflagen, daß sie geradezu innovationshemmend wirken ${ }^{2}$. Dies wird zum einen damit begründet, daß die Administration bei der Festlegung der Emissionsobergrenzen auf Informationen der Wirtschaft über den stand der Technik angewiesen ist. Für die wirtschaftssubjekte bedeutet der technische Fortschritt zunächst einmal höhere Kostenbelastungen; das daraus resultierende Verhalten im Bargaining-Prozeß wird häufig mit dem "Schweigekartell der oberingenieure" umschrieben ${ }^{3}$. Zum anderen sind Auflagen an genehmigte Anlagen, d.h. an deren physischen Bestand gebunden. Die Emissionsrechte werden reduziert, wenn durch weitere Vermeidungsmaßnahmen die Emissionen gesenkt werden, und sie sind aufgehoben, wenn die Anlage stillgelegt wird. Altanlagen sind deshalb für ihre Betreiber häufig wertvolle

1 Eine praxisbezogene Beschreibung diesbezüglich mangelhafter Auflagenwirkungen nimmt Siebert vor. Vgl. Siebert, $H_{.:}$Instrumente .... a.a.O., s. 286 .

2 Stellvertretend für viele: vgl. Maier-Rigaud, G.: Umweltpolitik in der Marktwirtschaft, in: Wirtschaftsdienst, 60. Jg. (1980), Heft 7, S. 342; steger, U.: Umweltmanagement: Erfahrungen und Instrumente einer umweltorientierten Unternehmensstrategie, Wiesbaden 1988 , S. 63 .

3 Vgl. u.a. Bonus, H.: Marktwirtschaftliche Instrumente im Umweltschutz, in: Wirtschaftsdienst, 64. Jg. (1984), S. 170, der diese Wendung F.J. Dreyhaupt zuschreibt. 
Produktionsfaktoren, weshalb sie möglichst lange unverändert weitergefahren werden ${ }^{1}$. Damit wird gleichzeitig auch die Expansion und Neuansiedlung von Betrieben verhindert, wenn das Belastungsreservoir einer Region bereits ausgeschöpft ist ${ }^{2}$.

Aus den genannten Gründen spricht man Emissionsabgaben eine im Verhältnis zu den Auflagen größere dynamische Allokationseffizienz $z u^{3}$. Cansier räumt allerdings ein, daß die kurzfristigen Innovationswirkungen von (verschärften) Auflagen vermutlich größer sind als die von Abgabenlösungen, denn letztere erlauben eine Verzögerung der Anpassungsreaktionen der Emittenten ${ }^{4}$. Eine solche widerspräche jedoch dem sonst unterstellten kostenminimierenden Verhalten.

1 Vgl. Bonus, $H_{.}:$Marktwirtschaftliche Instrumente .... a.a.0., S. 169 f.; Siebert, H.: Instrumente ..., a.a.0., 1982, S. 286 f.; ders.: Voerde und eine neue Umweltpolitik, in: Wirtschaftsdienst, 58. Jg. (1978), Heft 1, S. $36 \mathrm{ff}$.

2 Vgl. dazu auch Maloney, M.T., MCCormick, R.E.: A Positive Theory of Environmental Quality Regulation, in: Journal of Law and Economics, Vol. 25 (1982), S. 99 ff.

3 Vgl. u.a. Fischer, H.P.: Die Finanzierung ..., a.a.0., S. 362; Kabelitz, K.R., Köhler, A.: Abgaben ..., a.a.O., S. 14. Letztere stellen allerdings genau diese später in Frage. Wenngleich die "Produktionsfunktion" des technischen Fortschritts weitgehend im Dunkeln läge, wären innovative Entwicklungen und Anwendungen gemäß der bisher gültigen wirtschaftstheoretischen Hypothese eine Funktion der Gewinnerwartungen. Träfe dies zu, dann wirke die Abgabe für die Restverschmutzung dysfunktional, "da zusätzlich zu den Vermeidungskosten und der Abgabe auf die Restverschmutzung noch Aufwendungen für in ihrem Ergebnis ungewisse Forschungen finanziert werden müssen und dies alles bei unter Umständen gleichzeitig verringerter Ertragslage infolge unvollständiger Abgabenüberwälzung" (Kabelitz, K.R., Köhler, A.: Abgaben ..., a.a.O., S. 30). Diese Argumentationskette erscheint aber insofern nicht als überzeugend, als verfahrensinnovative Forschung traditionell in den Händen der Anlagenbauer und nicht der -betreiber liegt.

4 Vgl. Cansier, D.: Förderung der umweltfreundlichen technischen Fortschritts, in: wirtschaftsdienst, 58 . Jg. (1978), Heft 9, S. 457. 
Weniger vorteilhaft ist die Abgabenlösung dagegen, wenn es um die genaue und sichere Verwirklichung von Emissions- und damit auch von Immissionszielen geht. Da es den potentiellen Emittenten freigestellt ist, gegen Abgabe Schadstoffe $z u$ emittieren oder Emissionen zu unterbinden, arbeitet die Abgabe in ökologischer sicht weniger zielgerichtet als eine Auflage ${ }^{1}$. Gerade weil das Abgabenmodell auf dem Marktmechanismus aufbaut, wirkt es "notwendig ungenau"2. "Die Schwierigkeit dieser indirekten Lenkung besteht darin, daB die Rückwirkungen monetärer Maßnahmen nicht mit unbedingter Zuverlässigkeit vorauszuberechnen sind. Sie haben den erstrebten Effekt nur dann, wenn die wirtschaftsbeteiligten rational reagieren und alle Möglichkeiten zu markttaktischen Auswegen und Umgehungen erkannt und verschlossen werden."3

Das Unschärfemoment der Abgabe, das Einbußen der ökologischen Effizienz bedeuten kann, entsteht auch dadurch, das die Grenzvermeidungskosten, die zur Festlegung des Abgabesatzes herangezogen werden, in der Regel nicht bekannt sind4. Der "trial-and-error-ProzeB", mit dem der Abgabesatz, welcher zur Erreichung des gesetzten Umweltstandards erforderlich ist, ermittelt wird, kostet zeit und führt zu Investitionsunsicherheiten, weil die zukünftigen Belastungen aus der Abgabe von den Wirtschaftssubjekten nicht kalkuliert werden können .

1 Vgl. Cansier, D.: Okonomische Grundprobleme der Umweltpolitik, Berlin 1975, S. 95 f.

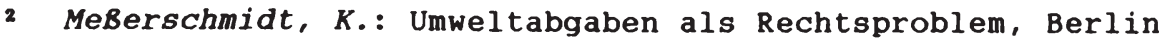
1986, S. 80 .

3 Huber, E.R.: Wirtschaftsverwaltungsrecht, 2. Aufl., 2. Bd., Tübingen 1954, S. 203, zitiert nach MeBerschmidt, K.: Umweltabgaben ..., a.a.0., s. 80 .

1 Vgl. Cansier, D.: Offentliche Finanzen im Dienst der Umweltpolitik. Neuere theoretische Ansätze, in: Schmidt, $K$. (Hrsg.), Offentliche Finanzen und Umweltpolitik I, Schriften des Vereins für Socialpolitik, Gesellschaft für Wirtschafts- und Sozialwissenschaften, Neue Folge Bd. $176 /$ I, S. 19 . 
Die oben angesprochene Dispositionsfreiheit der Emittenten verhindert auch eine regional gezielte Beeinflussung der Emissionsaktivitäten. Weisen z.B. die Anlieger eines Gewässers allesamt hohe marginale Vermeidungskosten auf, werden sie, ökonomische opportunität vorausgesetzt, die Entrichtung der Abgabe präferieren. Daß daraus Effizienzmängel der Abgabenlösung resultieren, wird besonders offenkundig, wenn es darum geht, akute Notstände zu bekämpfen. Hier zeigen sich - vordergründig - die Vorteile von Auflagen .

Zum einen können sie einfacher aus administrativer sicht differenziert werden. Die Wasserhaushaltsgesetz macht seit 1976 davon Gebrauch, indem es die Auflagen in den

Verwaltungsvorschriften nach Verursachergruppen differenziert und den Ländern darüber hinaus die Möglichkeit schärferer Einleitungsbedingungen gibt, um regionalen Anforderungen gerecht $\mathrm{zu}$ werden (\$ $7 \mathrm{a}$ WHG). Zum anderen geben die Auflagen Emissionsobergrenzen verbindlich vor und gewährleisten deshalb überall einen gewissen Mindestschutz ${ }^{1}$. Voraussetzung zur Realisierung dieser Grenzwerte ist jedoch der strikte Vollzug der Gesetze. Und hier zeigten sich in der Vergangenheit gravierende Mängel.

Gerade die Vollzugsdefizite bei der Abwasserreinigung, die auf "administrative, lokalpolitische und interessenbeeinflußte Hindernisse"z zurückgingen, entfachten in den

1 Diese sind, worin ein weiterer Vorteil gesehen werden kann, frei von inflationären Einflüssen, welche die Anreizwirkung eines - konstanten - Abgabesatzes hinfällig machen können. Vgl. u.a. Fischer, H.P.: Die Finanzierung ..., a.a.0., s. 378 f.; Cansier, D.: Förderung .... a.a.O., s. 458 .

2 Rat von Sachverständigen für Umweltfragen: Umweltgutachten 1974, a.a.O., S. 60. Besonders $z u$ verweisen ist in diesem Zusammenhang auch auf die Untersuchung vom Mayntz. Vgl. Mayntz, R. u.a.: Vollzugsprobleme der Umweltpolitik. Empirische Untersuchung der Implementation von Gesetzen im Bereich der Luftreinhaltung und des Gewässerschutzes, stuttgart 1978. Vgl. weiterhin Boehm, V.: Abwasserabgabe und Gewässerschutz, in: Institut für gewerbliche Wasserwirtschaft und Luftreinhaltung e.V., Köln (Hrsg.), 
siebziger Jahren die Kritik an der reinen Auflagenlösung. Vor dem Hintergrund lückenhaften Vollzugs hielt der Sachverständigenrat die Verschärfung der damaligen Einleitebedingungen und-auflagen dann auch für nicht ausreichend und plädierte für die Einführung einer Abwasserabgabe als ökonomischem Hebel der Gewässergütepolitik ${ }^{1}$. Wäre der ökonomische Hebel allerdings nur in der besseren Durchsetzung der Auflagen zu sehen, müßte die Abgabe lediglich bis zur Erfüllung des Emissionsstandards erhoben werden. Aber unter dem Gesichtspunkt einer weitergehenden Reinigung und des technischen Fortschritts muß sie den Emittenten auch für die Restverschmutzung belasten.

\section{Okonomische (allokative) Effizienz}

Die Suche nach der geringeren gesamtwirtschaftlichen Kostenbelastung soll im folgenden am Vergleich einheitlicher Auflagen und einheitlicher Abgabesätze für alle Emittenten durchgeführt werden².

In $\mathrm{Abb} .1$ ist unterstellt, daB die Grenzkosten der Vermeidungsmaßnahmen mit höherem Reinheitsgrad (Reinigungsgrad) steigen. Die Grenzkostenkurven liegen zwischen K1 (Verursacher 1) und K2 (Verursacher 2), K' sei ihr gewogenes

Abwasser-Abgaben-Gesetz, IWL-Forum 74/II, Köln 1974, S. 2; Cansier, D.: a.a.0., S. 98 .

1 Vgl. Rat von Sachverständigen für Umweltfragen: Die Abwasserabgabe ..., a.a.0., s. 10.

2 Einheitliche Auflagen und Abgaben werden hier als Grundlage des Effizienzvergleichs gewählt, weil diese Kombination dem Sachverständigenrat 1974 als Argumentationsbasis für die Einführung der Abwasserabgabe diente. Vgl. im folgenden ebenda S. $12 \mathrm{ff.;}$ Oberhauser, A.: Abgrenzung .... a.a.0., s. $32 \mathrm{ff}$.

Einen umfassenden - ökologischen als auch ökonomischen Effizienzvergleich von Emissionsabgaben mit Emissionsstandards in ihren verschiedenen Ausprägungen nehmen Fischer und Osterkamp vor. Vgl. Fischer, H.P.: Die Finanzierung ....,a.a.O., s. $374 \mathrm{ff}$.; Osterkamp, R.: Emissionsstandards .... a.a.o. 
Mittel1. Der Reinheitsgrad OC, das anzustrebende Gewässergüteziel, resultiert aus dem schnittpunkt $s$ zwischen den mittleren Grenzkosten $K^{\prime}$ und den jeweiligen externen Kosten (sozialen Zusatzkosten), d.h. den Grenzbelastungen B', die beim jeweiligen Vermeidungsgrad verbleiben. Da die externen Kosten schwer quantifizierbar sind, bezeichnet $\mathbf{s}$ lediglich einen fiktiven optimalpunkt.

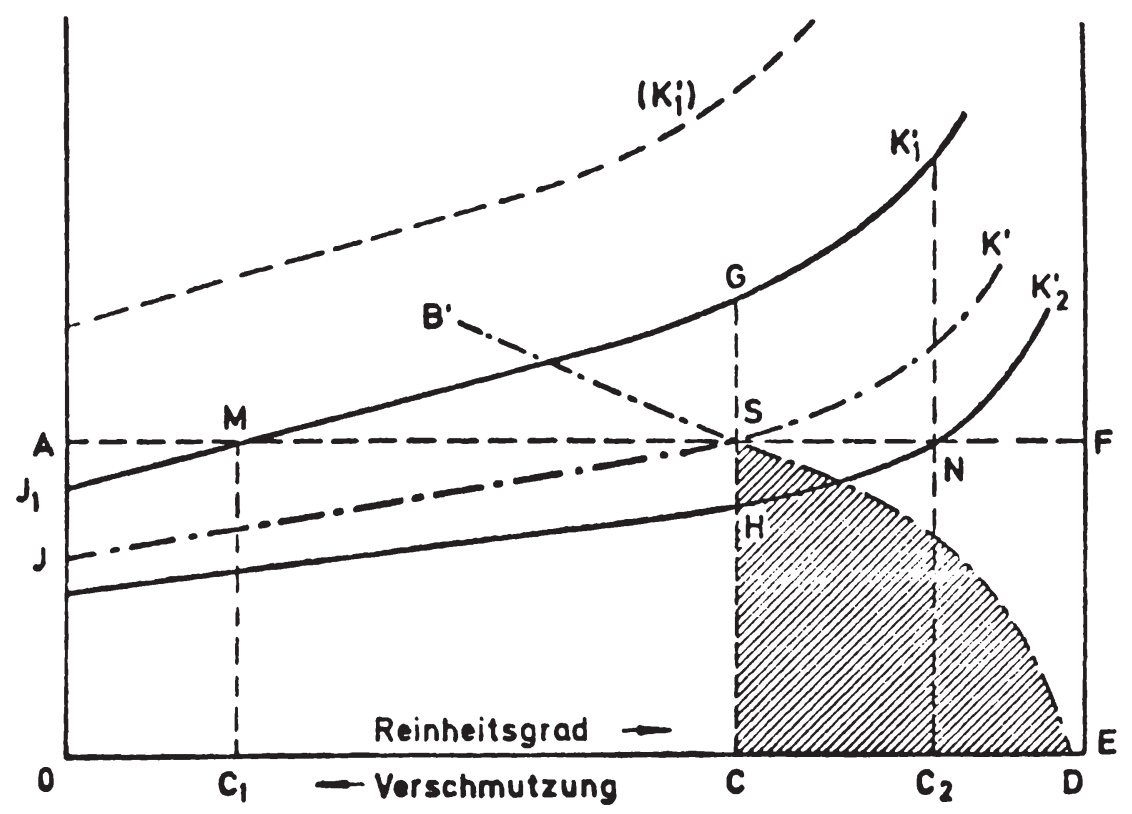

$\mathrm{Abb}$. 1: Berücksichtigung unterschiedlicher Grenzkosten der Abwasserreinigung ${ }^{2}$

Wollte man das Gewässergüteziel mittels einer einheitlichen Auflage verwirklichen, so müßten alle Verursacher bis zur vertikalen Gerade CG reinigen. Verursacher 1 hätte somit bedeutend höhere Grenzkosten (CG) als verursacher 2 ( $\mathrm{CH}$ ). Gesamtwirtschaftlich betrachtet bedeutet dies, daB das

1 Kann ein bestimmter Reinheitsgrad nur über den Bau/Ausbau einer Anlage erreicht werden, verläuft die Grenzkostenkurve an diesem Punkt stufenförmig.

2 Rat von Sachverständigen für Umweltfragen: Die Abwasserabgabe.... a.a.0., s. 13 . 
volkswirtschaftliche Kostenminimum nicht erreicht wird. Denn Verursacher 2 könnte mit relativ geringem Aufwand einen höheren Reinigungsgrad erzielen, und Verursacher 1 erreicht den Emissionsstandard nur mit überdurchschnittlichen Vermeidungskosten. Die postulierte "gesamtwirtschaftlich möglichst günstige Mittelverwendung" wird nicht erfüllt.

Würde man eine Abgabe erheben, die gemäß dem Schnittpunkt $S$ in Höhe von $O A$ ausfällt, reinigten kostenminimierend handelnde Emittenten bis zum Schnittpunkt ihrer Grenzkosten mit der Geraden AF. Die Grenzkosten wären also für alle Verursacher gleich hoch. Verursacher 1 würde nur bis $C_{1}$ reinigen und für die verbleibenden Emissionen Abgabe zahlen, während Verursacher 2 über $\mathrm{C}$ hinaus bis $\mathrm{zu} \mathrm{C}_{2}$ Reinigungsmaßnahmen ergreifen würde. Auf diese Weise wird derselbe Reinheitsgrad wie bei der Auflagenlösung, jedoch mit geringerer gesamtwirtschaftlicher Kostenbelastung erreicht. Fazit: Einheitliche Abgaben zeigen sich auch in der statischen Allokationseffizienz den einheitlichen Auflagen überlegen. Der Sachverständigenrat quantifizierte die Kosteneinsparungen der (reinen) Abgabenlösung gegenüber der (reinen) Auflagenlösung aufgrund seiner Berechnungen für die Bundesrepublik Deutschland mit 0,8-1 Mrd. DM/Jahr'

Abschließend sei darauf hingewiesen, daß die Abwasserabgabe auch insofern als ökonomischer Hebel der Gewässergütepolitik gesehen werden kann, als das Abgabenaufkommen neben der Deckung des Verwaltungsaufwandes gewässergütewirtschaftlichen Maßnahmen dienen soll und somit auch die für subventionen typische Wirkung entfaltet ${ }^{2}$. Die Mittel können bei den Einleitern, denen sie zugute kommen, zugleich die Basis für einen bis dahin nicht vorhandenen Abgabenanreiz schaffen oder eine Aufstockung des Abgabenanreizes herbeiführen.

1 Vgl. Rat von Sachverständigen für Umweltfragen: Die Abwasserabgabe ..., a.a.0., s. 17 .

2 Zu Wirkungsbeziehungen zwischen AbwAG und Subventionen vgl. Hoffmann, V., Ewringmann, D.: Auswirkungen .... a.a.0., s. 15 ff. 


\subsection{Weitere Ansätze zur Beurteilung von Auflagen und Abgaben}

Der vorgenommene "klassische" Vergleich zwischen Auflagen und Abgaben baut auf allokativen Effizienzkriterien auf. Im folgenden sollen vergleichsweise neuere modelltheoretische Ansätze für die Beurteilung von Auflagen und Abgaben - sowie anderer umweltpolitischer Instrumente - aufgezeigt werden. Im einzelnen wird auf Verteilungseffekte, die Unsicherheit über die Schadens- und Vermeidungskostenfunktionen, die unterschiedlichen Belastungswirkungen der Emissionen und die Verminderung der Zusatzlasten des allgemeinen steuersystems durch Verwendung des Abgabenaufkommens für steuersenkungen hingewiesen.

Verteilungswirkungen des Umweltschutzes werden in der Umweltökonomie in erster Linie auf allgemeiner, also nicht nach Instrumenten differenzierender Ebene diskutiert'. Im folgenden wird im wesentlichen auf Merck Bezug genommen, der einen Vergleich der Verteilungswirkungen von Auflagen und Abgaben in die umweltökonomische Literatur eingebracht hat ${ }^{2}$.

Auf der einzelwirtschaftlichen Ebene kann grundsätzlich zwischen direkten und indirekten Kostenverteilungseffekten unterschieden werden. Erstere betreffen die Kostenbelastungen derjenigen wirtschaftseinheiten, bei denen die umweltpolitischen Maßnahmen ansetzen, letztere die Möglichkeiten der uberwälzung dieser Kosten auf die Nachfrager der Produkte.

Bei (einheitlichen) Auflagenregelungen weichen die Kostenbelastungen der einzelnen Emittenten um so stärker voneinander $a b$, je unterschiedlicher die jeweiligen Vermeidungskostenfunktionen sind. Die einzelwirtschaftlichen Kosten, die durch (einheitliche) Abgaben verursacht werden, dürften

1 Siehe dazu die in Fußnote 4 auf S. 11 angegebene Literatur.

2 Vgl. zu den folgenden Ausführungen Merck, $P_{\text {.: Verteilungs- }}$ wirkungen .... a.a.O., s. $130 \mathrm{ff}$. 
erheblich weniger divergieren, da der Abgabesatz eine obergrenze der Belastungen vorgibt.

Geht man davon aus, daß der Abgabesatz etwa in Höhe der durchschnittlichen Grenzvermeidungskosten liegt, kann zwischen Emittenten mit über- und mit unterdurchschnittlichen Vermeidungskosten unterschieden werden. Während bei ersteren nicht eine allgemeingültige Antwort darauf gegeben werden kann, ob für sie die Auflagen- oder die Abgabenlösung kostengünstiger ist - dies hängt insbesondere von der Höhe des Abgabesatzes und dem Verlauf der Grenzvermeidungskostenfunktionen $a b$-, sind letztere, also die "effizient reinigenden" Emittenten, von Abgabenregelungen immer stärker belastet als von Auflagen ${ }^{1}$. Denn zum einen resultiert aus der beabsichtigten Anreizwirkung der Abgabe, daB höhere Reinigungsleistungen als bei einer Auflagenlösung erbracht werden. Zum anderen ist für die Restemission die Abgabe zu zahlen. Diejenigen Emittenten, die besonders effizient reinigen, sind also von Abgaben kostenmäBig am meisten betroffen. Unter der Annahme, daß kleine und mittlere Betriebe im Verhältnis zu großen Betrieben relativ höhere - durch die Produktion oder den Umsatz relativierte - umweltschutzbezogene Kosten haben, belasten Auflagen kleine und mittlere also stärker als größere Betriebseinheiten. Dagegen wirken Abgaben tendenziell egalisierend auf die Kostenverteilung zwischen Betrieben unterschiedlicher Größe.

Die Möglichkeiten der Uberwälzung von Kosten auf den Verbraucher ${ }^{2}$ sind grundsätzlich um so besser, je preisunelastischer die Nachfrage und je elastischer das Angebot ist. Dabei ist die Annahme der vollständigen Uberwälzung von

1 Nichols leitet analytisch her, daß fast alle Emittenten durch Abgaben kostenmäBig stärker belastet sind als durch Auflagen. Vgl. Nichols, A.L.: Targeting Economic Incentives for Environmental Protection, Cambridge/Mass., London 1984, S. $22 \mathrm{ff}$.

2 Vgl. im weiteren Merck, P.: Verteilungswirkungen .... a.a.0., s. $143 \mathrm{ff}$. 
Umweltschutzkosten weder theoretisch zwingend noch praktisch wahrscheinlich, berückichtigt man z.B. die stagnation und sättigung der Märkte.

Da der Preis sowie die preiselastizität eines Gutes auf einem Konkurrenzmarkt einheitlich sind, kann der einzelne Emittent die Umweltschutzkosten nur in der Höhe überwälzen, in der sie beim kostengünstigsten Emittenten anfallen. Als Folge der größeren Belastungsunterschiede durch Auflagen ist bei diesen auch die spanne der jeweils verbleibenden effektiven Belastungen weiter als bei den Abgaben. Bei letzteren dürfte die einheitlichere Kostenbelastung der Emittenten zudem eine leichtere und höhere Uberwälzbarkeit bedingen, weil beispielsweise von ähnlichen ưberwälzungsaktivitäten ausgegangen werden kann.

Die weiteren Kriterien für den Vergleich umweltpolitischer Instrumente sollen im folgenden nur vom Ansatz her aufgezeigt werden, weil sie für die Erfolgskontrolle des Abwasserabgabengesetzes, wie sie im Rahmen der vorliegenden Arbeit durchgeführt wird, nicht relevant sind.

Zunächst kann ein Vergleich der umweltpolitischen Instrumente unter dem Aspekt der Unsicherheit bzgl. der Schadens- und Vermeidungskostenfunktionen durchgeführt werden ${ }^{1}$. Es wird davon ausgegangen, daß die Umweltbehörde das Optimalziel auf der Grundlage der durchschnittlichen erwarteten Nutzen und Kosten festlegt, und Unsicherheit nicht nur hinsichtlich dieser Größen, sondern auch darüber besteht, inwieweit dieses Optimum vom tatsächlichen optimum abweicht. Das Verhältnis zwischen Umweltbehörde und Emittenten wird durch den sogenannten "principal-agent"-Ansatz beschrieben²: Die Umweltbehörde benötigt zur Bemessung der Instrumente Informationen über die Emissionen und die Vermeidungskostenfunktionen der Emittenten. Da diese nicht unbedingt bereit

1 Vgl. dazu Cansier, D.: Offentliche Finanzen ...., a.a.o., $\mathrm{s} .23 \mathrm{ff}$. und die dort angegebene Literatur.

2 Vgl. auch Siebert, H.: Umweltschäden ..., a.a.0., s. 13 f. 
sind, entsprechende Auskünfte zu erteilen, kann die Umweltbehörde das einleiterindividuelle optimum nur unzureichend festlegen. Der Instrumentenvergleich behandelt nun die Frage, ob Auflagen, Abgaben oder andere Instrumente besser an das Optimum heranführen.

Entstehen Schadwirkungen nicht erst durch das großräumige Zusammenwirken der einzelnen Emissionsquellen, sondern bereits am ort der Emission, so sind die Einzelemissionen ökologisch ungleichwertig, weshalb die Kostenmiminimierungseigenschaft der Emissionsabgabe aufgehoben ist. In diesem Kontext stellt sich die Frage, welches der umweltpolitischen Instrumente bei räumlicher Ungleichwertigkeit ökologisch und ökonomisch am effizientesten arbeitet ${ }^{1}$.

Der letzte zu erwähnende Ansatz für die Beurteilung umweltpolitischer Instrumente berücksichtigt die Möglichkeit, daB das Abgabenaufkommen zur senkung allgemeiner, mit hohen Zusatzlasten verbundenen steuern eingesetzt werden kann. Die Verminderung der "excess burden" ist ökonomisch bedeutend und rückt die Abgabenlösung - und damit auch die anderen Instrumente - in ein anderes Licht ${ }^{2}$.

Mit diesen neueren modelltheoretischen Aspekten ist die Beschreibung der umweltökonomischen Grundlagen abgeschlossen. Das Augenmerk richtet sich nun auf das Abwasserabgabengesetz und seine konkrete Ausgestaltung. Da es in das Wasserrecht eingebunden und darüber hinaus mit anderen wassergesetzen verknüpft ist, wird das gesetzliche Umfeld, sowelt notwendig, in die Darstellung einbezogen.

1 Eine Analyse nimmt Cansier vor. Vgl. Cansier, D.: Offentliche Finanzen .... a.a.0., s. 32 ff.

2 Weitere Ausführungen dazu vgl. ebenda, s. 37; Görres, P.A.: Der Zusatznutzen einer Umweltsteuer, in: Zeitschrift für Umweltpolitik \& Umweltrecht, 7. Jg. (1985), S. $45 \mathrm{ff}$. 


\section{Rechtliche Grundlagen des Abwasserabgabensystems}

\subsection{Das Wasserrecht in der Bundesrepublik Deutschland}

Das Wasserrecht regelt die Wasserwirtschaft, unter der nach DIN 4049 die "zielbewußte Ordnung aller menschlichen Einwirkungen auf das ober- und unterirdische wasser" verstanden wird.

Wassergesetzgebung und -verwaltung sind in der Bundesrepublik Deutschland auf Bund und Länder verteilt. Dem Bund hat laut Art. $75 \mathrm{Nr} .4$ Grundgesetz auf dem Gebiet der Wasserwirtschaft nur das Recht, Rahmenvorschriften zu erlassen.

Rahmengesetzgebung bedeutet, daß der Bund das Rechtsgebiet lediglich in groben zügen regeln kann. Die Rahmengesetzgebung kann jedoch punktuelle Vollregelungen enthalten, wenn den Ländern daneben ein genügend großer Regelungsspielraum gelassen wird.

Im Hinblick auf die Reformierung des Wasserrechts schlug die Bundesregierung Anfang der siebziger Jahre eine Verfassungsänderung vor, die dem Bund die konkurrierende Gesetzgebungskompetenz geben solltei. Sie wurde jedoch für den Bereich der Wasserwirtschaft von den Ländern, denen die Ausfüllung der Rahmengesetze obliegt, abgelehnt; gleichwohl erklärten sich diese aus Interesse an relativ bundeseinheitlichen Regelungen mit der praktizierten extensiven Auslegung des Begriffs "Rahmenvorschrift" einverstanden.

Der Bund hat weiterhin das Recht, allgemeine Verwaltungsvorschriften, die vor allem einen möglichst einheitlichen Vollzug der Rahmengesetze bewirken sollen, zu erlassen. Sie richten sich an die Vollzugsbehörden und sind de facto für die Bürger weitgehend verbindlich, da die Vollzugsbehörden nach diesen verfahren.

1 Vgl. Deutscher Bundestag 6. Wahlperiode: Drucksache $6 / 1298$ vom 20.10 .1970 . 
Die Länder sind neben der Ausfüllung der Rahmengesetze für die ergänzende Wassergesetzgebung zur Regelung selbständiger Bereiche, wie z.B. der Zweckverbände im Wasserwirtschaftsbereich, sowie für den Vollzug der Vorschriften zuständig.

Um die 1971 im Umweltprogramm aufgestellten Ziele der Gewässergütepolitik realisieren zu können, reformierte der Bund Mitte der siebziger Jahre das Wasserrecht grundlegend. Als zentrales Gesetz dieser "neuen" Wassergesetzgebung ist das Wasserhaushaltsgesetz (WHG) vom 16. Oktober $1976^{1} \mathrm{zu}$ nennen. Es regelt die allgemeinen Grundlagen der Wasserwirtschaft und bildet zusammen mit den wasserrechtlichen Landesgesetzen sowie einigen spezialgesetzen den ordnungsrechtlichen, wasserrechtlichen Teil der Gewässerschutzregelungen. Wie das WHG stellt das 1976 als Novum des deutschen Wasserrechts erlassene Abwasserabgabengesetz (AbWAG) vom 13. September $1976^{2}$ ein Rahmengesetz dar. Es regelt zusammen mit den ergänzenden landesrechtlichen Vorschriften den abgaberechtlichen Teil.

Im Rahmen der Reformierung des Wasserrechts wurden darüber hinaus vom Bund erlassen:

- das Gesetz über die Umweltverträglichkeit von Wasch- und Reinigungsmitteln (Waschmittelgesetz) vom 20. August 1975 (BGB1. I S. 2255); dieses Gesetz fällt in die konkurrierende Gesetzgebungskompetenz des Bundes für das Recht der Wirtschaft,

- das Gesetz über Maßnahmen zur sicherung der Altölbeseitigung (Altölgesetz) vom 11. Dezember 1979 (BGBI. I S. 2113) und

- das Gesetz über Umweltstatistiken vom 14. März 1980 (BGBI. I S. 311).

1 Bekanntmachung der Neufassung des Gesetzes zur Ordnung des Wasserhaushalts (Wasserhaushaltsgesetz - WHG) vom 16. Oktober 1976, BGB1. I S. 3017.

2 Gesetz über Abgaben für das Einleiten von Abwasser in Gewässer (Abwasserabgabengesetz - AbwAG) vom 13. September 1976, BGBI. I S. 2721. 
Es sei darauf hingewiesen, daB das nationale wasserrecht von den supranationalen Vorschriften der EG und den internationalen Regelungen ergänzt und teilweise überlagert wird ${ }^{1}$. So decken die 11 Richtlinien der Europäischen Gemeinschaft bereits weite Bereiche des Gewässerschutzrechts ab, und ihre verpflichtenden Normen sind in entsprechende nationale Regelungen umzusetzen, wenn es im Recht der Mitgliedstaten noch nichts Gleichwertiges gibt².

Wichtig für den Vollzug und die Wirkungsweise des AbwAG sind von oben genannten Regelungen jedoch nur das WHG und die Ausführungsgesetze der Länder zum AbwAG, auf die deshalb im weiteren näher eingegangen wird.

\subsection{Das Wasserhaushaltsgesetz unter besonderer Berück- sichtigung des $\$ 7$ a WHG}

Auch nach Einführung des AbwAG dominiert im deutschen Wasserrecht das Gesetz zur Ordnung des Wasserhaushalts. Es trat am 1. März 1960 erstmalig in Kraft, wurde mit dem 4. Anderungsgesetz 1976, das für diese Arbeit maßgeblich ist, grundlegend novelliert und mit dem 5. Anderungsgesetz 1986 nochmals erweitert ${ }^{3}$. Die 1976 eingeführten Regelungen umfassen insbesondere die Bereiche

1 Vgl. Roth, H. (Hrsg.): Wasserhaushaltsgesetz. Abwasserabgabengesetz. Textausgabe mit Einführung, schriftlichen Berichten des Innenausschusses des Deutschen Bundestages und Sachregister, Berlin 1977, S. 27 ff.; Veh, G.M., Hulsch, J., Edom, E.: Vorschriften der Europäischen Gemeinschaften auf dem Gebiet des Wassers - systematische Darstellung und Textsammlung, Köln 1984.

2 Weitere Ausführungen $\mathrm{zu}$ internationalen Regelungen und ihren Auswirkungen auf das nationale wasserrecht vgl. Kibat, K. $-D$.: Wasserverbände als Träger der Gewässergütepolitik, München 1988, S. $136 \mathrm{ff}$.

3 Wasserhaushaltsgesetz in der Fassung der Bekanntmachung vom 23. September 1986, BGB1. I S. 1529. 
- Gewässergüte,

- Lagern wassergefährdender Stoffe,

- Schutz bestimmter Gebiete,

- Uberwachung und

- straf- und Bußgeldbestimmungen ${ }^{1}$.

Für das Verständnis des AbwAG ist es notwendig, innerhalb der Gewässergüteregelungen auf den \$7a Abs. 1 WHG ${ }^{2}$ einzugehen, der die Anforderungen an das Einleiten von Abwasser regelt.

Mit dem $\$ 7$ a WHG ist die Erlaubnis für das Einleiten von Abwasser in ein Gewässer (Vorfluter) erstmalig an die Bedingung geknüpft, daß Menge und Schädlichkeit des Abwassers so gering gehalten werden müssen, wie es bei Anwendung der jeweils in Betracht kommenden Verfahren nach den allgemein anerkannten Regeln der Technik (a.a.R.d.T.) möglich ist. Darunter versteht man die Regeln, die in der praktischen Anwendung erprobt wurden und von den auf dem Fachgebiet tätigen Personen - insbesondere von denjenigen, die Anlagen planen, entwickeln, bauen, betreiben, begutachten, prüfen, genehmigen oder überwachen - für richtig gehalten werden ${ }^{3}$. Hierzu gehören sowohl Abwasserreinigungsmaßnahmen im engeren Sinn als auch Maßnahmen im Produktionsprozeß. "Allgemein anerkannte Regel der Technik i.s. des $\$ 7$ a ist beispielsweise, daß Abwasser, das biologisch abgebaut werden kann, in einer vollbiologischen Kläranlage behandelt wird." Mit der

1 Deutscher Bundestag 7. Wahlperiode: Drucksache 7/4546 vom 6.1.1976, S. $4 \mathrm{f}$.

2 Im weiteren nur als $\$ 7$ a WHG bezeichnet.

3 Diese Auslegung der "allgemein anerkannten Regeln der Technik" wurde von der Rechtsprechung zum Begriff "Regeln der Baukunst" in $\$ 330$ a. F. StGB entwickelt und von der Lehre auf die anderen gleichgelagerten Bestimmungen übertragen. Vgl. Gieseke, P., Wiedemann, W., Czychowski, M.: Wasserhaushaltsgesetz unter Berücksichtigung der Landeswassergesetze und des Wasserstrafrechts. Kommentar, 4.. neubearb. Auf 1.. München 1985, S. 242 (Hervorhebungen von Gieseke/Wiedemann/Czychowski).

4 Ebenda, S. 243, vgl. ebenso: Deutscher Bundestag 7. Wahlperiode: Drucksache $7 / 4546$ vom 6.1 .1976$, S. 6 . 
Formulierung "Anwendung der jeweils in Betracht kommenden Verfahren" wird der Gesetzgeber der Tatsache gerecht, daB es keine a.a.R.d.T. gibt, die für alle Einleiter bzw. deren Produktionsverfahren und Abwasserbeseitigung gleichermaßen gelten.

Diese Regelung hatte zur Folge, daß der Rahmen der Einleitungsmöglichkeiten in der Tat einschneidend neu definiert wurde: Bis 1976 konnten auch gänzlich ungereinigte Abwassereinleitungen rechtlich zulässig sein. Nach Berendes/Winters waren derartige Genehmigungen "nicht einmal selten"1.

Die a.a.R.d.T. wurden, differenziert nach der Herkunft des Abwassers, in 46 allgemeinen Verwaltungsvorschriften als sogenannte Mindestanforderungen, in der Regel für die Schadparameter Absetzbare Stoffe (AS)2, chemischer Sauerstoffbedarf $(\mathrm{CSB})^{3}$ und biochemischer sauerstoffbedarf (BSB⿺ $)^{4}$ festgelegt'. Darüber hinaus wurden für andere gruppen-

1 Berendes, K., Winters, K.P.: Das neue Abwasserabgabengesetz. Eine systematische Darstellung der wasser- und abgaberechtlichen Bestimmungen des ab 1.1 .1981 geltenden Abwasserabgabengesetzes mit Wiedergabe der wichtigsten Rechtsvorschriften, München 1981, S. 16.

2 Unter Absetzbaren Stoffen (AS) versteht man die in Abwässern vorkommenden ungelösten stoffe, die innerhalb einer bestimmten Zeit zu Boden sinken und sich dort absetzen.

3 Der CSB ist der Sauerstoff, der für die chemische Oxidation der organischen und anorganischen Inhaltstoffe verbraucht wird. Vgl. Institut Fresenius GmbH TaunussteinNeuhof W. Fresenius und W. Schneider, Forschungsinstitut für Wassertechnologie an der RWTH Aachen (FiW) B. Böhnke und $K$. Pöppinghaus (Hrsg.): Abwassertechnologie. Entstehung, Ableitung, Behandlung, Analytik der Abwässer, Berlin, Heidelberg, New York, Tokyo 1984,, S. 4.

- Der BSBs ist die Menge des Sauerstoffes, die bei $20^{\circ} \mathrm{C}$ in 5 Tagen beim Abbau der organischen Stoffe durch Mikroorganismen verbraucht wird. Vgl. ebenda, S. 3 .

- Zu den verwendeten Analyseverfahren vgl. Anlage zu $\$ 3$ AbwaG (siehe im Anhang der Arbeit) und die Allgemeinen Verwaltungsvorschriften nach $\$ 7$ a WHG. Die 19. AbwasserVwV (Zellstoff, Papier, Pappe) befindet sich im Anhang der Arbeit. 
individuelle Schadstoffe von Einleitern und für die Giftigkeit des Abwassers in Bezug auf Quecksilber, Cadmium, Fischgiftigkeit, soweit eine solche gegeben war, Grenzwerte aufgestellt. Dabei muß hervorgehoben werden, daß es sich um Minimalstandards handelt, denn aus Gründen des Gewässerschutzes können von den Ländern stets höhere Anforderungen an das Abwasser gestellt werden, als in den Mindestanforderungen festgelegt'.

Das WHG vom 23. September 1986 erweitert den \$7a WHG um die Behandlung sogenannter gefährlicher stoffe. Hierunter fallen stoffe, "die wegen der Besorgnis einer Giftigkeit, Langlebigkeit, Anreicherungsfähigkeit oder einer krebserzeugenden, fruchtschädigenden oder erbgutverändernden Wirkung als gefährlich zu bewerten sind."2 Für ihre Verminderung ist der stand der Technik, unter dem man die "besten verfügbaren technischen Hilfsmittel" 3 versteht, anzuwenden. Die relevanten stoffe bzw. Stoffgruppen und ihre Grenzwerte werden wiederum in den jeweiligen Verwaltungsvorschriften festgelegt.

1 Vgl. Deutscher Bundestag 7. Wahlperiode: Drucksache 7/4546 vom 6.1.1976, s. 6 .

2 \$ 7a Abs. 1 Satz 3 WHG vom 8. Oktober 1986.

3 Artikel 6 Abs. 1 Satz 4 der Richtlinie des Rates der Europäischen Gemeinschaften vom 4. Mai 1976, betreffend die Verschmutzung infolge der Ableitung bestimmter gefährlicher stoffe, in: Amtsblatt der Europäischen Gemeinschaften vom 26. Januar 1980, Nr. 20/43. Der "stand der Technik" für die Einleitung gefährlicher stoffe ist eine EG-rechtliche Vorgabe. 


\subsection{Struktur des Abwasserabgabengesetzes}

Untersuchungsgegenstand der vorliegenden Arbeit ist das AbwAG in der Fassung vom 13. September 1976. Seine wesentlichen Regelungen werden im folgenden beschrieben.

\section{Abgabetatbestand}

Für das Einleiten von Abwasser in ein Gewässer ist eine Abgabe zu zahlen. Sie wird durch die Länder erhoben

(\$ 1 AbwAG). Unter Abwasser wird sowohl Schmutz- als auch Niederschlagswasser, das von bebauten oder befestigten Flächen abfließt, verstanden ( $\$ 2$ AbwAG).

\section{Bemessungsgrundlage}

Die Höhe der Abwasserabgabe richtet sich nach der Schädlichkeit des Abwassers ( $\$ 3$ Abs. 1 AbwAG).

Die Schädlichkeit berechnet sich unter Zugrundelegung der Abwassermenge und der Schadparameter Absetzbare stoffe, oxidierbare Stoffe (CSB) und der Giftigkeit des Abwassers (Quecksilber, Cadmium, Fischgiftigkeit) in Anzahl der Schadeinheiten nach der Anlage zu \$ 3 AbwAG.

Eine Schadeinheit entspricht annähernd dem ungereinigten Abwasser, das ein Einwohner pro Jahr verursacht.

\section{Ermittlung der Schädlichkeit}

Die Anzahl der Schadeinheiten wird außer bei Niederschlagswasser und bei Kleineinleitungen aus den Werten des wasserrechtlichen Bescheids ermittelt (\$ 4 AbWAG)1. Dieser Bescheid, der aufgrund des wHG und des jeweiligen Landeswassergesetzes ergeht, enthält mindestens die Jahresschmutzwassermenge und für die einzelnen schadparameter folgende Werte:

1 Sind die benötigten werte noch nicht bescheidlich festgelegt, werden sie aufgrund behördlicher Uberwachung oder Schätzung ermittelt (\$ 6 Abs. 1 AbwAG). 
- den Regelwert; er ist der Wert, der im Mittel einzuhalten ist, d.h. das arithmetische Mittel aller Proben soll ihn nicht überschreiten; und

- den Höchstwert, der in keinem Fall überschritten werden darf.

Durch Halbierung des Höchstwertes erhält man den Bezugswert. Bei der Ermittlung der Schadeinheiten sind die Regelwerte, mindestens jedoch die Bezugswerte zugrundezulegen. Wird der Höchstwert mehr als einmal überschritten, wird das arithmetische Mittel der Differenzen zum Höchstwert auf den Bezugswert aufgeschlagen (erhöhter Bezugswert) 1 .

4. Abgabepflicht und Abgabesatz

Abgabepflichtig sind alle, die Abwasser in Gewässer einleiten ( $\$ 9$ Abs. 1 AbwAG). Mithin gilt das AbwaG nur für die sogenannten Direkteinleiter. Von Einleitern in kommunale Reinigungsanlagen oder Abwasserverbandsanlagen (Indirekteinleiter) werden vom abgabepflichtigen Betreiber dieser Anlagen Abgaben in Form von Beiträgen oder Gebühren erhoben.

Die Abgabepflicht begann am 1. Januar 1981 mit einem Abgabesatz von 12 DM pro Schadeinheit und erhöhte sich jedes Jahr um 6 DM bis 1985. Seit 1986 beträgt der Abgabesatz 40 DM ( $\$ 9$ Abs. 4 AbwAG).

Hält der Abwassereinleiter die Mindestanforderungen nach \$ 7a WHG ein, halbiert sich der Abgabesatz. Gelten im Bescheid höhere Anforderungen, liegen die sogenannten Uberwachungswerte also über den Mindestanforderungen, so ist deren Einhaltung Bedingung für die Abgabenhalbierung (\$ 9 Abs. 5 AbwAG).

1 Nähere Erläuterungen $z u$ dem höchst komplizierten System aus Regel-, Höchst- und Bezugswert vgl. Schendel, F.A.: Die Vielfalt der wasserrechtlichen werte und ihre Bedeutung insbesondere im Gewässerstrafrecht, in: Korrespondenz Abwasser, 32. Jg. (1985), Heft 9, S. 752 ff. 
Die Bundesregierung kann unter Zustimmung des Bundesrates "zur Abwehr erheblich nachteiliger wirtschaftlicher Entwicklungen" Einleiter, die Maßnahmen zur Verringrung der Schädlichkeit durchführen oder durchführen lassen, längstens bis zum 31. Dezember 1989 ganz oder teilweise von der Abgabepflicht befreien (sogenannte Härteklausel, \$ 9 Abs. 6 AbwAG).

\section{Ausnahmen von der Abgabepflicht}

Für einen Zeitraum von drei Jahren vor der geplanten Inbetriebnahme einer Abwasserbehandlungsanlage entsteht die Abgabepflicht nicht in der Höhe, die der Schädlichkeit entspricht, die durch diese Anlage vermindert wird. Dabei muß die Minderung wenigstens $20 \%$ betragen

(5 10 Abs. 3 AbwAG).

Die Abgabepflicht entsteht rückwirkend, insoweit die erwartete Minderung nicht eintritt.

6. Verwendung des Abgabeaufkommens

Das Aufkommen ist zweckgebunden für Maßnahmen, die der Erhaltung oder Verbesserung der Gewässergüte dienen (\$ 13 Abs. 1 AbwAG). Als solche gelten z.B. der Bau von Abwasserreinigungsanlagen, der Bau von Anlagen zur Beseitigung des Klärschlamms und Maßnahmen im und am Gewässer zur Beobachtung und Verbesserung der Gewässergüte wie Niedrigwasseraufhöhung oder sauerstoffanreicherung sowie zur Gewässerunterhaltung ( $\$ 13$ Abs. 2 AbwAG). Die Länder können weiterhin den Verwaltungsaufwand, der durch den Vollzug des AbwAG und der ergänzenden landesrechtlichen Vorschriften entsteht, durch das Abgabeaufkommen decken ( $\$ 13$ Abs. 1 AbwAG).

Das skizzierte AbwAG wurde 1987 novelliert ${ }^{1}$ und tritt in den wesentlichen Punkten dieser neuen Fassung am 1. Januar 1989 in Kraft. Zwei Ziele bestimmen die Ausgestaltung der Novellierung:

1 Bekanntmachung der Neufassung des Abwasserabgabengesetzes vom 5. März 1987, BGBl. I S. 880 . 
1. Im Hinblick auf die Verbesserung der Gewässergüte soll die Abwasserabgabe einen Anreiz zur Realisierung weiterer Reinigungsmaßnahmen, insbesondere auch zur Behandlung "gefährlicher stoffe" ausüben. Der Anreiz soll erreicht werden, indem

- für bislang nicht berücksichtigte Schadparameter eine Abgabe erhoben wird,

- nicht mehr die Regel-, Höchst- und Bezugswerte, sondern die ordnungsrechtlichen Uberwachungswerte Grundlage der Abgabenberechnung sind und sich deshalb die Abgabe drastisch erhöhen kann'1,

- Ober- und Unterschreitungen der in \$7a WHG gestellten Anforderungen an die Abwasserreinigung abgaberechtlich überproportional erfaBt werden und

- ein Teil der Investitionsausgaben gegen die Abgabe verrechnet werden kann.

2. Der Verwaltungsaufwand soll gesenkt werden, indem der Abgabenvollzug eben durch die uberwachungswerte als Bemessungsgrundlage noch stärker an den ordnungsrechtlichen Vollzug anknüpft.

Wenngleich die Novellierung nicht in den Untersuchungszeitraum der vorliegenden Arbeit fällt, wird sie am Ende der Arbeit im Lichte der gewonnenen Erkenntnisse kritisch gewürdigt. Die nun anschließenden Ausführungen beziehen sich wieder auf das AbwAG vom 13. September 1976.

1 Da der Uberwachungswert in der Regel etwa 40 \% höher als der Regelwert liegt, erhöht sich, wenn der Uberwachungswert nicht geändert wird, auch die Abgabe um etwa $40 \%$. Vgl. Berendes, $K_{.}$: Was bedeutet die Neufassung der Wassergesetze für die Industrie?, in: Verband Deutscher Papierfabriken (Hrsg.), VDP-Frühjahrstagung '86, Teil I, Nr. 58 der Schriftenreihe, Bonn 1986, S. 13. Schätzungen der Bayer AG belaufen sich sogar auf $50 \%$. Vgl. O.V.: Schlag ins Abwasser, in: wirtschaftswoche, 40. Jg. (1986), Nr. 26 vom 20.6.1986, S. 22 . 
2.4 Die technische Ausgestaltung des Abwasserabgabensystems

\subsubsection{Die instrumentelle Verknüpfung von Wasserhaushalts- und Abwasserabgabengesetz}

Das AbwAG kann nicht isoliert vom wasserhaushaltsgesetz (WHG) untersucht werden, da, wie schon aus der struktur des AbwAG ersichtlich, zwischen den beiden Gesetzeswerken zwei wichtige Verknüpfungen bestehen ${ }^{1}$ :

Zum einen bildet der wasserrechtliche Bescheid die Grundlage der Abgabenerhebung, weil er die Bemessungswerte (Jahresschmutzwassermenge, Regel- und Höchstwerte der Schadparameter) für die Ermittlung der Anzahl der Schadeinheiten enthält. Der Abgabenvollzug ist somit unmittelbar an den Vollzug des Wasserhaushaltsgesetzes gekoppelt.

Zum anderen orientieren sich beide Regelwerke an den a.a.R.d.T.; beim WHG dienen sie als Kriterium für die Einleitungserlaubnis, und bei ihrer Einhaltung - bzw. bei der Einhaltung strengerer Auflagen - halbiert sich die Abwasserabgabe. Das Eingriffsniveau der beiden Gesetze ist damit weitgehend identisch.

Die angesprochenen Regelungen dokumentieren nicht nur die enge Verzahnung von WHG und AbWAG, sondern verdeutlichen auch die Vorherrschaft des Ordnungsrechts vor dem Abgabenrecht, sei es in der Rahmengesetzgebung oder in den Ausführungsgesetzen der Länder.

1 Vgl. dazu auch Ewringmann, D.: Wirtschaftliche Auswirkungen der Abwasserabgabe - theoretische und praktische Uberlegungen, in: Universität Dortmund, Institut für Umweltschutz (Hrsg.): Umweltschutz der achtziger Jahre. Eine standortbestimmung ökologischer und ökonomischer Anforderungen, Reihe B, Bd. B 14, Berlin 1981, S. 114. 


\subsubsection{Die Ausführungsgesetze der Länder als Vollzugs- instrumente}

WHG und AbwAG werden, da sie nur in Einzelbereichen unmittelbar anwendbar sind, erst durch die ausfüllenden Landesgesetze vollzugsfähig. Auch wenn die Rahmengesetze eine gemeinsame Basis geschaffen haben, eröffnet sich hier ein nicht unwesentlicher Regelungsspielraum. Aus dem Katalog der Ausführungsbestimmungen, zu denen das AbwAG die Länder ermächtigt, seien hier einige Tatbestände genannt:

- Bewertung absetzbarer stoffe nach ihrem Gewicht anstelle ihres Volumens ( $\$ 3$ Abs. 4 AbwAG),

- Festlegung abzugsfähiger Vorbelastungen einheitlich für Gewässer oder Teile von Gewässern ( $\$ 4$ Abs. 3 AbwAG),

- Abwälzbarkeit der Abgabe auf Indirekteinleiter ( 99 Abs. 2 AbwAG),

- Erklärungspflicht des Abgabepflichtigen ( $\$ 11$ Abs. 2 AbwAG) und

- Deckung des Verwaltungsaufwandes aus dem Abgabeaufkommen ( $\$ 13$ AbWAG).

Neben diesen und weiteren Regelungen im materiellen Abgaberecht unterliegt den Ländern fast vollständig das formelle Abgabenrecht, das die Zuständigkeiten der Behörden und das Verwaltungsverfahren, also insbesondere die Festsetzung, Erhebung und Vollstreckung der Abgabe umfaBt.

Weil von seiten der Länder ein Bedürfnis nach möglichst einheitlichen Regelungen bestand, erarbeitete die Länderarbeitsgemeinschaft "Wasser" (LAWA) eine Mustervorlage für die Ausführungsgesetze der Länder. Da diese dennoch unterschiedlich ausfielen, kann von einer einheit-

1 Vgl. dazu auch Rat von Sachverständigen für Umweltfragen: Umweltgutachten 1978, stuttgart, Mainz 1978, S. 120. 
lichen Abwasserabgabenerhebung in der Bundesrepublik nicht die Rede sein'1.

1 Vgl. dazu auch Bundesminister des Innern (Hrsg.): Erfahrungsbericht zum Abwasserabgabengesetz, Bonn 1983, S. 9 f. 


\section{Finanzwirtschaftliche Würdigung der Abwasserabgabe}

\subsection{Beschreibung des Abgabetatbestandes anhand "steuer"systematischer Merkmale}

Die Abwasserabgabe ist ein finanzwirtschaftliches Instrument und soll in diesem und im nächsten Abschnitt als solches gekennzeichnet werden. Zunächst wird die Abwasserabgabe anhand "steuer"systematischer Kriterien beschrieben. "steuer"systematik impliziert in diesem Fall nicht, das es sich bei der Abwasserabgabe um eine steuer handelt; vielmehr wird der Begriff gemäß dem Vorschlag Dickertmanns in einer umfassenden Betrachtungsweise verwendet, weil "bekannt ist, daß steuerpolitiker aus verschiedenen Gründen - nicht zuletzt auch in Zeiten mit hohen fiskalischen Belastungen der Bürger - dazu neigen, aus dem steuersystem 'auszubrechen' und jenseits davon 'steuerähnliche Abgaben' (sog. Quasisteuern) einzurichten (hidden finance), diese aber aus mancherlei Gründen dem steuersystem vorenthalten."1

Im Anschluß an diese Betrachtung wird die Abwasserabgabe in das system der öffentlichen Abgaben eingeordnet.

Dickertmann hat für die Beschreibung von finanzwirtschaftlichen Regelungen mit umweltschützenden Zielen ein Ordnungsraster entworfen, das in Tab. 1 ausschnittweise wiedergegeben ist $^{2}$. GemäB dieser systematik sind finanzwirtschaftliche Regelungen mit Umweltbezug folgendermaßen $\mathrm{zu}$ kategorisieren:

1 Dickertmann, D.: Maßnahmen für den Umweltschutz im Rahmen des bestehenden steuersystems, in: Schmidt, $K$. (Hrsg.), offentliche Finanzen und Umweltpolitik I, Schriften des Vereins für Socialpolitik, Gesellschaft für Wirtschaftsund Sozialwissenschaften, Neue Folge Bd. 176/I, Berlin 1988 , s. 100 .

2 Vgl. ebenda, S. 94. Gemäß der Thematik dieses Abschnitts sind die von Dickertmann vorgeschlagenen Kriterien umweltspezifischer Art, die er ebenfalls zur Beschreibung steuerlicher Regelungen verwendet, nicht aufgeführt. 
Kriterien steuersystematischer Art

1. Lenkungsstrategie

- steuerbelastung (z.B. Emissionsabgabe)

- Entlastung (z.B. Steuervergünstigung)

2. Instrumenteneinsatz

- mit Primärziel

- als Nebeneffekt

durch

- Veränderung bestehender Regelungen

- Einführung neuer Regelungen

3. Besteuerungsprinzipien

- Leistungsfähigkeitsprinzip

- Aquivalenzprinzip

4. Finanzierungsfolgen

- Mehreinnahmen-Verwendung

* allgemeine Haushaltsmittel

* Ersatzleistungen (passive Sanierung)

* umweltbezogene Zweckbindung (aktive Sanierung)

* umweltbezogene Zweckbindung ("Zangenwirkung")

- Mindereinnahmen

* echte steuermindereinnahmen

* steuerkredit (Zinsverzichte)

b. 1: Merkmale "steuer"systematischer Art zur Beschreibung von finanzwirtschaftlichen Regelungen mit umweltschützenden Zielen

stens ist zu festzustellen, welche Lenkungsstrategie sich nter der untersuchten Regelung verbirgt. Das umweltzogene Verhalten der Wirtschaftssubjekte kann zum einen rch zusätzliche steuerbelastungen, zum anderen durch euerliche Entlastungsmaßnahmen beeinflußt werden.

e beiden Lenkungsstrategien verhalten sich aus fiskalische cht diametral entgegengesetzt, denn steuerbelastungen deuten - wenn die Ideallösung der Pigou-steuer ausgeschlos n wird' - für den staat zunächst einmal Mehreinnahmen,

Vgl. ebenda, S. 97 und die dort angegebene Literatur. 
während Entlastungsmaßnahmen Einnahmeminderungen zur Folge haben. Eine weitere Polarität ist darin zu sehen, daß steuerliche Entlastungsmaßnahmen im Widerspruch zum Verursacherprinzip stehen', während beispielsweise Emissionsabgaben auf diesem aufbauen.

Zweitens ist $z u$ prüfen, ob die steuerlichen Regelungen in erster Linie umweltpolitische Ziele anstreben oder ob diese mehr beiläufig bei insgesamt anderer Zielorientierung der Maßnahme verfolgt werden. In diesem Zusammenhang ist auch die Frage zu stellen, ob es sich um gänzlich neue Abgabetatbestände handelt oder ob bestehende Steuern um umweltschützende Aspekte erweitert wurden.

Drittens sind die umweltbezogenen Regelungen daraufhin zu beleuchten, ob die Besteuerung stärker an das Leistungsfähigkeitsprinzip oder an das aquivalenzprinzip anbindet ${ }^{2}$. Sucht man nach Gemeinsamkeiten mit umweltpolitischen Handlungsprinzipien, so läßt sich ersteres eher dem Gemeinlastprinzip, letzteres mehr dem Verursacherprinzip zuordnen ${ }^{3}$. Aquivalenzbeziehungen können bei zahlreichen Umweltabgaben über die Zweckbindung und Verwendung des steueraufkommens hergestellt werden`.

1 Vgl. MeBerschmidt, K.: Umweltabgaben ..., a.a.o., s. 44.

2 Während das Leistungsfähigkeitsprinzip auf die individuelle Wirtschaftskraft der Abgabepflichtigen abstellt, werden beim Aquivalenzprinzip bei denjenigen Abgaben erhoben, denen die zu finanzierenden Leistungen zugute kommen. Vgl. Zimmermann, H., Henke, K.-D.: Finanzwissenschaft. Eine Einführung in die Lehre von der öffentlichen Finanzwirtschaft, 4., überarbeitete und ergänzte Auflage, München 1985, S. 115 f. und 122 f.

3 Vgl. Dickertmann, D.: Maßnahmen ..., a.a.o., s. 98; Isensee, J.: Nichtsteuerliche Abgaben - ein weiBer Fleck in der Finanzverfasung, in: Hansmeyer, K.H. (Hrsg.), staatsfinanzierung im Wandel, Schriften des Vereins für Socialpolitik, Gesellschaft für Wirtschafts- und Sozialwissenschaften, Neue Folge Band 134, Berlin 1982, S. 446; im selben Band: Cansier, D.: Steuer und Umwelt: Zur Effizient von Emissionsabgaben, S. 766.

- Vgl. Ewringmann, D., Schafhausen, F.: Abgaben ..., a.a.o., S. 29 . 
Viertens sind umweltschützende Abgabetatbestände anhand der Verwendung der steuer(mehr)einnahmen bzw. der Finanzierung der in Anspruch genommenen steuervergünstigungen zu beurteilen'. Werden steuermehreinnahmen nicht gemäB dem Nonaffektationsprinzip den allgemeinen Haushaltsmitteln zugeführt, ist ihr Einsatz mehr oder weniger zweckgebunden, also umweltbezogen. Bei den steuermindereinnahmen ist zwischen dem endgültigen Einnahmeausfall (z.B. bei steuerbefreiungen) im Jahr der Inanspruchnahme einer steuervergünstigung und dem steuerkredit (z.B. bei Sonderabschreibungen) zu unterscheiden.

Wird nun auf die Abwasserabgabe Bezug genommen², so läßt sich diese anhand der vorgestellten Kriterien beschreiben als eine zusätzliche steuerbelastung, die in einem "eigenen" Gesetz geregelt ist, welches von vornherein aus umweltpolitischen Gründen in das Abgabensystem eingeführt und zwischenzeitlich novelliert wurde. Die Abgabenerhebung knüpft an das Aquivalenzprinzip an, und das Abgabenaufkommen ist zweckgebunden für den mit dem Gesetzesvollzug entstehenden Verwaltungsaufwand und für Maßnahmen, die zur Erhaltung oder Verbesserung der Gewässergüte dienen.

1 Vgl. Dickertmann, D.: Maßnahmen ..., a.a.O., s. 98 f. und die dort angegebene Literatur.

2 Vgl. dazu auch ebenda, S. 161. 


\subsection{Die Abwasserabgabe im System der öffentlichen Abgaben}

Die umweltökonomische Diskussion hat für Abgaben mit umweltbezogenen Zielen eine Fülle von Wortschöpfungen hervorgebracht. Man spricht von Umweltsteuern ${ }^{1}$, Emissionssteuern und -abgaben ${ }^{2}$, steuern im sinne von nichtfiskalischen Anreizsteuern ${ }^{3}$, Verschmutzungsabgaben ${ }^{4}$, Umweltgebühren ${ }^{5}$, Umweltpfennigen ${ }^{6}$ und Umweltabgaben ${ }^{7}$. Letztere, also die Umweltabgaben, dürften sich gewissermaßen als oberbegriff für all diese Bezeichnungen durchgesetzt haben. In der politischen Diskussion werden geradezu inflationistisch die verschiedensten bestehenden und vorgeschlagenen Regelungen als Umweltabgaben bezeichnet. "In Anbetracht der positiven öffentlichen Bewertung von nahezu allem, was mit Umweltschutz zusammenhängt oder mit ihm in Verbindung gebracht werden kann, besitzt der Begriff der Umweltabgabe unweigerlich auch

1 Vgl. Frey, B.S.: Umweltökonomie, Göttingen 1972, S. 114; Görres, P.A.: Der Zusatznutzen einer Umweltsteuer, in: Zeitschrift für Umweltpolitik \& Umweltrecht, 7. Jg. (1985), Heft 1, S. 45 ff.

2 Vgl. Dickertmann, D.: Maßnahmen ..., a.a.0., S. 169; Nowotny, E.: Wirtschaftspolitik und Umweltschutz, Freiburg i.Br. 1974, S. 187; Pethig, R.: Umweltökonomische Allokation mit Emissionssteuern, Tübingen 1979;

3 Vgl. Siebert, H.: Analyse ..., a.a.O., S. 19.

4 Vgl. Rehbinder, E.: Allgemeines Umweltrecht, in: Salzwedel, J. (Hrsg.), Grundzüge des Umweltrechts, Berlin 1982 , S. 109 .

- Vgl. Rat von Sachverständigen für Umweltfragen: Umweltgutachten 1974, S. 159 f.

6 Vgl. Hansmeyer, K.H.: Abgaben ..., a.a.0., S. 262.

7 Vgl. u.a. Brunowsky, R. - D., Wicke, L.: Der Okoplan. Durch Umweltschutz zum neuen Wirtschaftswunder, München, Zürich 1984, S. 91; Hansmeyer, K.H., mit Caesar, R., Koths, D., Siedenberg, A.: Steuern auf spezielle Güter, in: Handbuch der Finanzwissenschaft, Bd. 2, 3., gänzl. neubearb. Aufl., Tübingen 1980, S. 729; Hartkopf, G., Bohne, E.: Umweltpolitik .... a.a.0., s. 197; Hauff, V.: Umweltpolitische Konzeptionen aus politischer sicht, in: Wirtschaftsdienst, 64. Jg. (1984), Heft 4, S. 163 . 
eine finanzpsychologische Qualität, die sich der Abgabengesetzgeber verständlicherweise zunutze machen möchte."1

Umweltabgaben können als Entgelt für eine Umweltnutzung, als Mittel der Verhaltenslenkung, als Ausgleichsmaßnahme bei Umweltschutzinvestitionen und als Finanzierungsmaßnahme dienen ${ }^{2}$. Zumeist vereinigen Umweltabgaben mehrere dieser Funktionen in sich.

Aus finanzwirtschaftlichem Blickwinkel wirft sich die Frage auf, wie sich die wie auch immer gearteten Umweltabgaben in das System der öffentlichen Abgaben einordnen lassen.

Das klassische deutsche Abgabentrias besteht aus den steuern, Gebühren und Beiträgen. Steuern sind gemäß $\$ 3$ Abs. 1 AO "Geldleistungen, die nicht eine Gegenleistung für eine besondere Leistung darstellen und von einem öffentlichrechtlichen Gemeinwesen zur Erzielung von Einnahmen allen auferlegt werden, bei denen der Tatbestand zutrifft, an den das Gesetz die Leistungspflicht knüpft; die Erzielung von Einnahmen kann Nebenzweck sein. Zölle und Abschöpfungen sind Steuern im Sinne dieses Gesetzes." Für den Begriff der steuer ist demgemäß maßgebend, daß

- es sich um Geldleistungen handelt,

- die Geldleistung hoheitlich auferlegt wird und

- die Geldleistung einem öffentlich-rechtlichen Gemeinwesen zufließt ${ }^{3}$.

Weiteres Merkmal des steuerbegriffs ist zum einen die Absicht, Einnahmen zur Deckung des allgemeinen Finanzbedarfs des staates bzw. der Gemeinden zu erzielen und zum anderen,

1 Meßerschmidt, K.: Umweltabgaben ..., a.a.O., s. 18.

2 Vgl. ebenda, S. 35 ff.

3 Vgl. Patzig, W.: Steuern - Gebühren - Beiträge und "Sonderabgaben" - Uberlegungen aus AnlaB der Urteile des Bundesverfassungsgerichts zur Berufsausbildungs- und zur Schwerbehindertenabgabe, in: Die offentliche Verwaltung, 34. Jg. (1981), Heft 19, s. 733. 
daß eine besondere Gegenleistung des steuergläubigers nicht vorliegt'1.

Von den steuern unterscheiden sich die Gebühren durch das Prinzip der speziellen Entgeltlichkeit. Die Gebühr stellt eine Abgabe dar, "die für individuell zurechenbare öffentliche Leistungen $\mathrm{zu}$ entrichten ist und deren Höhe sich nach politischen Zielen unter Berücksichtigung der Nachfragestruktur richtet."2 Sie ist jedoch in der Regel an den Kosten der in Anspruch genommenen öffentlichen Leistung bzw. Einrichtung orientiert.

Beiträge als dritte Abgabenart sind dagegen eher als Umlage zu kennzeichnen, die "aus Anlaß einer oder mehrerer Leistungen des Abgabeberechtigten zur Deckung der Kosten dieser Leistungen erhoben wird und einen Ausgleich für die wirtschaftlichen Vorteile bezweckt, die dem Abgabepflichtigen durch diese Leistungen erwachsen, wobei im Gegensatz zur Gebühr nicht erforderlich ist, daß der Abgabenpflichtige den angebotenen Vorteil auch tatsächlich in Anspruch nimmt."3 Als Leistungsempfänger lassen sich nur ganze Gruppen identifizieren, auf deren einzelne Mitglieder die Kosten nach festgelegten Hilfsmaßstäben umzulegen sind4. Auch dem Beitrag liegt also das Prinzip der Gegenleistung bzw. Entgeltlichkeit zugrunde. Im Gegensatz zur Gebühr ist es jedoch nicht erforderlich, daß der Abgabenpflichtige den angebotenen Vorteil auch wirklich in Anspruch nimmts.

Dieses System hoheitlicher Abgaben ist in den letzten Jahren um eine weitere Abgabenart, nämlich die Sonderabgaben,

1 Vgl. ebenda, S. 734.

2 Hansmeyer, K.H., Fürst, D.: Die Gebühren, stuttgart, Berlin, Köln, Mainz 1968, S. 34.

3 Patzig, W.: Steuern ..., a.a.0., s. 735 .

4 Vgl. Bohley, P.: Gebühren und Beiträge, in: Handbuch der Finanzwissenschaft, Bd. 2, 3., gänzl. neubearb. Aufl., Tübingen 1980, s. 924.

- Vgl. Patzig, w.: steuern ..., a.a.O., s. 735. 
ergänzt worden. Unter diesen werden Abgaben zusammengefaßt, die sich nur schwer in die herkömmliche Nomenklatur einordnen lassen. Sie werden auch als "zweckgebundene öffentliche Abgaben"1, "Quasisteuern"2, "außersteuerliche Sonderabgaben"3 und "Pfennigabgaben"4 bezeichnet.

Sonderabgaben werden in der Regel zweckgebunden erhoben und haben Finanzierungs-, Ausgleichs- und/oder Lenkungsfunktion' . Caesar nennt als vierten Funktionstyp die Verursacherabgaben, mit denen die Anlastung externer Effekte bei den Verursachern bezweckt wird ${ }^{6}$. Verursacherabgaben können jedoch den Lenkungsabgaben zugeordnet werden, weil sie ebenfalls auf die Beeinflussung des Verhaltens der Wirtschaftssubjekte ausgerichtet sind? .

Was nun die Einordnung der oben angesprochenen Umweltabgaben in das deutsche Abgabensystem betrifft, so scheint aus funktionaler sicht ihre Zuordnung $z u$ den Sonderabgaben

1 Mußgnug, $R_{\text {.: }}$ Die zweckgebundene öffentliche Abgabe, in: Festschrift für E. Forsthoff, München 1972, S. 259 ff.

2 Schemmel, L.: Quasi-Steuern - Gegen den Wildwuchs steuerähnlicher Sonderabgaben, hrsg. vom Karl-BreuerInstitut des Bundes der Steuerzahler, Heft 46, Wiesbaden 1980 .

3 Friauf, K.H.: Zur Zulässigkeit von außersteuerlichen Sonderabgaben, in: Festschrift für W. Haubrichs, Der Bürger als objekt der staatlichen Finanzpolitik, 2. Aufl., Bad Wörrishofen 1977, S. 103 ff.

4 Caesar, R.: "Pfennigabgaben" - fiskalisch motivierte steuertarnung und Rückfall in die Fondswirtschaft? Eine finanzwissenschaftliche Analyse, in: Finanzarchiv Neue Folge Bd. $38(1980)$, S. 385 ff.

- Vgl. u.a. Kirchhoff, P.: Verfassungsrechtliche Beurteilung der Abwasserabgabe des Bundes. Die Grundkonzeption des Abwasserabgabengesetzes des Bundes im verfassungsrechtlichen System der öffentlichen Abgaben, Berlin 1983, S. $24 \mathrm{ff}$.

- Vgl. Caesar, R.: "Pfennigabgaben" ..., a.a.0., s. 389; ebenso Patzig, W.: Steuern ....,a.a.O., s. 738 und Isensee, J.: Nichtsteuerliche Abgaben ..., a.a.O., S. 445.

7 Vgl. Ewringmann, D., Schafhausen, F.: Abgaben ..., a.a.0., S. 27 . 
prädestiniert. So versteht Brandt Umweltabgaben (Lenkungsabgaben) als einen "Unterfall"1 von Sonderabgaben, und auch Henseler nimmt eine gewisse Zuordnung vor, wenn er von "umweltrechtlichen Sonderabgaben"2 spricht, deren "Prototyp" er in der Abwasserabgabe sieht. Wie Meßerschmidt belegt - und wie hier nicht vertiefend ausgeführt werden soll - können Umweltabgaben jedoch als steuern, Gebühren, Beiträge und Sonderabgaben ausgestaltet sein ${ }^{3}$. Das bedeutet allerdings nicht, daß jede Umweltabgabe in jeder Abgabenart realisiert werden kann.

Wird nun das Augenmerk auf die Abwasserabgabe gelenkt, so ist zunächst festzustellen, daß lange Zeit streitig war, wie sie in das system der öffentlichen Abgaben einzuordnen sei. In den Entstehungsjahren wurde mehrfach die Meinung vertreten, die Abwasserabgabe gleiche einer Gebühr für die Inanspruchnahme von Gewässern als Entsorgungsmedium4. Anfang der achtziger Jahre nahm Kirchhoff im Auftrag des Umweltbundesamtes eine verfassungsrechtliche Beurteilung der Abwasserabgabe vor's.

GemäB seinen Ausführungen ist die Abwasserabgabe

1 Brandt, E.: Rechtliche Fragen beim Einsatz von Lenkungsabgaben als Instrumente der Umweltpolitik - unter besonderer Berücksichtigung der Abwasserabgabe, in: Jarre, J. (Hrsg.), Umweltrecht in der Bundesrepublik Deutschland. Erfolge, Probleme, Perspektiven, Loccumer Protokolle, Bd. 18, Rehburg-Loccum 1984, S. 77.

2 Vgl. Henseler, P.: Begriffsmerkmale und Legitimation von Sonderabgaben, Baden-Baden 1984, S. 16 .

3 Vgl. MeBerschmidt, K.: Umweltabgaben ..., a.a.0., S. $20 \mathrm{ff}$. und $110 \mathrm{ff}$.

1 Vgl. u.a. Dahme, H.: Abwasserabgabengesetz, Kissing 1976, S. 15; Salzwedel, J.: Studien zur Erhebung von Abwassergebühren, Berlin 1972, S. $48 \mathrm{ff}$. Als Beitrag wird die Abwasserabgabe z.B. angesprochen bei Zeitel, G.: Gebühren und Beiträge, in: Handwörterbuch der Wirtschaftswissenschaft, Bd. 3, stuttgart, New York 1981, S. 349;

- Eine höchstrichterliche prüfung steht noch aus. 
- weder eine steuer, weil sie an den Tatbestand einer Gewässerschädigung und nicht an die Zahlungsfähigkeit der Abwassereinleiter anknüpft und die Zweckbindung des Abgabeaufkommens das haushaltsrechtliche Non-AffektationsPrinzip durchbricht,

- noch eine Gebühr, weil sie nicht als Entgelt für das Recht zum Einleiten, sondern als Mittel gegen das Einleiten von Abwasser ausgestaltet ist,

- noch ein Beitrag, weil sie das Einleiten erschwert und somit nicht als Vorzugslast verfaßt ist. Des weiteren wird sie für gewässerdienliche Maßnahmen und nicht für die dem Abwassereinleiter dienlichen Gewässer verwendet .

Die Abwasserabgabe stellt, wie des öfteren angenommen wird, auch kein "strafgeld für Umweltsünder"2 dar, weil das Einleiten nicht schlechthin verboten und somit schon gar nicht strafwürdig ist ${ }^{3}$.

Die Abwasserabgabe ist eine Sonderabgabe

1. mit Finanzfunktion, da das Abgabeaufkommen für gewässerdienliche Maßnahmen verwendet wird und

2. mit Lenkungsfunktion, da sie beim Abwassereinleiter über das wasserordnungsrechtlich festgelegte Maß hinaus Abwasserreinigungsmaßnahmen induzieren sol14.

Mit der Abwasserabgabe werden also primär emissionsvermindernde und damit gewässergütewirtschaftliche Wirkungen intendiert, und sie hat ihren Zweck gerade dann erfüllt, wenn das Abgabeaufkommen den Wert Null erreicht hat ${ }^{5}$.

1 Vgl. ebenda, S. 9 ff.

2 Berendes, K., Winters, K.P.: Das neue Abwasserabgabengesetz ...., a.a.0., s. 19 .

3 Vgl. Kirchhof, P.: Verfassungsrechtliche Beurteilung ..., a.a.o., s. 20 .

4 Vgl. ebenda, s. 31 .

- Vgl. ebenda, S. 11. 
Wie das Ziel der Emissionsverminderung erreicht werden soll und welche ökonomischen Wirkungen mit der Abwasserabgabe intendiert sind, soll im folgenden erläutert werden. 


\section{Intendierte Wirkungsweise des Abwasserabgabengesetzes}

Der Bericht des Innenausschusses zum AbwAG ${ }^{1}$ legt dar, welche Wirkungen der Gesetzgeber mit der Ausgestaltung des AbwAG herbeiführen möchte.

Mit der Abwasserabgabe soll eine wirksame Reinhaltung der Gewässer erreicht werden, indem sie einen Anreiz bietet,

"- in stärkerem Maße als bisher Kläranlagen zu bauen,

- den stand der Abwasserreinigungstechnik zu verbessern,

- abwasserarme oder abwasserlose Produktionsverfahren zu entwickeln und einzusetzen,

- Güter, die nur abwasserintensiv hergestellt werden können, sparsamer $\mathrm{zu}$ verwenden."2

Neben diesen ökologisch ausgerichteten wirkungen soll das AbwAG distributive Wirkungen zeigen. Die Kostenlast für die Vermeidung, die Beseitigung und den Ausgleich von Gewässerbelastungen soll gerechter verteilt und wettbewerbsvorteile, die dadurch entstanden, daß Gewässer kostenlos verschmutzt wurden, sollen abgebaut werden.

Insgesamt soll das AbwAG als ökonomischer Hebel der Gewässergütepolitik wirken. Bei Abwassereinleitern, deren potentielle Reinigungskosten niedriger als die Abgabe liegen, "wird der von der Erhebung der Abgabe ausgehende Anreiz für sich allein bereits ausreichen, um Reinigungsmaßnahmen herbeizuführen." 3 Dies gilt vor allem für Betriebe, bei denen die schädlichkeit des nicht oder kaum gereinigten Abwassers besonders hoch ausfällt, aber auch allgemein bei Einleitern, die einen großen

1 Vgl. Deutscher Bundestag 7. Wahlperiode: Drucksache 7/5183 vom 13.5.1976; die weiteren Ausführungen beziehen sich auf diesen Bericht.

2 Ebenda, S. 2 .

3 Ebenda, S. 3 . 
Nachholbedarf an Abwasserreinigung haben oder kostengŭnstige innerbetriebliche Maßnahmen ergreifen können.

Der Innenausschuß räumt ein, daß die Anreizwirkung nicht ausreichen wird, wenn die Reinigungskosten über der Abgabe liegen. Hier kann die Wirkung "in umweltpolitisch oder wirtschaftlich besonders begründeten Fällen durch Finanzierungshilfen noch 'aufgestockt' werden."1 Insbesondere Mittel aus dem Abgabeaufkommen können hier ihren gezielten Einsatz finden.

Eine weitere grundlegende ökologische Wirkung der Abwasserabgabe bezieht sich auf die Verknüpfung der beiden Rahmengesetze. "Die Festsetzung und Durchsetzung verhältnismäBig strenger Einleitebedingungen oder -auflagen wird insofern erleichtert, als der Einleiter um so mehr Abgabe erspart, je besser er reinigt."2 Durch die Anbindung der Abwasserabgabe an das Bescheidsystem soll der Einleiter dazu angehalten werden, das Verschmutzungsrecht nicht großzügiger als benötigt zu beantragen.

Erwartet wird weiterhin eine Beschleunigung der Anwendung der a.a.R.d.T. "Die Veranlagung des Restschmutzes mit dem halben Abgabesatz enthält einen gewissen Anreiz zu weitergehenden Reinigungsmaßnahmen und bedeutet gegenüber dem bisherigen Zustand eine deutliche Verbesserung."3

Der spätere Beginn der Abgabepflicht' soll zum einen den Ländern ausreichend Zeit zur Umstellung der Landeswassergesetze und der Bescheide geben. Zum anderen soll er zusammen mit der Abgabenstaffelung, -halbierung und der Härteregelung

1 Ebenda.

2 Ebenda.

3 Ebenda.

4 Der Gesetzesentwurf hatte den Beginn der Abgabepflicht für 1976 vorgesehen. Vgl. Deutscher Bundestag 7. Wahlperiode: Drucksache $7 / 2272$ vom 18.5 .1974 , s. 36 . 
eine finanzielle Uberforderung ${ }^{1}$ - und die damit verbundene Existenzgefährdung und Arbeitsplatzverluste - bei stärker belasteten Einleitern vermeiden. Eine Gefahr wird allerdings darin gesehen, daß die Härteklausel zu weit ausgedehnt wird.

Die staffelung der Abgabe soll weiterhin eine sprunghafte Nachfrage nach Abwasserreinigungsmaßnahmen und die damit einhergehenden negativen distributiven wirkungen wie eine diskontinuierliche Kapazitätsauslastung vermeiden, indem erst Einleiter mit relativ niedrigen und dann Einleiter mit relativ hohen spezifischen Vermeidungskosten Maßnahmen ergreifen.

Der Nachholbedarf an Abwasserreinigungsmaßnahmen soll "im wesentlichen bis zum Jahr 1985 gedeckt sein"2.

Bemerkenswert ist, daß der Innenausschuß im Rahmen der ökonomischen Wirkungsintentionen zwar distributive Ziele nennt, die allokative "gesamtwirtschaftlich günstige Mittelverwendung" jedoch nicht mehr als ziel deklariert. Die - vermutlichen - Hintergründe dieses Aussparens werden im nächsten Abschnitt deutlich.

1 In diesem Zusammenhang fällt im Bericht auch der später in Teil B der Arbeit übernommene Begriff der "tragbaren wirtschaftlichen Belastung" der Abgabepflichtigen. Vgl. ebenda, S. 4 .

2 Ebenda. 


\section{Das Abwasserabgabengesetz im Lichte der Effizienz- kriterien}

"Das Abwasserabgabengesetz ist ein Modellfall für die konsequente Anwendung des Verursacherprinzips, nach dem derjenige, der die Umwelt belastet oder beschädigt, auch für die Kosten zur Beseitigung dieser Schäden aufzukommen hat."1

Diese auf 1973 datierte würdigung des AbwAG durch den damaligen Bundesminister des Innern H.-D. Genscher liegt zeitlich noch vor dem ersten Entwurf des AbwAG, der dem Bundestag am 18. Juni 1974 vorgelegt wurde. Die Annahme liegt nahe, die Würdigung gehe zurück auf die in Abschnitt A.1.3. geschilderte wissenschaftliche Auseinandersetzung über die Effizienz verursachungsorientierter Instrumente. Betrachtet man jedoch das 1976 erlassene AbwaG sowie die mit dem Gesetz intendierte Wirkungsweise neben der "abgabentheoretischen" Effizienz näher, muß man feststellen, daß die wissenschaftlichen Erkenntnisse nur zum Teil im Gesetz berücksichtigt wurden.

Im folgenden sollen die Diskrepanzen zwischen der ökonomischen Theorie der Emissionsabgabe und der realen Ausgestaltung des AbwAG als Ergebnis des politischen Entscheidungsprozesses herausgearbeitet werden. Denn sie geben AufschluB darüber, inwieweit nach "theoretischen" Erkenntnissen ökologische und ökonomische Wirkungen von der Abwasserabgabe $z u$ erwarten bzw. nicht $z u$ erwarten sind. Dabei kristallisiert sich auch heraus, inwieweit das Verursacherprinzip realisiert wurde.

Der grundlegende Unterschied zwischen den Uberlegungen Anfang der siebziger Jahre und dem 1976 erlassenen AbwAG besteht darin, daß die Abwasserabgabe als eigenständiges, wenn nicht gar zentrales Instrument der Gewässergütepolitik zunächst diskutiert, später aber nicht realisiert wurde. Zwar stand

1 Genscher, H.D.: Umweltpolitik in der Bundesrepublik Deutschland, in: Das Umweltprogramm ..., a.a.O., S. 8 . 
wohl von Anfang an eine Verschärfung der Auflagen im Raum, die ökonomische Effizienz einer Abwasserabgabe wurde jedoch ceteris paribus untersucht. So geht auch die studie des Sachverständigenrats, in der "Vergleichende Berechnungen zur Wirkung einer Auflagen- und einer Abgabenlösung auf die volkswirtschaftlichen Kosten und die Reinhalteleistung im öffentlichen Bereich der Bundesrepublik"1 angestellt wurden, von einer reinen Auflagen- und einer reinen Abgabenlösung aus, die auf dem damals bereits realisierten Reinigungsgrad aufbauen sollte. Das war eine Untersuchung, mit der die Einführung einer Abwasserabgabe begründet wurde, deren Ergebnisse jedoch mit der heutigen Ausgestaltung des Abwasserabgabensystems vollkommen hinfällig sind. Betrachten wir also den "neuen" Erwartungshorizont in bezug auf das AbWAG.

\section{Okologische Effizienz}

Da bereits der $\$ 7$ a WHG zur Einhaltung der a.a.R.d.T. oder strengerer Auflagen verpflichtet, kann die Abwasserabgabe bis zu diesem Reinigungsgrad lediglich einen flankierenden Charakter besitzen, dergestalt, daß sie die Durchführung der Maßnahmen beschleunigt ${ }^{2}$. Weil der Abgabenvollzug keinen Aufschub kennt - am 1. Januar 1981 begann die Abgabepflicht wird mangelhaftes Reinigungsverhalten entsprechend quittiert. Auch die Abgabenhalbierung, die bei Einhaltung der Auflagen gewährt wird, kann in diese Richtung wirken, weil sie die kalkulatorische Vorteilhaftigkeit der geplanten Maßnahmen erhöht ${ }^{3}$. Daneben dürfte sie die kontinuierliche Einhaltung der Auflagen fördern. Dysfunktional auf diese Ziele müBten dagegen die mit der Abgabenstaffelung reduzierten Abgabesätze sowie der spätere Beginn der Abgabepflicht und die Härteklausel wirken.

1 Rat von Sachverständigen für Umweltfragen: Die Abwasserabgabe ..., a.a.o., s. $16 \mathrm{ff}$. und s. $63 \mathrm{ff}$.

2 Vgl. Hansmeyer, K.H.: Das AbwAG und seine Bedeutung im Rahmen der Bemühungen um eine Sanierung der Gewässer, in: gwf-wasser/abwasser, 119. Jg. (1987), Heft 11, S. 531.

3 Vgl. ebenda, S. 532 . 
Betrachtet man die Wirkungsmöglichkeiten des AbwAG im Bereich der sogenannten Restverschmutzung, so dürfte sowohl durch die Abgabenhalbierung als auch durch die Abgabenstaffelung und die Härteklausel der finanzielle Anreiz für weitergehende Maßnahmen - und damit auch für den umweltfreundlichen technischen Fortschritt - entsprechend schwächer ausfallen'. Dieser Wirkungsverlust müBte sich noch durch den exponentiellen Anstieg der Reinigungskosten bei zunehmendem Reinigungsgrad verstärken. Dabei ist auch zu berücksichtigen, daB bei vielen Direkteinleitern die Auflagen verschärft werden (wurden), so daß den halbierten Abgabesätzen entsprechend höhere Vermeidungskosten pro Schadeinheit gegenüberstehen ${ }^{2}$.

Ausdrücklich soll an dieser stelle aber darauf hingewiesen werden, daB mit der Abgabenhalbierung das Verursacherprinzip nicht in dem Maße verletzt wurde, wie teilweise dargestell ${ }^{3}$. Die Veranlagung der Restverschmutzung mit dem vollen Abgabesatz korrespondiert nämlich nicht mit dem Pigou'schen Internalisierungsansatz. Dieser in der Literatur häufig vernachlässigte Aspekt läßt sich an $\mathrm{Abb}$. 1 verdeutlichen: Sinken die Grenzbelastungen $B^{\prime}$ rechts des Schnittpunktes $S$, werden die mit der Fläche CSD beschriebenen Kosten geringer als das Produkt aus Restverschmutzung und Abgabenhöhe CSFE4. Oder anders formuliert: Nehmen die Grenzbelastungen der Umwelt mit zunehmenden Reinheitsgrad $a b$, müBte analog auch der Abgabesatz mit steigendem Reinheitsgrad sinken. Insofern kann man

1 Zu den Auswirkungen der Abgabenhalbierung vgl. Maas, Ch.: Einflus des Abwasserabgabengesetzes auf Emissionen und Innovationen, in: Zeitschrift für Umweltpolitik \& Umweltrecht, 9. Jg (1987), Heft 1, S. 69 ff.

2 Vgl. Cansier, D.: steuer ..., a.a.O., s. 770 .

3 "Vom richtigen Verständnis des Verursacherprinzips her ('wer verschmutzt, zahlt') ist... der Restschmutz mit der vollen Abgabe zu belegen." Berendes, K., Winters, K.P.: Das neue Abwasserabgabengesetz ..., a.a.0., s. 102.

- Vgl. Rat von Sachverständigen für Umweltfragen: Die Abwasserabgabe ..., a.a.0., s. 40 . 


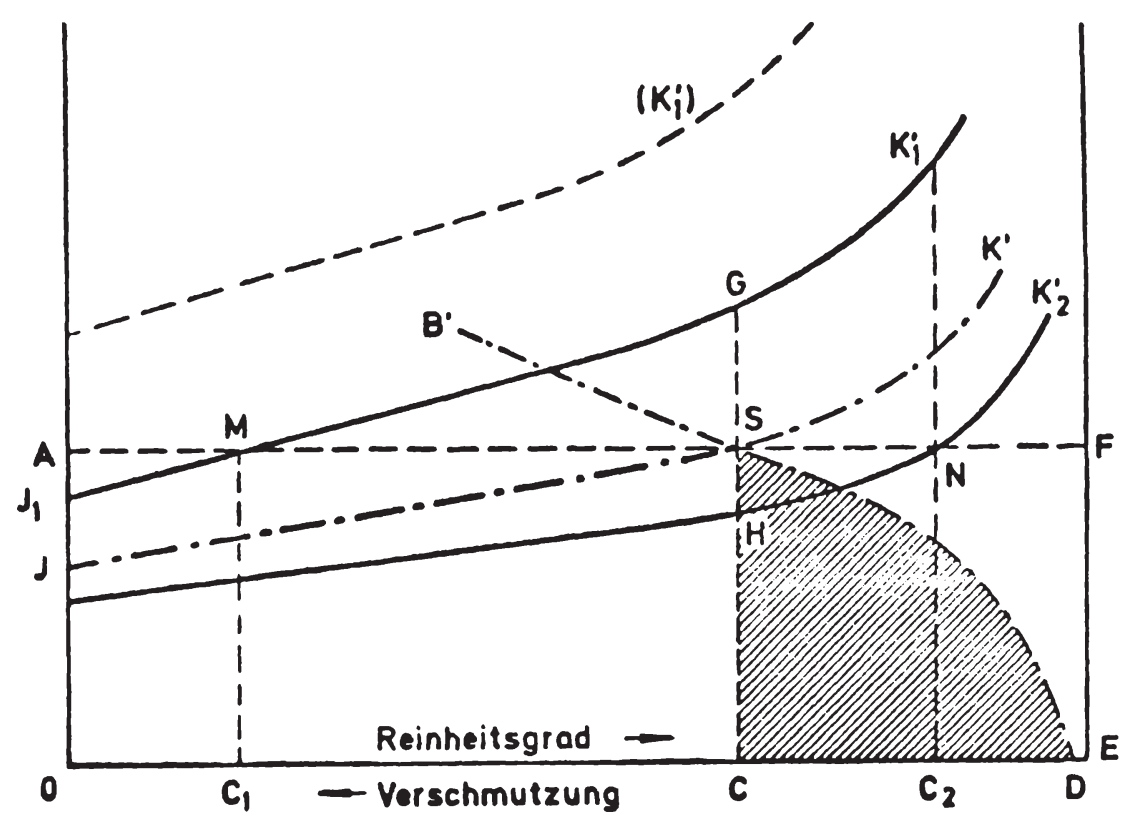

Abb. 1: Berücksichtigung unterschiedlicher Grenzkosten der Abwasserreinigung ${ }^{1}$

die Abgabenhalbierung als einen ersten und noch "ungelenken" Versuch gerade des Verursacherprinzips qualifizieren.

Indessen muß als Verstoß gegen das Verursacherprinzip gewertet werden, daß im Interesse einer Reduzierung des Verwaltungsaufwandes die Schadparameterwerte sowie die Jahresschmutzwassermenge nicht durch Messung ermittelt, sondern dem wasserrechtlichen Bescheid entnommen werden ${ }^{2}$. So wird der Einleiter nicht gemäB der "realen" Beschaffenheit des Abwassers, sondern gemäß dem, was er einleiten darf, veranlagt. Nichtsdestoweniger dürfte diese Regelung ökolo-

1 Rat von Sachverständigen von Umweltfragen: Die Abwasserabgabe ..., a.a.0., s. 13.

2 Vgl. dazu Brandt, E.: Rechtliche Fragen ..., a.a.o., S. 80; Endres, A.: Umwelt- und Ressourcenökonomie, a.a.0., s. 31 . 
gisch vorteilhaft sein, weil sie eine genaue und umfassende Uberprüfung der Einleitungsbefugnisse erfordert. Sie trägt deshalb zu einem Abbau hier herrschender Vollzugsmängel bei.

Dagegen dürfte die Höhe des Abgabesatzes die ökologische Effizienz vermindern, sollte sie, wie allgemein angeprangert, in der Tat zu niedrig gewählt sein, um die Emittenten entscheidend in ihrem Reinigungsverhalten zu beeinflussen. Die Senkung des Abgabesatzes ${ }^{1}$ sowie seine zeitliche Staffelung wurden gerade in der Endphase des Gesetzgebungsverfahrens zusammen mit der Härteklausel, der Abgabenhalbierung und dem späteren Beginn der Abgabepflicht heftig diskutiert. Denn all diese Regelungen, die von der Arbeitsgruppe "Wassergesetze" des Innenausschusses des Deutschen Bundestages beschlossen worden waren und die den ursprünglichen Gesetzesentwurf wesentlich umgestalteten ${ }^{2}$, empfand man aus gewässergütepolitischer sicht als gravierende Verschlechterung. Sie brachten dem AbwAG dann auch den Ruf des "Verschmutzerschutzgesetzes" ein und führten zu Bezeichnungen wie der "license to pollute"3.

1 Die Bundesregierung stellte in der Begründung des Gesetzesentwurfs von 1974 fest, "daß die Abgabe etwa 80 DM betragen (müBte), um das Ziel (Gesamtreinigungsgrad von 90 \%) allein durch die Anreizwirkung der Abwasserabgabe zu erreichen". Gleichwohl senkte man den Abgabesatz auch damals schon, nicht zuletzt "um zu starke Friktionen des deutschen Wirtschaftsgefüges zu vermeiden" (Deutscher Bundestag 7. Wahlperiode: Drucksache 7/2272 vom 18.6.1974, S. 36). Immerhin legte man ihn aber noch mit $25 \mathrm{DM}$ ab 1976 und $40 \mathrm{DM}$ ab 1980 fest. Zur Höhe des Abwasserabgabesatzes nach dem Kriterium des Reinigungsgrades vgl. Rat von Sachverständigen für Umweltfragen: Die Abwasserabgabe .... a.a.0., s. 32 ff.

2 Eine umfassende Gegenüberstellung der Entwürfe und der endgültigen Fassung des AbwaG gibt Hansmeyer, K.H.: Die Abwasserabgabe .... a.a.0., s. 92 ff.

3 Fischer, H.P.: Die Finanzierung ..., a.a.o., s. 372. 


\section{Okonomische Effizienz}

Wegen des weitgehend identischen Eingriffsniveaus ${ }^{1}$ von $\$ 7$ a WHG und AbWAG dürfte sich auch die traditionell hervorgehobene kostenminimierende Wirkung der Abgabe abschwächen. Bereits im erwähnten Sondergutachten zur Abwasserabgabe versäumte es der sachverständigenrat nicht, darauf hinzuweisen, daß die allokative Effizienz der Abgabe umso mehr abnimmt, als der Emittent durch Auflagen zu Vermeidungsmaßnahmen gezwungen wird ${ }^{2}$. Da nun auch diejenigen Einleiter bis zu einem bestimmten Grad Reinigungsmaßnahmen vornehmen müssen, bei denen wegen verhältnismäßig hoher spezifischer Abwasserreinigungskosten nicht die abgaberechtliche Anreizwirkung greift ${ }^{3}$, wird die statische Allokationseffizienz, die man einer Emissionsabgabe zuschreibt, weitgehend auBer Kraft gesetzt. Da auf der anderen seite auch Einleiter über die Auflagen hinaus reinigen, weil für sie die Anreizwirkung der Abgabe zutrifft, sieht Hansmeyer sogar die Möglichkeit der Ubererfüllung des ökologisch ausgerichteten Teilzieles "Kläranlagenbau"4.

Die gesamtwirtschaftlich möglichst günstige Mittelverwendung wird auch durch die Halbierung des Abgabesatzes für den Restschmutz beeinträchtigt` . Eine Ermäßigung des steuersatzes kann jedoch damit begründet werden, daß die privaten Gesamtkosten bei Abgabenlösungen sehr viel höher als bei Auflagen liegen. ErmäBigte steuersätze - wie auch Finanzierungshilfen und Freibeträge - können deshalb nicht nur als Mittel der politschen Durchsetzbarkeit, sondern auch aus verteilungs- und wachstumspolitischen Gründen "notwendig

1 Beide Regelwerke orientieren sich an den a.a.R.d.T.

2 Vgl. Rat von Sachverständigen für Umweltfragen: Die Abwasserabgabe ..., a.a.0., s. 15 f.

$3 \mathrm{An} \mathrm{Abb} .1$ verdeutlicht bedeutet dies, das Kosteneinsparungen, die etwa der Fläche SNH entsprächen, aufgehoben werden.

4 Vgl. Hansmeyer, K.H.: Das AbwAG ..., a.a.o, S. 533.

- Vgl. Cansier, D.: Offentliche Finanzen ..., a.a.0., s. 40. 
oder erwünscht"1 sein. Die Halbierung der Abwasserabgabe reduziert "- zumindest bei statischer Betrachtungsweise mögliche kontraproduktive Wirkungen der Abgabe auf andere gesamtwirtschaftliche Zielbereiche."2

Einen möglichen Mangel an ökonomischer Effizienz - mit ökologischen Auswirkungen - kann man darauf zurückführen, daß sich der \$ 7 a wHG und das AbwAG auf die gleichen schadparameter konzentrieren und deshalb eventuell ein zu hohes Mittelvolumen auf nur einige der gewässergütewirtschaftlich relevanten schadparameter gerichtet wird, während die anderen Schadstoffe ungebrochen weiter in die Vorfluter flieBen ${ }^{3}$. Dieser Effizienzmangel betrifft allerdings weniger das AbwAG an sich, als die Ausgestaltung des Zusammenspiels von Abgaben-und Auflagenregelungen.

Ein tiefer Einschnitt sowohl in die ökologische als auch in die ökonomische Effizienz des AbwAG dürfte die Ausparung von Regelungen sein, die die Indirekteinleiter betreffen': Das AbWAG nimmt insofern keine steuerungsfunktion bei dieser Gruppe wahr, als sie die Abwälzbarkeit der Abgabe nicht regelt. Da der Frischwasser-bzw. Abwassermengenbezug in der Praxis dominiert, unterliegt nur einer der abgabe- und gewässergüterelevanten Parameter einer Anreizwirkung. Das Ausmaß des Wirkungsverlustes durch die Nichtintegration der Indirekteinleiter wird anschaulich, wenn man sich vergegenwärtigt, daß rein zahlenmäßig rund 90 \% der deutschen Unternehmen dieser Gruppe angehören' !

1 Ebenda.

2 Maas, Ch.: Einfluß ..., a.a.0., s. 72 .

3 Vgl. ebenda, S. 534 .

4 Vgl. Hansmeyer, K.H.: Abgaben .... a.a.O., S. 258 ff.; vgl. zur Indirekteinleiterproblematik auch Brandt, E.: Rechtliche Fragen ..., a.a.0., s. 80 f.

- Vgl. ebenda, S. 259.

- Vgl. Ewringmann, D.: Wirschaftliche Auswirkungen .... a.a.0., s. 114 . 
Zusammenfassend ist festzuhalten, "daß die für die Abwasserbehandlung zur Verfügung stehenden knappen Ressourcen unter ökonomischen, aber auch unter gewässergütepolitischen Gesichtspunkten partiell fehlgeleitet werden"1. Von einer Anwendung des Verursacherprinzips darf beim AbwAG nur noch in "peripheren Bereichen"2 gesprochen werden.

Die mangelhafte Realisierung des Verursacherprinzips schlägt allerdings - und deshalb sind die vernichtenden Urteile von Gesetzeskritikern zu relativieren - ökologisch nicht entsprechend durch. Denn die für die ökonomische Effizienz so ungesunde Zangenkonstruktion von WHG und AbwAG bewirkt, daB bis zur Anwendung der a.a.R.d.T., und bei strengeren Auflagen sogar über diese hinaus, zwei Instrumente gleichermaßen eingesetzt werden und damit sozusagen ein "doppelter" Gewässergüteschutz praktiziert wird. Wenngleich das Verursacherprinzip abgaberechtlich nur eingeschränkt Anwendung findet, kann man sich deswegen einiges an ökologischer Effizienz des Instrumentensets erhoffen. Im Bereich der Restverschmutzung freilich dürften aufgrund der mangelhaften Umsetzung des Verursacherprinzips Wirkungspotentiale verschenkt werden.

Abschließend sei auch die ökonomische Effizienz kritisch gewürdigt. Daß sie allgemein als unzureichend qualifiziert wird, läßt sich auf eine Inkonsistenz in der grundsätzlichen Einschätzung der Abgabenlösung zurückführen. Auf der einen Seite wird die Emissionsabgabe in der umweltökonomischen Theorie auf breiter Ebene so hochgeachtet und empfohlen, daß kritische Anmerkungen einen gewissen seltenheitswert haben ${ }^{3}$. Auf der anderen seite scheint das Vertrauen in die

1 Hansmeyer, K.H.: Das AbWAG ..., a.a.O., s. 534 .

2 Ders.: Die Abwasserabgabe ..., a.a.o., s. 84 .

3 Als zwei von wenigen Vertretern, die grundlegendere Zweifel an der Abgabenlösung anmelden, sind Kabelitz und Köhler zu nennen. Vgl. dazu Kabelitz, K.R., Köhler, A.: Abgaben ...., a.a.0., s. 42 ff. 
Abgabewirkungen bemerkenswert unterentwickelt ${ }^{1}$. So betont auch Hansmeyer, daß ein vollkommener Ersatz des klassischen Regulierungsinstrumentariums durch eine Abgabenlösung nicht nur politisch nicht zu verwirklichen, sondern auch aus Umweltschutzaspekten fragwürdig ist² . Bundesumweltminister Töpfer zielt in dieselbe Richtung, wenn er bemerkt: "Abgabenlösungen können umweltpolitisch sinnvoll nur durch Einbindung in ein Auflagensystem entwickelt werden."3 Hier im allgemeinen wie beim AbwAG im speziellen werden eindeutige Prioritäten gesetzt: Sicherheit im Umweltschutz vor "gesamtwirtschaftlich möglichst günstiger Mittelverwendung", womit der Forderung nach (vollkommener) ökonomischer Effizienz sowie der Kritik an ihrem Mangel der Boden entzogen ist.

Es bleibt allerdings die Frage nach der Ausgestaltung eines derartigen Instrumentensets: ob Auflagen - gleichsam als Abfangnetz - zur Flankensicherung der Abgabe dienen, was eine gewisse ökonomische "Resteffizienz" impliziert, oder ob umgekehrt, die Abgabe, wie im bundesdeutschen Wasserrecht exekutiert, den Auflagenvollzug unterstützt.

Wenn also die Abwasserabgabe so gestaltet wurde, wie sie sich heute darstellt, dann ist sie vermutlich keine Ausnahme unter weiteren denkbaren Emissionsabgaben, sondern eher eine von zwei fließend ineinander übergehenden Ausgestaltungsvarianten eines Auflagen-Abgabensystems. Umso interessanter erscheint die Frage, welche Wirkungen die Abwasserabgabe - für sich genommen und im Verbund mit den Auflagen - bislang entfalten

1 Dabei konnte es Enttäuschungen bisher nicht geben, weil in der Bundesrepublik noch keine Abgabenlösungen in Reinform praktiziert und auch etwaige Erfahrungen aus anderen Ländern nicht rezipiert wurden.

2 Vgl. Hansmeyer, K.H.: Abgaben ..., a.a.0., S.260.

3 Töpfer, K.: Anwendungsbedingungen und -restriktionen "neuer" ökonomischer Instrumente, in: Deutsche stiftung für Umweltpolitik (Hrsg.), Umweltpolitisches Gespräch: Okonomische Instrumente der Umweltpolitik - Neuer Weg oder Sackgasse?, Beiträge zur Umweltgestaltung, Bd. A 93, Berlin 1984, s. 33 . 
konnte. Im folgenden werden die Grundlagen für eine solche Untersuchung beschrieben. 
TEIL B: ANALYTISCHE GRUNDLAGEN EINER ERFOLGSKONTROLLE DES ABWASSERABGABENGESETZES

\section{Theoretische Grundlagen der Evaluation}

\subsection{Entwicklungslinien der Evaluation}

Evaluation (Evaluierung, Evaluierungsforschung) bezeichnet im allgemeinen die ex-post-überprüfung von Wirkungen, die durch das öffentliche Handeln, insbesondere durch statiche Programme - und hier u.a. durch Gesetze - ausgelöst werden. Hellstern/Wollmann kistallisieren fünf Perspektiven heraus, die das deutsche Interesse an Evaluationen ausmachen und ihren Einsatz fördern und gefördert haben ${ }^{1}$ :

1. Als Begleit- und Auswertforschung experimenteller Politik (Modellversuchspolitik), welche gerade in der reformfreudigen Zeit Ende der sechziger, Anfang der siebziger Jahre Hochkonjunktur hatte, dient die Evaluation der systematischen Erkenntnisgewinnung über Verläufe und Ergebnisse innovativer Politikansätze.

2. Anderen reformatorischen Bemühungen der gleichen "Epoche", nämlich denen der "Politik der inneren Reformen", entspringt der Einsatz der Evaluation als Rückmeldeschleife im politisch-administrativen Planungs- und EntscheidungsprozeB. Mit der Evaluation sollte damals wie heute ein Informationssystem über Verlauf und Ergebnisse staatlichen

1 Vgl. Hellstern, G.-M., Wollmann, H.: Evaluierung und Evaluierungsforschung - ein Entwicklungsbericht, in: dies. (Hrsg.), Handbuch zur Evaluierungsforschung, Bd. 1, Opladen 1984, S. $38 \mathrm{ff}$. Die Autoren erläutern die genannten Perspektiven und illustrieren sie mit Beispielen. 
Handelns mit dem Ziel, dieses zu verbessern, geschaffen werden ${ }^{1}$.

3. Geringes wirtschaftliches Wachstum und notorische Haushaltsengpässe gehören $\mathrm{zu}$ den weiteren Motoren des Evaluierungsbooms seit Mitte der siebziger Jahre. Informationen über Wirksamkeit, Folgelasten und Nebenwirkungen öffent-

1 Fast ebenso häufig, wie von den einen die (theoretische) Bedeutung der Evaluation als Instrument der Programmkorrektur oder der Ausgestaltung neuer Programme betont wird, sie sogar zum "Kernstück eines kontinuierlichen Planungsprozesses" avanciert (Eekhoff, J. u.a.: Methoden und Möglichkeiten der Erfolgskontrolle städtischer Entwicklungsmaßnahmen, Schriftenreihe "städtebauliche Forschung" des Bundesministers für Raumfordnung, Bauwesen und Städtebau 03.060, Bonn-Bad Godesberg 1977, S. 19; vgl. u.a. auch Derlien, $H_{.}-U .:$ Die Erfolgskontrolle staatlicher Planung. Eine empirische Untersuchung über Organisation, Methode und Politik der Programmevaluation, Schriften zur öffentlichen Verwaltung und öffentlichen Wirtschaft, Bd. 17, Baden-Baden 1976, S. 31; Volz, J.: Erfolgskontrolle kommunaler Planung. Eine Untersuchung über Möglichkeiten und Grenzen der Erfolgskontrolle kommunaler Planungen, Köln, Berlin, Bonn, München 1980, S. 52; siehe auch S. 80 dieser Arbeit), wird von anderen (und zum Teil auch von ersteren) die mangelnde Integration ihrer Ergebnisse in den politisch-administrativen Planungs-und EntscheidungsprozeB beklagt (vgl. u.a. Kiresuk T.J., Larsen, N.E., Lund, S.H.: Wissenstransfer als strategie in ProgrammManagement und Evaluierung, in: Hellstern, G.-M., Wollmann, H. (Hrsg.), Handbuch zur Evaluierungsforschung, Bd. 1, Opladen 1984, S. 198 ff.; Zavelberg, H.G.: Staatliche Rechnungsprüfung und Erfolgskontrolle - Möglichkeiten und Grenzen, in: Eichhorn, P., Kortzfleisch, G. V. (Hrsg.), Erfolgskontrolle bei der Verausgabung öffentlicher Mittel, Baden-Baden 1986, S. 114; Weihe, U.: Evaluationsforschung als Politikersatz? in: Hellstern, G.-M., Wollmann, H. (Hrsg.), Experimentelle Politik - Reformstrohfeuer oder Lernstrategie, Opladen 1983, S. 270). Friedrich faßt seine - allerdings frühen empirischen Ergebnisse über die politische Handhabung von Forschung wie folgt zusammen: Die Gutachten haben in erster Linie eine Unterstützungs- und Absicherungsfunktion, eine Schiedsrichter- und Versachlichungsfunktion, sodann eine Ideologie- und Prestigefunktion, Aufschiebungs- oder Abschiebungsfunktion, Integrationsfunktion, und erst zum Schluß dienen sie der Kritik und Planung. Vgl. Friedrich, H.: staatliche verwaltung und Wissenschaft, Frankfurt 1970, s. 140 ff., zitiert nach Weihe, U.: Evaluationsforschung ..., a.a.0., s. 272 . 
licher Auf- und Ausgaben sollen über deren Kürzungen, Prioritäten und Posterioritäten entscheiden².

4. Im "Kampf" gegen die Gesetzesflut der letzten Jahre wird mit der Evaluation intendiert, legislatorische "uber"- und Fehlentwicklungen zu vermeiden bzw. aufzudecken und damit einer Entbürokratisierung zuzuarbeiten.

5. Das Parlament unterstützt die Evaluation staatlichen Handelns, weil es darin eine Möglichkeit sieht, die "in Frage gestellte Initiativ- und Kontrollfunktion gegenüber Regierung und Verwaltung und deren Informationsvorsprung geltend zu machen und damit der schleichenden Aushöhlung der Gewaltenteilung gegenzuwirken."2

Aus diesen Motivationen heraus hat sich in der Bundesrepublik eine "überwiegend disziplinär und politikbereichsbezogene[n] Evaluierungsforschung"3, die sich mittlerweile über viele Politikbereiche auf Bundes-, Landes- und kommunaler Ebene erstreckt, mit unterschiedlichen konzeptionellen und methodischen Ansätzen entwickelt. Den Mittelpunkt dieser Evaluationsvielfalt bilden die zwei zentralen Aufgaben, denen sich

$1 \quad 1973$ wurde im deutschen Verwaltungsrecht erstmals die regelmäBige Evaluierung gefordert: In den vorläufigen Verwaltungsvorschriften zu \$ 7 der Bundeshaushaltsordnung heiBt es, daB neben vorausschauenden (ex ante) KostenNutzen-Analysen etc. "im Wege der Erfolgskontrolle (Ergebnisprüfung) ... insbesondere untersucht werden (solle),

- während der Durchführung von mehrjährigen Maßnahmen mindestens jährlich, ob die Zwischenergebnisse im Rahmen der Planung liegen, die Planung anzupassen ist und die Maßnahmen weiterzuführen oder einzustellen sind,

- nach der Durchführung von Maßnahmen, ob das erreichte Ergebnis der ursprünglichen oder angepasten Planung entspricht, die Maßnahmen zu revidieren sind und Erfahrungswerte gesichert werden können."

Ministerialblatt des Bundesministers der Finanzen und des Bundesministers für Wirtschaft, $\mathrm{Nr} .13 / 1973 \mathrm{v} .11 .7 .1973$, S. 194 .

2 Hellstern, G.-M., Wollmann, H.: Evaluierung ..., a.a.o., S. 39. Vgl. auch die Beiträge, die im gleichen Band unter "II.2 Evaluierung - Verfahren parlamentarischer Kontrolle?" erschienen sind.

3 Ebenda, S. 38 . 
jede Evaluation stellt (bzw. stellen sollte) und die Gegenstand des nächsten Abschnitts sind.

\subsection{Die zentralen Aufgabestellungen}

Evaluationen lassen sich inhaltlich eingrenzen durch die beiden Aufgaben, die sie zu lösen haben, nämlich

1. die Bestimmung des relevanten Wirkungsfeldes und

2. die Lösung des Kausalitätsproblems ${ }^{1}$.

Bei der Bestimmung des relevanten Wirkungsfeldes steht die Frage im Mittelpunkt, welche Wirkungen vom untersuchten Programm, einem Gesetz oder einer Maßnahme ${ }^{2}$ ausgehen können. während in den siebziger Jahren häufig das ausschließliche Forschungsinteresse der Feststellung intendierter wirkungen, die aus den Programmzielen abgeleitet werden, galt ${ }^{3}$, verbreitete sich später die Forderung, auch nicht-intendierte Wirkungen (Nebenwirkungen oder -folgen) in die Analyse des Wirkungsspektrums aufzunehmen.

Der potentiellen "Outputseite" Wirkungen steht die "Inputseite", d.h. zunächst das Programm mit seinen speziell gestalteten Elementen gegenüber, das eben als unabhängige (UV) die abhängige Variable (AV) "Wirkungen" induziert. Als weitere unabhängige Variable, die das (intendierte) Wirkungsfeld kontrollieren, kommen andere staatliche Maßnahmen mit

1 Vgl. ebenda, S. 25 .

2 Im weiteren wird vereinfachend nur von Programmen gesprochen.

3 Vgl. u.a. Aderhold, D.: Kybernetische Regierungstechnik in der Demokratie, Planung und Erfolgskontrolle, Deutsches Handbuch der Politik, Bd. 7, München, Wien 1973. 
ähnlicher oder gleichgearteter Zielsetzung und weitere, sogenannte exogene' Einflußgrößen in Betracht.

Sowohl abhängige als auch unabhängige Variable sind im Rahmen der Bestimmung des relevanten Wirkungsfeldes zu konzipieren, d.h. zunächst festzustellen und dann in ihrer Veränderung während des Betrachtungszeitraums zu messen. Zentrale stellung nimmt dabei die wahl der Indikatoren ein, anhand derer die Wirkungen gemessen werden sollen.

Die maßgebliche Bestimmung der Evaluation ist jedoch die Lösung des Kausalitätsproblems, die, wegen der hohen methodischen Anforderungen und der empirischen Probleme, die sie aufwirft, immer Gefahr läuft, nicht ihrer Bedeutung als Kernstück der Evaluation angemessen in einzelnen Evaluationsarbeiten behandelt zu werden.

Die Aufgabe der Kausalitätsforschung besteht darin, aufzuspüren, inwieweit die festgestellten Wirkungen auf das Programm bzw. seine Elemente und nicht auf andere Einflußgrößen zurückzuführen sind. Durch diese Zurechnung sollen Ursache-Wirkungs-Zusammenhänge aufgezeigt, mithin die Wirksamkeit und die Auswirkungen des öffentlichen Handelns ermittelt werden.

Auch die Lösung des Kausalitätsproblems unterliegt insofern einer Entwicklung, als man methodisch lange Zeit nur experimentelle Verfahren, die sogenannten harten Methoden, anerkannte und heute auch für andere, als weiche Methoden bezeichnete Verfahren (z.B. Fallstudien) plädiert.

1 Exogen in dem Sinne, daß die zuständigen politischadministrativen Instanzen keinen Einflus auf sie nehmen. Vgl. dazu Eekhoff, J. u.a.: Methoden ..., a.a.0., s. 13. 


\subsection{Inhaltliche Bedeutung der Erfolgskontrolle}

Gemäß einem differierenden erkenntnisleitenden Interesse bei der Lösung des Kausalitätsproblems bietet die Evaluationsliteratur ein breit gefächertes Angebot an inhaltlichen Ausrichtungen von Evaluationsstudien. Umfangreich und einigermaßen verwirrend gestaltet sich dabei die Terminologie, weil einzelne Ausrichtungen unter verschiedenen Begriffen gehandelt werden und zudem auch noch inhaltliche Doppelbelegungen auftreten.

Der gebräuchlichste - und zugleich der schillerndste Begriff dürte der der Erfolgskontrolle sein. Volz wertete 27 inhaltliche Abgrenzungen der Erfolgskontrolle nach der Methodik der Begriffsexplikation aus und erhielt die folgenden relevanten Dimensionen der Erfolgskontrolle, aufgereiht nach der Häufigkeit der Nennungen:

"Bei der Erfolgskontrolle handelt es sich ...

(1) um eine Uberprüfung der Wirksamkeit und der Auswirkungen politischer Maßnahmen und Programme,

(2) um einen Soll-Ist-Vergleichsprozeß,

(3) um eine Ex-post-Kontrolle und

(4) um einen Bestandteil des politischen Planungs- und Entscheidungsprozesses."1

In den bisherigen Ausführungen zur Evaluation noch nicht explizit genannt war das Merkmal "Soll-Ist-Vergleichsprozeß", mit dem eines der Erfolgsmaße bei der Messung der Zielerreichung angesprochen wird. Der Soll-Ist-Vergleich kann sich allerdings nur auf die Erfassung intendierter Wirkungen, der Zielwirkungen beziehen. Ein Konsens darüber, ob nichtintendierte Wirkungen in den Untersuchungsrahmen einer Erfolgskontrolle fallen, liegt bei den Evaluationsanhängern nicht vor. So sieht Derlien, bezugnehmend auf die amerikanische Literatur, das "mit" und das "ohne" von nichtintendierten Wirkungen als Spielarten der Erfolgskontrolle.

1 Volz, J.: Erfolgskontrolle..., a.a.O., s. 15. 
Bei Integration der nicht-intendierten Wirkungen (Nebenfolgen) spricht er von Impact-Evaluation. Eine

Erfolgskontrolle, welche die Nebenfolgen unberücksichtigt läßt, bezeichnet er als reine Effektivitätsanalyse ${ }^{\text {. Anders }}$ dagegen Reinermann, der in der Erfolgskontrolle nur den SollIst-Vergleich sieht und diesen als Teil der Evaluierung betrachtet, die zur Aufgabe hat, alle eingetretenen, also auch die nicht-intendierten Wirkungen aufzuspüren ${ }^{2}$. Ebenso sehen Hellstern/Wollmann in der Erfolgskontrolle im wesentlichen einen Soll-Ist-Vergleich und benutzen den Begriff deshalb diametral zur alle wirkungen umfassenden Wirkungsanalyse ${ }^{3}$. Der Begriff der Wirkungsanalyse läBt sich auch durch den Begriff der Wirkungskontrolle ersetzen, der den ex-post-Ansatz im Gegensatz zum ex-ante-Blickwinkel der Wirkungsprognose als anderer Variante der Wirkungsanalyse herausstreicht'.

1 Diese Typisierung nimmt er zwar unter dem Oberbegriff "Programmevaluation" vor, die er jedoch in der deutschen Evaluationsliteratur mit "Erfolgskontrolle" übersetzt sieht. Vgl. Derlien, H.-U.: Die Erfolgskontrolle .... a.a.O., S. $18 \mathrm{ff}$.

2 Vgl. Reinermann, H.: Erfolgskontrolle im öffentlichen Sektor. Beiträge des Rechnungswesens als Brücke zwischen Nutzen-Kosten-Untersuchung und Evaluierung, in: Die Betriebswirtschaft, 37. Jg. (1977), Heft 3, S. 401 und 406.

3 Vgl. Hellstern, G.-M., Wollmann, H.: Evaluierungsforschung - Ansätze und Methoden. Dargestellt am Beispiel des städtebaus, Basel, Boston, stuttgart 1983， S. 7 .

4 Vgl. Eekhoff, J.: Ansatzpunkte für die Beurteilung öffentlicher Maßnahmen. Erfolgskontrolle von strukturprogrammen, in: Eichhorn, P., Kortzfleisch, G. V. (Hrsg.), Erfolgskontrolle bei der Verausgabung öffentlicher Mittel, Baden-Baden 1986, S. 62; Hembach, K.: Der Stellenwert von Wirkungsanalysen für die Regionalpolitik. Eine Systematisierung der Problematik am Beispiel der regionalen Wirtschaftspolitik, Frankfurt, Bern, Circencester/U.K. 1980 , S. $16 \mathrm{f}$. 
Eekhoff (und sich ihm anschließend Fox ${ }^{1}$ ) sieht die wirkungskontrolle dagegen als Teil der Erfolgskontrolle ${ }^{2}$. Gleichwohl harmoniert diese Typologie inhaltlich mit der Hellstern/ wollmanns, denn Eekhoffs Erfolgskontrolle konzentriert sich auf die Zielwirkungen. Er zeigt nur - und hier liegt der Unterschied zu Hellstern/Wollmann - einen betont analytischen und in der Praxis häufig angewendeten konzeptionellen Aufbau von Evaluationsstudien auf, bei dem die Vorarbeiten, die bei jeder Kausalitätsuntersuchung geleistet werden müssen und oben unter "Bestimmung des relevanten Wirkungsfeldes" zusammengefaßt wurden, als eigenständige Evaluationsschritte ausgewiesen sind, auf die dann die Wirkungskontrolle zur Lösung des Kausalitätsproblems folgt. Eine vollständige Erfolgskontrolle umfaßt nach diesem Konzept die folgenden Teile:

\section{Die Zielerreichungskontrolle}

Mit ihr stellt man fest, inwieweit die vom untersuchten Programm verfolgten Ziele erreicht worden sind.

2. Die Vollzugs - oder Durchführungskontrolle

Hier wird untersucht, ob das Programm bzw. seine Maßnahmen wie geplant durchgeführt worden ist und damit die Möglichkeit einer Programmwirkung besteht.

3. Die Bedingungskontrolle

Aufschluß soll darüber gegeben werden, ob sich die weiteren Bedingungen (exogene Einflüsse), unter denen das Handeln der untersuchten subjekte steht, im Zeitablauf verändert haben.

1 Fox, K. -P.: Erfolgskontrolle der regionalen Wirtschaftsförderung, in: Eichhorn, P., Kortzfleisch, G. v. (Hrsg.), Erfolgskontrolle bei der Verausgabung öffentlicher Mittel, Baden-Baden 1986 , S. 35 - 58, hier S. 40 f.

2 Vgl. Eekhoff, J. u.a.: Methoden ..., a.a.o., z.B. S. 13;

Eekhoff, J.: Ansatzpunkte ..., a.a.0., s. 63. 
4. Die Wirkungskontrolle

Die Wirkungskontrolle schließlich fragt, ob die gemessene Zielerreichung auf das untersuchte Programm oder auf die anderen Einflüsse zurückzuführen ist.

Zielerreichungs-, Vollzugs- und Bedingungskontrolle sind zum einen Voraussetzung für das Hauptanliegen Wirkungskontrolle, zum anderen jedoch auch eigenständige Elemente der Erfolgskontrolle ${ }^{1}$. Streng genommen kann aber erst dann von einer Erfolgskontrolle die Rede sein, wenn das Kausalitätsproblem durch die wirkungskontrolle gelöst wird².

Dieses - in der Evaluationspraxis durchaus gängige - Erfolgskontrollkonzept kann um weitere Fragestellungen ergänzt werden. So subsummiert Fox darunter auch Untersuchungen wenn auch von untergeordneter Bedeutung -, die z.B. die Leistung der Verwaltung bei der Programmerwirklichung überprüfen sollen ${ }^{3}$.

Nach Eekhoff erreicht die Erfolgskontrolle ihre Vollendung in der Kontrolle des Möglichkeitsbereichs ${ }^{4}$. Deren Spezialität liegt darin, daß als Referenzbasis für die Beurteilung der verschiedenen Programmalternativen statt der gängigen Sollwerte, die vorzugsweise das Ergebnis politischer Kalküle sind, der sogenannte optimale Entwicklungspfad, der als jeweiliger Idealzustand das wirklich Machbare anzeigen soll, dient. Eekhoff räumt jedoch selbst ein, daß die umfassende Durchführung dieser Evaluationsvariante, wenn sie überhaupt realisierbar sein sollte, noch in ferner zukunft liegt. "Solange es in der Ex-ante-Planung noch eher die Ausnahme als

1 Vgl. Eekhoff, J. u.a.: Methoden ..., a.a.o., s. 12 f.

2 Vgl. Eekhoff, J., Werth, G.: Einige Grundprobleme der Erfolgskontrolle staatlicher Maßnahmen, in: Gesellschaft für Regionalforschung (Hrsg.), Jahrbuch für Regionalwissenschaft, 2. Jg. (1981), s. 11, bezugnehmend auf Lauschmann, E.: Grundlagen einer Theorie der Regionalpolitik, 3. Aufl., Hannover 1976, S. 287.

3 Vgl. Fox, K.-P.: Erfolgskontrolle ..., a.a.o., s. 41.

' Vgl. Eekhoff, J. u.a.: Methoden ..., a.a.o., s. $103 \mathrm{ff}$. 
die Regel ist, daß mehrere Alternativen intensiv untersucht werden, kann nicht gefordert werden, in der Erfolgskontrolle über das durchgeführte Handlungsprogramm hinaus eine Vielzahl von Handlungsalternativen $\mathrm{zu}$ beurteilen."1

Als eine Spielart der Wirkungskontrolle bzw. Programmevaluation nennen Eekhoff und Derlien die Untersuchung der relativen Vorzüglichkeit eines bestimmten Programms gegenüber alternativen laufenden oder geplanten Programmen, die sie unter dem Begriff Effizienzkontrolle thematisieren². Diese soll Informationen darüber erschließen, ob nicht ein anders ausgestaltetes als das durchgeführte programm zu besseren Ergebnissen - im Sinne des Rationalprinzips - geführt hätte.

Hingegen betrachtet Reding die Evaluation insgesamt als Kontrolle der Programmeffizienz ${ }^{3}$, mit der er "das AusmaB des zustande gekommenen finalen Outputs"4 erfaßt sieht. Das Begriffspaar totale/partielle Effizienz interpretiert er u.a. derart, daB Nebenwirkungen auf andere (nicht untersuchte) Ziele berücksichtigt bzw. außer acht gelassen werden ${ }^{\text {s }}$.

Einen ganz anderen Weg schlagen Hellstern/Wollmann ein, wenn sie, die sich ebenfalls an amerikanische Literatur anlehnen, die Wirkungsanalyse weiter verzweigen. Je nach Art der untersuchten Wirkungen und Wirkungszusammenhänge unter-

1 Ebenda, S. 105.

2 Vgl. Eekhoff, J.: Methoden ..., a.a.o., s. 101 ff.;

Derlien, H. $-U_{.}$: Die Erfolgskontrolle ...., a.a.O., s. $21 \mathrm{f}$. Zur Unterscheidung zwischen Effektivitäts- und Effizienzanalysen vgl. auch Deniston, O.L., Rosenstock, I.M., Welch, W., Getting, V.A.: Evaluation of Program Effectiveness and Program Efficiency, in: Lyden, F.J., Miller, E.G. (eds.), Planning, Programming, Budgeting. A Systems Approach to Management, 2nd ed., Chicago 1972, S. $141 \mathrm{ff}$.

3 Reding, K.: Die Effizienz staatlicher Aktivitäten: Probleme ihrer Messung und Kontrolle, Baden-Baden 1981, S. $178 \mathrm{ff}$.

4 Ebenda, S. 40 .

s Ebenda, S. 44 . 
scheiden sie zwischen Programmwirkungsanalysen, Programmstrategieanalysen und Projektevaluationen².

Programmwirkungsanalysen nehmen eine Untersuchung der "letztendlichen" Wirkungen (Gesamtwirkungen) eines Programms vor. Als "summative" (=abschließende) Evaluation setzen sie in einer möglichst fortgeschrittenen Durchführungsphase ein und sollen die langfristige Programm- und Politikplanung unterstützen.

\section{Programmstrategieanalysen (Programmdurchführungsanalysen)} versuchen, den Zusammenhang zwischen bestimmten Programmwirkungen und bestimmten Programmelementen herauszuarbeiten. Sie können bereits frühzeitig in der Implementationsphase ansetzen und somit "formativ" (=steuernd) Impulse für inkrementale programmorrekturen geben.

Eher kurzfristig ist auch der Einsatz von Projektevaluationen, die Wirkungszusammenhänge im Rahmen eines einzelnen Projektes durchleuchten und ihr besonderes Augenmerk auf unerwünschte Wirkungen und mögliche störeinflüsse auf das Projekt richten. Als "trouble-shooting"-Untersuchungen sollen sie die Beratungstätigkeit bei den Vollzugsbehörden verbessern.

Diese Untergliederung der Wirkungsanalysen ist an die Dreiteilung der Planungsansätze in strategische, taktische und operationale Planung angelehnt. Ebenso nimmt die von Brümmerhoff/Wolff vorgenommene Auffächerung der Erfolgskontrolle Bezug auf die unterschiedlichen Ebenen des Planungsprozesses. Während die strategische Erfolgskontrolle das "Ob" eines Programms überprüft, bemüht sich die taktische Erfolgskontrolle um das "Wie". Die Untersuchung der Programm-

1 Vgl. Hellstern, G.-M., Wollmann, H.: Wirkungsanalysen: Eine neue Variante wissenschaftlicher Politikberatung, in: Transfer 4, Planung in öffentlicher Hand, Opladen 1977, S. 159 f.; Hellstern, G.-M., Wollmann, H.: Evaluierungsforschung ..., a.a.O., s. 7 und 98 . 
durchführung ist dagegen Aufgabe der operationalen Erfolgskontrolle ${ }^{1}$.

Das Beschreibung der verschiedenen Ansätze sollte einen Einblick in den Evaluationsarten- und Begriffsdschungel geben. Erstaunen muß derjenige, der sich durch die Evaluationsliteratur hindurcharbeitet, darüber empfinden, daß der mangelhafte Konsens über Ausdifferenzierung und Terminologie der Evaluation höchstens erwähnt ${ }^{2}$, jedoch nicht diskutiert und meistens sogar ignoriert wird.

Zur Untersuchung der inhaltlichen Bedeutung verschiedener Evaluationsbegriffe kann abschließend konstatiert werden, daß die unterschiedlichen Ansätze zwar zunächst nebeneinander stehen und in der Regel auch in dieser "reinen" Form Anwendung finden. Es ist jedoch durchaus denkbar, daß man die Ansätze ineinander verschachtelt, um ihre unterschiedlichen Vorzüge voll auszuschöpfen. So könnte z.B. die ImpactEvaluation (Derlien) bzw. die Wirkungsanalyse (Hellstern/Wollmann) mit dem sehr klaren konzeptionellen Aufbau der Eekhoff'schen Erfolgskontrolle verknüpft werden; mithin wäre letztere um eine Kontrolle nicht-intendierter Wirkungen $\mathrm{zu}$ erweitern.

1 Vgl. Brümmerhoff, D., Wolff, H.: Aufgabe und Möglichkeit einer Erfolgskontrolle der staatlichen Aktivität, in: Zeitschrift für die gesamte staatswissenschaft, 130. Band (1974), S. 484 ff.

2 Hinweise finden sich z.B. bei Eekhoff, J., Werth, G.: Einige Grundprobleme .... a.a.0., s. 7 f.; Fox, K.-P.: Erfolgskontrolle ..., a.a.0., s. 38. Nur Volz untersucht eingehend, wie oben beschrieben, die inhaltliche Bedeutung des Begriffs der Erfolgskontrolle. 


\subsection{Beschreibung der einzelnen Kontrollschritte}

So uneingeschränkt einerseits der in der Literatur geäußerten Meinung, eine Evaluation habe auch nicht-intendierte wirkungen festzustellen, zugestimmt werden muB, ist andererseits der erhebliche Umfang einer solchen Untersuchung zu sehen. Jede - zunächst nur vermutete - Nebenwirkung eines Programms steht in einem "eigenen" Wirkungsfeld, das mit all seinen unabhängigen und abhängigen Variablen beschrieben werden muß, und für jede Nebenwirkung ist gleichermaßen eine Wirkungskontrolle durchzuführen'1 . Es bedarf keiner Erläuterung, daB eine derartige Erweiterung des Blickwinkels den Rahmen dieser Arbeit sprengen würde. Auf eine Analyse nichtintendierter Wirkungen des AbwAG soll deshalb weitgehend verzichtet werden.

Wenn die vorliegende Arbeit also in erster Linie die Zielwirkungen des AbwaG feststellen möchte, so soll diese Untersuchung ihre struktur durch die Zielerreichungs-, Vollzugs-, Bedingungs- und Wirkungskontrolle erhalten. Die einzelnen Kontrollschritte werden im folgenden nicht als eigenständige Instrumente innerhalb des politischen Planungsund Entscheidungsprozesses, sondern als Bestandteil einer umfassenden Erfolgskontrolle näher erläutert.

In der zielerreichungskontrolle sind zunächst die Ziele des untersuchten Programms zu qualifizieren und im Hinblick auf die Indikatorenbildung und Zielmessung unter dem Gesichtspunkt der Operationalität zu prüfen. Operationalität bedeutet im einzelnen, das

1. der Zielinhalt genau bezeichnet ist,

2. ein Sollwert vorliegt,

3. das ziel zeitlich und räumlich fixiert ist und

1 Dies dürfte nicht zuletzt Ursache dafür sein, daß die Evaluationsliteratur den Eindruck erweckt, es bei der Forderung nach der Kontrolle nicht-intendierter Wirkungen zu belassen. 
4. zwischen konfligierenden Zielen Prioritäten gesetzt sind'

Während die Indikatorenbildung nur die genaue Bezeichnung des Zielinhalts erfordert, hängen die Möglichkeiten der Zielmessung davon $a b$, inwieweit auch die anderen operationalitätskriterien erfüllt sind.

Für die Zielmessung sind außerdem die Beziehungen der Ziele untereinander bedeutsam und deshalb zu untersuchen. Denn sie bestimmen, ob für sämtliche ziele die Zielerreichungen $\mathrm{zu}$ ermitteln und mithin Indikatoren $\mathrm{zu}$ bilden sind.

Die Indikatoren selbst haben gewissen Anforderungen zu genügen, um für die Erfolgskontrolle aussagekräftig zu sein. So sollten sie z.B. den Anspruch der Repräsentativität erfüllen. Dient ein ziel nicht unmittelbar selbst als Indikator, sollte es durch möglichst wenige Indikatoren möglichst erschöpfend konkretisiert werden. Daran schließt sich die Forderung nach inhaltlich präziser Abgrenzung der Indikatoren an, die sicherstellt, daß die Daten richtig erhoben, ausgewertet und die Schlußfolgerungen auch von Dritten nachvollzogen werden können. Nicht zuletzt sollten die Indikatoren "objektive" Daten erfassen, was bedeutet, daß sie nach Möglichkeit nicht Meinungen der Befragten, die u.U. interpersonell unter intertemporal nicht vergleichbare Ergebnisse zur Folge haben, sondern meBbare Fakten anzeigen ${ }^{2}$.

Anhand der aufgestellten Indikatoren erfolgt abschließend die Messung der Zielerreichungen durch einen Soll-Ist-Vergleich

1 Hellstern/Wollmann fordern nur die Möglichkeit von

Prioritätensetzungen. Vgl. Hellstern, G.-M., Wollmann, H.: Evaluierungsforschung ...., a.a.0., s. 12. Die Verfasserin plädiert bei Erfolgskontrollen für die Vorgabe von

Prioritäten durch den Zielsetzenden, um Wertungen, die der Subjektivität des Evaluierers entspringen, möglichst wenig Freiraum zu lassen und damit einer Verselbständigung der Erfolgskontrolle entgegenzuwirken.

2 Zu weiteren Kriterien, die an Indikatoren gestellt werden, vgl. u.a. Wolff, H.: Erfolgskontrolle in der Regionalpolitik, Basel 1975, S. 22 ff.; Wulf, J., d'Orville, H.: Entwurf eines systems der Erfolgskontrolle für die regionale Wirtschaftsförderung, Koblenz 1975, s. $11 \mathrm{ff}$. 
und/oder einen Ist-Ist-Vergleich vor und nach Einführung des Programms .

Inwieweit die aufgestellten Ziele erreicht worden sind, hängt u.a. davon $a b$, ob das untersuchte Programm wie geplant implementiert, d.h. durchgeführt und angewendet worden ist. So liegt die Bedeutung der Vollzugskontrolle in "der ebenso banalen wie unbestreitbaren Tatsache, daB politische Programme die Ergebnisse administrativen Handelns nur sehr unvollständig bestimmen, d.h. daß ihre Wirkung wesentlich von der Art der Durchführung abhängt"1. Eben letztere gilt es mit der Vollzugskontrolle zu erfassen. Der Bezugsrahmen, aus dem heraus der für die jeweilige Evaluation erforderliche Informationsbedarf zu konzipieren ist, setzt sich aus den Kategorien Programm, Implementationsträger (Durchführungsinstanzen) und Adressaten des Programms zusammen. Die Implementation des untersuchten Programms ist gemäß diesem Informationsbedarf festzustellen.

Neben dem Programmvollzug ist die Zielerreichung auch von exogenen Bedingungen, also Einflußgrößen, die neben dem statlichen Handeln das Verhalten der Adressaten eines Programms bestimmen, abhängig. Die Aufgabe der Bedingungskontrolle besteht darin, diese unabhängigen Variablen zu identifizieren und ihre Einflußnahme über die Zeit zu ermitteln.

Mit der Zielerreichungs-, Vollzugs- und Bedingungskontrolle sind die Voraussetzungen für die Lösung des Kausalitätsproblems durch die Wirkungskontrolle geschaffen. Erkenntnisleitendes Interesse ist, inwieweit die festgestellten Zielerreichungen durch das untersuchte Programm und nicht durch andere Einflußgrößen induziert wurden. Um eine Zurechnung der Wirkungen vornehmen zu können, sind zunächst Hypothesen über die Wirkungen des Programms zu entwickeln und

1 Mayntz, R.: Die Implementation politischer Programme: Theoretische uberlegungen zu einem neuen Forschungsgebiet, in: dies. (Hrsg.): Implementation politischer Programme, Bd. 1, Königstein/Ts. 1980, S. 236 . 
zu operationalsieren. Die angesprochenen Variablen müssen also definiert werden, und es sind uberlegungen anzustellen, wie der vermutete Wirkungszusammenhang empirisch überprüft werden soll. Der grundsätzliche Ansatz dafür ist das withand-without-Prinzip: wie hätten sich die abhängigen Variablen entwickelt, wenn das Programm nicht eingeführt worden wäre? Die methodischen Möglichkeiten, die zur uberprüfung von Wirkungshypothesen zur Verfügung stehen, werden im folgenden Abschnitt aufgezeigt.

\subsection{Methodische Durchführung}

"Wirkungsforschung muß versuchen, einen gangbaren Weg zwischen sozialwissenschaftlichen Methodenstandards, politisch-administrativer Relevanz und forschungsökonomischer Machbarkeit zu gehen."1 Hellstern/Wollmann zeigen hier das Spannungsfeld auf, in dem das methodische Gebäude für die praktische Durchführung einer Evaluationsstudie entsteht. Ein methodischer "Königsweg" zur Erfassung von Programm- oder Gesetzeswirkungen wird dabei allein deshalb nicht zu bestimmen sein, weil politisch-administrative Relevanz und forschungsökonomische Machbarkeit von Untersuchung $\mathrm{zu}$ Untersuchung variieren.

Grundsätzlich unterscheiden sich die sozialwissenschaftlichen Methoden darin, inwieweit es ihnen gelingt, den Untersuchungsgegenstand von den anderen unabhängigen Variablen des relevanten Wirkungsfeldes zu isolieren. Tab. 2 zeigt synoptisch die verschiedenen Methoden, die hier nach Umfang und stringenz, mit der sie die anderen unabhängigen Variablen bzw. deren Wirkungen zu neutralisieren vermögen, aufgelistet sind.

1 Hellstern, G.-M., Wollmannn, H.: Evaluierungsforschung ..., a.a.0., s. 106 . 


\begin{tabular}{|c|c|c|c|}
\hline & Vorgenen & Methodsersn Moglidtherten und Vorreile & Methodistie Frobirme und Nachieile \\
\hline $\begin{array}{l}\text { Enportmont. } \\
\text { vertahroen }\end{array}$ & 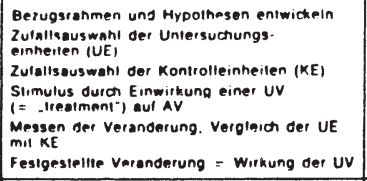 & 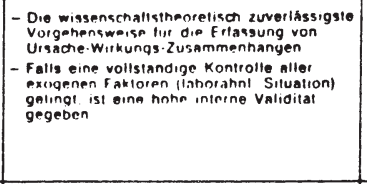 & 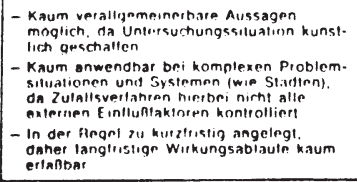 \\
\hline 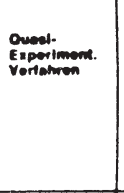 & 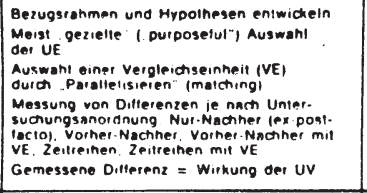 & 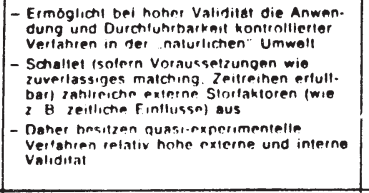 & 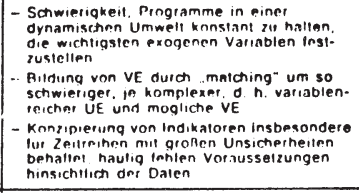 \\
\hline $\begin{array}{l}\text { Ousenthetions } \\
\text { Vertohren }\end{array}$ & 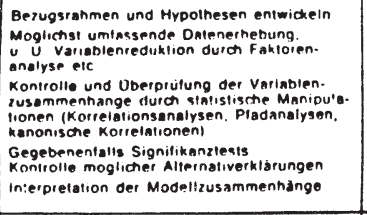 & 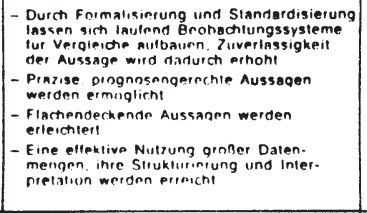 & 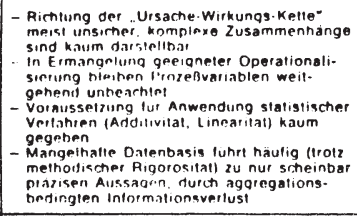 \\
\hline 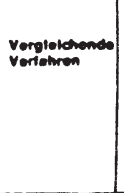 & 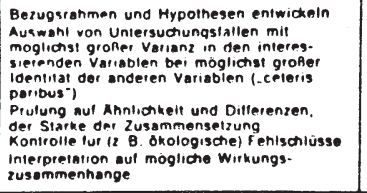 & 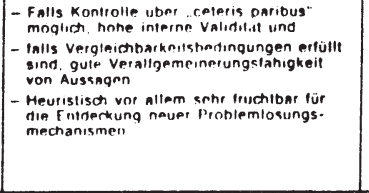 & 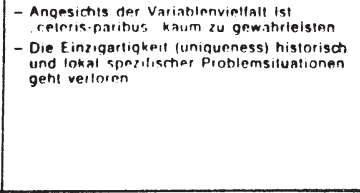 \\
\hline Follotedion & 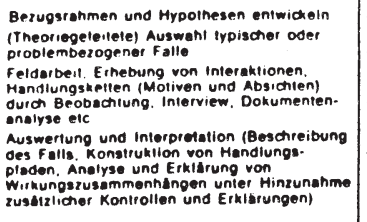 & 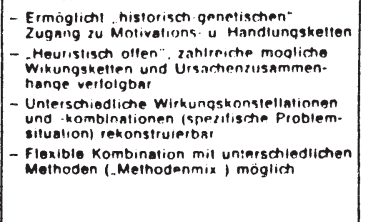 & 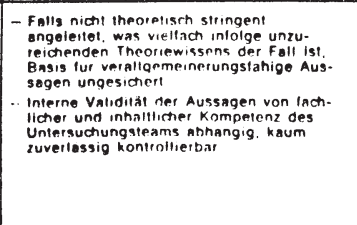 \\
\hline
\end{tabular}

Tab. 2: Synopse sozialwissenschaftlicher Methoden ${ }^{1}$ 
Da sich die zu evaluierenden Programme, Gesetze oder Maßnahmen in der Regel durch komplexe Wirkungsfelder auszeichnen, zeigen sich gerade diejenigen Methoden, die besonders strenge Anforderungen an die Vorgehensweise stellen - zu denken ist hier in erster Linie an das Experiment - , als wenig praktikabel, weil sie nur einen Teil der Variablen kontrollieren können ${ }^{1}$. Auch die in Tab. 2 nachfolgend aufgeführten quasi-experimentellen und quantitativen Verfahren zeigen sich in ihren Einsatzmöglichkeiten beschränkt. So können bei komplexen Wirkungsfeldern quantitativ-statistische Verfahren z.B. dann nicht angewendet werden, wenn relativ wenig Untersuchungseinheiten zur Verfügung stehen (Faustformel der Schwierigkeiten: "many variables, small number of cases"2).

Da zudem die Aussagefähigkeit einer jeden Methode beschränkt ist, schlagen Hellstern/Wollmann vor, den häufig unfruchtbaren Methodenpurismus durch ein Methoden-Mix zu ersetzen, wenn sich die Wirkungsforschung zu einem Programm noch in einem frühen stadium befindet ${ }^{3}$. Der dann unzulängliche Wissensstand läßt es sinnvoll erscheinen, neben den recht standardisierten quasi-experimentellen und quantitativen Verfahren die heuristisch offeneren und methodisch flexibleren Vorgehensweisen, wie es die Fallstudien darstellen, als Erkenntnisquelle auszuschöpfen und damit "die rigorose Trennung in Konstruktion von Hypothesen und ihre Uberprüfung aufzugeben, den 'Konstruktionsprozeß erster Ordnung'in die Wirkungsanalyse einzubeziehen und ein Zusammenfließen von

1 Vgl. Hellstern, G.-M., Wollmann, H.: Wirkungsanalysen ..., a.a.0., s. 164 .

2 Lijphart, A.: Comparative Politics and the Comparative Method. American Political Science Review, 1971, S. 682 ff., hier S. 685, zitiert nach Hucke, J., Wollmann, H.: Methodenprobleme..., a.a.0., s. 228 .

3 Hellstern, G.-M., Wollmann, H.: Evaluierungsforschung ..., a.a.0., s. $95 \mathrm{f}$. 
Entdeckungs- und Begründungszusammenhang zu akzeptieren."1

1 Ebenda, S. 95; vgl. dazu auch Cronbach, L.J.: Beyond the Two Disciplines of Scientific Psychology, in: American Psychologist, Vol. $30(1975)$, S. $116 \mathrm{ff}$. 
2. Das Abwasserabgabengesetz als Evaluationsgegenstand

\subsection{Die aktuelle Diskussion}

Wie bereits in der Einleitung vermerkt wurde, stellt das AbwAG als erste und bislang einzige bundesdeutsche Emissionsabgabe ein interessantes Evaluationsobjekt dar. Um so mehr überrascht es, daß zwar eine Reihe von empirischen Untersuchungen zur Wirkung des AbwAG vor Beginn der Abgabepflicht 1981 durchgeführt wurde, nach dieser sogenannten Signalwirkungsphase das Evaluationsinteresse aber offensichtlich nachließ, obwohl z.B. die abgabentheoretische Wirkungshypothese erst jetzt ex post hätte getestet werden können.

So liegen bislang nur Untersuchungen zur Signalwirkungsphase vor ${ }^{1}$, die teilweise, unter Zugrundelegung ihrer empirischen Ergebnisse, auch Prognosen über Wirkungen des AbwAG nach Beginn der Abgabepflicht wagten.

All diese Arbeiten wurden im Auftrag des Umweltbundesamtes Berlin am Institut für Finanzwissenschaft der Universität zu Köln durchgeführt. Es handelt sich hierbei um die folgenden Untersuchungen:

1. Auswirkungen des Abwasserabgabengesetzes auf Investitionsplanung und -abwicklung in Unternehmen, Gemeinden und

1 Es soll dabei allerdings nicht verkannt werden, daß dem Wirkungszeitraum vor Beginn der Abgabepflicht und damit auch seiner Untersuchung eine wichtige Bedeutung zukommt, unterstellt man der Emissionsabgabe die gleiche Wirkungsweise, wie man sie bei Wirkungszwecksteuern beobachtet. Diese speziellen Verbrauchssteuern sind wie die Emissionsabgabe weniger fiskalisch motiviert, sondern sollen ebenfalls in erster Linie verhaltensändernd wirken. Hier kennt man die Wahrnehmungs- und Informationsphase, in der der Veranlagte Anpassungs- und Ausweichreaktionen vornimmt, um die Abgabepflicht möglichst nicht oder nur in geringer Höhe entstehen zu lassen. Auf den Abwasseremittenten bezogen bedeutete dies, daß er Maßnahmen zur Abwasserreduzierung und -behandlung bereits in dieser Phase ergreift. Vgl. Hoffmann, V., Ewringmann, D.: Auswirkungen ... a.a.0., s. $9 \mathrm{f}$. 
Abwasserverbänden (Hoffmann, V., Ewringmann, D., Bonn 1977)

2. Die Abwasserabgabe als Investitionsanreiz. Auswirkungen des $\$ 7$ a WHG und des Abwasserabgabengesetzes auf Investitionsplanung und -abwicklung industrieller und kommunaler Direkteinleiter (Ewringmann, D., Kibat, K.-D., Schafhausen, F.J., Berlin 1980)

3. Auswirkungen des Abwasserabgabengesetzes auf industrielle Indirekteinleiter (Ewringmann, D., Hansmeyer, K.-H. , Hoffmann, V., Kibat, K.-D., Berlin 1981)

4. Okonomische Aspekte der Wirkungen wasserwirtschaftlicher Regelwerke (AbwAG/WHG) auf Abwasserverbände und deren Mitglieder (Kibat, K.-D., Berlin 1982)

5. Begleitende Untersuchung der angewandten Gebührenmodelle der Abwälzung der Abwasserabgabe auf Indirekteinleiter in ausgewählten Kommunen (Kibat, K.-D., Köln 1983, unveröffentlicht').

Die Ergebnisse der Arbeiten gingen in den Erfahrungsbericht zum AbwAG ein, der 1983 vom Bundesminister des Innern herausgegeben wurde ${ }^{2}$ und der neben den Wirkungen des Gesetzes auf die Abwassereinleiter die Ausführung und den Vollzug des Gesetzes zum damaligen Zeitpunkt beschrieb.

Ohne auf das methodische Vorgehen der oben genannten Arbeiten einzugehen, seien hier die wichtigsten der festgestellten Wirkungen kurz zusammengefast.

Bereits die erste studie kam zu dem Ergebnis, daß auch von den geltenden, gegenüber dem ersten Referentenentwurf stark reduzierten und darüber hinaus halbierten Abgabesätzen noch eine erstaunlich hohe Anreizwirkung ausgehen und die Abgabe

1 Veröffentlicht wurde ein Resümmee der studie: Kibat, $K$. $-D$.: Verursacherbezogene Entwässerungsgebühren und Abwasserabgabe, in: Korrespondenz Abwasser, $31 . \mathrm{Jg}$. $(1984)$, Heft 8, S. 708 ff.

2 Vgl. Bundesminister des Innern (Hrsg.): Erfahrungsbericht zum Abwasserabgabengesetz, Bonn 1983, S. 33 ff. 
auch ohne den Einsatz des WHG über eine relativ hohe Wirksamkeit verfügen würde. Es wurde festgestellt, daß die Koppelung von WHG und AbwAG die Wirksamkeit der Abgabe einengt und auch eine isolierte Wirkungsanalyse dieses Instrumentes erschwert, wenn nicht gar unmöglich macht. Gleichwohl konstatierte man, wie auch in der nachfolgenden Untersuchung, eine hohe Signalwirkung des AbwAG bei den Direkteinleitern'1.

So dürften rund $72 \%$ der in der $z$ weiten studie befragten gewerblichen Direkteinleiter die Abwasserbehandlungsmaßnahmen und -entscheidungen unter dem Druck der Zangenwirkung von AbWAG und WHG durchgeführt, beschleunigt oder verändert haben. Bei rund $37 \%$ der Befragten schien der signaleffekt stärker vom AbwAG auszugehen. Dieser Befund wurde auch dadurch gestützt, daß bei einem Drittel der Befragten, die über Kostentransparenz verfügten, der Kostenzuwachs pro zusätzlich vermiedener Schadeinheit niedriger lag als der Abgabesatz, sie also dem theoretischen Anreizeffekt der Abgabe unterlagen².

In der gleichen studie wurde bei etwa der Hälfte der maßnahmenergreifenden kommunalen Direkteinleiter ebenfalls die erwartete Abgabenbelastung als ausschlaggebend erkannt ${ }^{3}$.

Die dritten studie kam zu dem Ergebnis, daß von den rund $80 \%$ der befragten Gemeinden, die weitergehende Reinigungsmaßnahmen planten oder bereits bauten, rund $60 \%$ dies aufgrund der Zangenwirkung taten ${ }^{4}$.

Wie die vierte studie ergab, berücksichtigen 77 \% der Abwasserverbände die Regelungen des AbwAG und des $\S 7$ a WHG als Aktionsparameters.

1 Vgl. Hoffmann, V., Ewringmann, D.: Auswirkungen ..., a.a.O., s. $164 \mathrm{ff}$.

2 Vgl. Ewringmann, D., Kibat, K.-D., Schafhausen, F.J.: Die Abwasserabgabe..., a.a.0., s. 16 .

3 Vgl. ebenda, S. 17.

4 Vgl. Ewringmann, D., Hansmeyer, K.-H., Hoffmann, V., Kibat, K.-D.: Auswirkungen ..., a.a.0., s. 22.

- Vgl. Kibat, K. $-D .:$ Okonomische Aspekte ..., a.a.0., s. 183. 
Sowohl die dritte als auch die diese begleitende fünfte studie sahen die gewässergütepolitische und die ökonomische Lenkungseffizienz der Abgabe bei den Indirekteinleitern durch das festgestellte Vorherrschen der Abgabenabwälzung nach dem Frischwassermaßstab eingeschränkt. Denn dieser bietet nur einen mengenreduzierenden, nicht aber einen schädlichkeitsreduzierenden Anreiz. Die Verfasser prognostizierten, daß die mengenbezogene Abwälzung Wettbewerbs- und strukturverzerrungen insbesondere zwischen Direkt- und Indirekteinleitern induziert. Bei nur knapp 11 \% der Gemeinden veranlaßte das neue gewässergütepolitische Instrumentarium den vbergang $z u$ einem schädlichkeitsbezogenen Maßstab'

Hervorzuheben ist abschließend die in der zweiten studie festgestellte Wirksamkeit der neuen Regelungen bei den Aufsichtsbehörden. Sie äußerte sich in verstärktem Druck und einer Zunahme der Kontrollen bei den gewerblichen und kommunalen Direkteinleitern und diente somit als Katalysator derer Anpassungsbemühungen² .

Dieses Resümee vermittelt, unabhängig von der Problematik der isolierten Wirkungsanalyse, einen ersten Eindruck über die inhaltliche Vielfalt von Evaluationsansätzen zum AbwAG. Der nächste Abschnitt bemüht sich um eine umfassende Darstellung von Wirkungsuntersuchungen $\mathrm{zu}$ diesem Gesetz.

1 Vgl. Ewringmann, D., Kibat, K.-D., Schafhausen, F.J.: Auswirkungen ..., a.a.O., s. 22 .

2 Vgl. Ewringmann, D., Kibat, K.-D., Schafhausen, F.J.: Die Abwasserabgabe ..., a.a.0., s. 17 . 


\subsection{Das Spektrum möglicher Evaluationsansätze zum AbwAG}

Der Versuch, das weite Feld möglicher Evaluationsansätze zum AbwaG aufzuzeigen und zu systematisieren, geht von der Uberlegung aus, daß es insbesondere drei Kriterien sind, die diese Ansätze inhaltlich abstecken:

- die Untersuchungseinheit,

- die untersuchten Wirkungen bzw. Wirkungskomplexe und

- der Untersuchungszeitpunkt bzw. -zeitraum.

Wie diese drei Kriterien bestimmt werden können, soll näher erläutert werden.

Welche Untersuchungseinheiten für eine Evaluationsstudie ausgewählt werden, hängt maßgeblich von den untersuchten Wirkungen bzw. Wirkungszusammenhängen ab. Grundsätzlich sind die Untersuchungseinheiten aus den Adressaten des AbwAG zu rekrutieren, die man zunächst grob unterteilen kann in ${ }^{1}$

1. die Direkteinleiter als die Rechtsgenossen, weil sich das AbWAG an sie richtet,

2. die Vollzugsbehörden, die als Rechtsstab das AbwAG auf die Direkteinleiter anwenden und

3. die Vollstreckungsorgane, die die Erfüllung des AbwAG erzwingen, also Polizei und Gerichte.

Bei den Direkteinleitern unterscheidet man weiter zwischen gewerblichen (industriellen) Direkteinleitern, die in den Mindestanforderungen zum $\$ 7$ a WHG nach der Zusammensetzung ihrer Abwässer weiter aufgefächert werden, kommunalen Direkteinleitern und Abwasserverbänden. Als "indirekter Adressat" des AbwAG sind darüber hinaus die Indirekteinleiter zu beachten.

1 Zur rechtstheoretischen Terminologie vgl. Ellermann, $R_{\text {.: }}$ Anregungen zur Konzeptualisierung einer Effektivitätsforschung rechtlicher Regelungen, in: Hellstern, G. $-M$. Wollmann, H. (Hrsg.), Experimentelle Politik - Reformstrohfeuer oder Lernstrategie, Opladen 1983, S. 131. 
Mögliche Wirkungen bzw. Wirkungskomplexe und Untersuchungen über diese lassen sich nach Meinung der Verfasserin folgendermaßen gliedern:

1. Der Anteil des AbWAG an der Verbesserung der Gewässergüte Unter diesem Blickwinkel betrachtete man das AbwAG im Kanon sämtlicher Subprogramme der Gewässergütepolitik und versuchte, seinen Anteil an der Erreichung der Gewässergüte II als oberstem Ziel des übergreifenden Programms herauszuarbeiten.

2. Der Anteil des AbWAG an der Emissionsverminderung Diese Untersuchung setzte eine stufe tiefer an und hätte zum Inhalt, den Anteil des AbwaG an der Erreichung seines eigenen ökologischen "Gesamtziels", der Emissionsverminderung, festzustellen.

3. Der Anteil des AbWAG an der Erreichung seiner "Teilziele" Hier spaltete man den Untersuchungsgegenstand weiter auf, um $z u$ erforschen, inwieweit die in Abschnitt A.4 aufgeführten intendierten Ziele durch die Wirkungen des AbwAG erreicht wurden. Im Sinne von Brümmerhoff handelte es sich, wie auch bei der ersten und zweiten Untersuchung, um eine strategische Erfolgskontrolle, im sinne Hellstern/Wollmanns um eine Programmwirkungsanalyse, betrachtete man das AbwAG gleichsam als Programm².

1 Mayntz weist darauf hin, daß es "ausnahmsweise" erlaubt ist, ein "klar umgrenztes, abgeschlossenes Ganzes .... wie es etwa ein Gesetz darstellt, das eine bestimmte Materie abschließend regelt" als Programm aufzufassen. Mayntz, $R$.: Implementation von regulativer Politik, in: dies.

(Hrsg.), Implementation politischer Programme, Bd. 2: Ansätze zur Theoriebildung, Opladen 1983, s. $54 \mathrm{f}$. Im übrigen regelt das AbwAG als Rahmengesetz die Materie nicht abschließend. Genau genommen dürte man allerdings erst dann von einer Programmwirkungsanalyse sprechen, wenn man auch die Untersuchung nicht-intendierter Wirkungen integrierte. 
4. Die Auswirkungen des AbwAG auf das Emissionsverhalten der Indirekteinleiter

Das rahmenrechtliche AbwaG regelt zwar nicht die Abwälzung der Abgabe auf die gewerblichen Indirekteinleiter. Gerade deswegen interessierte aber, inwieweit das AbwAG auch auf sie, die die Abgabe letztlich zu tragen haben, Wirkungen ausübt.

\section{Nicht-intendierte Wirkungen}

Die vorangegangenen Thematiken befaßten sich lediglich mit intendierten wirkungen, sieht man von der Neutralität der vierten Variante, bei der keine Intention von seiten des Gesetzgebers ausgesprochen wurde, ab.

Erweiterte man das jeweils untersuchte intendierte Wirkungsspektrum um die Möglichkeit nicht-intendierter Wirkungen, ginge man von der reinen Effektivitätsanalyse zur Impact-Evaluation bzw. von der Erfolgskontrolle zur Wirkungsanalyse im sinne von Hellstern/Wollmann über.

6. Die Wirksamkeit des AbWAG als Ergebnis der Ausführungsgesetze der Länder

$\mathrm{Zu}$ überprüfen wäre, ob und wie die Ländergesetze die Wirksamkeit des Rahmengesetzes beeinflussen und damit Ursache für ausbleibende oder "Uber-"Wirkungen des AbwAG sind.

7. Die Wirksamkeit des AbWAG als Ergebnis seiner Wirkungen auf die Vollzugsbehörden

Im Vordergrund stünde die Frage, ob sich das Verhalten der Vollzugsbehörden verändert hat (Druck und Kontrollen) und wie die Verhaltensänderung die Abwasserreinigung der Emittenten beeinfluBt.

8. Die Wirksamkeit des AbWAG als Ergebnis des Vollstreckungsprozesses

Es wäre zu untersuchen, ob die Nichtbefolgung der abgaberechtlichen Regelungen von seiten der Emittenten durch die Vollstreckungsorgane entsprechend sanktioniert 
und gerichtlich festgestellte Forderungen tatsächlich erfüllt werden und das AbwAG deshalb eine gewisse Wirksamkeit entfaltet, oder ob Sanktionierungen unzureichend sind und Gerichtsentscheidungen durch Reaktion der Betroffenen konterkariert werden. Die in der dritten Untersuchung aufgegriffene Terminologie weiterführend spräche man bei dieser wie auch bei der 7 . Untersuchung von einer operationalen Erfolgskontrolle bzw. von einer Projektevaluation.

9. Die Wirksamkeit des AbwAG durch die Verwendung des Abgabenaufkommens

Es wäre zu ermitteln, wie hoch der Anteil des Abgabenaufkommens zur Deckung des Verwaltungsaufwandes ist und ob der Restbetrag von den Ländern gewässergütewirksam angelegt wird. Die in Abschnitt A.3.2 angesprochene Finanzfunktion stünde hier also im Mittelpunkt des Interesses.

10. Das Wirkungsausmaß einzelner Gesetzeselemente

Unter diesem Gesichtspunkt interessierte der Zusammenhang zwischen einzelnen, in der dritten Untersuchung festgestellten Teilzielwirkungen und einzelnen Gesetzeselemementen. Dabei wären nicht nur positive Kausalitäten festzustellen, sondern im Kontext der heftigen Diskussionen um die von vielen aus gewässergütewirtschaftlicher Sicht als zu lasch empfundenen Regelungen wäre auch $z u$ ermitteln, inwieweit durch die spezifische Ausgestaltung Wirkungspotentiale wirklich verschenkt wurden - und damit Wirkungshypothesen aus den Reihen der Kritiker verifiziert werden können. In eine derartige Kontrolle strittiger Gesetzeselemente könnten insbesondere der spätere Beginn der Abgabepflicht, die Höhe des Abgabesatzes sowie seine staffelung, die Abgabenhalbierung für den Restschmutz und die Härteklausel fallen. Während im erstgenannten Schritt also die ökonomische Wirksamkeit dieser Gesetzeselemente im Vordergrund stünde, wäre anschließend ihre ökologische Wirksamkeit von erkenntnisleitendem 
Interesse. Insgesamt handelte es sich um eine taktische Erfolgskontrolle bzw. um eine Programmstrategieanalyse.

11. Uberprüfung der modelltheoretischen Wirkungshypothese der Abgabe

Hier wäre zu untersuchen, ob die Emittenten in der Tat ihr Abwasser theoriegetreu bis zum schnittpunkt von Reinigungskosten und Abgabesatz behandeln, sofern dieser Schnittpunkt in den eigenständigen Wirkungsbereich des AbwAG fällt.

\section{Okonomische Effizienz des AbwAG}

Das AbWAG wäre unter Berücksichtigung der Ergebnisse der elften Untersuchung auf seine in Abschnitt A.1.3 beschriebene ökonomische Effizienz bzw. unter weiterer Berücksichtigung der Zangenwirkung durch die Auflagenregelungen auf seine ökonomische "Resteffizienz" hin zu qualifizieren.

An diese Effektivitätsuntersuchungen anschließen könnten sich dann Uberlegungen zur Effizienz des AbWAG', indem alternative Ausgestaltungen eines Abgabengesetzes oder ganz anders geartete Lösungen ebenfalls auf ihre Effektivität hin bewertet und anschließend auf dieser Basis mit dem AbwAG verglichen werden, um dessen relative Vorzüglichkeit herauszufinden.

Die Wahl des Untersuchungszeitpunktes bei einem Soll-IstVergleich von Wirkungen und des Untersuchungszeitraums bei einem Ist-Ist-Vergleich (before-and-after) hängt ebenfalls primär von der untersuchten Wirkung ab. Grundsätzlich läßt sich der gesamte Wirkungszeitraum des AbwAG in die signalwirkungsphase von Ankündigung des Gesetzes bis zum Beginn der Abgabepflicht und in die Phase nach Beginn der Abgabepflicht splitten. Einige Wirkungsuntersuchungen sind bereits während der Signalwirkungsphase möglich, andere, wie eine abschlie-

1 Angesprochen sind Effizienzkontrollen im Sinne Eekhoffs und Derliens; siehe dazu s. 84 . 
Bende Beurteilung des Gesetzes, müssen beide Zeiträume, insbesondere auch mehrere Jahre nach Beginn der Abgabepflicht umschließen, und wieder andere benötigen nur den zweiten Zeitabschnitt, so z.B. diejenigen, bei denen es um die Uberprüfung der modelltheoretischen Wirkungshypothese geht.

Die Wahl des Evaluationsansatzes wird von der Motivation der Untersuchung determiniert. Bevor diese für die vorliegende Arbeit erörtert wird, seien in Tab. 3 abschließend mögliche Kombinationen der angesprochenen Kriterienausprägungen vorgestellt. 


\begin{tabular}{|c|c|c|c|c|}
\hline $\begin{array}{l}\text { Untersuchungseinheit } \\
\text { Wirkungen des AbwAG }\end{array}$ & 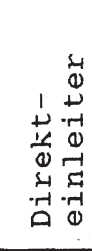 & 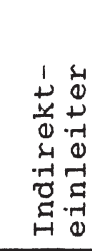 & 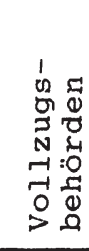 & 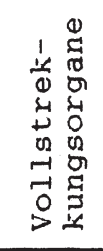 \\
\hline 1. auf die Gewässergüte & VG & & & \\
\hline 2. auf die Emissionen & VG & & & \\
\hline 3. auf seine Teilziele & VG & & & \\
\hline 4. auf Indirekteinleitungen & & VG & & \\
\hline 5. nicht-intendierte & \multirow{2}{*}{\multicolumn{4}{|c|}{$\begin{array}{l}\text { in Abhängigkeit der } \\
\text { untersuchten Wirkung }\end{array}$}} \\
\hline 6. durch Ausführungsgesetze & & & & \\
\hline 7. über die Vollzugsbehörden & & & VGN & \\
\hline 8. durch d. Vollstreck.prozess & & & & $\mathrm{N}$ \\
\hline 9. durch das Abgabenaufkommen & & & $\mathrm{N}$ & \\
\hline 10. seiner Gesetzeselemente & N & & & \\
\hline 11. laut Wirkungshypothese? & N & & & \\
\hline 12. ökonomische Effizienz & N & & & \\
\hline
\end{tabular}

Untersuchungszeitpunkt/raum:

V: vor Beginn der Abgabepflicht

$\mathrm{G}$ : vor und nach Beginn der Abgabepflicht (gesamter Wirkungszeitraum)

$\mathrm{N}$ : nach Beginn der Abgabepflicht

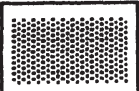

Kombination ist nicht sinnvoll

Tab. 3: Mögliche Evaluationsansätze zum Abwasserabgabengesetz 


\subsection{Eingrenzung des Untersuchungsbereichs}

Die aufgezeigte Vielfalt möglicher Wirkungsuntersuchungen zum AbwAG läBt erkennen, daß eine Evaluationsstudie, wenn es sich um ein einigermaßen komplexes Programm oder Gesetz handelt, nur einen Ausschnitt aus dem Wirkungsspektrum untersuchen kann'1. So stellt sich auch für diese Arbeit die Aufgabe, die Fragestellung einzugrenzen.

Grundsätzlich kann das forschungsauslösende Moment der Programm-/Gesetzegevaluation eher theoretisch-wissenschaftlicher oder eher praktisch-politischer Art sein². Beide orientierungen versuchen, die Wirkungen eines Programms/Gesetzes festzustellen; erstere mit dem vorrangigen Ziel, Wirkungshypothesen zu testen, letztere - vielleicht ${ }^{3}$ - mit der Absicht, Korrekturen des politischen Handelns auf der Basis der gewonnenen Erkenntnisse durchzuführen, wenn diese einen Handlungsbedarf anzeigen. Die letztendliche Bestimmung beider orientierungen ist jedoch dieselbe, denn auch die Uberprüfung der Wirkungshypothesen soll zu besseren Entscheidungen führen.

Berücksichtigt man, daß die Novellierung des AbwAG bereits erlassen wurde und somit die Weichen für die Zukunft gestellt sind, kann es kaum befriedigen, die Auswirkungen des derzeitig noch gültigen AbwAG auf die Direkt- und Indirekteinleiter mit dem Anliegen zu erforschen, Vorschläge für eine Gesetzesverbesserung einzubringen. Auch für eine Evaluationsstudie, deren Hauptanliegen es ist, eine Wirkungsprognose der Novellierung, die aus den Erfahrungen mit dem "alten" AbwaG

1 Vgl. u.a. Eekhoff, J., Werth, G.: Einige Grundprobleme ..., a.a.0., s. 23 .

2 In Anlehnung an Hembach, K.: Der stellenwert ..., a.a.o., S. $43 \mathrm{f}$.

3 Eine beispielhafte Aufzählung von Interessensphären praktisch-politischer Herkunft in Abhängigkeit der an den Evaluationsergebnissen interessierten Gruppen bringen Kiresuk, T.J., Larsen, N.E., Sander, H.L.: Wisgenstransfer ..., a.a.o., s. 202 ff. 
resultieren könnte, vorzunehmen, ist die Zeit überschritten, eben weil die neuen Regelungen schon erlassen sind und man wohl nicht der Illusion erliegen sollte, mit Wirkungsprognosen, wenn diese negativ ausfallen, bei den gegebenen Zuständigkeiten eine Reform der Reform auszulösen. Bessere Perspektiven böte dagegen eine Untersuchung über die Wirksamkeit des AbwAG in Abhängigkeit der Ausführungsgesetze oder als Ergebnis des Vollzugs- und Vollstreckungsprozesses. Denn die Anderung eines Ausführungsgesetzes ist allein wegen der kleineren Gruppe der davon Betroffenen weniger einschneidend als die des Rahmengesetzes, so daß man bei den Behörden auf eine gegenüber Verbesserungsvorschlägen aufgeschlossenere Haltung trifft ${ }^{1}$. Der Vollzugsprozess zeichnet sich zum einen, weil nie wirklich endend, durch eine relative Zeitlosigkeit aus, was dann auch für die Möglichkeit der Umsetzung einiger Evaluationsergebnisse gilt. Zum anderen könnten die durch eine Evaluation generierten Informationen gerade bei der Einführung der Novellierung für Schwachstellen sensibilisieren und den "neuen" Vollzugsprozeß dadurch positiv beeinflussen ${ }^{2}$. Entsprechend kann man für den Vollstreckungsprozess argumentieren.

Interessanter erscheint jedoch die uberprüfung von Wirkungshypothesen zur Abwasserabgabe. Gerade weil die Wirkungsforschung zum AbwAG noch sehr lückenhaft ist, könnte eine empirische Untersuchung die vorliegenden, bislang nur teilweise getesteten Wirkungsannahmen festigen oder auch entkräften und damit mehr Licht in die Wirkungsweise der Abwasserabgabe bringen. Darüber hinaus könnte sie Hinweise für die mögliche Ausgestaltung wirksamer Emissionsabgaben geben ${ }^{3}$.

1 Voraussetzung dafür ist allerdings eine positive Einstellung zum AbWAG.

2 Man beachte in diesem Zusammenhang allerdings die grundlegenden Veränderungen, die die Novellierung für den Abgabenvollzug vorsieht (siehe s. 47)!

3 Siehe in diesem Zusammenhang auch die bereits in der Einleitung zitierten Ausführungen von siebert. 
Dieses Argument des "Wissenstransfers" läßt sich natürlich auch für Untersuchungen über den Einfluß der Ausführungsgesetze, des Vollzugs- und Vollstreckungsprozesses in Anspruch nehmen. Der besondere Reiz einer Untersuchung der Abwasserabgabe als Instrument der Umweltpolitik und eben nicht als objekt politisch-administrativer Ausführung liegt aber darin, daß sie die erste und bisher einzige Emissionsabgabe in der Bundesrepublik Deutschland ist. Die politischadministrative Ausführung stellt dagegen zunächst eine Folge der Einführung dar und ist als Vorgang auch nicht abgabenspezifisch.

Es sollte jedoch nicht verkannt werden, daß auch die intendierte Untersuchung den Gesetzesvollzug in seinen wesentlichen Zügen erfassen muß, um die festgestellten - oder ausgebliebenen - Gesetzeswirkungen relativieren zu können. Insofern sind auch in dieser Evaluationstudie Aspekte der politisch-administrativen Ausführung enthalten.

Mangel an Wirkungsannahmen zum AbwAG herrscht keineswegs. So existieren neben der modelltheoretischen Wirkungshypothese einer Emissionsabgabe, wie bereits oben angesprochen, noch Wirkungsintentionen, die vom Gesetzgeber formuliert wurden und die den Zusammenhang zwischen dem AbwaG bzw. seinen Ausgestaltungselementen und den zielen, die mit dem Gesetz aufgestellt wurden, herstellen. Es folgen die "apokalyptischen" Wirkungs- bzw. Nichtwirkungshypothesen der Gesetzesgegner und die Frage nach der verbleibenden ökonomischen Effizienz der Abwasserabgabe bzw. des Abgaben-Auflagensystems. Empirisch gestützt sind dagegen die wenigsten dieser Wirkungshypothesen. Es stellt sich deshalb die Aufgabe, den vorliegenden Hypothesendschungel $\mathrm{zu}$ testen, soweit dies unter den gegebenen Bedingungen methodisch und empirisch möglich erscheint. Erfaßt werden sollen also sowohl die Gesamtwirkungen des Gesetzes als auch der Zusammenhang zwischen Gesetzeswirkungen und Gesetzeselementen. Am Rande werden außerdem Uberlegungen zu nicht-intendierten Wirkungen angestellt. 
Die vorliegende Arbeit versucht demnach, die Wirkungsweise des AbWAG aus mehr theoretisch-wissenschaftlicher sicht zu erforschen. Diese Position harmoniert auch mit der Ansicht, das "Controlling" eines Programms/Gesetzes gehöre in die Hände oder wenigstens in die Mitarbeit der dafür Verantwortlichen, weil sie ja diejenigen sind, die die festgestellten Abweichungen in Gesetzesänderungen transponieren müssen - wenngleich die mit dieser Kontrolle geforderte Selbstkritik an die Grenzen des menschlich Erwartbaren trifft und dies sicher ein Grund dafür ist, daß Evaluation lange Zeit nicht systematisch und auch heute noch lückenhaft betrieben wird. Anders begründet, nämlich wegen der methodischen und inhaltlichen Anforderungen der Kausalitätsuntersuchungen, macht sich Eekhoff dezidiert für die grundsätzliche Verankerung der Evaluation im Forschungsbereich stark: "Mit der Wirkungskontrolle als Teil der Erfolgskontrolle wird ... empirisch überprüft, welche Wirkungen von einer Maßnahme ausgegangen sind. Die Wirkungskontrolle ist im Prinzip ein Forschungsansatz, bei dem strittige Hypothesen getestet werden. Sie zielt darauf ab, neue Erkenntnisse über Wirkungszusammenhänge zu gewinnen. Eine methodisch streng abgesicherte wirkungskontrolle kann deshalb nicht als standardaufgabe der Verwaltung oder des Rechnungshofes angesehen werden, sondern gehört grundsätzlich in den Aufgabenbereich der Forschung." Und an anderer stelle: "Solide aussagefähige Analysen sind aufwendig und zeitraubend. Sie erfordern nicht nur methodische, sondern vor allem inhaltliche Kenntnisse. Das Untersuchungspotential in der Verwaltung ist dafür häufig zu gering." 1

Mit der groben Abgrenzung der zu untersuchenden Wirkungskomplexe stehen genauso holzschnittartig die Untersuchungs-

1 Eekhoff, J.: Ansatzpunkte ..., a.a.0., S. 79 und 60. Hembach kommt dagegen bei einer Gegenüberstellung der Institutionalisierung von Wirkungsforschung innerhalb des politisch-administrativen systems und bei externen Sachverständigen zu dem SchluB: "Grundsätzlich kann weder von den Durchführungs- noch von den Umsetzungsbedingungen eine der beiden Grundformen favorisiert werden." Hembach, K.: Der Stellenwert..., a.a.0., s. 225. 
einheiten fest: Es sind die Direkteinleiter, denn auf sie beziehen sich die Wirkungshypothesen bzw. aus ihrem Verhalten resultieren die vermuteten Wirkungen. Wenngleich die empirische Untersuchung anhand einer definierten gewerblichen Einleitergruppe, nämlich den direkteinleitenden Papierfabriken durchgeführt wird, soll das Evaluationskonzept allgemein für gewerbliche Direkteinleiter entwickelt werden ${ }^{1}$. Damit ist intendiert, einen allgemeiner anwendbaren Baustein eines umfassenden Evaluationssystems des AbwAG zur Verfügung $\mathrm{zu}$ stellen ${ }^{2}$.

Was den Untersuchungszeitpunkt/raum betrifft, so wird der gesamte Wirkungszeitraum und nicht die Signalwirkungsphase für sich genommen untersucht. Speziell auf die Signalwirkungsphase zugeschnittene Wirkungsuntersuchungen liegen bereits, wie in Abschnitt B.2.1 beschrieben, vor, und die fortgeschrittene Zeit erlaubt nunmehr eine abschlieBende Betrachtung.

Wie eingangs bereits gesagt, unterscheiden sich die beiden forschungsauslösenden Momente höchstens in der Verwertung der Ergebnisse. Mithin hätte das vorzustellende Konzept auch für "Controlling"-Zwecke verwendet werden können.

1 Das Evaluationskonzept könnte über weite strecken auch für kommunale Direkteinleiter und Abwasserverbände übernommen werden; beide Gruppen zeigen jedoch auch Spezifika, die gänzlich andere Denkansätze erfordern, weshalb sie im folgenden ausgeklammert werden.

2 Projezierte man diesen Baustein auf das "neue" AbwAG, müßte er allerdings der veränderten Gesetzesausgestaltung angepaßt werden. 


\subsection{Aufbau der durchzuführenden Erfolgskontrolle}

Die Erfolgskontrolle wird weitestgehend so aufgebaut, wie in Abschnitt B.1.4 beschrieben. Die abhängigen und unabhängigen Variablen sollen allerdings aus Gründen der Ubersicht vorab bestimmt werden. Auf ihrer Untersuchung bauen dann die Zielerreichungskontrolle und die Bedingungskontrolle auf. Weiterhin wird im Rahmen der Erfassung des relevanten Wirkungsfeldes der Vollzug des AbwAG als Grundlage der Abgabenwirkungen festgestellt. Mit diesem Untersuchungskomplex sollen die Voraussetzungen für den anschließenden Versuch geschaffen werden, anhand der Wirkungskontrolle das Kausalitätsproblem zu lösen. 
TEIL C: DARSTELLUNG EINER ERFOLGSKONTROLLE DES ABWASSERABGABENGESETZES

1. Identifizierung des relevanten Wirkungsfeldes

\subsection{Bestimmung der abhängigen und unabhängigen Variablen}

1.1.1 Ziel- und Programmstruktur als Angelpunkt der Erfolgskontrolle

Im Mittelpunkt des Interesses stehen das gewässergütepolitische staatliche Handeln und die damit intendierten Wirkungen. Erstere gilt es als unabhängige, die Zielwirkungen als abhängige Variable zu isolieren.

Allgemein hat sich die Auffassung durchgesetzt, daß die Bildung von Zielsystemen ein systematisches Angehen derartiger Aufgaben darstellt. Mit einem Zielsystem, auch bekannt als Zielhierarchie, Relevanz- oder Entscheidungsbaum, versucht man, den relevanten Bereich "in Form klassifizierter 'Zielebenen' verästelt zu strukturieren. ... Die Ziele werden durch die nachfolgenden Ebenen bis zu den Programmelementen hin konkretisiert (und nach Möglichkeit quantifiziert); die Programmelemente erhalten durch ihren Einbau in die Zielhierarchie erst ihren politischen Bezug und zweckorientierten Sinn"1. Die Notwendigkeit dieser systemanalytischen Denkweise beginnt bereits bei der Planung und endet mit der Kontrolle. Aderhold begründet dies für den politischen Bereich folgendermaßen : ${ }^{2}$

1. Zielsystematik ist unverzichtbares Hilfsmittel der Planintegration, weil einzelne ziele und Programme in einem gesamtplanerischen Bezugsrahmen relativiert werden. Die weitergefaßte Problemsicht verdeutlicht suboptimale

1 Aderhold, D.: Kybernetische Regierungstechnik ..., a.a.o., S. 151 und 153 .

2 Vgl. ebenda, S. $154 \mathrm{ff}$. 
Zielvorstellungen und macht spill-overs einzelner Programme transparenter. Die offenlegung von Zieldivergenzen, konfligierenden Programmen, aber auch synergieeffekten kann die Korrektur von Teilplänen im Sinne der Optimierung des Gesamtplanes einleiten.

2. Zielsystematik ist unabdingbare Voraussetzung wirksamer Erfolgskontrolle. Erfolgskontrolle als "kybernetische Komponente der Planung" erfordert Sollwertangaben bereits in der Planungsphase. Ober- und Unterziele sollten nicht nur vorgegeben, sondern von vornherein operationalisiert werden ${ }^{1}$.

Zielsysteme haben eine pyramidenartige Konstruktion, deren aufeinanderfolgenden Ebenen typischerweise mit

Hauptziele - Unterziele - Programme - Subprogramme

- (Sub-) Programmelemente oder z.B. auch mit

Oberziel - Programme - Maßnahmen

bezeichnet werden ${ }^{2}$. Inwieweit derartige, über weite strecken aus Programmstrukturen bestehende Konstrukte mit "Zielsystem" richtig benannt sind, sei dahingestellt. Bestenfalls kann man die Wortwahl mit dem Argument verteidigen, der Baustein des Zielsystems sei die Zweck-Mittel-Beziehung. Jedoch besteht Finalität (Zweck-Mittel-Beziehung) zwischen Unterziel und Programm auch nur dann, wenn letzteres speziell, d.h. nur auf ersteres zugeschnitten ist. In der Praxis dürfte aber ein Programm, insbesondere wenn es, wie oben vorgesehen, auch noch Subprogramme mit (Sub-) Programmelementen enthält, meist Mittel für mehrere, thematisch ähnliche Unterziele sein. Zweck-Mittel-Beziehung besteht dann lediglich zwischen den

1 Als weitere, oben nicht erwähnte Begründung für Zielsystematiken nennt Aderhold ihre Bedeutung für die Demokratisierung des politischen Entscheidungsprozesses. Vgl. ebenda, S. 156.

2 Vgl. u.a. ebenda, S. 152; Wittkämper, G.: Analyse und Planung in Verwaltung und Wirtschaft, stuttgart 1972, S. 31 f.; ähnlich auch Hellstern, G.-M., Wollmann, H.: Evaluierungsforschung ..., a.a.O., s. 17 . 
Ebenen "Unterziele" und "Programmelemente" oder "Subprogramme"1.

Aufgrund der Unzulänglichkeiten herkömmlicher Darstellungsweisen soll vom gängigen Aufbau eines Zielsystems Abstand genommen und dem Vorschlag Königs gefolgt werden, Ziel- und Programmstrukturen in getrennter Darstellung derart gegeneinanderzusetzen, daß die Unterziele den Programmelementen gegenüberstehen². Der "Zielkegel" beinhaltet dann die abhängigen, der "Programmkegel" die unabhängigen Variablen.

Gemäß der oben genannten Notwendigkeit eines integrierenden Bezugsrahmens, der darauf hinweist, von welchen anderen gewässergütepolitischen Maßnahmen gleichfalls Wirkungen auf die Ziele des AbwAG ausgehen können, setzt die Untersuchung auf der Ebene der Gewässergütepolitik an.

Das Umweltgutachten von 1978 bietet einen Einstieg in den Aufbau der Ziel- und Programmstruktur der Gewässergütepolitik. Wenngleich man auf eine Visualisierung verzichtete, hat man doch versucht, sie als die Kausalkette

$$
\text { Ziele - Programme - Maßnahmen }
$$

verbal zu systematisieren ${ }^{3}$.

Auf der Zielebene werden die "Hauptziele" durch die Festlegung der Gewässergüte (Gewässergüte II) konkretisiert, auf der Programmebene "Programmbereiche" wie Emissionsverminderung genannt und auf der "operativen Ebene" administrative Maßnahmen wie Ge- und Verbote oder Abgaben aufgelistet. Der Sachverständigenrat wählte für die Präsentation der Gewässergütepolitik also die oben beschriebene klassische systematik. Diese wird in $\mathrm{Abb} .2$ in die präferierte Gegen-

1 Vgl. dazu auch König, H.: Dynamische Verwaltung. Bürokratie zwischen Politik und Kosten, 2. Aufl., stuttgart 1977 , s. 52 .

2 Vgl. ebenda, S. 54 und 56.

3 Vgl. Rat von Sachverständigen für Umweltfragen: Umweltgutachten 1978, a.a.O., S. $80 \mathrm{ff}$. und $110 \mathrm{ff}$. 
überstellung von Ziel- und Programmstruktur transponiert. Die Programmbereiche sind als Unterziele und die Maßnahmen als Subprogramme ${ }^{1}$ aufgeführt. Die Verbindungslinien zwischen Unterzielen und Subprogrammen resultieren aus den Erläuterungen des Sachverständigenrats, die er zu den instrumentellen Möglichkeiten innerhalb der operativen Ebene, also den Maßnahmen bzw. Subprogrammen gab².

Für die Erfolgskontrolle des AbwaG enthält die systematik folgende Informationen:

1. Gesamtziel des AbWAG ist, wie bereits in Teil A dieser Arbeit angesprochen, die Emissionsverminderung, die ihrerseits als Regulativ der Gewässergüte dient.

2. Neben der Abgabenlösung sollen alle fünf anderen Subprogramme emissionsmindernd wirken. Es liegt also ein nicht unbeträchtliches Potential an Wirkungsüberschneidungen vor.

Von hervorzuhebender Bedeutung dürften aufgrund des weitgehend identischen Eingriffsniveaus wirkungsüberschneidungen von WHG und AbwAG sein. Das WHG, oder genauer gesagt der § 7a WHG, wird deshalb auch als unabhängige Variable explizit neben dem AbwaG in die Untersuchung eingehen, was bedeutet, daB in der Wirkungskontrolle, soweit möglich, sein Anteil an der Erreichung der abgaberechten Ziele (Gesamt- und Teilziele) festgestellt werden soll.

Weiterhin sind "Finanzierungshilfen und subventionen" als unabhängige Variable zu berücksichtigen, denn sie sind neben den Auflagen des WHG und der Abwasserabgabe das dritte

1 Die aufgeführten Subprogramme entsprechen der Zusammenstellung des gewässergütepolitischen Instrumentariums auf S. 110 besagten Umweltgutachtens. Der Sachverständigenrat spricht zwar von "theoretischen" Möglichkeiten. Diese wurden jedoch - im Gegensatz zu der Zusammenstellung auf S. 81 - die auch die Zertifikatlösung enthält, in Maßnahmen umgesetzt.

2 Vgl. ebenda, S. $110 \mathrm{ff}$. 
Oberste zieleben

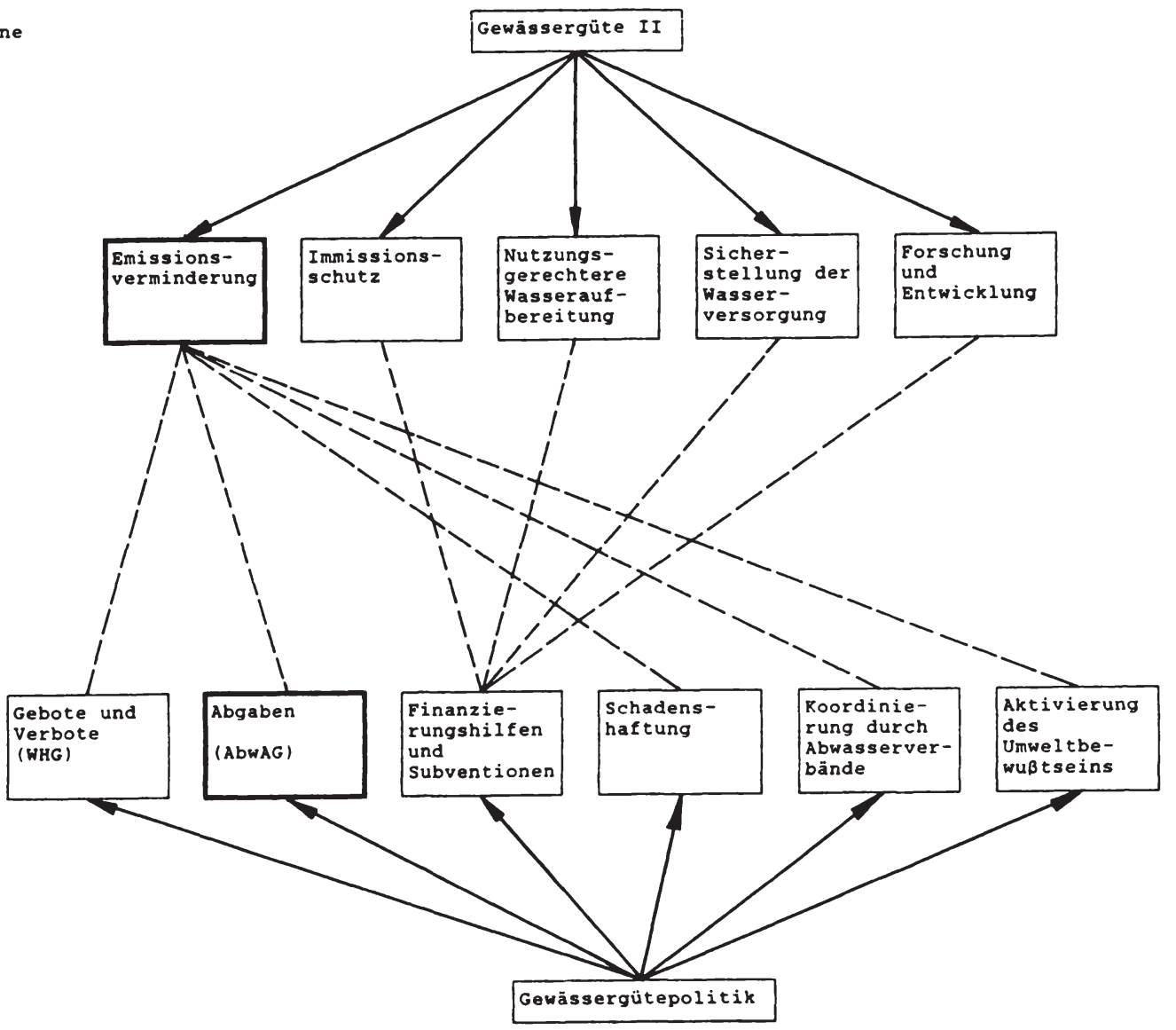

Programm

Abb 2: Ziel- und Programmstruktur der Gewässergütepolitik, Teil I: allgemeiner Uberblick 
wichtige standbein der Gewässergütepolitik ${ }^{1}$. Dabei richtet sich das Augenmerk nebenbei mit Interesse darauf, ob sich unter den Abgabepflichtigen auch Nutznießer des Abgabeaufkommens befinden.

Kausalitäten zwischen "Schadenshaftung" und "Emissionsverminderung" zu untersuchen dürfte genauso problematisch sein wie der Versuch, festzustellen, ob das (hier insbesondere unternehmerische) Umweltbewußtsein aktiviert werden konnte. Eine entsprechende Zurechnung von Wirkungen findet deshalb nur insofern beschränkt statt, als es den Untersuchungseinheiten anheim gestellt ist, eine derartige Ursache ihres Abwasserreinigungsverhaltens "von sich aus" unter "sonstigen Gründen" zu äußern.

Spill-overs von der "Koordinierung durch Abwasserverbände" auf das Emissionsverhalten gewerblicher Direkteinleiter sind nur dann $\mathrm{zu}$ erwarten, wenn letztere sich einem solchen Verband anschließen - und dann nicht mehr Untersuchungseinheit dieser Arbeit sind.

Neben die in Abb. 2 dargestellte ökologische Zielstruktur tritt die Forderung des Sachverständigenrats nach der Berücksichtigung gesamtwirtschaftlicher Belange, so daß schließlich eine mehrdimensionale zielstruktur vorliegt. Die ökonomische Komponente wurde sowohl für die Umweltpolitik im allgemeinen ${ }^{2}$ als auch für die Gewässergütepolitik im besonderen formuliert. Für letztere konkretisiert sie sich insbesondere

1 Vgl. dazu auch Kibat, K. $-D$. : Wasserverbände ..., a.a.O., S. 46 .

2 "Vor allem ökonomische Niveau- und strukturziele [nehmen] den Rang strenger Nebenbedingungen für die Umweltpolitik ein. So wird vor allem darauf hingewiesen, daß die stabilität der Volkswirtschaft bei der Verwirklichung des Umweltprogramms nicht gefährdet werden und daß der Ordnungsrahmen der Marktwirtschaft grundsätzlich als leistungsfähigster steuerungsmechanismus aufrechterhalten werden soll. ... Die Umweltpolitik muß darüber hinaus die Intensität der internationalen Handelsverflechtungen der deutschen Wirtschaft berücksichtigen." Rat von Sachverständigen für Umweltfragen: Umweltgutachten 1974, a.a.O., s. 7 . 
durch die Zielsetzung der gesamtwirtschaftlich günstigen Mittelverwendung bei der Verwirklichung der Gewässergüteziele $e^{1}$.

Verfolgt man Ziel- und Programmstruktur auf der Ebene des AbWAG weiter, so ergeben sich die in Abb. 3 wiedergegebenen Strukturen, die aus den in Abschnitt A.4 abgehandelten gesetzgeberischen Wirkungsintentionen induktiv hergeleitet wurden $^{2}$. Sämtliche Ziele der unteren Zielebene im linken Teil der Abbildung, also auch die auf das wHG bezogenen Ziele, lassen sich als ökologisch ausgerichtet qualifizieren, weil sie auf die Emissionsverminderung hinwirken sollen. Daneben tritt eine recht differenzierte ökonomisch ausgerichtete Zielansammlung, die von den Programmelementen des AbwaG "bedient" werden soll. Wenngleich sie nur distributive Ziele enthält, wird später in der Wirkungskontrolle auch untersucht, in welchem Maße die gewählte Auflagen-Abgabenkombination noch eine "gesamtwirtschaftlich günstige Mittelverwendung" zuläßt.

Die Informationen, die die Ziel- und Programmstruktur der Gewässergütepolitik, hier wegen ihres "ausladenden" Umfangs in zwei Etappen dargestellt, für die Erfolgskontrolle bietet, lassen sich abschließend folgendermaßen zusammenfassen: Als "intendierte" abhängige Variable des abgaberechtlichen wirkungsfeldes sind die "Emissionsverminderung" als Gesamtziel sowie die Ziele der unteren Zielebene als Teilziele identifiziert. Als unabhängige Variablen sind das AbwAG und seine aufgeführten Gesetzeselemente sowie aus dem Raum der anderen gewässergütewirtschaftlichen subprogramme besonders der $\$ 7$ a WHG und die "Finanzierungshilfen und subventionen" zu qualifizieren. Der (intendierte) Wirkungszusammenhang

1 Vgl. Rat von Sachverständigen für Umweltfragen: Umweltgutachten 1978, a.a.O., S. 48 .

2 Die Abbildung enthält gemäß der Abgrenzung des Untersuchungsbereichs nur Variablen und intendierte Kausalitäten, die auf die Einleiter bzw. deren Verhalten abstellen. Die Finanzfunktion des AbwAG sowie das auf die Verwaltungsarbeit abstellende Ziel der ausreichenden Zeit zur Umstellung der Bescheide wurden also ausgeblendet. 


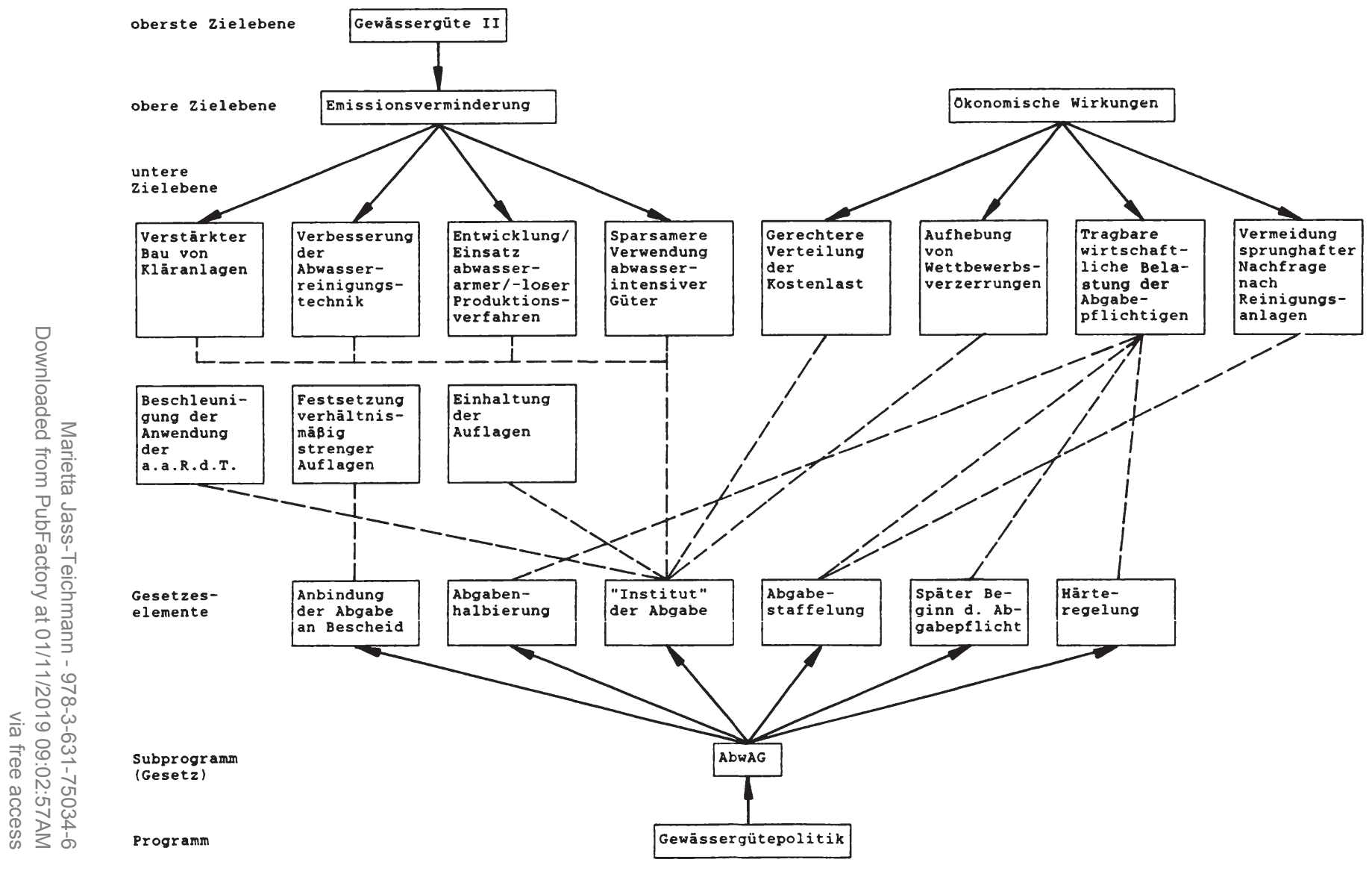

Abb. 3: Ziel- und Programmstruktur der Gewässergütepolitik, Teil II: das Abwasserabgabengesetz 
zwischen abhängigen und unabhängigen Variablen wird dabei durch die dargestellte Finalität zwischen den Zielen und den Subprogrammen bzw. Gesetzeselementen des AbwAG hergestellt.

Nachdem in diesem Abschnitt das vom Gesetzgeber intendierte Wirkungsfeld beschrieben wurde, wirft sich nun die Frage auf, welche weiteren unabhängigen Variablen besagtes Wirkungsfeld charakterisieren. 


\subsubsection{Exogene Einflußgrößen}

Neben dem gewässergütepolitischen Instrumentarium beeinflussen die exogenen Größen als weitere unabhängige Variable die Zielerreichung der Gewässergütepolitik. So sind z.B. klimatische Bedingungen und nicht abwasserbegründete Gewässerbelastungen wie die Deposition von Schadstoffen in der Atmosphäre oder uberdüngungen in der Landwirtschaft exogene Größen, die unmittelbar auf die Gewässergüte einwirken. Mittelbar auf die Gewässergüte wirken u.a. diejenigen exogenen Bedingungen ein, die das Emissionsverhalten der Einleiter mitbestimmen, also die intendierte Emissionsverminderung beschneiden oder verstärken können. Ihre Kenntnis ist Voraussetzung für die Wirkungskontrolle des AbwAG, weshalb sie im folgenden für die gewerblichen Direkteinleiter qualifiziert werden sollen'1.

Exogene Einflüsse auf das Emissionsverhalten der Direkteinleiter waren offensichtlich nicht das Gebiet, mit dem man sich bei der Reformierung des Wasserrechts befaßte, jedenfalls drangen diesbezügliche uberlegungen nicht an die offentlichkeit. Entsprechend läßt sich heute nicht auf einen exogenen Einflußgrößenkatalog aus diesen oder auch aus späteren Jahren zurückgreifen.

Es sind nach Meinung der Verfasserin fünf Gruppen von exogenen Bedingungen, die entweder über die Beeinflussung der Teilzielerreichungen oder "direkt" auf die Erreichung des Gesamtzieles "Emissionsverminderung" Einfluß nehmen können:

1. Schadstoffentstehung und -entsorgung beeinflussende Normen außerhalb des Wasserrechts

Nicht im Wasserrecht verankerte Normen, die bestimmte Produktionsverfahren, Einsatzstoffe oder Fertigprodukte reglementieren, wirken sich dann abwassersäubernd aus,

1 Von diesen Bedingungen gehen über die Beeinflussung der ökologischen Zielerreichung teilweise auch Wirkungen auf die Erreichung der ökonomischen Ziele aus. 
wenn sie die Entstehung von Schadstoffen, die durch das Abwasser entsorgt werden würden, von vornherein unterbinden. Normen, die Emissionen in andere Umweltmedien und Schadstoffe in Fertigprodukten verbieten, wirken eher wasserverschmutzend bzw. können die Wirkungen gewässergütepolitischer Instrumente, die auf eine Emissionsverminderung abstellen, abschwächen, wenn eine substitution des Emissionsträgers möglich ist.

\section{Bedingungen der Abwasserreinigungstechnik}

Die Abwasserreinigung kann letztendlich nur so gut sein wie die Technik, die dahinter steht. Als exogene Einflußgröße auf die Zielerreichungen des AbwAG ist genaugenommen nur ein Teil des technisch Machbaren bzw. seiner Entwicklung angesprochen, nämlich derjenige, der nicht durch das AbwAG induziert wurde.

\section{Innerbetriebliche Einflußgrößen}

Das Emissionsverhalten ist weiterhin eine Funktion der produktions - und betriebswirtschaftlich spezifischen Situation des Einleiters. Darüber hinaus spielt es eine Rolle, in welchem Maße der Umweltschutz in der jeweiligen Unternehmensphilosophie verwurzelt ist.

4. Volkswirtschaftliche Bedingungen

Hierunter fallen inflatorische - und theoretisch natürlich auch deflatorische - Erscheinungen, die die wirksamkeit der Abgabe beschneiden bzw. verstärken, wenn sich bei konstantem Abgabesatz die Inflationsrate verändert.

5. Das soziale Umfeld

Die Sensibilität des sozialen Umfelds auf Wasserverschmutzungen kann, wenn sie z.B. durch Proteste artikuliert wird, emissionssenkende Bemühungen der Direkteinleiter einleiten oder verstärken.

Die in Tab. 4 vorgenommene Ausfüllung der einzelnen Gruppen mit zugehörigen exogenen Einflußgrößen erhebt nicht den Anspruch auf Vollständigkeit, sondern soll lediglich einen 


\begin{tabular}{|c|c|c|}
\hline & \multicolumn{2}{|c|}{$\begin{array}{l}\text { Normen außerhalb des Wasserrechts (mit dem Datum des } \\
\text { Ersterlasses) }\end{array}$} \\
\hline & $\begin{array}{l}\text { für Emissionen in } \\
\text { andere Umweltmedien }\end{array}$ & $\begin{array}{l}\text { Bundesemissionsschutzgesetz } \\
\text { vom 15. März } 1974 \\
\text { mit verschiedenen Verordnungen } \\
\text { und der } \\
\text { Technischen Anleitung zur Rein- } \\
\text { haltung der Luft vom 28. August } \\
1974\end{array}$ \\
\hline & für Einsatzstoffe & $\begin{array}{l}\text { Chemikaliengesetz vom } 16 \text {. Sep- } \\
\text { tember } 1980 \text { mit der } \\
\text { Arbeitsstoffverordnung vom } \\
11 \text {. Februar } 1982 \text { (abgelöst durch } \\
\text { die Gefahrstoffverordnung vom } \\
26 \text {. August 1986) }\end{array}$ \\
\hline & für Produktionsanlagen & $\begin{array}{l}\text { Verordnung über Großfeuerungs- } \\
\text { anlagen vom } 22 \text {. Juni } 1983\end{array}$ \\
\hline & für Fertigprodukte & $\begin{array}{l}\text { Lebensmittel- und Bedarfsgegen- } \\
\text { ständegesetz vom } 15 \text {. August } \\
1974 \text { mit verschiedenen Verord- } \\
\text { nungen }\end{array}$ \\
\hline & $\begin{array}{l}\text { für die Feststoff- } \\
\text { entsorgung }\end{array}$ & $\begin{array}{l}\text { Abfallbeseitigungsgesetz vom } \\
\text { 7. Juni } 1972 \\
\text { Klärschlammverordnung vom } \\
25 \text {. Juni } 1982\end{array}$ \\
\hline 2 & $\begin{array}{l}\text { Bedingungen der Abwas- } \\
\text { serreinigungstechnik }\end{array}$ & $\begin{array}{l}\text { Stand der Abwasserreinigungs- } \\
\text { technik }\end{array}$ \\
\hline 3 & $\begin{array}{l}\text { Innerbetriebliche } \\
\text { Einflußgrößen }\end{array}$ & \\
\hline & produktionsbedingt & $\begin{array}{l}\text { Produktionsumfang } \\
\text { Produktionsverfahren } \\
\text { Einsatzstoffe } \\
\text { (weitere) Rationalisierungsmaß- } \\
\text { nahmen, Wirtschaftlichkeits- } \\
\text { und Kostenüberlegungen } \\
\text { Planbarkeit des Abwasseranfalls } \\
\text { und der Schadstoffkonzentra- } \\
\text { tionen bei einer (neuen) } \\
\text { Produktionsanlage }\end{array}$ \\
\hline
\end{tabular}




\begin{tabular}{|c|c|c|}
\hline & $\begin{array}{l}\text { betriebswirtschaftlich } \\
\text { bedingt }\end{array}$ & $\begin{array}{l}\text { wirtschaftliche Situation des } \\
\text { Einleiters } \\
\text { Relevanz der Abwasservermei- } \\
\text { dungskosten (Kosten in \& vom } \\
\text { Umsatz) } \\
\text { betriebswirtschaftliche Oppor- } \\
\text { tunität bei der Entscheidungs- } \\
\text { findung (Minimierung der Kosten) }\end{array}$ \\
\hline & $\begin{array}{l}\text { Unternehmens- } \\
\text { philosophie }\end{array}$ & $\begin{array}{l}\text { "genuines" Umweltschutzverhalten } \\
\text { umweltschützendes Verhalten als } \\
\text { PR-Maßnahme }\end{array}$ \\
\hline & $\begin{array}{l}\text { Volkswirtschaftliche } \\
\text { Bedingungen }\end{array}$ & Inflation \\
\hline & Soziales Umfeld & $\begin{array}{l}\text { Beschwerden der Bevölkerung } \\
\text { ( } \mathrm{z} . \text { B. über Geruchsemissionen } \\
\text { und Gewässertrübungen) } \\
\text { umweltpolitisch ausgerichtete } \\
\text { Bürgerinitiativen } \\
\text { Impulse aus dem partei- } \\
\text { politischen Raum } \\
\text { Bedeutung des Vorfluters für } \\
\text { die Freizeitgestaltung in der } \\
\text { Region }\end{array}$ \\
\hline
\end{tabular}

Tab. 4: Exogene Einflußgrößen auf das Emissionsverhalten gewerblicher Direkteinleiter

Eindruck von der Vielfältigkeit exogener Bedingungen, die auf die Zielerreichungen des AbwAG bei gewerblichen Direkteinleitern Einfluß nehmen können, vermitteln. 


\subsection{Entwicklung einer Zielerreichungskontrolle}

\subsubsection{Stellenwert und Aufbau der Zielerreichungskontrolle}

Die Zielerreichungskontrolle dürfte sich in der Praxis am besten von den einzelnen Blöcken der Erfolgskontrolle durchgesetzt haben. Als Soll-Ist-Vergleich einer politischen Zielgröße, aber auch als Ist-Ist-Vergleich (before-and-after) hat sie einen unbestrittenen Platz in der politischen Diskussion. Ihre Popularität begründet sich nicht zuletzt mit dem "Ungleichgewicht" zwischen der im Verhältnis zur Wirkungskontrolle einfachen Durchführung der Untersuchung und ihrer recht hohen Aussagekraft. Die mit ihr generierten Informationen zeigen zwar keine Ursachen für die Entwicklungen an, weisen aber immerhin auf einen möglichen staatlichen Handlungsbedarf hin.

So bemüht man sich auch im Bereich der Gewässergütepolitik um Zielerreichungskontrollen bzw. um eine Darstellung der Veränderungen, sei es auf oberster Zielebene durch die im Turnus von fünf Jahren $\mathrm{zu}$ erstellende Gewässergütekarte der Bundesrepublik Deutschland' oder durch entsprechende Statistiken auf den nachfolgenden Zielebenen. Von zentraler Bedeutung sind die Veröffentlichungen "Daten zur Umwelt", die vom Umweltbundesamt herausgegeben werden, und die unter der Rubrik "Wasser" vom Grundwasservorkommen über Einträge von Schadstoffen in die Nordsee und die Wasserversorgung bis hin zur Abwasserbehandlung sowohl den status quo als auch die beobachteten Entwicklungen darlegen ${ }^{2}$. Auch kann in diesem Zusammenhang auf Publikationen von einzelnen Einleitern und

1 Vgl. Länderarbeitsgemeinschaft Wasser (LAWA) (Hrsg.): Die Gewässergütekarte der Bundesrepublik Deutschland, München 1985, stuttgart 1980 und stuttgart 1974 zum Vergleich.

2 Vgl. Umweltbundesamt (Hrsg.): Daten zur Umwelt 1984, Berlin 1984, S. $168 \mathrm{ff}$. und ders.: Daten zur Umwelt $1986 / 87$, Berlin 1986, S. 262 ff. In diesen Veröffentlichungen sind z.B. die Daten aufbereitet, die im Rahmen des Gesetzes über Umweltstatistiken (siehe S. 24) erhoben werden. 
Fachverbänden ${ }^{1}$ sowie auf journalistische Aufbereitungen der Wasser- und Abwassersituation als "Ablegern" der Zielerreichungskontrolle verwiesen werden².

Im folgenden sind zunächst die operationalität der abgaberechtlichen Ziele sowie die Beziehungen der Ziele untereinander zu diskutieren. Daran schliebt die Bildung von Indikatoren an, anhand derer die Zielerreichung dann gemessen wird.

\subsubsection{Voraussetzungen der Indikatorenbildung und Zielmessung}

\subsubsection{Operationalität der Zielinhalte}

Voraussetzung für die Bildung von Indikatoren, die intendierte Wirkungen anzeigen sollen, und Eckpunkt für die Ausgestaltung der Zielmessung ist die Operationalität der Zielsetzungen. Operational sind Zielinhalte dann, "wenn sie auf praktisches Handeln gerichtet sind und ihre Verwirklichung kontrolliert werden kann" ${ }^{3}$.

1 Vgl. BASF: BASF Umweltschutz - Denken Planen Handeln, 0.0. 1981; Verband der Chemischen Industrie (Hrsg.): Mehr Wachstum - mehr Umweltschutz. Eine Bilanz der chemischen Industrie, 0.0 . und $0 . \mathrm{J} .$.

2 Vgl. Koch, E.R., Vahrenholt, F.: Die Lage der Nation, Umwelt-Atlas der Bundesrepublik, Hamburg 1983. Die beiden Autoren versuchen, auf der Basis veröffentlichter Umweltdaten der Landesbehörden und der Forschungseinrichtungen des Bundes und der Länder eine Bilanz der Umweltbelastungen zu ziehen und behandeln dabei auch die Gewässerbelastungen.

3 Hellstern, G.-M., Wollmann, H.: Evaluierungsforschung .... a.a.0., S. 12. Siehe für das weitere Vorgehen S. 87 f. dieser Arbeit. 
Die Ziele des AbwAG ${ }^{1}$ lassen sich nach den Kriterien der Operationalität folgendermaßen qualifizieren² :

\section{Genaue Beschreibung der Zielinhalte}

Die meisten Ziele des AbwaG zeichnen sich durch eine mehr oder weniger genaue, zur Indikatorenbildung ausreichende inhaltliche Abgrenzung aus. $\mathrm{Zu}$ diesen dürfte auch noch die "Verbesserung der Abwasserreinigungstechnik" zählen, wenngleich dieses Ziel mehrdimensional ist, weil man es in die Entwicklung neuer und in die optimierung herkömmlicher Reinigungsverfahren unterteilen kann. Diffiziler, aber der Zielerreichungskontrolle auch zugänglich, ist das Gesamtziel des AbwAG, die "Emissionsverminderung". Sie läßt sich als absolute (pro Jahr) und als relative Veränderung (pro Produkteinheit) deuten und sollte, eben weil der Gesetzgeber keine spezifikation vornahm, in beiden Formen ermittelt werden.

Für die Zielerreichungskontrolle unzureichend beschrieben ist dagegen die "Festsetzung verhältnismäßig strenger Auflagen". Der Innenausschuß führt in diesem Zusammenhang aus: Die Anbindung der Abgabe an den Bescheid stellt sicher, "daß die Einleiter kein größeres Verschmutzungsrecht beantragen werden, als sie tatsächlich benötigen."3 Hier stellt sich erstens die Frage, was der Gesetzgeber unter "verhältnismäßig streng" versteht und zweitens, nach welchen Kriterien die Parameterwerte eines Verschmutzungsrechtes als "tatsächlich benötigt" qualifi-

1 Siehe dazu Abb. 3.

2 Nicht berücksichtigt wird bei den folgenden Ausführungen das Ziel "Okonomische Wirkungen", weil es sich bei diesem nur um eine Hilfskonstruktion handelt, das erst durch die darunterliegende Zielebene operationalisiert wird.

3 Deutscher Bundestag 7. Wahlperiode: Drucksache 7/5183 vom 13.5 .1976$, S. 3 . 
ziert werden ${ }^{1}$. Wegen der mangelhaften Präzisierung scheidet das Ziel "Festsetzung verhältnismäßig strenger Auflagen" aus der Zielerreichungskontrolle aus.

Als gleichermaßen interpretationsoffen und damit "kontrollunfähig" erweist sich das Ziel "Tragbare wirtschaftliche Belastung der Abgabepflichtigen". Die Auffassungen über die Abgrenzung der "Tragbarkeit" dürften sehr differieren; Einigkeit besteht vermutlich nur über den Endpunkt der Tragbarkeitsskala: die Liquidation des Unternehmens aufgrund der finanziellen Beanspruchungen.

\section{Vorgabe eines Sollwertes}

Geht man von der in der Literatur beschriebenen Beobachtung aus, in der obersten Hierarchiestufe seien vielfach nur Leerformeln vorzufinden, die dann in den nachfolgenden Ebenen operationalisiert werden², so nimmt das AbwAG diesbezüglich eine Außenseiterstellung ein. Denn ein Sollwert, der die Operationalität eines Zieles in hohem Maße bestimmt, wird gerade für das oberste ziel der Gewässergütepolitik in Form der Gewässergüte II, also als Immissionswert postuliert. Eine ebenbürtige Operationalisierung liegt für die "Emissionsverminderung" nicht vor, und von den ökologisch ausgerichteten Teilzielen des AbwAG kann nur der "Verstärkte Bau von Kläranlagen" mit einem Sollwert, wenngleich dieser nur für die Abwässer der privaten Haushalte beziffert wurde, aufwarten. Der Sachverständigenrat forderte seinerzeit, für 90 \& der Bevölkerung bis 1985 biologische oder gleichwertige Kläranlagen zu schaffen - und entsprechende ReinigungsmaBnahmen für Industrieabwässer zu erreichen. Die Vorgaben für die anderen ökologischen zielsetzungen erschöpfen sich in der Angabe der Anderungsrichtung, soweit die Zielin-

1 Die Maschinenkapazität, die dem wasserrechtlichen Bescheid zugrunde liegen sollte, dürfte nur eines von vielen Kriterien sein.

2 Vgl. u.a. Hellstern, G.-M., Wollmann, H.: Evaluierungsforschung ..., a.a.0., s. 12 und die dort angegebene Literatur. 
halte eine solche erfordern. Gerechterweise muß man dem Gesetzgeber jedoch zugestehen, daß sich eine Quantifizierung der ökologischen Teilziele - jedenfalls auf einer Ebene, die nicht zwischen den Einleitergruppen differenziert -, schwierig gestaltete.

Angriffsfläche aufgrund des Fehlens verbindlicher Sollwertvorgaben bieten auch die ökonomischen Zielsetzungen. Zwar beinhalten die "Gerechtere Verteilung der Kostenlast" sowie die "Aufhebung der Wettbewerbsverzerrungen" einen maximalen Veränderungsgrad. Dieser ist dann erreicht, wenn bei allen Einleitern, die am Markt miteinander konkurrieren, die gleichen abwasserbezogenen Kosten anfallen. Der maximale Veränderungsgrad deckt sich aber nicht unbedingt mit einem anzustrebenden optimalen Veränderungsgrad, der auch durch die ebenfalls in der zielstruktur verankerte "Tragbare wirtschaftliche Belastung der Abgabepflichtigen" determiniert ist.

\section{Zeitliche und räumliche Fixierung}

Wo keine Sollwerte vorgegeben sind, erübrigt sich auch weitgehend eine zeitliche Fixierung. So wurde ein "Solljahr" auch nur im Rahmen des Kläranlagenbaus für die Reinigung der Abwässer privater Haushalte festgelegt. Einen gewissen Bezug zeigt das AbwAG trotz allem zu dem Jahr, in dem die Gewässergüte II in allen Gewässern realisiert sein sollte. Im Bericht des Innenausschusses zum AbwaG heiBt es: "Die letzte stufe des Abgabesatzes wird für das Jahr 1986 vorgesehen. Dieses Datum ist orientiert am Umweltprogramm der Bundesregierung, wonach der 'Nachholbedarf' an Abwasserreinigungsmaßnahmen im wesentlichen bis zum Jahr 1985 gedeckt sein soll."1 Räumlich erstrecken sich die Zielsetzungen des AbwAG auf die Bundesrepublik Deutschland (einschlieBlich Berlin).

1 Deutscher Bundestag 7. Wahlperiode: Drucksache 7/5183 vom 13.5.1976, S. 4. 


\section{Prioritätensetzungen}

Der Innenausschuß listet in seinem Bericht zum AbwAG die angestrebten Ziele auf, ohne Gewichtungen anzugeben. Prioritätensetzungen sind immer dann besonders notwendig, wenn Ziele untereinander konfligieren. Da dies bei den ökologisch ausgerichteten Zielen des AbwAG weitestgehend nicht zutrifft und gerade durch die Erreichung einiger dieser Ziele Wettbewerbsverzerrungen aufgehoben und Kosten gerechter verteilt werden können, sind Prioritätensetzungen hier nicht erforderlich. Problematisch ist dagegen die Polarität zwischen der geforderten Emissionsverminderung und der insbesondere von seiten der Emittenten befürchteten damit einhergehenden finanziellen Be- und Uberbeanspruchung, die sich in dem Ziel "Tragbare wirtschaftliche Belastung der Abgabepflichtigen" niederschlug und die Ausgestaltung des AbwAG maßgeblich beeinflußte. Zwischen diesen gegensätzlich angesiedelten Zielen, nämlich der wie auch immer zu realisierenden "Emissionsverminderung" auf der einen und der - wenn auch unzureichend beschriebenen - "Tragbaren wirtschaftlichen Belastung der Abgabepflichtigen" auf der anderen seite bedürfte es einer Gewichtung für eine "vollkommene" Zielerreichungskontrolle.

Die im Umweltgutachen gewählte Formulierung "Gewässergüteziele unter Beachtung gesamtwirtschaftlicher Belange"1 läßt vermuten, daß besagte ökonomische Zielsetzung grundsätzlich als Nebenbedingung fungiert. Die Tatsache, daß mehrere Programmelemente des AbwAG (Abgabenhalbierung, Abgabenstaffelung, Härteregelung und später Beginn der Abgabepflicht) auf die finanzielle Entlastung der Emittenten abstellen und der Innenausschuss der intendierten Wirkung dieser Programmelemente recht viele Worte widmete, verleiht der finanziellen Entlastung jedoch so viel Gewicht, daß sie den Anschein erweckt, zu einem Hautpziel

1 Rat von Sachverständigen für Umweltfragen: Umweltgutachten 1974 , a.a.O., S. 48 . 
zu avancieren: Insgesamt bleibt unklar, wie die Prioritäten gesetzt sind.

Zusammenfassend kann gesagt werden, daß die operationale Schwäche der untersuchten Zielsetzungen in der mangelhaften Beschreibung zweier Ziele, nämlich der "Festsetzung verhältnismäßig strenger Auflagen" und der "Tragbaren wirtschaftlichen Belastung der Abgabepflichtigen", in fehlenden Sollvorgaben und eindeutigen Prioritätensetzungen dort, wo sie notwendig sind, liegt. Das folgende, aus vbersee importierte und sich in der deutschen Literatur großer Beliebtheit erfreuende Gedankengut gilt somit wohl auch für das AbwAG: "Gerade im Bereich politischer ... Aktionsprogramme ... [sind] die Ziele überwiegend vage, vieldimensional, ambivalent, wenn nicht unter sich konfligierend formuliert, vor allem weil diese Zielfindung in den politischen Prozeß eingebettet ist, in dem sich konfligierende Interessen vielfach auf vage und ambivalente Zielformulierungen verständigen, um die aktuelle Konfliktaustragung $\mathrm{zu}$ entlasten und die Konfliktentscheidung auf den weiteren Implementationsund Bargaining-Prozeß zu verschieben."1

\subsubsection{Diskussion der Zielbeziehungen}

Die Genese von Indikatoren aus Zielen setzt nicht nur Uberlegungen zu deren operationalität, sondern auch eine Untersuchung der Zielbeziehungen untereinander voraus. Denn von ihnen hängt $a b$, ob für sämtliche Ziele die Zielerreichungen $\mathrm{zu}$ messen und deshalb Indikatoren $\mathrm{zu}$ bilden sind.

1 Hellstern, G. - M., Wollmann, H.: Evaluierungsforschung ..., a.a.O., S. 12 (Hervorhebungen von Hellstern/Wollmann), bezugnehmend auf die amerikanische Literatur (etwa $C . H$. Weiss: Evaluation Research in the Political Context, in: Struening, E.L., Guttentag, M, (eds.), Handbook of Evaluation Research, Bd. 1, Beverly Hills 1975, S. 16. Aufgegriffen u.a. auch von Derlien, H.-U.: Die Erfolgskontrolle ...., a.a.O., S. 110 f.; Hembach, K.: Der stellenwert ...., a.a.O., s. 47; Voss, G.: Erfolgskontrolle regionaler strukturpolitik, Diss. Köln 1973, S. 37. 
Die Zielsetzungen des AbwAG sollen gemäB folgenden Beziehungstypen geordnet werden ${ }^{1}$ :

1. Komplementarität (Kompatibilität)

Komplementarität ist zwischen Zielen gegeben, wenn die Erfüllung eines Zieles die Erfüllung des anderen steigert. Unterschieden wird zwischen wechselseitiger (symmetrischer) und einseitiger (asymmetrischer) Komplementarität. Letztere zeigt eine Zweck-Mittel-Beziehung an und erlaubt damit die Konstruktion entsprechender Zielstrukturen.

2. Konkurrenz (Inkompatibilität)

Ziele konkurrieren miteinander, wenn die Erfüllung des einen die Erfüllung des anderen mindert. Zielkonkurrenz erfordert Kompromisse bzw. die bereits angesprochene Gewichtung von Zielen.

\section{Indifferenz (Neutralität)}

Die Erfüllung eines Zieles nimmt keinen Einfluß auf die Erfüllung eines anderen Zieles.

Für die Bildung von Indikatoren liegt nun das Hauptaugenmerk auf der Identifizierung symmetrisch komplementärer Beziehungen. Denn bei ihrem Vorliegen genügt es, nur die Erreichung eines der Ziele zu überprüfen, woraus eine Reduzierung des Problemumfangs resultiert.

Betrachtet man unter diesem Aspekt die Zielstruktur des AbwAG (siehe Abb. 3), so impliziert bereits sein bloBes Vorliegen asymmetrische Komplementarität zwischen den Zielebenen ${ }^{2}$. Damit ist der Fundus an - wie auch immer

1 Vgl. zu den folgenden Ausführungen Heinen, E.: Das Zielsystem der Unternehmung, Wiesbaden 1966, S. $94 \mathrm{ff} . ;$ Zangemeister, C.: Nutzwertanalyse in der Systemtechnik. Eine Methodik zur multidimensionalen Bewertung und Auswahl von Projektalternativen, 3. Aufl., München 1973, S. 94 ff.

2 Gemeint sind nur die ökologischen Zielebenen, weil bei den ökonomischen Zielen genaugenommen nur eine Ebene vorliegt. 
gearteter - Komplementarität allerdings auch fast erschöpft. Die untere Ebene der ökologisch ausgerichteten Zielsetzungen weist nur Ziele auf, die sich weitgehend' indifferent zueinander verhalten. Auf der ökonomischen seite geht der Fächer an technischen Zielbeziehungen dann auseinander. So bedingen sich die "Gerechtere Verteilung der Kostenlast" und die "Aufhebung von Wettbewerbsverzerrungen" gegenseitig, womit eine symmetrische Komplementarität vorliegt, die eine Tautologie darstellt2. Die "Gerechtere Verteilung der Kostenlast"3 kann gegen die "Tragbare wirtschaftliche Belastung der Abgabepflichtigen" konkurrieren, insbesondere dann, wenn bei Einleitern, die einen großen Nachholbedarf an Reinigungsmaßnahmen haben, bereits eine finanzielle Schwäche vorliegt. Zwischen der "Vermeidung sprunghafter Nachfrage nach Reinigungsanlagen" und den anderen ökonomischen Zielen herrscht Indifferenz, wobei sie zu der "Gerechteren Verteilung der Kostenlast" vermutlich dann in Konkurrenz umschlägt, wenn diese durch den Bau von Kläranlagen in einem sehr kurzen Zeitintervall verwirklicht wird4.

Konfrontiert man nun die ökologisch ausgerichteten mit den ökonomischen Zielsetzungen, so ist, wie in Abschnitt C.1.2.2.1. bereits angeklungen, darauf $\mathrm{zu}$ verweisen, daß der "Verstärkte Bau von Kläranlagen", die innerbetriebliche Verbesserung der Abwasserreinigungstechnik und auch die "Entwicklung und der Einsatz abwasserarmer/-loser Produktionsverfahren", soweit sie mit Ausgaben verbunden sind, die

1 Eine asymmetrische Komplementarität könnte man z.B. darin sehen, daB die "Verbesserung der Abwasserreinigungstechnik" die "Einhaltung der Auflagen" begünstigt.

2 Strenggenommen liegt asymmetrische Komplementarität vor, weil zwischen der gerechteren Verteilung der Kostenlast und der Aufhebung von Wettbewerbsverzerrungen eine MittelZweck-Beziehung herrscht.

3 Im folgenden wird die "Aufhebung von Wettbewerbsverzerrungen" nicht mehr genannt.

4 Diesen Wechsel der technologischen Beziehung zwischen zwei Zielen, der vom Zielerreichungsgrad abhängt, bezeichnet man als Erfüllungsvariabilität. 


\begin{abstract}
"Gerechtere Verteilung der Kostenlast" fördern und damit eine asymmetrische Komplementarität vorliegt. Der verstärkte sowie der beschleunigte ${ }^{1}$ Bau von Kläranlagen könnte die "Sprunghafte Nachfrage nach Reinigungsanlagen" induzieren, so daB eine gewisse Konkurrenz zwischen erst- und letztgenanntem Ziel möglich ist. Die anderen ökologisch ausgerichteten Ziele verhalten sich $\mathrm{zu}$ den ökonomischen Zielen weitestgehend indifferent.

Resümierend kann festgestellt werden, daß mit Ausnahme der "Aufhebung von Wettbewerbsverzerrungen", die durch die "Gerechtere Verteilung der Kostenlast" mitgemessen wird, für alle Ziele Indikatoren $\mathrm{zu}$ bilden und Zielerreichungen festzustellen sind.
\end{abstract}

\title{
1.2.3 Indikatorenauswahl
}

Im folgenden soll ein Indikatorenkatalog zur Messung der Gesamt- und Teilzielerreichungen des AbwAG vorgestellt werden. Dabei ist hervorzuheben, daß die letztlich getroffene und präsentierte Auswahl auch und gerade das Ergebnis der in Teil D aufbereiteten empirischen Untersuchung ist. Denn weil auf eine bereits vorhandene, theoretisch begründete und empirisch erprobte umfassende Indikatorenliste zur Fragestellung der vorliegenden Arbeit nicht zurückgegriffen werden konnte, mußten die Indikatoren erst im Hinblick auf ihre Meßbarkeit und Aussagekraft getestet werden.

Die Ausführungen zum Indikatorenkatalog gliedern sich deshalb folgendermaßen: Zunächst werden jeweils das Ziel und die Indikatoren, die die Zielerreichung messen sollen, vorgestellt. Die getroffene Indikatorenauswahl wird dann kurz erörtert und es wird, wenn vorhanden, auf weitere getestete

1 Hier ist das Ziel "Beschleunigte Anwendung der a.a.R.d.T." angesprochen. 
Indikatoren, die sich für die Zielerreichungskontrolle jedoch nicht qualifizieren konnten, eingegangen.

\section{Gesamtziel "Emissionsverminderung"}

\section{Indikatoren: - Schadfracht/Jahr \\ - Schadfracht/Produkteinheit}

Da der Gesetzgeber die "Emissionsverminderung" nicht näher spezifiziert hat, wird vorgeschlagen, durch den ersten Indikator die absolute und durch den zweiten die relative Emission festzustellen. Die jahresbezogene Schadfracht, die auch beim zweiten Indikator die Berechnungsbasis bildet, soll als Anzahl emittierter Schadeinheiten erfaßt werden ${ }^{1}$. Diese berechnet sich nach der abgaberechtlichen Bemessungsgrundlage ${ }^{2}$ unter Zugrundelegung der vom Einleiter gemessenen Durchschnittswerte der schadparameter und der realen Jahresschmutzwassermenge ${ }^{3}$.

Die beiden Indikatoren kann man gleichsam als ökologische Gesamtindikatoren des AbwAG verstehen, weil sie die Auswirkungen der Zielerreichungen bei den ökologisch ausgerichteten Teilzielen zusammenfassen.

Teilziel "Verstärkter Bau von Kläranlagen"

Indikatoren: - Vorhandene Reinigungsstufen

- Anzahl der Reinigungseinheiten/Reinigungsstufe

1 Die Bezeichnung "Schadfracht" leitet sich also - ebenso wie die der "Schadmenge" - aus der Bezeichnung "Schadeinheit" ab.

2 Siehe Anlage zu $\$ 3$ AbwAG im Anhang der Arbeit.

3 Alternativ können statt der Durchschnittswerte die Regelbzw. Bezugswerte und statt der realen die bescheidliche Jahresschmutzwassermenge in die Formel eingehen, wie es auch für die Abgabenberechnung üblich ist. Der Vorteil bestünde darin, daß diese Anzahl der Schadeinheiten bereits in der Abgabenerklärung berechnet ist und die Regelwerte eventuell eine größere Reliabilität als die Durchschnittswerte aufweisen. Die Validität allerdings würde leiden: Die Bescheidwerte decken sich nämlich nicht unbedingt mit den realen Emissionswerten, weshalb für die andere Vorgehensweise plädiert wird. 
Der "Kläranlagenbau" läßt sich unterteilen in den Bau neuer Reinigungsstufen ${ }^{1}$, der Anzahl und Art vorhandener Reinigungsstufen erhöht, und den Ausbau bereits bestehender Reinigungsstufen, der sich in der Anzahl der Reinigungseinheiten pro Reinigungsstufe (z.B. Anzahl der mechanischen Reingungsbecken) niederschlägt.

Getestet wurde in der empirischen Untersuchung auch die Kennzahl "Einwohnergleichwerte (EGW) der Abwasserreinigungsanlage" 2 als Indikator für die Größe und Reinigungsleistung der vorhandenen Anlagen. Es stellte sich jedoch heraus, daß die meisten der untersuchten gewerblichen Direkteinleiter nicht mit dieser Kennzahl arbeiteten, weshalb sie als Indikator ausscheidet.

Teilziel "Verbesserung der Abwasserreinigungstechnik"

Indikator: - Wirkungsgrad der Reinigungsstufen, gemessen am CSB- und am BSBs-Abbau

Findet die Datenerhebung beim Anlagenbetreiber und nicht beim Anlagenbauer statt, so kann die "Verbesserung der Abwasserreinigungstechnik" nur als Prozeßoptimierung vor ort und nicht im sinne der Entwicklung neuer Verfahren, die in der Regel in den Händen des Anlagenbauers liegt, festgestellt werden. Die ProzeBoptimierung schlägt sich im Wirkungsgrad der einzelnen Reinigungsstufen nieder. Definiert ist der Wirkungsgrad als das auf den Zulauf bezogene Verhältnis der beseitigten Konzentration eines

1 Eine für den Untersuchungszeitraum gängige und deshalb für diesen Indikator gewählte Einteilung der Reinigungsstufen ist die in mechanische, mechanisch-chemische und biologische Reinigung. Die biologische Reinigung wird weiter nach einstufiger und zweistufiger Biologie, Tropfkörpern sowie anderen, weniger gebräuchlichen Verfahren differenziert. Darüber hinaus ermöglicht die Indikatorausprägung "sonstige Reinigung" die Erfassung von Spezialitäten der Abwasserreinigung.

2 Ein Einwohnergleichwert entspricht der Menge an Schadstoffen, die von einem Einwohner pro Tag erzeugt und mit dem Abwasser entsorgt werden. Der EGW ist eine gängige Kennzahl zum Vergleich der Verschmutzung des gewerblichen und des industriellen Abwassers. 
Schadparameters ((Einlaufwert-Auslaufwert)/Einlaufwert). wie allgemein üblich, soll er auch hier für den CSB und den BSBs berechnet werden. Es ist $z u$ beachten, daß die Veränderung der Wirkungsgrade nicht allein das Ergebnis einer verbesserten Reinigungstechnik, sondern auch das eines Ausbaus der Reinigungsstufe sein kann. Liegt ein solcher vor, zeigt der Indikator das Ergebnis beider Veränderungen an.

Die Einleiter wurden in der empirischen Untersuchung außerdem nach den maximalen und minimalen Einlauf- und Auslaufkonzentrationen der schadparameter bei den einzelnen Reinigungsstufen gefragt. Hintergrund dieser Frage, die für den Indikator "Schwankungsbreite der Schadparameterwerte" stand, war die Arbeitshypothese: je niedriger die Schwankungsbreite der Schadparameter, desto besser die Abwassereinigungstechnik. Es stellte sich jedoch heraus, daß der Indikator keine validen Ergebnisse liefert, weil nicht nur Unzulänglichkeiten der Abwasserreingungstechnik, sondern auch Produktionsstörungen und das An- und Abstellen eines Produktionsprozesses zu Extremwerten führen. Der Indikator mußte deshalb verworfen werden.

Teilziel "Entwicklung und Einsatz abwasserarmer/-1oser Produktionsverfahren"

Indikatoren: - Anwendung abwasserloser Produktionsverfahren

- Abwasserreduzierende Maßnahmen im ProduktionsprozeB (bei offenem Wasserkreislauf)

- Spezifischer Abwasseranfall (bei offenem Kreislauf)

Die Indikatorenbildung für dieses Teilziel soll sich auf den Einsatz abwasserarmer/-loser Produktionsverfahren konzentrieren. Denn wie beim vorangegangenen Teilziel liegt der Vorgang der Entwicklung mehr in den Händen der Anlagenbauer als der-betreiber. Letztendlich kann sich die Entwicklung aber auch im Einsatz dieser Produktionsverfahren widerspiegeln. 
Der oben erstgenannte Indikator zeigt an, ob die Untersuchungseinheit ohne Abwasseremission produziert ${ }^{1}$ oder Abwasser in den Vorfluter einleitet, also mit offenem Wasserkreislauf arbeitet ${ }^{2}$. Ist letzteres der Fall, so werden mit dem zweitgenannten Indikator abwasserreduzierende Maßnahmen im Produktionsprozeß erfaßt. Dieser Indikator gibt qualitativ wieder, was durch den spezifischen Abwasseranfall (Abwassermenge pro Produkteinheit) quantitativ ausgedrückt wird. Verringert sich der spezifische Abwasseranfall auch deshalb, weil die "Verbesserung der Abwasserreinigungstechnik" die Wasserrücknahme in den Produktionsprozeß erhöht oder überhaupt erst ermöglicht, so ist der spezifische Abwasseranfall das Resultat zweier Zielerreichungen.

\section{Teilziel "Sparsamere Verwendung abwasserintensiver Güter"}

Indikatoren: - Transparenz der Einleiter über die produktspezifischen Abwasserbelastungen

- Bestehen einer Kostenstelle

- Anderung des Produktionsprogramms aus Abwassergründen

Zur sparsameren Verwendung abwasserintensiver Güter durch die Verbraucher kommt es hauptsächlich dann, wenn der Produzent Erhöhungen der Abwasserkosten ${ }^{3}$ und der Kosten

1 Diskussionswürdig ist dabei die Frage, ob zu den abwasserlosen Produktionsverfahren auch diejenigen zählen, die "in seltenen Fällen", z.B. bei störungen im ProduktionsprozeB, Abwasser emittieren. In dieser Arbeit werden derartige Fahrweisen $\mathrm{zu}$ den abwasserlosen Produktionsverfahren gerechnet.

2 Die Bezeichnung "offener Kreislauf" wird als Abgrenzung zu den "geschlossenen" Kreisläufen verwendet und beinhaltet alle Zwischenstufen partieller Kreislaufschließung.

3 Die Abwasserkosten sollen definiert werden als die summe aus Betriebs- und (kalkulatorischen) Kapitalkosten der externen Abwasservermeidung, der Klärschlammbehandlung und -entsorgung und der Abwasserabgabe.

Davon zu unterscheiden sind die Abwasserreinigungskosten, die als Abwasserkosten abzüglich der Abwasserabgabe spezifiziert werden sollen.

Weiterhin abzugrenzen sind die Gesamtkosten der Abwasservermeidung, die neben den Abwasserreinigungskosten auch 
der innerbetrieblichen Vermeidungsmaßnahmen auf die Produktpreise überwälzt und die Käufer daraufhin mit sinkender Nachfrage reagieren. Die sparsamere Verwendung kann aber auch "direkt" vom Produzenten ausgehen, so z.B., wenn seine Produkte extrem unterschiedlich das Abwasser belasten und er für ein Produkt von untergeordneter Bedeutung kostenträchtige und nicht ausgelastete Abwasserbehandlungsmaßnahmen zur Einhaltung der Auflagen bauen müBte ${ }^{1}$.

Antworten der Untersuchungseinheiten auf die Frage, ob sie erhöhte Abwasserkosten auf die Produktpreise überwälzen, laufen - nicht zuletzt wegen der recht komplexen Preisfindung - Gefahr, subjektiv zu sein²; dies gilt in noch stärkerem Maße für die Feststellbarkeit von Auswirkungen derartiger Kostenüberwälzungen auf die ebenfalls mehrdimensional determinierte Nachfrage. Es wird deshalb vorgeschlagen, $z u$ überprüfen, ob beim Einleiter "rechnerische" Voraussetzungen für die Erfassung und Uberwälzung der Abwasserkosten geschaffen wurden. Zu diesen zählt zunächst, wie auch für andere abwasserbegründete Veränderungen des Produktionsprogramms, das Wissen des Produzenten um die produktspezifischen Abwasserbelastungen, geht man von einem Mehrproduktbetrieb aus. Die

die Betriebs - und (kalkulatorischen) Kapitalkosten der innerbetrieblichen Vermeidungsmaßnahmen enthalten. $\mathrm{Zu}$ letzteren sollen auch die "indirekten" Kosten der Abwasserreinigung zählen, die sich aus notwendigen Umstellungen im Produktionsbereich ergeben. $\mathrm{Zu}$ den indirekten Kosten der Abwasserreinigung vgl. Albach, H.: Gutachten über "Methodische Probleme der Ermittlung von betriebs - und volkswirtschaftlichen Auswirkungen des geplanten Abwasserabgabengesetzes auf die Papier- und Zellstoffindustrie", Bonn 1976, s. 21.

1 Es handelt sich hier allerdings nur um eine mikroökonomisch sparsamere Verwendung abwasserintensiver Güter, weil andere Hersteller die Produktion aufnehmen könnten, so daß makroökonomisch der alte Zustand wiederhergestellt würde.

2 Dies ergab auch die Umfrage in dieser Arbeit, in der ein derartiger Indikator getestet wurde. Die Frage, ob die Abwasserabgabe in die Preiskalkulation einginge, reizte offensichtlich dazu, "aus der hohlen Hand" zu antworten. 
produktspezifische Kostenüberwälzung (Kostenträgerrechnung) bedingt weiterhin eine gesonderte Erfassung der Abwasserkosten durch eine entsprechende Kostenstelle. Indem das Vorhandensein dieser beiden Voraussetzungen abgefragt wird, kann bei verneinenden Antworten eine produktspezifische Kostenüberwälzung - und eine dadurch induzierte sparsamere Verwendung abwasserintensiver Güter - ausgeschlossen werden. Bei Bejahung freilich bleibt offen, ob der Produzent die Verbraucher zu einer Anderung ihres Kaufverhaltens anregt.

Weitere Veränderungen des Produktionsprogramms, die aus der Beschaffenheit des Abwassers resultieren, werden mit dem dritten Indikator ermittelt.

Teilziel "Beschleunigte Anwendung der allgemein anerkannten Regeln der Technik"

Indikatoren: - Vorverlegung geplanter Maßnahmen - Sachliche Umgestaltung geplanter Maßnahmen

Für die Abwasserbehandlung manifestieren sich die a.a.R.d.T. seit Mitte der siebziger Jahre in der - aeroben - biologischen Reinigung und natürlich den vorgeschalteten "klassischen" Reinigungsstufen. Insofern sind alle Investitionen, die im Bereich der Abwasserreinigung getätigt werden, ein schritt zur Anwendung der a.a.R.d.T. oder, wenn diese bereits erreicht sind, ein Schritt darüber hinaus. Wie in Abschnitt A.2.2. beschrieben, betreffen die a.a.R.d.T. auch die Produktionsverfahren. Für diese können sie jedoch wegen der unüberschaubaren Verfahrensvielfalt kaum und wenn, dann nicht allgemeingültig spezifiziert werden, so daB sie sich m.E. auch einer Kontrolle der Anwendung entziehen. Bleibt also der Abwasserreinigungsaspekt. Der Einsatz der a.a.R.d.T. kann durch die zeitliche Vorverlegung von Reinigungsmaßnahmen und durch die sachliche Umgestaltung bereits geplanter Maßnahmen beschleunigt werden. Ein gewisses Manko an Repräsentativität läßt sich bei diesen beiden Indikatoren allerdings nicht ausschlieBen: Zum 
einen sind die Abwasserbehandlungsmaßnahmen, die allein aufgrund der "neuen" Regelungen durchgeführt wurden, nicht erfaßt, und unberücksichtigt bleiben auch die Veränderungen der Produktionsverfahren. Zum anderen gelangen Maßnahmen, die über die Anwendung der a.a.R.d.T. hinausgehen, mit in die Kontrollmasse.

\section{Teilziel "Einhaltung der Auflagen"}

Indikator: Anspruch auf Abgabenhalbierung

Wird dem Einleiter die Abgabenhalbierung gewährt, zeigt dies an, daß die Auflagen von den Behörden als eingehalten erachtet wurden.

\section{Teilziel "Festsetzung verhältnismäßig strenger Auflagen"}

Wie bereits in Abschnitt C.1.2.2.1. ausgeführt, kann für dieses Ziel aufgrund seiner mangelhaften Beschreibung kein Indikator gebildet werden.

Teilziele "Gerechtere Verteilung der Kostenlast" und "Aufhebung von Wettbewerbsverzerrungen"

Indikator: Vergleich konkurrierender Unternehmen bzgl. der auf den Umsatz bezogenen Summe aus den Gesamtkosten der Abwasservermeidung und der Abwasserabgabe

Neben der Relativierung der Gesamtkosten der Abwasservermeidung zuzüglich der Abwasserabgabe durch den Umsatz ist die Bezugnahme dieser Kosten auf das cbm Abwasser und auf die Produkteinheit zu diskutieren. Bei der Indikatorenauswahl muß berücksichtigt werden, daß die Werte aussagefähig sein müssen für den Vergleich zwischen Unternehmen, die auf der Produktseite miteinander konkurrieren. Unter diesem Gesichtspunkt scheidet der Bezug auf das cbm Abwasser aus, weil auch konkurrierende Unternehmen u.U. sehr unterschiedliche produktspezifische Abwassermengen einleiten und diese in einem variablen Verhältnis zu den Vermeidungskosten stehen, mithin die Indikatorenwerte nicht repräsentativ für die Kostenbela- 
stung und nicht aussagekräftig im zwischenbetrieblichen Vergleich sind. Der Bezug auf die Produkteinheit sagt, wie auch der Bezug auf das cbm Abwasser, nichts über die Größenordnung der Vermeidungskosten zu den anderen Kosten aus, so daB er einer Relativierung entbehrt. Am besten geeignet dürfte der oben vorgeschlagene Indikator sein, denn durch die Bezugnahme auf den Umsatz sind die Indikatorenwerte sowohl repräsentativ als auch aussagekräftig.

Um die Kosten der Unternehmen miteinander vergleichen $\mathrm{zu}$ können, ist der in der Regel nicht einheitlich berechnete Kapitaldienst zu homogenisieren. Die kalkulatorischen Abschreibungen und die Zinsen sollen dafür bei allen Unternehmen nachträglich so berechnet werden, wie die Befragten mehrheitlich verfuhren.

\section{Teilziel "Tragbare wirtschaftliche Belastung der Abgabe-} pflichtigen"

Die mangelhafte Zielbeschreibung macht es auch hier unmöglich, eine Indiaktorenbildung vorzunehmen.

Teilziel "Vermeidung sprunghafter Nachfrage nach Reinigungsanlagen"

Indikator: Jahr der Planung, des Baubeginns und der Inbetriebnahme der Anlagen

Die zeitliche Verlauf der Nachfrage nach Reinigungsanlagen läßt sich, wenn er über den Anlagenbetreiber zu ermitteln ist, daran ablesen, ob Anlagenplanung, -bau bzw. Inbetriebnahme sich einigermaßen gleichmäßig über Jahre verteilen oder geballt auftreten.

Die vorgeschlagenen Indikatoren sind als Ubersicht abschlieBend in Tab. 5 zusammengestellt. 


\begin{tabular}{|c|c|}
\hline Ziel & Indikatorenkatalog \\
\hline Emissionsverminderung & $\begin{array}{l}\text { 1. Schadfracht/Jahr } \\
\text { 2. Schadfracht/Produkteinheit }\end{array}$ \\
\hline $\begin{array}{l}\text { Verstärkter Bau von } \\
\text { Kläranlagen }\end{array}$ & $\begin{array}{l}\text { 3. Vorhandene Reinigungsstufen } \\
\text { 4. Anzahl der Reinigungsein- } \\
\text { heiten/Reinigungsstufe }\end{array}$ \\
\hline $\begin{array}{l}\text { Verbesserung der } \\
\text { Abwasserreinigungs- } \\
\text { technik (als Prozeß- } \\
\text { optimierung) }\end{array}$ & $\begin{array}{l}\text { 5. Wirkungsgrad der Reinigungs- } \\
\text { stufen, gemessen am CSB- und } \\
\text { am } \mathrm{BSB}_{5}-\mathrm{Abbau}\end{array}$ \\
\hline $\begin{array}{l}\text { Einsatz abwasserarmer/ } \\
\text { - loser Produktions- } \\
\text { verfahren }\end{array}$ & $\begin{array}{l}\text { 6. Anwendung abwasserloser } \\
\text { Produktionsverfahren } \\
\text { 7. Abwasserreduzierende Maßnah- } \\
\text { men im Produktionsprozeß } \\
\text { 8. Spezifischer Abwasseranfall }\end{array}$ \\
\hline $\begin{array}{l}\text { Sparsamere Verwendung } \\
\text { abwasserintensiver } \\
\text { Güter }\end{array}$ & $\begin{array}{l}\text { 9. Transparenz der Einleiter } \\
\text { über die Abwasserbelastung } \\
\text { ihrer verschiedenen Produkte } \\
\text { 10. Bestehen einer Kostenstelle } \\
\text { für Abwasser } \\
\text { 11. Ânderung des Produktions- } \\
\text { programms aus Abwassergründen }\end{array}$ \\
\hline $\begin{array}{l}\text { Beschleunigte Anwendung } \\
\text { der a.a.R.d.T. }\end{array}$ & $\begin{array}{l}\text { 12. Vorverlegung geplanter } \\
\text { Maßnahmen } \\
\text { 13. Sachliche Umgestaltung } \\
\text { geplanter Maßnahmen }\end{array}$ \\
\hline Einhaltung der Auflagen & $\begin{array}{l}\text { 14. Anspruch auf Abgaben- } \\
\text { halbierung }\end{array}$ \\
\hline $\begin{array}{l}\text { Gerechtere Verteilung } \\
\text { der Kostenlast und } \\
\text { Aufhebung von } \\
\text { Wettbewerbsverzerrungen }\end{array}$ & $\begin{array}{l}\text { 15. Vergleich konkurrierender } \\
\text { Unternehmen bzgl. der auf den } \\
\text { Umsatz bezogenen Gesamtkosten } \\
\text { der Abwasservermeidung }\end{array}$ \\
\hline $\begin{array}{l}\text { Vermeidung sprunghafter } \\
\text { Nachfrage nach } \\
\text { Reinigungsanlagen }\end{array}$ & $\begin{array}{l}\text { 16. Jahre der Planung, des Bau- } \\
\text { beginns und der Inbetrieb- } \\
\text { nahme der Anlagen }\end{array}$ \\
\hline
\end{tabular}

Tab. 5: Indikatorenkatalog für die Messung der Zielerreichungen des Abwasserabgabengesetzes bei gewerblichen Direkteinleitern 


\subsubsection{Messung der Zielerreichungen}

Die vorangegangenen Abschnitte galten der Vorbereitung dieses letzten Schrittes der Zielerreichungskontrolle, der darin besteht, festzustellen, inwieweit die Ziele des AbwAG erreicht worden sind, sei es durch die Wirkungen des AbwAG selbst, des $\S 7$ a WHG, anderer gewässergütepolitischer Maßnahmen oder exogener Einflußgrößen.

Grundsätzlich kommen folgende Arten der Zielmessung in Betracht :

1. der Soll-Ist-Vergleich und

2. der Ist-Ist-Vergleich.

Der soll-Ist-Vergleich steht klassischerweise als synonym für die Kontrolle als kybernetischer Komponente der Planung. Voraussetzung für seine Durchführung ist - selbstredend - die Vorgabe von Sollwerten, auf die der Gesetzgeber bei der Formulierung der Zielsetzungen des AbwAG aber verzichtete, sieht man von der Reinigung der Abwässer privater Haushalte $a b$. Infolge dieses Mangels an Operationalität erübrigt sich dann auch ein Soll-Ist-Vergleich. Mit Eekhoff kann jedoch festgestellt werden, daß sich zum Soll deklarierte Werte vielfach sowieso nicht als Maß der Erfolgsträchtigkeit eines Programms eignen: "Anspruchsniveaus oder Richtwerte sind in der Regel ... wenig geeignet als Vergleichsbasis für den tatsächlichen Erfolg von Maßnahmen, weil sie häufig zu sehr den Charakter von Idealwerten oder großzügigen politischen Versprechungen haben und selbst mit den besten programmen nicht zu erreichen sind. Umgekehrt ist es denkbar, daß der Sollwert bewuBt niedrig festgelegt wird, damit es leichter ist, Erfolge vorzuweisen. Mit dem Soll-Ist-Vergleich wird zwar festgestellt, ob Versprechungen gehalten wurden, aber eine Aussage, ob mit einem Handlungsprogramm relativ viel oder wenig erreicht wurde, kann nicht gemacht werden."1

1 Eekhoff, J. u.a.: Methoden ..., a.a.o., s. 28. 
Bleibt der Ist-Ist-Vergleich, auch als Before-and-afterVergleich bezeichnet. Er miBt die Werte, die ein Indikator vor und nach Einführung eines Gesetzes annimmt, und ermittelt das Ausmaß der Veränderung. Fragen wirft hier die Spezifikation des Zeitintervalls auf. Da das AbwAG 1976 erlassen wurde, empfehlen sich 1975 oder 1974 als Untersuchungsjahr vor Einführung des Gesetzes. Die Wahl des zweiten Datums hängt maßgeblich von der Fragestellung ab, die der Erfolgskontrolle zugrunde liegt; infolge der hier intendierten auch abschließenden Beurteilung des AbwAG sollten einige Jahre seit Beginn der Abgabepflicht verstrichen sein. 


\subsection{Entwicklung einer Vollzugskontrolle}

\subsubsection{Inhaltliche Abgrenzung}

Die Vollzugskontrolle soll erfassen, ob und wie das zu evaluierende Programm bzw. Gesetz implementiert worden ist. Die Implementation selbst wird chronologisch zwischen Entwicklung und Wirkung (Impact) eines Programms/Gesetzes eingeordnet ${ }^{1}$. Eine Betrachtungsweise, die übrigens nur begrenzt richtig ist, wenn man die "Signalwirkungen" berücksichtigt, die von einem erlassenen, aber noch nicht vollzogenen Gesetz ausgehen können. Gleichwohl ist die Implementation, und sei es nur die drohende, Bedingung für mögliche Programmwirkungen. Unter diesem Aspekt soll sie hier auch untersucht werden.

Die Vollzugskontrolle dient in dieser Arbeit als Voraussetzung für die Durchführung der Wirkungskontrolle. Untersuchungsgegenstand ist deshalb nicht, inwieweit die relevanten Gesetze ordnungsgemäß implementiert wurden und worin die Ursachen für mögliche Implementationsmängel liegen ${ }^{2}$. Es handelt sich vielmehr um eine Bestandsaufnahme der wasserund abgaberechtlichen Rahmenbedingungen ${ }^{3}$ bei den jeweiligen

1 Vgl. Mayntz, R.: Die Implementation politischer .... a.a.O., S. 238 f.; Caro, F.G.: Evaluation Research. An Overwiew, in: ders. (Ed.), Readings in Evaluation Research, New York 1977, S. 3.

2 Es ist dies das weite Feld, das innerhalb der sogenannten Implementationsforschung bearbeitet wird. Hinzuweisen ist auch auf die Untersuchung Terhardts, der die einzelwirtschaftliche Entscheidung, Umweltschutzvorschriften $\mathrm{zu}$ befolgen oder gegen sie $\mathrm{zu}$ verstoßen, analysiert und Vorschläge unterbreitet, wie der Gesetzgeber auf einen besseren Gesetzesvollzug seitens der Adressaten hinwirken kann. Vgl. Terhardt, $K_{\text {.: Die }}$ Befolgung von Umweltschutzauflagen als betriebswirtschaftliches Entscheidungsproblem, Berlin 1986.

3 Da der Abgabenvollzug unmittelbar an den Vollzug des wHG gekoppelt ist, wird dieser teilweise mitkontrolliert. 
Einleitungen ${ }^{1}$. Denn diesbezügliche Kenntnisse sind sowohl Voraussetzung dafür, festgestellte Zielerreichungen der richtigen Wirkungsursache zuzurechnen, als auch grundsätzlich einschätzen zu können, ob ausbleibende Wirkungen auf einen mangelnden Gesetzesvollzug zurückzuführen und deshalb nicht dem Gesetz selbst anzulasten sind. Bevor das Konzept für eine derartige Bestandsaufnahme entwickelt wird, soll der Bezugsrahmen der Vollzugskontrolle abgesteckt werden.

\subsubsection{Kategorialer Bezugsrahmen}

"In der Phase de( $r$ ) Implementation wirken Implementationsträger und Adressaten in Handlungssituationen zusammen, die durch ein gegebenes programm vorstrukturiert sind."2 Die gewässerrechtliche Situation des Einleiters ist das Ergebnis dieses Implementationsprozesses.

Von den drei Kategorien dieses Bezugsrahmens der Implementation wurden als hier interessierende Adressaten bereits die gewerblichen Direkteinleiter und als gegebenes Programm bzw. Gesetz das AbwAG identifiziert. Die Implementationsträger als dritte Kategorie sollen im folgenden kurz skizziert werden.

An der Implementation des AbwAG sind neben den administrativen Vollzugsbehörden Vollstreckungsorgane wie Polizei und Gerichte und unter Umständen auch halbstaatliche und private Organisationen wie staatlich anerkannte Untersuchungsstellen für Abwasser und nicht-staatliche Gutachter beteiligt. Der größte und für die Vollzugskontrolle wichtigste Part des Implementationsprozesses obliegt jedoch den administrativen Vollzugsbehörden. Da die Behördenzuständigkeit länderindi-

1 Kontrolle versteht sich hier also nicht als Soll-IstVergleich, sondern als ein Vorgang, der feststellt, inwieweit durch den Vollzug die Voraussetzung für die volle Wirkungsentfaltung des AbwAG geschaffen wurde.

2 Mayntz, R.: Die Implementation ..., a.a.o., S. 239 (Hervorhebungen von Mayntz). 
viduell geregelt ist1, kann sie nicht allgemeingültig für die Einleiter qualifiziert werden. Deshalb müssen sich die weiteren Ausführungen mit dem Aufbau des Behördensystems, dem der Gewässerschutz in den Bundesländern² obliegt, begnügen. Man unterscheidet die folgenden Instanzen:

a. Oberste Wasserbehörde: das für die Wasserwirtschaft zuständige Ministerium.

b. Obere Wasserbehörde: der Regierungspräsident bzw. in Niedersachsen und Rheinland-Pfalz die Bezirksregierung; in Bayern, Saarland und Schleswig-Holstein entfällt diese Ebene.

C. Untere Wasserbehörde: Landkreise bzw. die kreisfreien städte.

Daneben steht das Wasserwirtschaftsamt als technische Fachbehörde.

Die aufgeführten Instanzen sind organisatorisch unterschiedlich verankert. So ist die Untere Wasserbehörde in das Ordnungsamt, Tiefbauamt, Umweltamt oder sonstige Amter eingebunden ${ }^{3}$.

Beispielhaft sei hier die hessische Regelung der wasserrechtlichen Behördenzuständigkeit ${ }^{4}$ wiedergegeben: In Hessen ist die zuständige Wasserbehörde, "soweit nichts anderes bestimmt ist,

1 Für den Vollzug des Abwasserabgabengesetzes ist die Behördenzuständigkeit in den Ausführungsgesetzen der Länder zum AbwAG, für die Durchführung des WHG in den jeweiligen Landeswassergesetzen geregelt.

2 Die stadtstaaten bleiben unberücksichtigt.

3 Vgl. dazu die tabellarische Ubersicht von Mayntz, R. u.a.: Vollzugsprobleme der Umweltpolitik. Empirische Untersuchung der Implementation von Gesetzen im Bereich der Luftreinhaltung und des Gewässerschutzes, stuttgart 1978, S. 519 .

4 Vgl. \$ 12 HAbwaG und $\$ 91$ HWG. 
1. für oberirdische Gewässer erster und zweiter Ordnung die obere Wasserbehörde;

2. für alle anderen Gewässer sowie die Einleitung gefährlicher stoffe in öffentliche Abwasseranlagen die untere Wasserbehörde."1

Es stellt sich nun die Frage, welche Implementationsergebnisse, die aus dem Zusammenspiel der drei Kategorien Implementationsträger, Adressaten und Programm resultieren, für die Wirkungskontrolle des AbwAG benötigt werden.

\subsubsection{Für die Wirkungskontrolle relevante Implementations- ergebnisse}

Die Wirkungskontrolle des AbwAG benötigt, um die in der Zielerreichungskontrolle ermittelten Wirkungen richtig analysieren zu können, Informationen aus den folgenden Bereichen:

\section{Informationen zur Genehmigungspraxis}

Unabdingbar für die Wirkungskontrolle sind Kenntnisse über die Einleitungsbedingungen des jeweiligen Emittenten. Hier stellt sich zunächst die Frage, ob der wasserrechtliche Bescheid bereits den "neuen" Regelungen angepaßt wurde, oder andernfalls die Abgabe noch nach einer Erklärung erhoben wird. Als Parameterwerte interessieren dann die Jahresschmutzwassermenge, die ordnungsrechtlichen uberwachungswerte ${ }^{2}$ und die abgaberechtlichen Regel- und Höchstwerte. Das Wissen um die uberwachungswerte ist z.B. erforderlich, um feststellen zu können, inwieweit die in

$1 \S 91$ Abs. 1 HWG.

2 Aus der oft großen Anzahl der Parameter ( $\mathrm{pH}$-Wert, Temperatur etc.) sind diejenigen auszuwählen, die im Hinblick auf den Abgabenvollzug relevant sind. Weiterhin empfiehlt es sich, den BSB, abzufragen, weil für diesen zumeist Grenzwerte in den Mindestanforderungen zum $\$ 7$ a WHG festgelegt wurden. 
der Zielerreichungskontrolle gemessenen durchschnittlich emittierten Schadfrachten unter denjenigen liegen, die die Auflagen erlauben. Dies ist dann der erste Schritt für die Beantwortung der Frage, ob die Abwasserabgabe eine Reinigung über die Auflagen hinaus induziert hat.

Variationen der Bemessungsgrundlage treten bei der Jahresschmutzwassermenge auf: Diese geht bei einigen Einleitern - gemäß dem für sie gültigen Landesabwasserabgabengesetz - als real eingeleitete Menge in die Abgabenberechnung ein, obwohl eine höherliegende Bescheidmenge vorliegt. Auch gibt es Fälle, in denen neben der Bescheidmenge eine von dieser abweichende abgabenrechtliche Jahresschmutzwassermenge fixiert ist. Zur Vermeidung von MiBverständnissen und falschen Berechnungen empfiehlt es sich deshalb, nach der Bemessungsgrundlage der Jahresschmutzwassermenge zu fragen.

Liegen beim Einleiter für den Untersuchungszeitraum noch keine oder nicht alle Bescheidwerte vor, sollten die Parameterwerte abgefragt werden, die ersatzweise durch behördliche Messungen oder Schätzungen nach Maßgabe des \$ 6 AbwAG im Untersuchungszeitraum für die Abgabenberechnung angesetzt wurden.

\section{Weitere BestimmungsgröBen der Abgabenhöhe}

Neben den unter 1. angesprochenen Parameterwerten gibt es weitere Bestimmungsgrößen der Abgabenhöhe. Kenntnisse über diese einleiter-, zum Teil auch länderindividuellen Konditionen sind Voraussetzung dafür, die jährliche Anzahl der emittierten schadeinheiten bzw. den entrichteten Abgabenbetrag richtig $\mathrm{zu}$ interpretieren. So könnte man eine über mehrere Jahre gleichbleibende Anzahl von Schadeinheiten - bei beachtlicher Produktionssteigerung als hervorragende Verbesserung der Reinigungsleistung des Einleiters deuten, obwohl dieser lediglich in den GenuB einer Ausnahme von der Abgabepflicht kam. 
3. Oberwachung der Abwassereinleitungen

Informationen über die Kontrolltätigkeit der dazu beauftragten staatlichen oder staatlich anerkannten stellen geben Aufschluß darüber, inwieweit der Einleiter von dieser seite zu normkonformem Verhalten veranlaßt wird und die Möglichkeit zur Aufdeckung aktueller Verstöße oder Risiken besteht ${ }^{1}$. Im Rahmen des Abgabenvollzugs interessiert diese Uberwachung, weil die bei der Kontrolle festgestellten Werte die Grundpfeiler bei der Festlegung der abgaberechtlichen schadparameterwerte sowie bei der jährlichen Berechnung der Abgabenhöhe sind².

\subsubsection{Entwurf einer Bestandsaufnahme der wasser- und} abgaberechtlichen Rahmenbedingungen

Als Resultat dieser uberlegungen wird der in Tab. 6 präsentierte Katalog der Vollzugskontrolle zur Erfassung der wasser- und abgaberechtlichen Rahmenbedingungen vorgeschlagen.

1 Vgl. Mayntz, R. u.a.: Vollzugsprobleme ..., a.a.0., s. 60 .

2 Informationen darüber, ob die Behörden die Verletzung von Vorschriften ordnungsgemäß ahnden, zeigen - so sie erhoben werden können - ebenfalls an, ob die Einleiter zu normkonformem Verhalten motiviert werden. 
1. Informationen zur Genehmigungspraxis

a. Erhebung der Abwasserabgabe durch Bescheid oder Erklärung

b. Wenn ein "neuer" Bescheid vorliegt: Datum (Jahr)

c. Bescheidwerte, die im Untersuchungszeitraum galten (inclusive Veränderungen im Zeitablauf; ersatzweise Erklärungswerte nach Maßgabe des $\$ 6$ AbwAG)

- Uberwachungs-, Regel- und Höchstwerte der nachfolgenden Schadparameter, soweit sie für die Abgabenerhebung - mit Ausnahme des $\mathrm{BSB}_{5}$ - relevant sind

* Absetzbare Stoffe/Feststoffe

$\star \mathrm{CSB}$

* $\mathrm{BSB}_{5}$

* Quecksilber und seine Verbindungen

* Cadmium und seine Verbindungen

* Fischgiftigkeit

- Jahresschmutzwassermenge laut Bescheid; Jahresschmutzwassermenge bei der Abgabenerhebung

2. Weitere Bestimmungsgrößen der Abgabenhöhe

a. Gewährung eines Vorwegabzugs, der über dem regulären Vorwegabzug des AbwAG (Anlage zu $\$ 3$ AbwAG) liegt

b. Durchführung von Teilstrommessungen, die Grundlage für die Abgabenberechnung sind

c. Abgabenverminderung vor Inbetriebnahme einer Abwasserbehandlungsanlage gemäß $\$ 10$ Abs. 3 AbwAG, Angabe der betroffenen Jahre

3. Uberwachung der Abwassereinleitungen

a. Durchschnittliche Anzahl der Abwasserkontrollen pro Jahr von seiten der Behörde oder der damit beauftragten Organisation

b. Einsichtnahme der Behörden in die Eigenkontrolle

Tab. 6: Informationskatalog zum wasser- und abgaberechtlichen Vollzug 


\subsection{Entwicklung einer Bedingungskontrolle}

\subsubsection{Inhaltliche Abgrenzung}

Die Aufgabe der Bedingungskontrolle besteht darin, festzustellen, ob sich die exogenen Größen, also Bedingungen, die außerhalb des gewässergütepolitischen statlichen Handelns mittelbar oder unmittelbar die Zielerreichungen beeinflussen, im Zeitablauf verändert haben. Nimmt die Bedingungskontrolle innerhalb des politischen Planungs- und Entscheidungsprozesses eine eigenständige Funktion ein, soll sie die prognostizierten mit den tatsächlich eingetretenen exogenen Bedingungen vergleichen, um durch eine Relativierung der bisherigen Annahmen Politikern und Planern die Möglichkeit zu geben, geplante oder bereits laufende Programme zu korrigieren, wenn die tatsächlichen Wirkungen der Einflußgrößen eben nicht mit den prognostizierten übereinstimmen ${ }^{1}$. Sich neu eröffnende Chancen sollen genutzt und Fehlentwicklungen vermieden werden. Dient die Bedingungskontrolle dagegen als Voraussetzung für eine Wirkungskontrolle, zeigt sie nur an, welche weiteren abhängigen Variablen neben dem relevanten staatlichen Handeln für die Zurechnung von Wirkungen bzw. Zielerreichungen in Frage kommen und wie sich diese Bedingungen im Untersuchungszeitraum verändert haben. In dieser Form soll sie hier gemäß dem abgesteckten Rahmen der Arbeit durchgeführt werden. Darüber hinaus wäre ein Soll-IstVergleich gar nicht denkbar, weil, wie bereits in Abschnitt C.1.1.2 bemerkt, der politische Planungs- und Entscheidungsprozess ohne die explizite Prognose und Berücksichtigung exogener Einflußgrößen stattfand.

1 Vgl. Eekhoff, J. u.a.: Methoden ..., a.a.0., S. 13 und 99. 


\subsubsection{Bestimmung der $\mathrm{zu}$ kontrollierenden exogenen Einflußgrößen}

Eine Auswahl möglicher exogener Bedingungen für das Emissionsverhalten gewerblicher Direkteinleiter wurde in Abschnitt C.1.1.2 zusammengestellt. Soll die Bedingungskontrolle nicht in einer zudem wenig ergiebigen sysiphusarbeit enden, besteht die erste uberlegung darin, diejenigen Bedingungen, die maßgeblichen Einfluß auf die ökologische Zielerreichung des AbwAG haben, herauszugreifen und andere Einflüsse, denen man nur marginale Auswirkungen zuschreibt, gewissermaßen zu einem "Gesamtpaket" zusammenzuschnüren. Erstere hieße es dann in ihrer Einflußnahme während des Untersuchungeszeitraums zu kontrollieren, letztere in einer solchen Betrachtung eher $z u$ vernachlässigen ${ }^{1}$. Dieser Selektiervorgang erforderte jedoch eine Fülle derzeit nicht verfügbarer theoretischer und empirischer Vorstellungen, so daB er hier nicht in die Tat umgesetzt werden kann. Mithin muB die Bestimmung der zu kontrollierenden exogenen Bedingungen eine gewisse Willkür beinhalten.

Unter dem Aspekt, die Untersuchung exogener Bedingungen in angemessenem und überschaubarem Rahmen zu halten, schlägt die Verfasserin vor, die jeweils vermutlich wichtigste exogene Einflußgröße auf die Erreichung des ökologischen Gesamtziels und der Teilziele - mit Ausnahme der "Sparsameren Verwendung abwasserintensiver Güter", das in der Zielerreichungskontrolle so unzureichend erfaßt wird, daß eine Zurechnung von Wirkungen nicht in Frage kommt - zu kontrollieren.

So dürfte der Produktionsumfang bzw. seine Veränderung wesentlich die Emissionsverminderung beeinflussen und auch den Bau von Kläranlagen auslösen. Es wird davon ausgegangen, daß der Produktionsumfang die Jahresschmutzfracht nicht

1 In der Wirkungskontrolle können diesen exogenen Einflüssen dann trotzdem Wirkungen zugerechnet werden, wenn man den Untersuchungseinheiten die Möglichkeit eröffnet, selbst den Einflus anderer als der explizit kontrollierten Einflüsse für ihr Verhalten geltend $z u$ machen. 
unbeträchtlich determiniert und daß er während des Untersuchungszeitraums, der vor ErlaB des AbwAG beginnt und einige Jahre nach Beginn der Abgabepflicht endet, dem gesamtwirtschaftlichen wachstum entsprechend erheblichen Veränderungen unterlegen hat.

Als exogene Einflußgröße auf den Einsatz Produktionsverfahren sollen Rationalisierungsmaßnahmen, Wirtschaftlichkeitsund Kostenüberlegungen als typische Auslöser für Verfahrensänderungen untersucht werden.

Die Verbesserung der Abwasserreinigungstechnik besteht auch aus Entwicklungen, die nicht auf das AbwAG zurückgehen. Wenngleich auf der einen seite feststeht, daß solche vorliegen, lassen sie sich wohl kaum von Entwicklungen, die durch das AbwAG induziert wurden, abgrenzen, so daß auf ihre Identifizierung hier verzichtet werden muß.

Das Feld der zu kontrollierenden exogenen Bedingungen ist damit abgesteckt, so daß auch die letzte Voraussetzung für die Lösung des Kausalitätsproblems geschaffen wäre. 


\section{Lösung des Kausalitätsproblems: Entwicklung einer Wirkungskontrolle}

\subsection{Vorgehensweise}

In dieser letzten stufe der Erfolgskontrolle sollen die in der Zielerreichungskontrolle generierten Zielwirkungen auf ihre "wahren" Bestimmungsgründe zurückgeführt werden. Die Verfasserin schlägt vor, diese Ursachenrecherche inhaltlich in zwei Schritten zu vollziehen. Der erste soll aufklären, inwieweit die festgestellten ökologischen und ökonomischen wirkungen auf das AbwAG und nicht auf das andere gewässergütewirtschaftliche Instrumentarium oder auf exogene Bedingungen zurückzuführen sind. Kristallieren sich bei diesem Zurechnungsversuch Wirkungen des AbWAG heraus, schlieBt sich die Frage an, welche Kausalität zwischen den einzelnen Gesetzeselementen und dieser "Gesamtwirkung"1 besteht. Der erste Schritt bemüht sich also um das "Wieviel" der Gesetzeswirkung, der zweite um das "Warum". Dieser Aufbau der Untersuchung resultiert aus der Intention der Arbeit, den wissensstand über die Wirkungen des AbWAG im besonderen und einer Emissionsabgabe im allgemeinen $\mathrm{zu}$ verbessern und dabei auch die Wirkungsweise einiger grundsätzlich denkbaren Ausgestaltungselemente, eben derjenigen, die für das 1976 erlassene AbwAG gewählt wurden, nach Möglichkeit zu durchleuchten.

Auch aus methodischer sicht gliedert sich die durchzuführende Wirkungskontrolle in zwei Abschnitte: der erste befaBt sich mit der Bildung und Operationalisierung von Hypothesen über die jeweiligen Ursache-Wirkungs-Zusammenhänge, der zweite mit der Prüfung dieser Hypothesen bzw. mit der methodischen Anlage der Erfolgskontrolle des AbwAG insgesamt.

1 "Gesamtwirkung" bezieht sich dabei nicht nur auf die Erreichung des Gesamtzieles, sondern auch auf die Erreichung der Teilziele des Abwá. 


\subsection{Konzeptualisierung der zu untersuchenden Wirkungszusammenhänge}

\subsubsection{Hypothesen über die "Gesamtwirkungen" des Abwasserabgabengesetzes}

Gemäß dem oben skizzierten ersten (inhaltlichen) schritt der Wirkungskontrolle sind die Hypothesen über die Gesamtwirkungen des AbwaG so zu formulieren, daB sie jeweils denjenigen Anteil der Wirkungen hervorheben, der dem AbwAG zuzurechnen ist.

Um komplizierte und unübersichtliche Hypothesen zu vermeiden, geht stellvertretend für die potentiellen Wirkungsträger die Auflagenregelung als wichtigste unabhängige Variable neben dem AbwaG dort, wo sie als Ursache möglich ist, in die Formulierung ein.

Hypothesen sind zunächst für all diejenigen Zielwirkungen zu formulieren, die auch in der zielerreichungskontrolle gemessen werden konnten. Die Hypothesen über die ökologischen Wirkungen des AbwAG stellen sich wie folgt dar :

1. Das AbwAG bewirkt eine Verringerung der schädlichkeit des Abwassers, die über die Einhaltung der Auflagen hinausgeht.

2. Das AbwAG bewirkt über die Einhaltung der Auflagen hinausgehend
a. den Bau von Kläranlagen
b. die Verbesserung der Abwasserreinigungstechnik im Sinne der Prozeßoptimierung
c. den Einsatz abwasserarmer/-loser Produktionsverfahren
d. die sparsamere Verwendung von Gütern, die nur abwasser- intensiv hergestellt werden können.

1 Die erste Hypothese bezieht sich auf den Anteil des AbwaG an der Erreichung der Gesamtziels Emissionsverminderung, die nachfolgenden auf die verbleibenden Teilziele des AbWAG . 
3. Das AbwaG hat die Anwendung der allgemein anerkannten Regeln der Technik (a.a.R.d.T.) beschleunigt.

4. Das AbwAG bewirkt eine bessere Einhaltung der Auflagen.

Die Hypothesen über die distributiven Wirkungen des AbwAG sollen lauten:

1. Durch das AbwAG werden die Kosten gerechter verteilt als dies der Fall wäre, wenn nur die Auflagen einzuhalten wären.

2. Trotz der Abwasserabgabe wird eine sprunghafte Nachfrage nach Reinigungsanlagen vermieden.

Weiterhin soll untersucht werden, inwieweit die statische Allokationseffizienz, die man einer Emissionsabgabe bei isoliertem Einsatz zuschreibt, bei der Abwasserabgabe aufgehoben ist:

Das Eingriffsniveau von AbwAG und $\$ 7$ a WHG ist weitgehend identisch, weshalb die Voraussetzungen für die ökonomische Effizienz der Abwasserabgabe nicht mehr gegeben sind.

Das Bestehen einer allokativen (Rest)effizienz setzt neben einem unterschiedlichen Eingriffsniveau von AbwAG und $\S 7$ a WHG das Handeln der Emittenten gemäß der abgabentheoretischen Wirkungshypothese voraus. Diese geht aufgrund des instrumentellen Verbundes von Auflagen- und Abgabensystem wie folgt in die Analyse ein:

Der Emittent reinigt bis zu dem Vermeidungsgrad, bei dem die Grenzkosten der Vermeidungsmaßnahmen gleich dem Abgabesatz sind, sofern die Auflagen nicht einen höheren Abbau der Schadeinheiten verlangen.

Die Verfasserin sieht die Notwendigkeit, den vorgestellten Hypothesenkatalog vor seiner Prüfung um diejenigen Hypothesen zu bereinigen, bei denen die Lösung des Kausalitätsproblems auf zu große Schwierigkeiten stößt. Dies dürfte bei den im Rahmen der ökologischen Wirkungen aufgestellten Hypothesen 
2.b., 2.d., und 4. der Fall sein. Bei der "Verbesserung der Abwasserreinigungstechnik im Sinne der Prozeßoptimierung" handelt es sich in der Regel um eine stete Entwicklung, so daß es äußerst problematisch sein dürfte, einen bestimmten Auslöser ausfindig zu machen. Bei der "sparsameren Verwendung abwasserintensiver Güter" wird die Zielerreichung selbst nur unbefriedigend ermittelt'1 , so daß eine anschließende Wirkungskontrolle auf unzureichendem Datenmaterial aufbauen würde. Zur Kausalitätsuntersuchung der "besseren Einhaltung der Auflagen" benötigte man ein Referenzverhalten; entweder das "historische" Verhalten der untersuchten Einleiter oder das Verhalten einer Kontrollgruppe. Die einhergehende Fragestellung dürfte jedoch zu brisant sein, um objektive Daten zu produzieren.

Für die drei genannten Ziele beschränkt sich die Erfolgskontrolle also auf die Messung der Zielerreichungen.

\subsubsection{Hypothesen über die Wirkungen einzelner Gesetzes- elemente}

Es existiert bereits ein facettenreicher Bestand an Hypothesen, die in der Vergangenheit zur Wirkungsweise einzelner Gesetzeselemente geäußert wurden; seien es die Kausalitäten, die der Gesetzgeber intendierte, die "Nichtwirkungshypothesen" der Kritiker oder die in empirischen Untersuchungen zum AbWAG festgestellten und prognostizierten wirkungszusammenhänge. Die nachfolgende Auswahl zu überprüfender Hypothesen soll von zwei uberlegungen geleitet sein.

Die erste Ubberlegung knüpft an eine methodische Restriktion an: "Kausalität läßt sich ... empirisch niemals zweifelsfrei nachweisen. ... Dessen ungeachtet unterscheiden sich hypothesenprüfende Untersuchungen graduell in der 'logischen stringenz der Beweisführung' bzw. in der Anzahl kausaler

1 Siehe S. 137 f. 
Erklärungsalternativen für die Ergebnisse. Ein Ergebnis gilt erst dann als Beleg für Kausalität, wenn sein Zustandekommen nur durch ein einziges Kausalmodell erklärbar ist." 1 Für die Hypothesenauswahl bedeutet diese Einschränkung, die unter dem stichwort "interne validität" diskutiert wird, folgendes: LäBt sich der festgestellte Wirkungsanteil des AbwAG bei einer Zielerreichung theoretisch mehreren seiner Gesetzeselemente als Auslöser der Wirkung zurechnen, oder besteht die Möglichkeit, daß einige Gesetzeselemente Wirkungen drosselten, können Kausalitäten nicht bestätigt werden. Fazit: Gerade unter dem Gesichtspunkt, daß bereits die Erfassung von "Gesamtwirkungen" des AbwAG sowohl methodisch als auch empirisch einigermaßen Probleme bereitet - auch hier liegen jeweils mehrere Kausalmodelle vor ${ }^{2}$ - sollte sich die anschließende Untersuchung auf solche Hypothesen konzentrieren, die Wirkungen unterstellen, welche nicht auf mehrere Ursachen zurückzuführen sind.

Betrachtet man unter diesem Gesichtspunkt die vom Gesetzgeber intendierten Wirkungszusammenhänge, die in Abb. 3 markiert wurden, so ist zu konstatieren, daß jeweils nur ein Gesetzeselement den noch relevanten Zielen zugeordnet ist. Das Vorliegen dieser stringenz muß allerdings überprüft werden.

Hier setzt die zweite Uberlegung an. Sie beschäftigt sich mit der weiteren Suche nach begründeten Ursache-Wirkungs-Zusammenhängen. Diese dürften sich am besten aus der "Abgabentheorie" ableiten lassen, die auch der Ausgangspunkt weiter Teile des oben erwähnten Hypothesenbestandes, gerade auch der "Nichtwirkungshypothesen" ist. Geht man also von der modelltheoretischen Wirkungshypothese einer Emissionsabgabe (Reinigung bis zum Schnittpunkt von Grenzkosten und Abgabesatz) aus, so lassen sich, den Ausführungen in Abschnitt A.5

1 Bortz, J.: Lehrbuch der empirischen Forschung: für Sozialwissenschaftler, Berlin, Heidelberg, New York, Tokyo 1984, S. 363 .

2 Die hier vorzufindende Vielfältigkeit von Kausalmodellen mus man allerdings akzeptieren, entschliest man sich überhaupt für eine Erfolgskontrolle des AbwAG. 
getreu, insbesondere die nachfolgenden Hypothesen über die Wirkungsweise der Ausgestaltungselemente des AbWAG formulieren:

1. Die Abgabenhalbierung beschleunigt die erforderlichen Maßnahmen zur Erfüllung der Auflagen.

2. Die Abgabenhalbierung unterstützt die Einhaltung der Auflagen.

3. Die Abgabenhalbierung wirkt sich anreizsenkend auf Maßnahmen aus, die über die Auflagen hinausgehen.

4. Die Abgabenhalbierung wirkt sich nachteilig auf die gerechtere Verteilung der Kostenlast aus.

5. Durch die Abgabestaffelung wird der Anreizeffekt der Abgabe in den Jahren 1980 bis 1985 um den jeweiligen Betrag reduziert.

6. Der späte Beginn der Abgabepflicht hat alle intendierten Wirkungen des AbwAG - ausgenommen die Vermeidung sprunghafter Nachfrage und die hier unberücksichtigte wirtschaftliche Tragbarkeit - zeitlich verzögert.

7. Die Härteregelung hat alle intendierten Wirkungen des AbWAG - mit Ausnahme der Vermeidung sprunghafter Nachfrage und der wirtschaftlichen Tragbarkeit - gedrosselt.

Die Frage, ob der Abgabesatz zu niedrig gewählt wurde, um den Immissionsstandard Gewässergüte II $\mathrm{zu}$ realisieren, läßt sich in dieser Evaluationsstudie, die auf der Ebene des AbwAG und nicht auf der der Gewässergütepolitik ansetzt, nicht beantworten, so daß sie auch nicht in eine Hypothese gefaßt wird.

Ergänzt man nun die intendierten Gesetzeswirkungen um die hier aufgezeichneten Wirkungshypothesen, so ergeben sich, wie aus der zusammengeschneiderten Gesamtschau in Abb. 4 ersichtlich, erhebliche Wirkungsüberschneidungen: sämtliche vom Gesetzgeber intendierten Ursache-Wirkungs-Zusammenhänge können durch andere Kausalmodelle ersetzt oder ergänzt werden. Sie scheiden deshalb für die Hypothesenprüfung dieser Arbeit aus. 
Ober die Einhaltung der Auflagen hinausgehende $(x)$

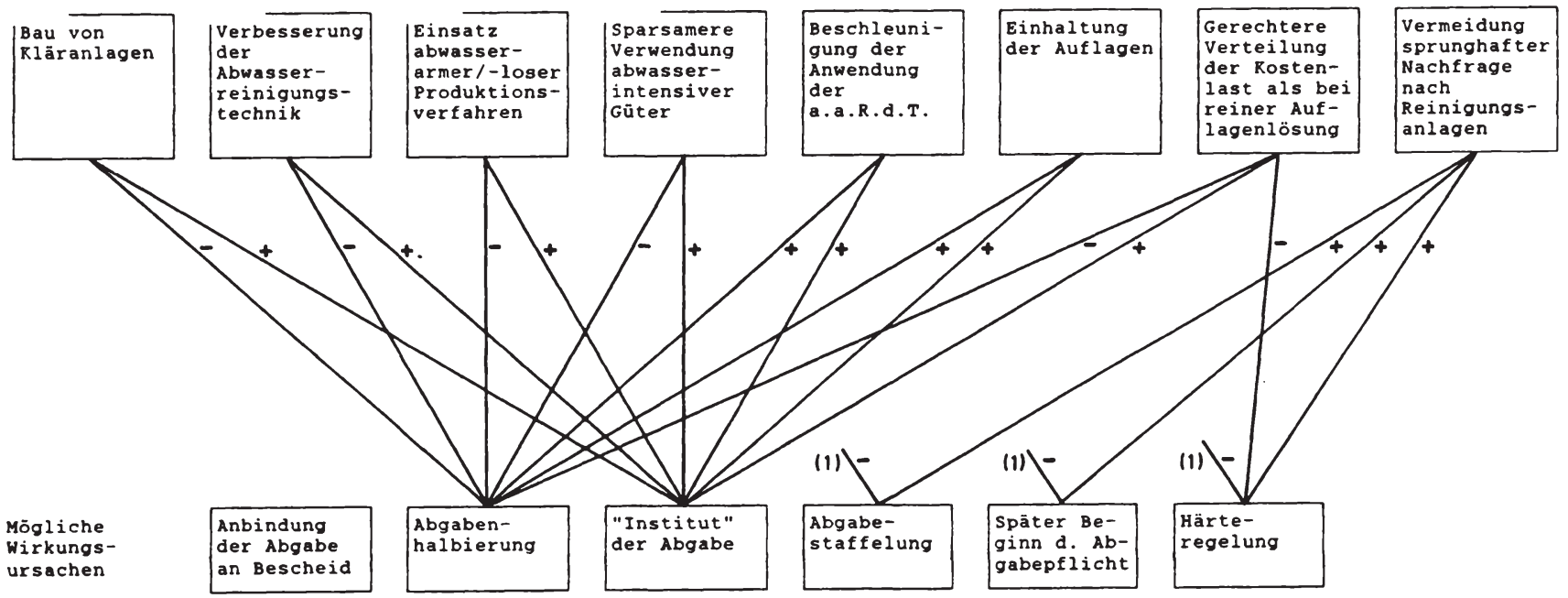

Abb. 4: Mögliche Kausalitäten zwischen den Wirkungen des Abwasserabgabengesetzes und seinen Gesetzeselementen 
Auch die Prüfung der oben entwickelten Hypothesen schließt sich zunächst aus, weil jeweils mehrere Erklärungsmodelle plausibel erscheinen. Gleichwohl kann die fünte Hypothese auf ihre Richtigkeit überprüft werden: Die Abgabestaffelung ist die einzige unabhängige Variable, die über die Zeit verschiedene Werte annimmt; aufgrund der Konstanz der anderen Gesetzeselemente können Emissionsveränderungen während der Abgabejahre dann auf sie zurückgeführt werden.

\subsubsection{Operationalisierung der Hypothesen}

Die zu überprüfenden Hypothesen müssen nun "meßfertig" gemacht werden. Dieser schritt umfaßt, soweit dies noch erforderlich ist, die Definition bzw. Operationalisierung der Variablen und die oberlegung, wie letztere in die empirische Untersuchung einzuführen sind.

Bereits im Rahmen der Bestimmung des relevanten Wirkungsfeldes wurden die Ziele des AbwAG als abhängige und das AbwAG und seine Ausgestaltungselemente als unabhängige Variablen identifiziert. Die Verfagserin schlägt die nachfolgenden operationalisierungen der einzelnen Hypothesen vor.

Hypothese: Das AbwAG bewirkt eine Verringerung der Schädlichkeit des Abwassers, die über die Einhaltung der Auflagen hinausgeht.

Die Zurechnung von Emissionsvermeidungen, die über die Auflagen hinaus vorgenommen werden, soll an die Zielerreichungskontrolle anknüpfen. Die dort ermittelte Schadfracht, die ein Einleiter pro Produkteinheit - im Untersuchungsjahr nach Einführung des AbwAG - emittiert hat' ${ }^{1}$ soll derjenigen gegenübergestellt werden, die laut den Auflagen des Einleiters hätte eingeleitet werden

1 Diese läßt einen Vergleich des Emissionsverhaltens zwischen Einleitern besser $z u$ als die Jahresfrachten, weil letztere vom Produktionsumfang geprägt sind. 
dürfen¹. Ergibt sich eine positive Differenz zwischen "erlaubter" und "eingeleiteter" Emission, kann zunächst festgestellt werden, daß eine Reinigung über die Auflagen hinaus stattfand. Sie ist jedoch nicht in voller Höhe als Wirkung der Abwasserabgabe zu qualifizieren. Denn zum einen sollte der Einleiter einen "Sicherheitsbereich" einhalten, beabsichtigt er, die Auflagen bei der behördlichen Kontrolle zu erfüllen². Dieser Sicherheitsbereich soll hier mit $20 \%$ angenommen werden. Eine Abwasserreinigung wird nach dieser Abgrenzung erst dann über die Auflagen hinaus vorgenommen, wenn höchstens 80 \% der erlaubten Schadfracht eingeleitet werden. Zum anderen sind einleiterindividuelle Gegebenheiten, so z.B. die Finanzierungshilfen und subventionen, als weitere Wirkungsursachen für eine über die Auflagen hinausgehende Reinigung $\mathrm{zu}$ berücksichtigen. Der Wirkungsanteil des AbwaG soll durch die Frage an die Einleiter, ob sie den derzeitigen Reinigungsstand auch verwirklicht hätten, wenn sie keine Abgabe entrichten bzw. Auflage erfüllen müßten, eingegrenzt werden.

Hypothese: Das AbwAG bewirkt den über die Einhaltung der Auflagen hinausgehenden Bau von Kläranlagen. Diese Hypothese soll in Anlehnung an frühere Untersuchungen ${ }^{3}$ durch die Befragung der Einleiter nach den Gründen für die Durchführung der Maßnahmen operationalisiert werden. Als mögliche Gründe kommen neben dem

1 Die Jahresschmutzwassermenge soll dabei wiederum als reale (eingeleitete) ausgewiesen werden, weil sich die bescheidliche Jahresschmutzwassermenge in der Regel auf die Maschinenkapazität, ausgedrückt in Menge Papier pro 24 stunden, bezieht und diese zumeist höher als die Produktion ist.

2 Eine Reinigung, die nicht den Sicherheitsbereich, aber die Auflagen einhält, kann auch eine Wirkung des AbwAG, nämlich die der Abgabenhalbierung darstellen. Oben soll jedoch der eigenständige Wirkungsbereich des AbwAG untersucht werden.

3 Vgl. Ewringmann, D., Hansmeyer, K.-H., Hoffmann, V., Kibat, K. $-D$. : Auswirkungen ..., a.a.0., s. $66 \mathrm{ff}$. 
AbwAG die Mindestanforderungen, darüber hinausgehende Auflagen, erhöhter Abwasseranfall durch Produktionssteigerungen sowie sonstige Gründe, unter denen der Einleiter dann weitere gewässergütewirtschaftliche oder exogene Auslöser nennen kann, in Betracht.

Hypothese: Das AbwAG bewirkt den über die Einhaltung der Auflagen hinausgehenden Einsatz abwasserarmer/ -loser Produktionsverfahren.

Die Einflußnahme des AbwAG auf die Ausgestaltung der Produktionsverfahren soll ebenfalls durch eine Hinterfragung der Beweggründe, die zu einer Veränderung der Produktionsweise führten, festgestellt werden. Im Gegensatz zur vorangehenden Hypothesenprüfung treten hier jedoch allgemeine Wirtschaftlichkeits-, Rationalisierungs- und Kostenüberlegungen als exogene Bedingungen in den Vordergrund. Da Produktionsumstellungen eher in kleineren Schritten als der Bau neuer oder Ausbau bestehender Reinigungsstufen erfolgen können, gewinnt die kontinuierliche Reduzierung der Abgabe über die Abgabenhalbierung hinaus an Bedeutung und wird dem Einleiter deshalb als mögliche Begründung vorgeschlagen.

Hypothese: Das AbwAG hat die Anwendung der allgemein anerkannten Regeln der Technik (a.a.R.d.T.) beschleunigt.

Die Beschleunigung der a.a.R.d.T. wird in der Zielerreichungskontrolle durch die zeitliche Vorverlegung baulicher Maßnahmen und die sachliche Veränderung von Planungen zum Kläranlagenbau, die bereits vor ErlaB der neuen Regelungen bestanden, erfaßt. Indem der Einleiter gefragt wird, ob seine Maßnahmen bzw. Planungen nicht nur durch die Abwasserabgabe, sondern auch oder nur durch die Mindestanforderungen oder darüber hinausgehende Auflagen beschleunigt bzw. verändert wurden, wird deutlich, ob rein abgabenspezifische Effekte vorliegen oder das AbwAG nur im Verbund mit dem $\$ 7$ a wHG gesehen werden kann. 
Hypothese: Durch die Abgabestaffelung wird der Anreizeffekt der Abgabe in den Jahren 1980 bis 1985 um den jeweiligen Betrag reduziert.

Zur Uberprüfung dieser Hypothese sollen die jährlichen Veränderungen der Schädlichkeit, für die die Einleiter die Abwasserabgabe zu entrichten hatten, beobachtet werden. Um Einflüsse des Produktionsumfangs auf die Anzahl der Schadeinheiten zu neutralisieren, erfolgt die Untersuchung auf der Basis von produktbezogenen Schadfrachten. Läßt sich eine Korrelation gemäß der aufgestellten Hypothese erkennen, spricht diese nicht nur für eine Wirkungsminderung des Gesetzes durch die Abgabestaffelung, sondern auch für den grundsätzlichen Einfluß der Abwasserabgabe auf das Emissionsverhalten.

Hypothese: Der Emittent reinigt bis zu dem Vermeidungsgrad, bei dem die Grenzkosten der Vermeidungsmaßnahmen gleich dem Abgabesatz sind, sofern die Auflagen nicht einen höheren Abbau der Schadeinheiten verlangen.

Die Grenzkosten der Vermeidungsmaßnahmen sind, da sich der Abgabesatz auf die Emission einer Schadeinheit bezieht, als Grenzkosten pro vermiedener Schadeinheit zu präzisieren. Die Grenzkosten, d.h. die Kosten für die letzte vom Einleiter vermiedene schadeinheit errechnen sich aus der Grenzkostenfunktion, die wiederum die erste Ableitung der Gesamtkostenfunktion der Vermeidungsmaßnahmen ist. Die Vermeidungsmaßnahmen untergliedern sich in innerbetriebliche und externe Maßnahmen. Unter ersteren sind Umstellungen des Produktionsverfahrens, unter letzteren ist die Restabwasserklärung $\mathrm{zu}$ verstehen. Zur Hypothesenprüfung sollen nach Möglichkeit jedoch nur die Kosten der biologischen Restabwasserklärung herangezogen werden. Denn über innerbetriebliche Vermeidungsmaßnahmen wie auch über mechanische bzw. mechanischchemische Reinigungsstufen verfügten die Einleiter in der Regel bereits vor Einführung des AbwAG. Die Anreizwirkung der Abwasserabgabe bezieht sich mithin in erster Linie 
auf den Bau von Biologien. Einer Berücksichtigung der innnerbetrieblichen Maßnahmen steht außerdem entgegen, daß das durch sie bewirkte Ausmaß der Emissionsvermeidung im allgemeinen nicht bekannt ist und zudem die einhergehenden Kosten durch die Rückgewinnung von Einsatzstoffen wenigstens teilweise kompensiert werden.

Zu den externen Vermeidungskosten zählen die Betriebskosten und der Kapitaldienst für die Reinigungsanlage sowie für die schlammbehandlung und -entsorgung. Damit die Abwasserreinigungskosten der Einleiter miteinander verglichen werden können, sind die häufig unterschiedlich berechneten Kapitaldienste zu homogenisieren ${ }^{1}$. Ist dagegen weniger die allgemeine Kostensituation als das Reinigungsverhalten der Einleiter das erkenntnisleitende Interesse, bleibt der Kapitaldienst so erhalten, wie von den Einleitern angegeben.

Expertenbefragungen ${ }^{2}$ ergaben, daß dem Einleiter die (einleiterindividuelle) Kostenfunktion der Abwasserreinigung, der man einen exponentiell steigenden Verlauf unterstellt, in der Regel nicht bekannt ist. stellt sich bei der Datenerhebung heraus, daß die Grenzkosten der Abwasserreinigung nicht ermittelt werden können, soll die Hypothesenprüfung fortgeführt werden, indem nach den durchschnittlichen Kosten pro vermiedener schadeinheit gefragt wird. Diese lassen sich - verhältnismäßig einfach - als Quotient aus Abwasserreinigungskosten und Anzahl vermiedener schadeinheiten während eines bestimmten Zeitraums ermitteln. In die Berechnung der vermiedenen Schadeinheiten gehen die eingeleiteten Jahresschmutzwassermengen sowie die Konzentrationswerte der Absetzbaren stoffe und des CSB ein, die sich als Differenz aus Einlauf- und Auslaufwerten der betrachteten Reinigungs-

1 Siehe dazu S. 141.

2 Befragt wurden Sachverständige für die Abwasserreinigung beim Verband Deutscher Papierfabriken sowie in papiererzeugenden Unternehmen. 
anlage (bzw. -stufe) ergeben. Da die Abwasserreinigungskosten in der Regel mit zunehmendem Reinigungsgrad exponentiell steigen, liegen die durchschnittlichen Kosten pro vermiedener Schadeinheit immer niedriger als die Kosten der letzten vom Einleiter vermiedenen Schadeinheit. Mithin erlauben die Durchschnittskosten folgende Interpretation:

Liegen sie unter dem (halbierten) Abgabesatz1, kann die aufgestellte Hypothese weder bestätigt noch widerlegt werden. Entsprechen sie dem Abgabesatz oder liegen sie höher als dieser, reinigen die Einleiter über den Schnittpunkt von Grenzkosten und Abgabesatz hinaus. In diesem Fall wäre die Hypothese dann widerlegt, wenn die Auflagen Wirkungsgrade erfordern, die wesentlich niedriger als die realisierten sind. Um dies feststellen zu können, sollen die Wirkungsgrade der betrachteten Reinigungsanlagen errechnet werden, die erforderlich sind, wenn die Anzahl der emittierten Schadeinheiten höchstens $80 \%$ der erlaubten Schadeinheiten - berechnet aus den uberwachungswerten und der eingeleiteten Jahresschmutzwassermenge - betragen soll. Damit wird also wiederum ein zur Einhaltung der Auflagen erforderlicher "sicherheitsbereich" definiert.

Hypothese: Das Eingriffsniveau von AbwAG und $\S 7$ a WHG ist weitgehend identisch, weshalb die Voraussetzungen für die ökonomische Effizienz der Abwasserabgabe nicht mehr gegeben sind.

Um beurteilen zu können, ob die statische Allokationseffizienz der Abwasserabgabe durch den Verbund von Abgaben- und Auflageninstrumentarium beeinträchtigt wird, muß überprüft werden, inwieweit das Eingriffsniveau von AbwAG und $\$ 7$ a WHG tatsächlich identisch ist. Dazu sind bei den Einleitern die Wirkungsgrade der Reinigungsanlagen, die der Anreizwirkung der Abwasserabgabe

Der Abgabesatz halbiert sich für die Einleiter, wenn sie die Auflagen einhalten. 
entsprechen, denjenigen Wirkungsgraden gegenüberzustellen, die sich unter Berücksichtigung des oben genannten "Sicherheitsbereichs" aus den ordnungsrechtlichen Uberwachungswerten der Bescheide errechnen, sofern diese bereits den neuen wasserrechtlichen Regelungen angepaßten wurden. Die Voraussetzungen für die ökonomische Effizienz der Abwasserabgabe sind dann gegeben, wenn bei allen Einleitern der "abgaberechtliche" größer als der "ordnungsrechtliche Wirkungsgrad" ist.

Können erstere, also die auf den Abgabesatz bezogenen wirkungsgrade nicht festgestellt werden, sind ersatzweise die realisierten Wirkungsgrade heranzuziehen. Die homogenisierten durchschnittlichen Kosten, die für diese ermittelt werden, geben Hinweise, ob der Anreizpunkt des AbWAG bei einem höheren oder bei einem niedrigeren als dem realisierten Wirkungsgrad liegt. Damit kann auch die Entfernung zu den Wirkungsgraden, die zur Einhaltung der Uberwachungswerte erforderlich sind, eingegrenzt werden.

Hypothese: Durch das AbwAG werden die Kosten gerechter verteilt als dies der Fall wäre, wenn nur die Auflagen einzuhalten wären.

Um die Gültigkeit dieser Hypothese feststellen zu können, sind den in der zielerreichungskontrolle ermittelten, auf den Umsatz bezogenen Kosten der Abwasservermeidung zuzüglich der Abwasserabgabe diejenigen Kosten gegenüberzustellen, die ohne das AbwaG entstanden wären. Dafür müssen die Gesamtkosten um die Abgabezahlung und die Vermeidungskosten, die auf wirkungen des AbwAG zurückgehen, bereinigt werden. Da Expertenbefragungen im Rahmen der Operationalisierung der Hypothesen ergaben, daß der Einleiter letztere in der Regel nicht genau beziffern kann, schlägt die Verfasserin vor, einen anderen Weg zu beschreiten: nämlich nur diejenigen konkurrierenden Einleiter kostenmäßig miteinander zu vergleichen, die gerade die Auflagen erfüllen und bei denen deshalb als abgabebedingte Kosten nur die Abgabezahlungen anfallen. Zu diesen zählen - bei gleicher 
Argumentationslinie wie oben - diejenigen Einleiter, bei denen die im Jahresdurchschnitt eingeleiteten Schadfrachten wenigstens $80 \%$ der Schadeinheiten betragen, die sie emittieren durften.

Hypothese: Trotz der Abwasserabgabe wird eine sprunghafte Nachfrage nach Reinigungsanlagen vermieden.

Zur Ubberprüfung dieser Hypothese sollen bei jedem Einleiter die Grenzkosten der externen VermeidungsmaBnahmen dem Jahr der letzten Inbetriebnahme einer neuen Reinigungsanlage gegenübergestellt werden. Damit soll überprüft werden, ob, wie vom AbwAG intendiert, zunächst die Einleiter mit relativ niedrigen und dann die Einleiter mit relativ hohen spezifischen Vermeidungskosten Reinigungsmaßnahmen ergriffen haben.

Lassen sich die Grenzkosten nicht ermitteln, sind ersatzweise die durchschnittlichen Kosten pro vermiedener Schadeinheit anzuführen.

Mit der vorgenommenen Operationalisierung der Wirkungshypothesen ist die Entwicklung eines Modells der Erfolgskontrolle auf theoretischer Ebene abgeschlossen. Es stellt sich nun die Frage, wie das ausgearbeitete Konzept methodisch in eine empirische Untersuchung umgesetzt werden kann. Uberlegungen dazu werden im folgenden Abschnitt angestellt.

\subsubsection{Methodenwahl}

Wie bereits in Abschnitt B.1.5 vermerkt, kann ein "Königsweg" für die methodische Durchführung einer Evaluationsstudie nicht aufgezeichnet werden. Dies gilt nicht nur für die wirkungsforschung im allgemeinen, sondern auch für die Erfolgskontrolle des AbwAG im besonderen. Darum seien hier, gleichsam als Bindeglied zwischen dem entwickelten Konzept einerseits und seiner praktischen Durchführung andererseits, 
einige grundsätzliche Anmerkungen zur methodischen Ausgestaltung von wirkungsuntersuchungen zum AbwAG gemacht.

Von den in Tab. 2 auf S. 91 aufgeführten sozialwissenschaftlichen Methoden muß das experimentelle Verfahren, das Einflußgrößen, die neben dem Untersuchungsgegengtand bestehen, am besten zu neutralisieren vermag, für die Erfolgskontrolle des AbWAG von vornherein ausscheiden: Da das AbwAG bereits existiert, kann die beim Experiment gebotene zufällige Zuweisung von Untersuchungseinheiten zu Versuchsund Kontrollgruppe (Randomisierung) nicht vorgenommen werden.

Die anderen in der Tabelle aufgeführten Methoden kommen dagegen grundsätzlich als Untersuchungspläne für die Erfolgskontrolle des AbwAG in Betracht. Einschränkungen für quantitative und quasi-experimentelle Versuchsdesigns ergeben sich allerdings dadurch, das der derzeitige Bestand an empirisch untermauertem Wissen über die Wirkungsweise der Abwasserabgabe verhältnismäßig gering ist. Die Bedeutung dieses wissensdefizits tritt besonders deutlich hervor, wenn die rigorose Einhaltung sozialwissenschaftlicher Methodenstandards (Prüfverfahren, Erklärungslogik etc.) gefordert wird.

Der Vorschlag Hellstern/Wollmanns, Wirkungsforschung mit Hilfe fallstudienorientierter Untersuchungspläne zu betreiben und diese darüber hinaus mit anderen Methoden zu kombinieren', greift deshalb auch für die Durchführung der oben entwickelten Erfolgskontrolle. Gerade weil die Vielschichtigkeit des abgaberechtlichen wirkungsfeldes bislang weitgehend unerforscht ist, empfiehlt es sich, auch eher qualitativ orientierte Verfahren zu Hilfe zu nehmen, um zunächst einmal die Wirkungsverläufe und ihre Bestimmungsgründe freilegen zu können.

1 Siehe dazu Abschnitt B.1.5 sowie die dort angegebene Literatur. 
TEIL D: SEKTORALE ANALYSE DER AUSWIRKUNGEN DES ABWASSERABGABENGESETZES

\section{Hinweise zum Verfahren}

\subsection{Anlage der Untersuchung}

Im Teil C dieser Arbeit wurde eine Erfolgskontrolle zur Erfassung der Auswirkungen des AbwAG entwickelt. Auf der Grundlage dieses Konzepts erfolgte eine empirische Untersuchnung bei papiererzeugenden Unternehmen'. Bevor die Auswertung der erhobenen Daten erfolgt, sei zunächst das methodische Vorgehen der Untersuchung geschildert.

Ausgehend von der bereits bekannten Tatsache, daB Sollwerte, anhand derer die Zielerreichungen des AbwAG gemessen werden könnten, nicht vorliegen, wurde die Erfolgskontrolle des AbwAG als Ist-Ist-Vergleich (before-and-after) angelegt. Es wurden also Veränderungen über die Zeit festgestellt, um diese anschließend, soweit möglich, den jeweiligen Ursachen zuzuordnen.

Der before-and-after-Vergleich konnte nur begrenzt auf Sekundärerhebungen aufbauen. Das statistische Bundesamt erfaßt neben Art und Menge der Wassernutzung lediglich die Abwasserbehandlung und unterscheidet nicht zwischen Zellstoff- und Papierindustrie ${ }^{2}$, weshalb die Daten nicht in die Untersuchung der vorliegenden Arbeit einbezogen werden konnten. Der Verband Deutscher Papierfabriken führte 1974 und 1985 bei seinen Mitgliedsfirmen Umfragen zur Abwasserreinigung durch, die jeweils als Vollerhebungen angelegt

1 Siehe dazu die Ausführungen auf S. 5 f.

2 Vgl. Statistisches Bundesamt Wiesbaden (Hrsg.): Wasserversorgung und Abwasserbeseitigung im Bergbau und Verarbeitenden Gewerbe und bei Wärmekraftwerken für die öffentliche Versorgung, Fachserie 19, Reihe 2.2, stuttgart, Mainz. 
waren. Die veröffentlichten Ergebnisse deckten jedoch die oben vorgestellte Zielerreichungskontrolle nur teilweise ab und behandelten Aspekte der Vollzugs-, Bedingungs- und Wirkungskontrolle gar nicht. Im Rahmen der vorliegenden Arbeit mußte deshalb eine Primärerhebung vorgenommen werden.

Damit die Wirkungsabläufe und die vorhandenen Handlungsspielräume der Untersuchungseinheiten besser erkannt werden konnten, erfolgte die Datenerhebung in der Form von (standardisierten) Interviews, die charakteristisch für Fallstudien sind. Wegen des Zeitaufwandes, der mit dieser Vorgehensweise verbunden ist, war eine Vollerhebung nicht möglich. Um die Ergebnisse der VDP-Umfragen einbeziehen und damit die Primärdaten objektivieren zu können, wurden als Untersuchungszeitpunkte des before-and-after-Vergleichs die Jahre 1974 und 1985 gewählt.

Nachdem die Interviews abgeschlossen waren und sich Wirkungszusammenhänge und Kontextbedingungen des Abwasserreinigungsverhaltens abzeichneten, wurde mit dem Ziel, den EinfluB des AbwAG besser kontrollieren zu können, der oben geschilderte before-and-after-Vergleich durch einen ebenfalls als Längsschnitt angelegten with-and-without-Vergleich ergänzt. Der Untersuchungsplan erhielt damit einen quasi-experimentellen Aufbau.

Der with-and-without-Vergleich erforderte eine "Kontrollgruppe", die sich möglichst nur dadurch von der "Versuchsgruppe" unterschied, das die in ihr zusammengefasten Untersuchungseinheiten keine Abwasserabgabe zu entrichten hatten. Daraus folgte zunächst, das die "Kontrolleinheiten" nicht auf nationaler Ebene rekrutiert werden konnten, weil sämtliche deutschen Direkteinleiter Adressaten des AbWAG sind. Damit die weitgehende Neutralisierung nicht abgabebedingter Wirkungen gewährleistet war, sollten sich die Kontrolleinheiten in ihren sonstigen Merkmalen möglichst wenig von den Versuchseinheiten unterscheiden. Während des Untersuchungszeitraums sollte also auch bei der Kontrollgruppe ein Auflagengesetz eingeführt worden sein, das wie der \$ 7 a WHG 
Grenzwerte für die Einleitung von Abwässern in Gewässer festlegt. Im Hinblick auf die als wichtig erachteten exogenen Einflußgrößen sollten die Kontrolleinheiten eine ähnliche Produktionsentwicklung wie die Versuchseinheiten aufweisen, über den gleichen Wissensstand in der Abwasserreinigungstechnik verfügen sowie das gleiche genuine Interesse loder Desinteresse) an der Anwendung abwasserarmer/-10ser Produktionsverfahren haben. Letzteres implizierte, das sich auch die Kontrollgruppe aus papiererzeugenden Unternehmen zusammensetzte.

Führt man die suche nach einer derart abgegrenzten Kontrollgruppe im westlichen mitteleuropäischen Raum durch, so reduziert sich die Anzahl in Betracht kommenden ausländischen Kontrollgruppen bereits dadurch, daß einige andere Länder ebenfalls eine wie auch immer geartete Abwasserabgabe erheben. Zu diesen zählen Frankreich, die Niederlande und Italien'. Hingegen weisen beispielsweise Osterreich und die Schweiz gute Bedingungen auf, eine Erfolgskontrolle zur Erfassung der Auswirkungen des AbwAG zu stellen. Denn in beiden Ländern bestehen keine Abwasserabgaben, wohl aber wurden während des Untersuchungszeitraums Grenzwerte für die Einleitung von Abwässern in Gewässer festgelegt. Was die exogenen Einflußgrößen betrifft, so weisen sowohl die österreichische als auch die schweizerische Papierindustrie ähnliche Produktionszunahmen wie die deutschen Papierfabriken auf. Da auf der produktionstechnischen wie auch auf der abwassertechnischen seite ein intensiver Gedankenaustausch zu beobachten ist2, kann von elnem identischen know-how bzgl. der Kreislaufeinengung und der Abwasserreinigung ausgegangen werden. Insofern kamen beide Länder für den with-and-withoutVergleich grundsätzlich in Betracht. Um jedoch das Vorliegen

1 Ausführungen zu den dort eingeführten Abwasserabgaben finden sich bei Ewringmann, D., Schafhausen, F.: Abgaben -.., a.a.o.

2 Beispielhaft sel hier die jährliche Dreiländertagung "Verfahrenstechnik und Umwelt" der österreichischen, schweizerischen und deutschen Zellstoff- und Papierindustrie genannt. 
möglichst einheitlicher wasserrechtlicher Rahmenbedingungen in der Kontrollgruppe zu gewährleisten, sollte diese nur aus Werken einer Nationalität zusammengesetzt werden. Da Vertreter der schweizerischen Papierindustrie bereits $\mathbf{z u}$ einem früheren Zeitpunkt das Interesse an und die Bereitschaft zu Wirkungsforschung im Bereich der Abwasserreinigung gezeigt hatten, wurde die Kontrolluntersuchung in der Schweiz vorgenommen ${ }^{1}$.

Auf der Grundlage der zuvor gewonnenen Interviewergebnisse konnte diese Untersuchung als schriftliche Befragung durchgeführt werden. Sie konzentrierte sich auf Daten zum Emissionsverhalten, zum Bau von Abwasserreinigungsanlagen, zum Einsatz abwasserarmer und abwasserloser Produktionsverfahren und zur Kostenbelastung, die aus der Abwasserreinigung resultierte. Des weiteren wurden die wasserrechtlichen Rahmenbedingungen der schweizerischen Untersuchungseinheiten, finanzielle Hilfen sowie die Einflußnahme derjenigen exogenen Bedingungen, die auch bei der Versuchsgruppe kontrolliert wurden, festgestellt.

Im folgenden sei auf den Umfang und die Zusammensetzung von Versuchs- und Kontrollgruppe eingegangen, nicht zuletzt um die Repräsentativität der erhobenen Daten einschätzen zu können.

1 Die schweizerische Wassergesetzgebung wird in Abschnitt D.2.2. skizziert. 


\subsection{Anzahl und struktur der untersuchten Papierfabriken}

Die Grundgesamtheiten waren alle deutschen bzw. schweizerischen Papierfabriken, die während des Untersuchungszeitraums weder über eine integrierte Zellstoffproduktion verfügten noch Indirekteinleiter waren. Die erste Einschränkung wurde vorgenommen, weil bei Papierfabriken mit integrierter Zellstoffproduktion eine grundsätzlich andere Abwasserproblematik vorliegt, die den Vergleich mit anderen Papierfabriken unmöglich macht. Die zweite Einschränkung resultiert aus dem Adressatenkreis des AbwAG: Es sind die Direkteinleiter, wobei in der vorliegenden Untersuchung auch diejenigen Werke berücksichtigt wurden, die von der Direkteinleitung auf die abwasserfreie produktionsweise umstellten, denn der Einsatz abwasserloser Produktionsverfahren ist eines der Ziele des AbwAG.

Während des Untersuchungszeitraums waren, marginale Veränderungen unberücksichtigt, von den 205 deutschen Papierfabriken 80 Werke an kommunale oder Verbandkläranlagen angeschlossen ${ }^{1}$. Berücksichtigt man weiterhin, daß von den verbleibenden 125 Werken insgesamt 7 Papierfabriken über eine integrierte Zellstoffproduktion verfügten, umfaßte die Grundgesamtheit zur Versuchsgruppe 118 Papierfabriken. Die Anzahl der zu untersuchenden deutschen Werke wurde auf 33 festgelegt. Es sei hier angemerkt, daß ein Unternehmen die Datenerhebung bei einem seiner Werke ablehnte und ein anderes seine Zusage wegen Uberlastungen der Ansprechpartner nachträglich zurückzog. Insgesamt wurden also 31 deutsche Papierfabriken und damit 26 der Grundgesamtheit untersucht.

Die Versuchsgruppe war so zusammenzusetzen, daß sie sich als "ein verkleinertes Abbild der Grundgesamtheit hinsichtlich der Heterogenität der Elemente und hinsichtlich der Repräsentativität der für die Hypothesenprüfung relevanten Variab-

1 Vgl. Jacobs, G.: Wasser ..., a.a.O., s. 16 . 
len"1 zeigte. Diese Forderung implizierte zum einen die Zufallsauswahl, zum anderen die Erfassung der für die

Thematik relevanten Schattierungen der Grundgesamtheit in der Versuchsgruppe (stichprobe). Bereits die 19. Allgemeine Verwaltungsvorschrift (Zellstoff, Papier, Pappe) dokumentiert das Vorliegen einer heterogenen Beschaffenheit der Papierabwässer, weil sie die Mindestanforderungen nach verschiedenen Papiersorten auffächert². In der Tat ist sowohl die Zusammensetzung des Abwassers als auch der spezifische Abwasseranfall primär eine Funktion der eingesetzten Faserund Hilfsstoffe und damit der produzierten Papiersorten. Letztere wurden deshalb als schichtungsmerkmal herangezogen. Da eine Aufgliederung sowohl der Werke als auch der Gesamtproduktion gemäß den Mindestanforderungen nicht vorlag, wurde auf die vom VDP präferierte Unterscheidung nach den "Hauptsorten" zurückgegriffen. Da die Abwasserbeschaffenheit innerhalb dieser Sorten verhältnismäBig homogen ist, konnte die geschichtete stichprobe inggesamt verhältnismäBig klein sein und trotzdem die Grundgesamtheit repräsentieren ${ }^{3}$. Die pro schicht erfaßte Produktion sollte sich proportional zum mengenmäBigen Anteil der jeweiligen Hauptsorte an der Gesamtproduktion (und damit das "erfaBte" Abwasser proportional zum "Gesamtabwasser") der deutschen Papierindustrie verhalten. Unter Berücksichtigung der Tatsache, daß gewisse Betriebsgrößen charakteristisch für die Produktion bestimmter Hauptsorten sind4, wurde die Anzahl der Untersuchungsein-

1 Friedrichs, J.: Methoden empirischer Sozialforschung, 9. Aufl., Opladen 1981, s. 125.

2 Vgl. Neunzehnte Allgemeine Verwaltungsvorschrift über Mindestanforderungen an das Einleiten von Abwasser in Gewässer (Zellstofferzeugung, Herstellung von Papier und Pappe) - 19. AbwasserVwV vom 15. Januar 1982, GMBl. S. 59, aufgeführt im Anhang der Arbeit.

3 Vgl. dazu Atteslander, P.: Methoden der empirischen Sozialforschung, Berlin 1969, S. 220.

11985 wurden z.B. in 18 \% der Werke graphische Papiere hergestellt, die inggesamt 47 der gesamten produktion ausmachten. Vgl. Verband Deutscher Papierfabriken (Hrsg.): Papier'86... a.a.0., S. 21 . 
heiten innerhalb der verschiedenen Schichten gemäB der Darstellung in Tab. 7 festgelegt und untersucht. Wie die Auswertung später ergab, wies die gesamte stichprobe Verhältnisse auf, die ein recht genaues verkleinertes Abbild der deutschen Gesamtproduktion nach Hauptsorten war (siehe Abb. 5 und 6). Die Verteilung der Werke nach den für sie geltenden Mindestanforderungen dokumentiert Tab. 8 .

\begin{tabular}{|l|c|}
\hline Hauptsorte & Anzahl der Werke \\
\hline Graphische Papiere & 9 \\
Papier für Verpackungszwecke & 7 \\
Karton und Pappe für Verpackungszwecke & 1 \\
Hygienepapiere & $4(6)^{\star}$ \\
$\begin{array}{l}\text { Papier und Pappe für technische und } \\
\text { spezielle Verwendungszwecke }\end{array}$ & Summe: 31 \\
\hline
\end{tabular}

* 2 Absagen

Tab. 7: Anzah1 der untersuchten deutschen Werke pro Hauptsorte 


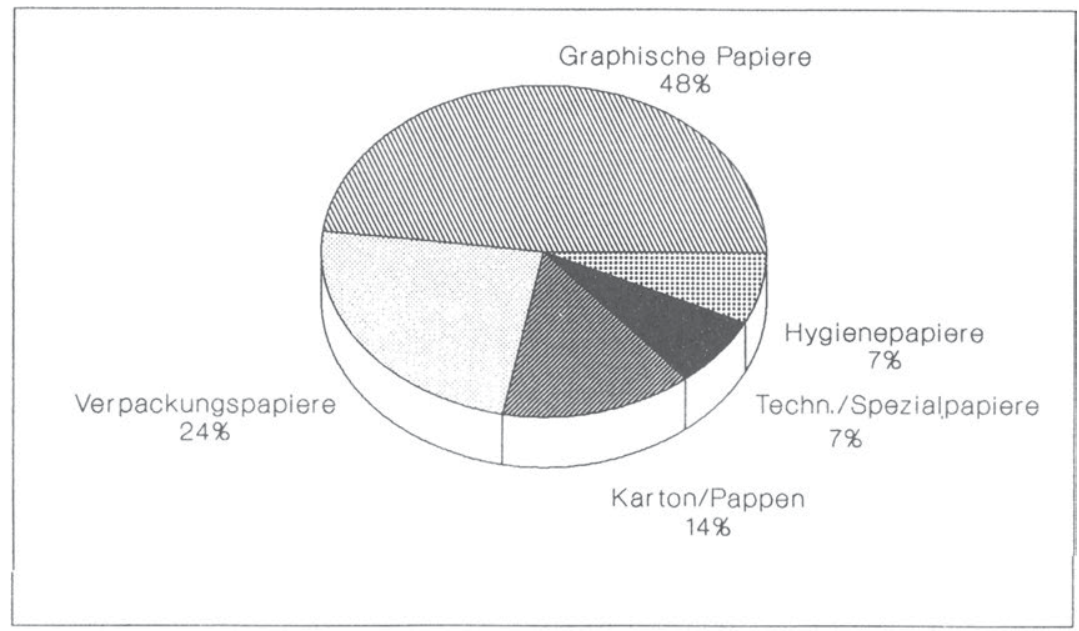

Abb. 5: Papierproduktion in der Bundesrepublik nach Hauptsorten (1985)

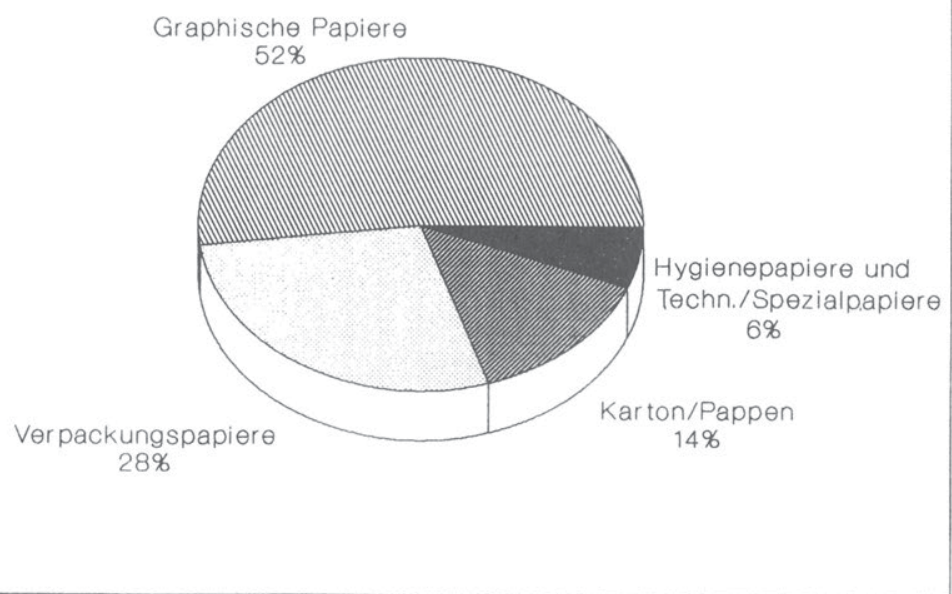

Abb. 6: Papierproduktion in der deutschen stichprobe nach Hauptsorten (1985) 


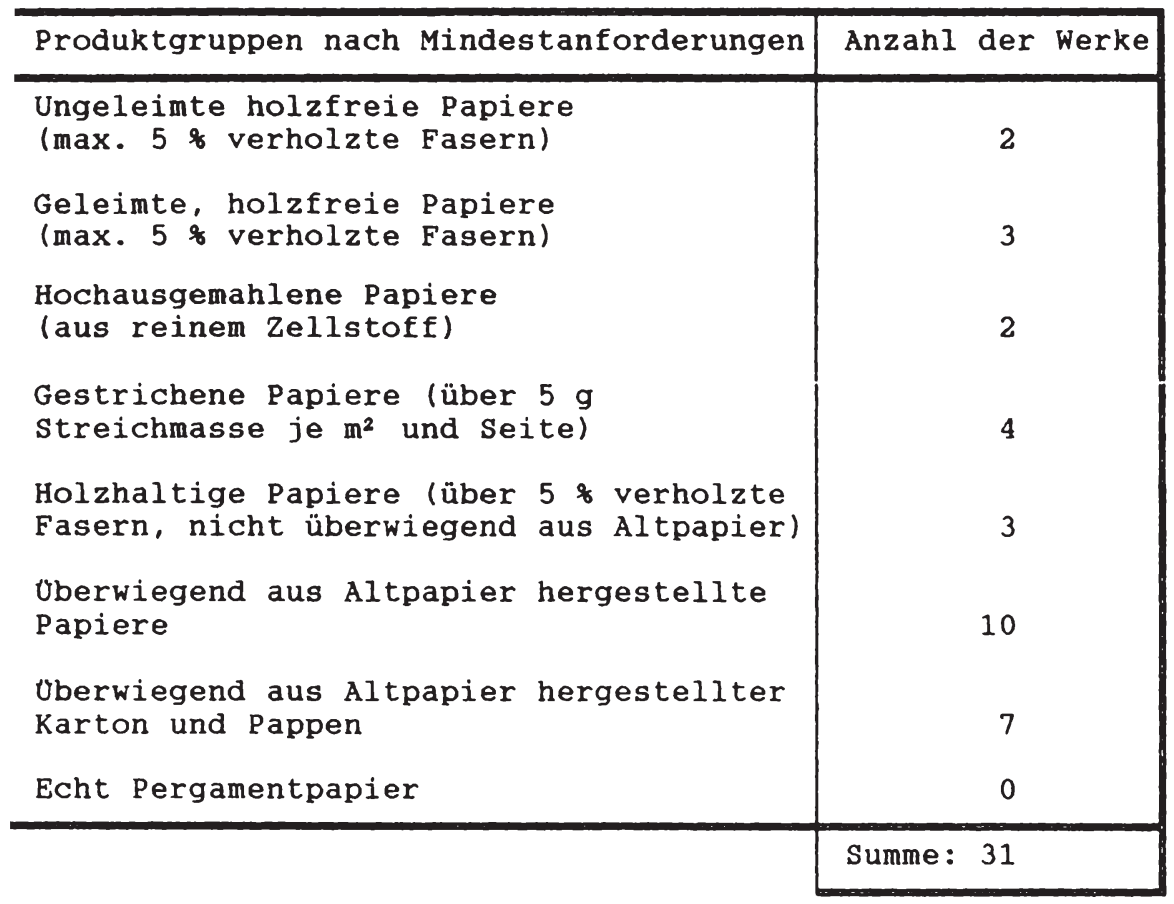

'ab. 8: Anzahl der untersuchten deutschen Werke je Produktgruppe nach den Mindestanforderungen ${ }^{1}$

iben weil für einige Hauptsorten spezifische Betriebsgrößen sharakteristisch sind, gewährleistete die vorgenommene schichtung auch eine streuung der Betriebsgrößen (siehe (bb. 7).

Die Produktgruppe "Uberwiegend aus Altpapier hergestellter Karton und Pappen" ist in der 19. Allgemeinen Verwaltungsvorschrift den "Uberwiegend aus Altpapier hergestellten Papieren" zugeordnet. Sie wird jedoch wegen ihres hohen Anteils sowohl an der gesamten bundesdeutschen Papierproduktion als auch an der stichprobe gesondert erfast und untersucht. 


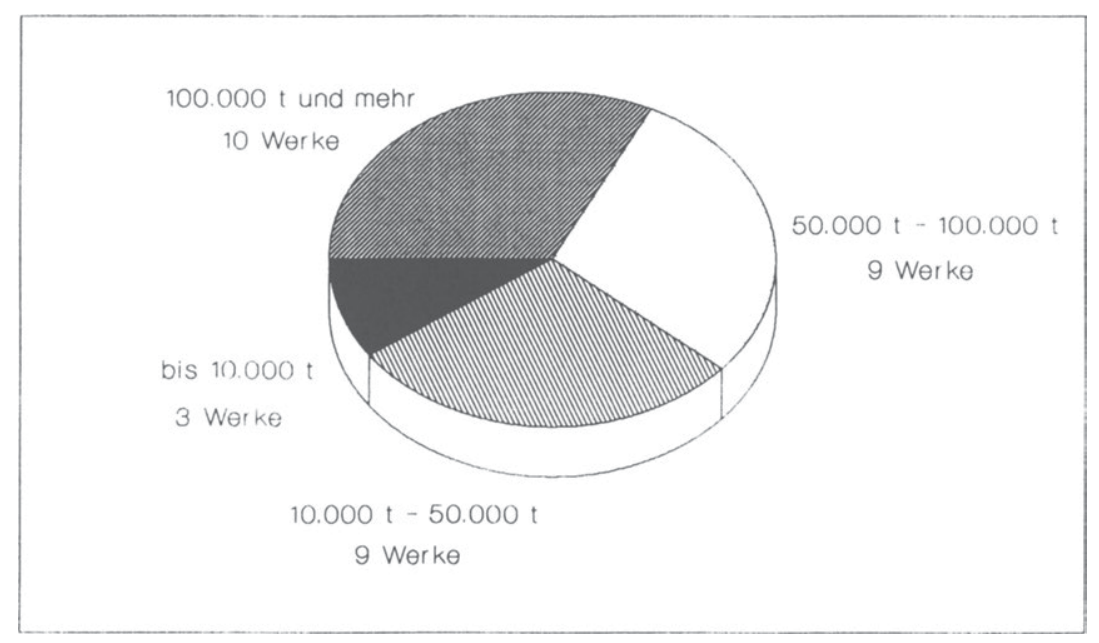

Abb. 7: Anzahl der untersuchten deutschen Werke nach Größenklassen (1985)

Die deutschen Untersuchungseinheiten produzierten im Jahr 1985 insgesamt 3.008.332 t Papier. Die deutsche Gesamtproduktion betrug im gleichen Jahr 9.168.092 $t$ Papier ${ }^{1}$. Da von 72,1 \% dieser Produktion das Abwasser direkt eingeleitet $(68,6$ \%) oder das Produktionswasser in geschlossenen Kreisläufen geführt wurde $(3,5 \%)^{2}$, umfaßt die Erhebung der vorliegenden Arbeit 45,5 \% des von der Grundgesamtheit produzierten Papiers bzw. des damit entstandenen Abwassers.

Die schweizerische Papierindustrie bestand während des Untersuchungszeitraums aus 30 Werken, von denen neun Papierfabriken nicht Indirekteinleiter waren. Eines dieser neun Werke verfügte über eine integrierte Zellstoffproduktion und mußte somit für die Untersuchung ausscheiden. Bei der von vornherein sehr viel kleineren Grundgesamtheit und der nun schriftlich durchgeführten Befragung wurde die Kontrolluntersuchung als Vollerhebung angestrebt. Da jedoch eine der

1 Vgl. Verband Deutscher Papierfabriken (Hrsg.): Papier '86. Ein Leistungsbericht der deutschen Zellstoff- und Papierindustrie, Bonn 1986, S. 21

2 Vgl. ders. (Hrsg.): Papier-Report, a.a.0., s. 4. 
eiden Papierfabriken, die mit geschlossenem Kreislauf roduzierten, den Fragebogen nicht beantwortete, reduzierte ich die Anzahl der Kontrolleinheiten auf sieben Werke. Die ufgliederung der Kontrollgruppe nach den Hauptsorten zeigt ab. 9, die Verteilung nach den Betriebsgrößen veranschauicht Tab. 10 .

\begin{tabular}{l|c|}
\hline Hauptsorte & Anzahl der Werke \\
\hline Graphische Papiere & 3 \\
Papier für Verpackungszwecke & $1(2)^{\star}$ \\
Karton und Pappe für Verpackungszwecke & 0 \\
Hygienepapiere & 1 \\
$\begin{array}{l}\text { Papier und Pappe für technische und } \\
\text { spezielle Verwendungszwecke }\end{array}$ & 2 \\
\hline
\end{tabular}

eine Absage

'ab. 9: Anzahl der schweizerischen Werke pro Hauptsorte

\begin{tabular}{|l|c|}
\hline GröBenklasse & Anzahl der Werke \\
\hline bis $10.000 t$ Papier & 4 \\
$10.000 t-50.000 t$ Papier & 1 \\
$50.000 t-100.000 t$ Papier & 2 \\
$100.000 t$ Papier und mehr & Summe: 7 \\
\hline
\end{tabular}

ab. 10: Anzahl der untersuchten schweizerischen Werke nach Größenklassen

Jusammenfassend kann festgestellt werden, daß die Versuchsrruppe ein repräsentatives Abbild der deutschen Grundgesamtleit war und die Kontrolluntersuchung beinahe als VollerheJung durchgeführt wurde. Es sei jedoch bereits jetzt darauf lingewiesen, daß sich die Anzahl der Untersuchungseinheiten sei einigen Wirkungsanalysen erheblich reduzierte. 


\subsection{Datenerhebung}

Bel den deutschen Papierfabriken erfolgte die Datenerhebung in zwei- bis vierstündigen standardisierten Interviews, die in der Regel in den untersuchten Werken stattfanden. Gesprächspartner waren zumeist Ingenieure, die für den Produktionsprozeß insgesamt oder für die Abwasserbehandlung speziell verantwortlich zeichneten. Für die Beantwortung der betriebswirtschaftlichen Fragen wurden Mitarbeiter des kaufmännischen Bereichs hinzugezogen.

Der Fragebogen, der den Interviews zugrundelag, war vor seinem Einsatz mit verschiedenen Experten (Gesetzesevaluation, Abwasserreinigung, Papiertechnologie)

diskutiert worden. Er gliederte sich in sechs Abschnitte: Der erste Teil erfaßte Daten zur allgemeinen Kennzeichnung der Untersuchungseinheit in der stichprobe, der zweite konzentrierte sich auf die Abwasserbehandlung (nachgeschaltete oder externe Maßnahmen), und der dritte Teil befaßte sich mit innerbetrieblichen Maßnahmen der Abwasserreduzierung. Der vierte Abschnitt ermittelte Veränderungen im Produktbereich, der funnfte die ordnungs- und abgaberechtliche situation des Einleiters, und die abschließenden Fragen versuchten wirtschaftliche Auswirkungen der neuen Regelungen festzustellen. Die Fragen wurden also nicht streng gemäß dem konzeptionellen Aufbau der Erfolgskontrolle nach Zielerreichung, Gesetzesvollzug, exogenen Einflüssen und Wirkungszurechnung zusammengestellt, sondern nach thematischen Schwerpunkten arrangiert.

In den ersten Interviews wurden vereinzelt Mängel in der Formulierung der Fragen offenkundig, die daraufhin behoben wurden. Informationsverluste bei den ersten Untersuchungen entstanden jedoch aufgrund der Möglichkeit des "Nachfragens" nicht.

Bei den schweizerischen Papierfabriken wurde die Untersuchung als schriftliche Befragung durchgeführt, nachdem aus dent "deutschen " ein "schweizerischer" Fragebogen unter Berücksichtigung der veränderten Fragestellung - insbesondere keine 
Daten zur Abgabenerhebung und Abgabenwirkung - entwickelt und bei einem der in der Schweiz untersuchten Werke in einem Interview erprobt worden war.

Beide Fragebögen sind im Anhang der Arbeit wiedergegeben.

\subsection{Auswertung der Daten}

Die Informationen, die im Rahmen der empirischen Untersuchung gewonnen werden konnten, sollen in den nächsten Abschnitten vorgestellt werden. Wenngleich 26 \% der deutschen Grundgesamtheit - und auf diesen Anteil entfielen immerhin 45,5 \% der Gesamtproduktion - in der stichprobe vertreten waren und die schweizerische Grundgesamtheit beinahe als Vollerhebung untersucht wurde, ist die vorliegende Arbeit im statistischen Sinne nicht repräsentativ, so daß sie nicht als Basis für Rückschlüsse auf die Grundgesamtheit sämtlicher Abwassereinleiter der Bundesrepublik bzw. der Schweiz dienen kann. Wegen der verhältnismäBig geringen Anzahl an Untersuchungseinheiten wird auf statistische Prūfverfahren verzichtet, so daß die Auswertung der Ergebnisse auf deskriptiver Ebene erfolgt.

Zunächst werden bei der Versuchs- und der Kontrollgruppe die ordnungs- und bei ersterer zudem die abgaberechtlichen Rahmenbedingungen vorgestellt. Ein Vergleich der Einleitungsbedingungen der deutschen und schweizerischen Papierfabriken zeigt, inwieweit aus wasserrechtlicher sicht die Voraussetzungen für einen with-and-without-Vergleich gegeben sind.

Im AnschluB werden die wirkungen des AbwAG, gegliedert nach ökologischer und ökonomischer Ausrichtung, kontrolliert. Die Erfolgskontrolle soll dabei für jedes einzelne der aufgestellten Ziele separat erfolgen.

In einer Gesamtschau der festgestellten Wirkungen wird das AbWAG nach den Kriterien der ökologischen und ökonomischen Effizienz und unter Berücksichtigung der Wirkungszusam- 
menhänge zwischen diesen beiden kritisch beurteilt. Anhand der festgestellten wirkungsketten wird abschließend erörtert, inwieweit die Abwasserabgabe die ihr zugedachte steuerungsfunktion erfüllt und welche allgemeinen schlußfolgerungen sich - bei aller Vorsicht - für den Einsatz und die Ausgestaltung von Emissionsabgaben ziehen lassen. Zuletzt wird die Novellierung des AbwAG kritisch gewürdigt. 
2. Bestandsaufnahme der wasser- und abgaberechtlichen Situation der untersuchten Papierfabriken

\subsection{Genehmigungspraxis, weitere Bestimmungsgrößen der Abgabenhöhe und behördliche Uberwachung bei der Versuchsgruppe}

Die Bescheidwerte, weitere Bestimmungsgrößen der Abgabenhöhe und nicht zuletzt die behördliche Kontrolle der Abwassereinleitungen können von Einleiter zu Einleiter variieren. Um die Daten, die für die Zielerreichungs- und die Wirkungskontrolle des AbwAG erhoben werden, richtig einordnen und auswerten zu können, bedarf es einer Bestandsaufnahme dieser einleiterindividuellen Gegebenheiten. Die Informationen, die im Rahmen dieser Vollzugskontrolle gewonnen werden, gehen dann in die Erfolgskontrolle ein, ohne zwangsläufig in der Diskussion der Ergebnisse in Erscheinung zu treten. Wenn in diesem Abschnitt ein Uberblick über sonst nicht offenkundig werdende Fakten gegeben wird, so soll der damit gewährte Einblick in die Vollzugspraxis verschiedene Informationsbedarfe decken.

Ein Informationsbedarf liegt in der Annahme begründet, daß das AbwaG nur dann seine wirksamkeit voll entfalten kann, wenn es umfassend implementiert wurde. Deshalb sind bei einer abschlieBenden Bewertung des AbwAG die Ergebnisse der Zielerreichungs - und der Wirkungskontrolle in dem MaBe zu relativieren, in dem sich bei der Vollzugskontrolle Implementationsmängel herausstellen und konstatiert werden kann, daß durch sie Wirkungspotentiale des AbwAG verloren gehen. Daneben erscheint die Frage interessant, in welchem Ausmaß die Länder den durch die Rahmengesetzgebung eröffneten Regelungsspielraum nutzen und wie häufig die Abgabenverminderung vor Inbetriebnahme einer neuen Abwasserbehandlungsmaßnahme Anwendung findet.

Der zweite grundlegende Informationsbedarf bezieht sich auf den intendierten Vergleich des Emissionsverhaltens von Versuchs- und Kontrollgruppe. Erst eine Gegenüberstellung der 
Einleitungsbedingungen beider Gruppen macht ersichtlich, ob sich diese wahrhaftig nur in der Entrichtung einer Abwasserabgabe oder auch in wasserrechtlichen Rahmenbedingungen unterscheiden.

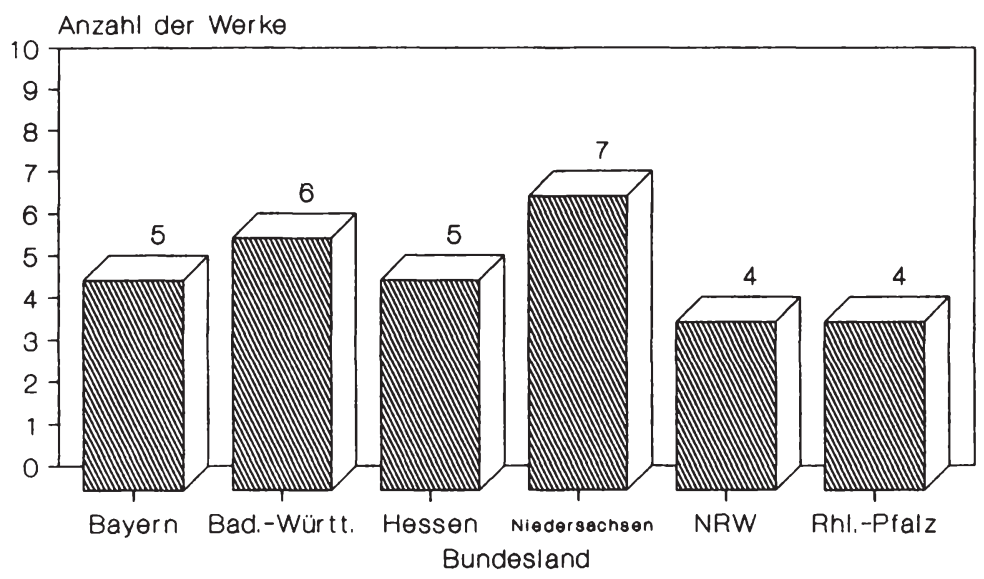

Abb. 8: Verteilung der untersuchten Werke auf die Bundesländer

Zunächst zu den Rahmenbedingungen, die den deutschen Einleitern gesetzt sind. Abb. 8 zeigt einführend, wie sich die untersuchten Papierfabriken auf die einzelnen Bundesländer, denen ja der Vollzug der Rahmengesetze obliegt, verteilen. Sämtliche Werke befinden sich in Flächenstaaten, wobei das saarland und Schleswig-Holstein in der stichprobe nicht vertreten sind.

Da die Vollzugspraxis bei denjenigen Untersuchungseinheiten von unmittelbarem Interesse ist, die regelmäBig Abwasser emittieren, konzentrieren sich die weiteren Ausführungen auf die 23 Werke, die 1985 mit einem offenem Wasserkreislauf produzierten $^{1}$. Die gewonnenen Daten werden gemäB dem Aufbau

1 Wie die Untersuchung ergab, liegen vereinzelt auch be1 Werken mit geschlossenen Kreisläufen Beschelde vor. Sie legen z.B. fest, welche Abwassermenge im Falle einer störung maximal emittiert werden darf. 
des Informationskatalogs, der für die Vollzugskontrolle entwickelt wurde, aufbereitet ${ }^{1}$.

1. Informationen zur Genehmigungspraxis

a. Da die Abwasserabgabe 1985 bei 15 der 23 Werke nach einem Bescheid ermittelt wurde, kann gefolgert werden, daß bei diesen sämtliche Grenzwerte, die die Vollzugsbehörde für die Abgabenerhebung als notwendig erachtete, bescheidlich festgelegt waren.

b. Eine Bescheidumstellung lag bis 1985 bei eben diesen Werken vor. Bei 35 \& der Untersuchungseinheiten, die mit einer Ausnahme - durchweg in Baden-Württemberg und Rheinland-Pfalz angesiedelt sind, war also auch nach fünf Abgabejahren eine Anpassung des Bescheids an die neuen Regelungen noch nicht erfolgt ${ }^{2}$. Nichtsdestoweniger reinigten auch diese durchweg nach den a.a.R.d.T., und Gegenüberstellungen von Einleitern einer Produktgruppe mit und ohne Bescheidumstellung ließen signifikante Unterschiede in den emittierten Produktfrachten nicht erkennen ${ }^{3}$. Umgekehrt beinhaltet eine Bescheidumstellung nicht zwangsläufig das

1 Siehe Tab. 6.

2 Der Abgabenerhebung lagen in diesen Fällen, wie es das AbwAG vorsleht ( $\$ 6 \mathrm{Abs} .1$ und $\$ 11$ Abs. 3 AbwAG), behördliche Messungen oder auch Messungen des Einleiters zugrunde. Hervorzuheben ist, das diese Art der Veranlagung unter Umständen mehr dem Verursacherprinzip entspricht als die Abgabenerhebung gemäß den Bescheidwerten.

3 So ergab z.B. eine der Untersuchungen, in der durchschnittlich emittierte CSB-Frachten von Papierfabriken mit ähnlichem Sortenprogramm gegenübergestellt wurden, für das Jahr 1985 folgendes Bild:

CsB-Fracht (kg/t Papier) bei Einleitern

\begin{tabular}{l|l} 
ohne Bescheidumstellung & mit Bescheidumstellung
\end{tabular}

1. Einleiter: $1,30 \mathrm{~kg} / \mathrm{t}$ 1. Einleiter: $1,25 \mathrm{~kg} / \mathrm{t}$

2. Einleiter: $1,41 \mathrm{~kg} / \mathrm{t} \quad 2$. Einleiter: $1,56 \mathrm{~kg} / \mathrm{t}$

3. Einleiter: $1,93 \mathrm{~kg} / \mathrm{t}$ 
grundsätzliche Vorliegen von Grenzwerten: Ein Einleiter, der über einen neuen Bescheid verfügte, konnte keine Rege1- und Höchst-, ein anderer keine uberwachungswerte angeben.

Wie Abb. 9 illustriert, wurden die meisten der im Untersuchungszeitraum erfolgten Bescheidumstellungen 1982 und 1983, also im Jahr der Herausgabe der Mindestanforderungen für Abwässer der Papiererzeugung bzw. ein Jahr später durchgeführt.

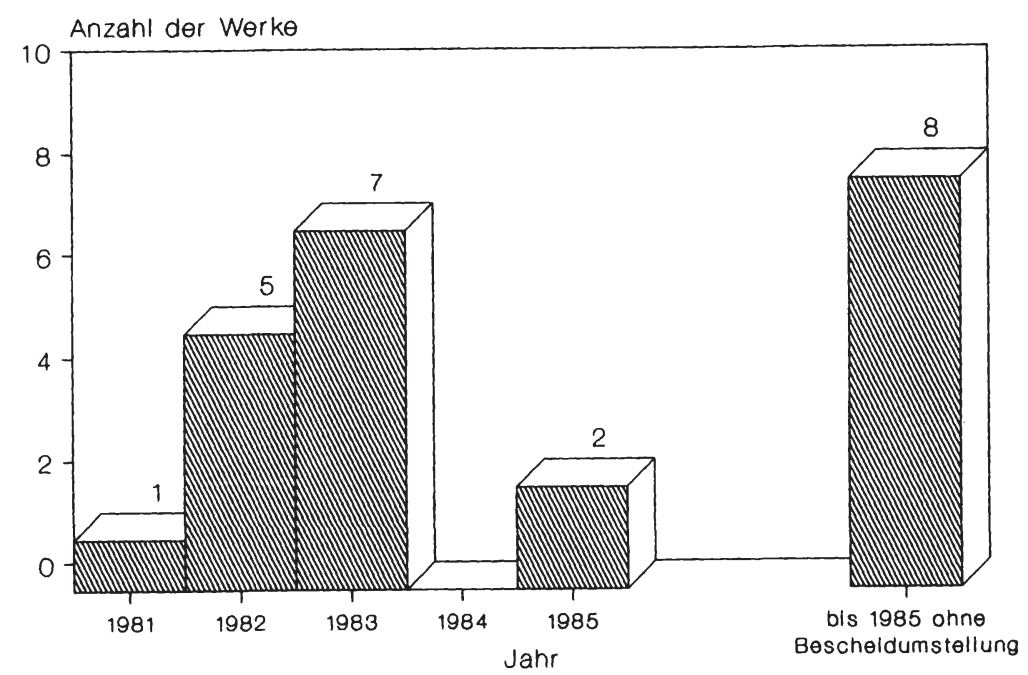

Abb. 9: Jahre der Bescheidumstellung bei den deutschen Werken

c. Aus dem Katalog der Schadparameter wurden die Grenz werte derjenigen Parameter abgefragt, für die auch Mindestanforderungen zu den Abwässern der Papiererzeugung vorliegen ${ }^{1}$. Es sind dies die Absetzbaren Stoffe $e^{2}$ der CSB, der BSBs und - ohne Bestehen einer Mindestanforderung - die Fischgiftigkeit. Wie erwartet,

1 Vgl. Neunzehnte Allgemeine Verwaltungsvorschrift ... a.a.o. aufgeführt im Anhang der Arbeit.

2 Wenn nicht die Absetzbaren stoffe, sondern alternativ die Feststoffe in die Abgabeberechnung eingingen, wurden deren Grenzwerte erfaßt. 
spielt letztere als schadparameter in der Papierindustrie eine untergeordnete Rolle ${ }^{1}$ : Sie erscheint nur bei vier der Untersuchungseinheiten als uberwachungswert und bei dreien von diesen als Abgabeparameter. Die Interviews bestätigten weiterhin, daß eine Abgabe auf Quecksilber und Cadmium bis 1985 bei keinem der Einleiter erhoben wurde.

Es fällt auf, daß - von einem Bescheid abgesehen - die abgaberechtlichen Regel- und Höchstwerte des CSB immer in Konzentrationen (mg/l) angegeben sind, während die Neunzehnte Allgemeine Verwaltungsvorschrift die Mindestanforderungen für Papierabwässer in Frachten (kg/t Produkt) festsetzt. Diese Umformung geht auf die Ausführungsgesetze der Länder zurück, die vorschreiben, daß die Grenzwerte in Konzentrationen festgelegt werden, um sie als solche - entsprechend den behördlichen Uberwachungsmöglichkeiten und der althergebrachten Praxis - auch kontrollieren zu können². Die Jahresfrachten der einzelnen Schadparameter lassen sich dann aus der bescheidlichen Jahresschmutzwassermenge und dem jeweiligen Konzentrationswert ermitteln. Die Auswirkungen, die diese Umformung der Mindestanforderungen auf das Emissionsverhalten haben kann, werden in Abschnitt D.3.3 hervortreten.

\section{Weitere Bestimmungsgrößen der Abgabenhöhe}

a. Bei der Bestimmung der Schädlichkeit des Abwassers wurde für die Vorbelastung des Gewässers bei drei

$1 \quad 1979$ durchgeführte Untersuchungen ergaben, daß die Fischgiftigkeit sowie Quecksilber-, Cadmium und deren Verbindungen bei der Papierherstellung im allgemeinen keine Relevanz besitzen. Vgl. Börner, F., Dalpke, H.-L., Geller, A., Göttsching, L.: Ermittlung von Abwasserparametern zur Festlegung von Mindestanforderungen gem. \$ 7a WHG bei Sulfitzellstoffabriken und bei Papier- und Pappenfabriken, Darmstadt 1979, S. 39.

2 Vgl. Berendes, K., winters, K.-P.: Das neue Abwasserabgabengesetz .... a.a.0., s. 65 . 
Einleitern ein Vorwegabzug gewährt, der über dem regulären nach Maßgabe von \$ 3 AbwaG lag.

b. Ebenfalls bei drei Werken gingen Teilstrommessungen in die Abgabenberechnung ein.

c. Eine Abgabenverminderung vor Inbetriebnahme einer neuen Abwasserbehandlungsanlage lag bei neun Einleitern vor. Die Zeiträume, in denen Ausnahmen von der Abgabepflicht gewährt wurden, verteilten sich recht gleichmäßig über die Jahre 1981 bis 1984 .

\section{Uberwachung der Abwassereinleitungen}

a. Die Kontrolle der Abwassereinleitungen durch die zuständige Behörde oder durch eine von dieser beauftragte Organisation wies, gemessen als durchschnittliche Anzahl der Kontrollen pro Jahr, als Modalwert 4 und 5 Probenahmen auf. Abb. 10 illustriert die ermittelten Häufigkeiten.

Zur Beurteilung der ermittelten Häufigkeiten muB angemerkt werden, daß \& 4 Abs. 4 AbwAG zwar ausdrücklich die behördliche Uberwachung der Bescheidwerte vorschreibt, jedoch keine Aussagen zur Häufigkeit der Messungen macht ${ }^{1}$. Auch in den Verwaltungsvorschriften zum 57 a WHG ist nur geregelt, daß bei der Bildung des arithmetischen Mittels zur Kontrolle der uberwachungswerte Untersuchungen, die länger als drei Jahre

1 Von den abgaberelevanten Regel-, Höchstwerten und der Jahresschmutzwassermenge werden laut Berendes/Winters nur die Höchstwerte kontrolliert (vgl. Berendes, $K_{.}$, Winters, K. -P.: Das neue Abwasserabgabengesetz ..., a.a.O., S. 66). Bei den Regelwerten und der Jahresschmutzwassermenge können Jedoch die Festsetzungsgrundlagen überprüft und gegebenenfalls im Bescheid geändert werden, was dann eine Korrektur der Werte einschliest, so daB man auch bei diesen von einer oberwachung sprechen kann. 


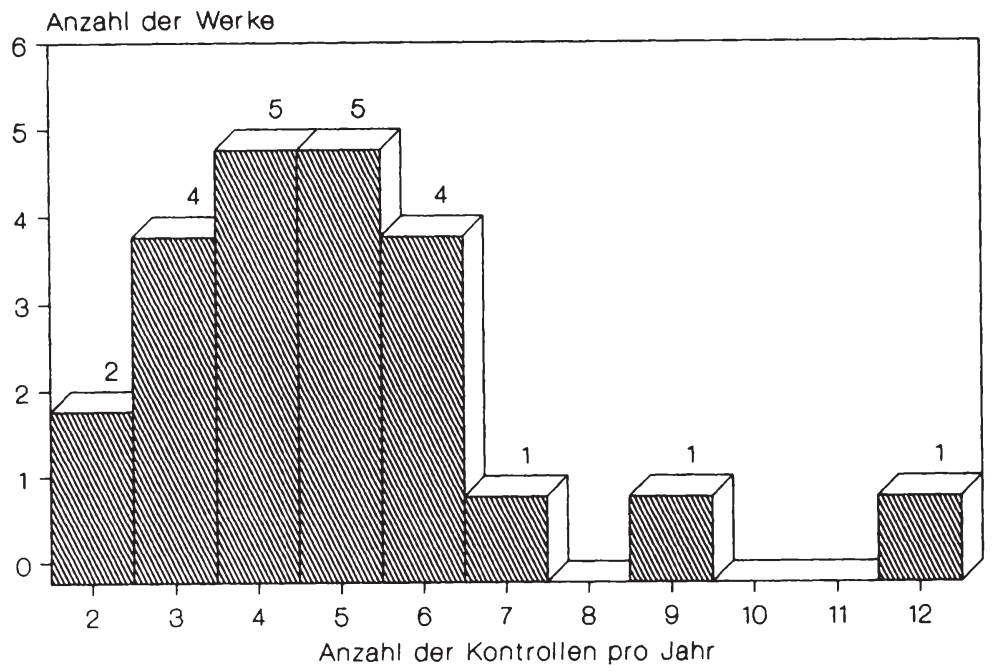

Abb. 10: Durchschnittliche Anzahl der behördlichen Kontrollen pro Jahr bei den deutschen Werken

zurückliegen, unberücksichtigt bleiben'. Zur Festlegung von Erklärungswerten führt "Das neue Wasserrecht für die betriebliche praxis" aus, daß bei der Frage, "wie viele Meßergebnisse vorliegen müssen, um von einer behördlichen Uberwachung zu sprechen, ... auf die im Zeitpunkt des Erlasses des AbwAG übliche oder zum mindesten gebotene Uberwachungshäufigkeit abgestellt werden (kann). Diese dürfte aber allenfalls bei vier Messungen im Jahr gelegen haben. ... Ausnahmsweise können allerdings auch weniger Werte ausreichen, wenn sie aufgrund der Art und des Umfangs des Schmutzwasseranfalls eine genügende Aussagekraft enthalten." 2

1 Vgl. Die Allgemeinen Verwaltungsvorschriften über Mindestanforderungen an das Einleiten von Abwasser in Gewässer nach \& 7 a WHG.

2 Zitzelsberger, W. (Bearb.): Das neue Wasserrecht für die betriebliche Praxis: Recht und Technik der Abwasserbeseitigung, der Wasserversorgung, der Lagerung und des Transports wassergefährdender stoffe; mit dem neuen Abwasserabgabengesetz, den neuen Mindestanforderungen für Abwassereinleitungen und sämtlichen praxisrelevanten Vorschriften, Losebl.-Ausg., Kissing, Zürich, Paris, 
b. Von den 23 Untersuchungseinheiten mußten drei Einleiter den zuständigen Kontrollbehörden weder Betriebstagebücher über die Eigenmessungen vorlegen noch Berichte über diese abgeben ${ }^{1}$. Auch hier ist zu erwähnen, daß allgemeine Vorschriften zur Uberwachung der Eigenkontrolle nicht vorliegen.

Fazit: Im Rahmen der Genehmigungspraxis lassen sich erhebliche Verzögerungen in der Bescheidumstellung konstatieren, die entsprechende Auswirkungen auf den Vollzug des AbwaG haben. So stellen Berendes/Winters fest, daß die Ermittlung der Abgabe nach einer Erklärung ein gewisses Vollzugsdefizit indiziert, "das in der Anlaufphase der Abgabenerhebung noch tragbar erscheint, dann aber allmählich abgebaut werden sollte."2 Die Frage, ob mit diesem Vollzugsdefizit Wirkungsverluste des AbwAG bei den Untersuchungseinheiten einhergehen, kann insofern verneint werden, als sich die Produktfrachten von Einleitern ohne und mit Bescheidumstellung nicht signifikant voneinander unterschieden. Auch kann eine Korrelation zwischen dem Zeitpunkt der Inbetriebnahme einer neuen Abwasserbehandlungsanlage und dem Zeitpunkt der Bescheidumstellung nicht beobachtet werden. Dies sind jedoch nur zwei von vielen Facetten, die Wirkungsverluste des AbwAG signalisieren können. So ist z.B. denkbar, daß die zukünftigen Bescheidwerte von Einleitern, die noch mit einer Erklärung veranlagt werden, niedriger als die bis dahin eingeleiteten Frachten sind, deshalb zu einer besseren Abwassereinigung anhalten und zu entsprechenden Gesetzeswirkungen verhelfen. Inwieweit der lückenhafte

Mailand, Amsterdam, Wien, London, Rechtsstand Januar 1981 - 1988, Bd. 3, Teil 07/3.1.2.2.3, s. 5.

1 Sämtliche Untersuchungseinheiten führten die Eigenkontrolle selbst durch, drei von ihnen waren dazu verpflichtet, das Abwasser außerdem von staatlich anerkannten stellen kontrollieren zu lassen.

2 Berendes, $K_{.}$, Winters, $K_{.}-P_{.}$: Das neue Abwasserabgabengesetz..., a.a.0., s. 84 . 
Vollzug zu Wirkungseinbußen des AbwAG geführt hat, kann also abschließend hier nicht beurteilt werden.

Bezüglich weiterer Bemessungsgrundlagen der Abgabenerhebung läßt sich resümmieren, daß von der Möglichkeit der Teilstrommessung sowie des überregulären Vorwegabzugs für Vorbelastungen der Gewässer bis 1985 nur wenig Gebrauch gemacht wurde. Die Abgabenverminderung vor Inbetriebnahme einer Abwasserbehandlungsanlage wurde dagegen von 40 \& der Einleiter in Anspruch genommen.

Die Uberwachung der Abwassereinleitungen zeigt insgesamt recht große streuungen auf. So reicht die durchschntttliche Anzahl der jährlichen Kontrollen der Abwasserwerte von 2 bis 12 Probenahmen und die behördliche Kontrolle der Eigenmessungen von "gar nicht" bis zur Uberprüfung der Abwassertageswerte.

Um wesentliche Unterschiede zwischen den hier aufgezeigten Einleitungsbedingungen der Versuchsgruppe und denen der Kontrollgruppe feststellen zu können, befaßt sich der nächste Abschnitt mit der wasserrechtlichen situation der schweizerischen Untersuchungseinheiten.

2.2 Genehmigungspraxis und behördliche Uberwachung bei der Kontrollgruppe

In der Schweiz wurde - ebenfalls vor dem Hintergrund der zunehmenden Gewässerverschmutzung - 1971 das "Bundesgesetz ủber den Schutz der Gewässer gegen Verunreinigung (Gewässerschutzgesetz)" 1 von der Bundesversammlung der Schweizerischen Eidgenossenschaft beschlossen. Gemäß den Bestimmungen dieses

1 Bundesgesetz über den Schutz der Gewässer gegen Verunreinigung (Gewässerschutzgesetz) vom 8. Oktober 1971, 814.20. 
Gesetzes" gab der Schweizerische Bundesrat 1975 die "Verordnung über Abwassereinleitungen"2 heraus. In dieser legte er für 52 Parameter (allgemeine Parameter, anorganische und organische stoffel Qualitätsziele für Fließgewässer und Flußstaue und für die meisten dieser Parameter auch Anforderungen an Einleitungen in ein Gewässer und an Einleitungen in eine öffentliche Kanalisation fest ${ }^{3}$.

Wie in der Bundesrepublik Deutschland die Bundesländer für den Vollzug der Rahmengesetze zuständig sind, obliegt in der Schweiz den Kantonen weitgehend die Ausführung des Gewässerschutzgesetzes mit seiner Verordnung über Abwassereinleitungen. Deshalb soll einleitend aufgezeigt werden, wo die Untersuchungseinheiten ansässig sind (siehe Tab. 11).

\begin{tabular}{|l|c|}
\hline Kanton & Anzahl der Werke \\
\hline Aargau & $1^{\star}$ \\
Bern & 2 \\
Graubünden & 1 \\
Solothurn & 1 \\
Tessin & 1 \\
Zürich & 1 \\
\hline
\end{tabular}

* geschlossener Kreislauf

Tab. 11: Verteilung der schweizerischen Werke auf die Kantone

Die nun folgenden Ausführungen sind ebenfalls, soweit es sich nicht um abgaberelevante Daten handelt, gemäß dem in Abschnitt C.1.3.4 vorgestellten Informationskatalog geglie-

1 Vgl. Art. 22 Abs. 1 Buchstabe b und Art. 23 Abs. 1 Buchstabe a des Gewässerschutzgesetzes.

2 Verordnung über Abwassereinleitungen vom 8. Dezember 1975 , 814.225.21.

3 Vgl. ebenda, s. 7 ff. 
dert. Da in der Schweiz eine Abwasserabgabe nicht erhoben wird, entfallen diesbezügliche Angaben.

\section{Genehmigungspraxis}

Die Genehmigungspraxis ergibt bei den schweizerischen Untersuchungseinheiten ein sehr viel homogeneres Bild als in der deutschen Stichprobe. Zwar wurden, wie Tab. 12 demonstriert, die Grenzwerte der Schadparameter ebenfalls

\begin{tabular}{|c|c|}
\hline Jahr & Anzahl der Werke \\
\hline 1975 & 2 \\
1978 & 1 \\
1979 & 1 \\
1984 & 1 \\
1985 & 1 \\
\hline
\end{tabular}

Tab. 12: Jahre der Festlegung der Grenzwerte bei den schweizerischen Werken

zu recht unterschiedlichen Zeitpunkten bei den Einleitern festgelegt. Die Parameterwerte, festgelegt in der Verordnung über Abwassereinleitungen, waren jedoch für sämtliche Einleiter ohne Rücksicht auf die Beschaffenheit der hergestellten Produkte identisch. Für die Absetzbaren Stoffe war der Wert $0,3 \mathrm{ml} / 1$ - die deutschen Mindestanforderungen an Papierabwässer begrenzen diese ebenfalls einheitlich, und zwar auf $0,5 \mathrm{ml} / 1$ - bzw. für die alternativ festgelegten Schwebstoffe, einem in der Bundesrepublik unüblichen Schadparameter, belief sich der Grenzwert auf $20 \mathrm{mg} / 1$. Weiterhin lag bei allen Einleitern ein - im Gegensatz zu den deutschen Mindestanforderungen -einheitlicher Grenzwert für den BSBy vor, und zwar in Höhe von $20 \mathrm{mg}$ $\mathrm{O}_{2} / 1$. Bei keinem der Einleiter fand sich dagegen ein

1 Als Schwebstoffe werden die gesamten ungelösten stoffe bezeichnet, die (von einem Liter Abwasser) mit einem Membranfilter von $0,45 \mathrm{\mu m}$ abfiltriert werden. Vgl. Verordnung über Abwasgereinleitungen, S. 8. 
maximaler Wert für den $\mathrm{CSB}^{1}$, und nur in einem Fall war die Abwassermenge - als 1/s. - limitiert.

2. Uberwachung der Abwassereinleitungen

a. Bei vier der sechs Einleiter wurden pro Jahr durchschnittlich vier, bei einem zwei und bei einem Werk keine Kontrolluntersuchungen von seiten der zuständigen Behörde durchgeführt.

b. Vier der sechs Einleiter mußten die selbst gemessenen Abwasserwerte den Behörden vorlegen, einer der beiden anderen zeigte sie "freiwillig".

\subsection{Unterschiede in den Rahmenbedingungen und Konsequenzen} für die Erfolgskontrolle des Abwasserabgabengesetzes

Stellt man zunächst die behördliche Uberwachungspraxis von Versuchs- und Kontrollgruppe gegenüber, so kann festgestellt werden, daß sich diese bei beiden Gruppen gleichermaßen unterschiedlich gestaltet. Insofern liegen sozusagen vergleichbare Verhältnisse vor.

Weniger spiegelbildlich zeigt sich dagegen die Genehmigungspraxis bei den Gruppen. Dabei dürfte der unterschiedliche Implementationszeitraum der Auflagen weniger Schwierigkeiten bereiten als die Tatsache, daß bei den schweizerischen Untersuchungseinheiten

1. keine Grenzwerte für den CSB vorliegen und

2. von einer Ausnahme abgesehen die Abwassermengen nicht limitiert sind.

Das Fehlen einer CSB-Auflage bedingt, daB eine Untersuchung, in der parallel zur Versuchsgruppe festgestellt wird, Inwieweit die schweizerischen Papierfabriken über die

1 Die Verordnung über Abwassereinleitungen überläBt dem Kanton die Festlegung von CSB-Grenzwerten. Vgl. ebenda, S. 14 . 
Auflagen hinaus reinigten, nicht auf der Basis der abgaberechtlichen Ermittlung der Schadeinheiten erfolgen kann. Ersatzweise lassen sich jedoch die erlaubten und tatsächlich emittierten BSBs-Produktfrachten vergleichen.

Vermutlich läBt sich auf das Fehlen einer CSB-Auflage auch zurückführen, daß nur vier der sechs Untersuchungseinheiten die durchschnittlich emittierte CSB-Konzentration angeben konnten, weshalb sich die Anzahl der Kontrolleinheiten für Untersuchungen, die mit diesem Wert rechneten, entsprechend reduzierte.

Das Fehlen einer Begrenzung der Abwassermenge als wesentliche Abweichung von den deutschen Einleitungsbedingungen kann auch Art. 4 Abs. 1 der schweizerischen Verordnung über Abwassereinleitungen nur bedingt ausgleichen. Er schreibt vor: "Die Grenzwerte dürfen nicht durch Verdünnen, zum Beispiel mit unverschmutztem Kühl-oder Brauchwasser, erreicht werden." Denn weil die Abwassermenge nicht grundsätzlich limitiert ist, kann die Produktfracht bei einer steigerung des Produktionsumfangs konstant gehalten werden, während eine Reihe deutscher Untersuchungseinheiten in diesem Fall zu einer Senkung der Produktfrachten gezwungen ist, weil sich die Werte der Abwassereinleitungen bereits an der Auflagengrenze bewegen und die Behörde eine Erhöhung der Bescheidwerte aus Gründen des Gewässerschutzes ablehnt. In diesen unterschiedlichen Rahmenbedingungen liegt jedoch auch ein interessantes Analysepotential: Lassen sich bei der Kontrollgruppe Veränderungen des spezifischen Abwasseranfalls feststellen, so zeigen diese denjenigen technischen Fortschritt in der Kreislaufeinengung an, der nicht in erster Linie auf wasserrechtliche Regelungen zurückzuführen ist.

Zusammenfassend kann festgehalten werden, daß insgesamt die Voraussetzungen für einen with-and-without-Vergleich zwischen deutschen und schweizerischen Papierfabriken gegeben sind. DaB bei letzteren keine CSB-Auflagen bestehen, bedeutet zwar eine methodische, jedoch keine inhaltliche Restriktion, weil das Abwasserreinigungsverhalten beider Gruppen über den BSBs 
verglichen werden kann. Eine Gegenüberstellung der deutschen und schweizerischen Auflagenwerte ergab allerdings, daß sowohl die Absetzbaren stoffe als auch der BSBo bei den deutschen Untersuchungseinheiten großzügiger bemessen waren: So betrugen die Absetzbaren stoffe in der Regel $0,5 \mathrm{mg} / 1$ (Kontrollgruppe: $0,3 \mathrm{mg} / 1$ ) und der BSBs zeigte einen Mittelwert von rund $30 \mathrm{mg} / \mathrm{l}$ (Kontrollgruppe: $20 \mathrm{mg} / 1$ ). Diese Unterschiede nivellieren sich jedoch bei der erlaubten Frachtemission, nicht zuletzt weil bei den deutschen Untersuchungseinheiten Begrenzungen der Abwassermenge bestehen. Insofern kann das Abwasserreinigungsverhalten schweizerischer Papierfabriken als Anhaltspunkt für die isolierte Wirksamkeit des deutschen WHG gelten bzw. Hinweise geben, inwieweit Veränderungen des "deutschen" Einleiterverhaltens vom AbwAG induziert wurden. Die damit angesprochene Zielerreichungs-, Bedingungs- und Wirkungskontrolle des AbWAG sind das Thema des nun folgenden Abschnitts. 


\section{Okologische Wirkungen}

\subsection{Verminderung der Emissionen}

Die Emissionsverminderung ist das ökologische Gesamtziel des AbwaG. Deshalb wurde untersucht, inwieweit es den deutschen - und im Vergleich dazu den schweizerischen - Werken gelang, die Schädlichkeit ihrer Abwässer während des Untersuchungszeitraums zu reduzieren.

Die Entwicklung der Emissionen von 1974 bis 1985 wurde zum einen in absoluter Höhe, d.h. jahresbezogen, zum anderen in relativer Höhe, $d . h$. produktbezogen gemessen. Die Anzahl der Papierfabriken, für die diese Werte festgestellt werden konnten, reduzierte sich allerdings sowohl in der Versuchsals auch in der Kontrollgruppe erheblich, weil bei den meisten Papierfabriken die Emissionswerte des Jahres 1974 nicht vorlagen. Teils führten die Einleiter zum damaligen Zeitpunkt noch nicht oder nur sporadisch Abwasserkontrollen durch1, teils waren die gemessenen Werte nicht mehr verfügbar. Insgesamt konnten nur sechs deutsche und zwei schweizerische Untersuchungseinheiten die zum Zeitvergleich notwendigen Daten zur Verfügung stellen.

Die sechs deutschen Papierfabriken verminderten ihre absoluten Emissionen von 1974 bis 1985 insgesamt um $71 \%$, obwohl die Produktion um 57 gesteigert werden konnte. Dagegen blieben bei den beiden schweizerischen Werken die

1 So nahmen immerhin 35 \& der deutschen Untersuchungseinheiten 1974 weder Messungen der Abwassermenge noch Messungen der abgaberechtlichen schadparameter und des BSBs vor. Nur 28 iffaßte mehrmals oder einmal wöchentlich den CSB, 30 \% die Absetzbaren stoffe bzw. Feststoffe und 35 \% den BSB。. Für 1985 ergab sich ein gänzlich anderes Bild: Bei allen untersuchten Einleitern wurden die Abwassermenge täglich bzw. kontinuierlich und die angesprochenen Schadparameter wenigstens wöchentlich gemessen. Beispielsweise erfaBten 80 \& der Papierfabriken den CSB täglich oder 4 - 5 Mal pro Woche. 
Emissionen in der summe konstant1, während die Produktion im gleichen Zeitraum um $43 \%$ erhöht wurde ${ }^{2}$.

Diese höchst unterschiedliche Emissionsverminderung von Versuchs- und Kontrolleinheiten läßt sich nicht grundsätzlich auf die Verschiedenartigkeit der wasserrechtlichen Regelungen in der Bundesrepublik und der Schweiz zurückführen. Bei dem vorgenommenen Vergleich kommt der unterschiedliche Ausbau der Abwasserreinigungsanlagen im Jahr 1974 in hohem Maße zum Tragen. Während sämtliche in die Untersuchung einbezogenen deutschen Einleiter damals noch keine Biologie betrieben, verfügten die beiden schweizerischen Werke bereits über eine derartige Reinigungsstufe. Ein Vergleich der relativen Emissionen (siehe Abb. 113) zeigt deshalb für 1974 bei den deutschen Einleitern ein sehr viel höheres, für 1985 jedoch ein mit den schweizerischen Werken gleiches Niveau der produktbezogenen Schadfrachten. Sieht man von Werk 2 ab, bei dem der Abbau der Schadfracht während des Untersuchungszeitraums $62 \%$ betrug, bewegte sich die Emssionsverminderung bei den deutschen Untersuchungseinheiten zwischen 83 und 97 \%. Bei den Werken, die während des Untersuchungszeitraums ihre wasserkreisläufe schlossen und deshalb in Abb. 11 unberücksichtigt blieben, verminderten sich die Emissionen bis zu $100 \%$.

1 Da bei den schweizerischen Papierfabriken keine Werte für die Absetzbaren stoffe vorlagen, basieren die angegebenen Zahlen nur auf den CSB-Verminderungen. Dadurch bedingte etwaige Verschiebungen dürften vernachlässigbar sein, weil die Höhe der Schadeinheiten maßgeblich vom CSB bestimmt wird.

2 Diese jahresbezogenen wie später auch die produktbezogenen Emissionen wurden als Schadeinheiten gemäß der Definition des AbwAG erfaBt und berücksichtigten mithin die Abwassermenge, den CSB sowie die Absetzbaren stoffe bzw. Feststoffe.

3 Wenn in diesem und in den folgenden Abschnitten die in den Abbildungen und Tabellen aufgeführten Werke durchnummeriert sind, so ist einem bestimmten Werk nicht eine "feste" Zahl zugeordnet. Entsprechendes gilt für die Gruppenbildungen. 


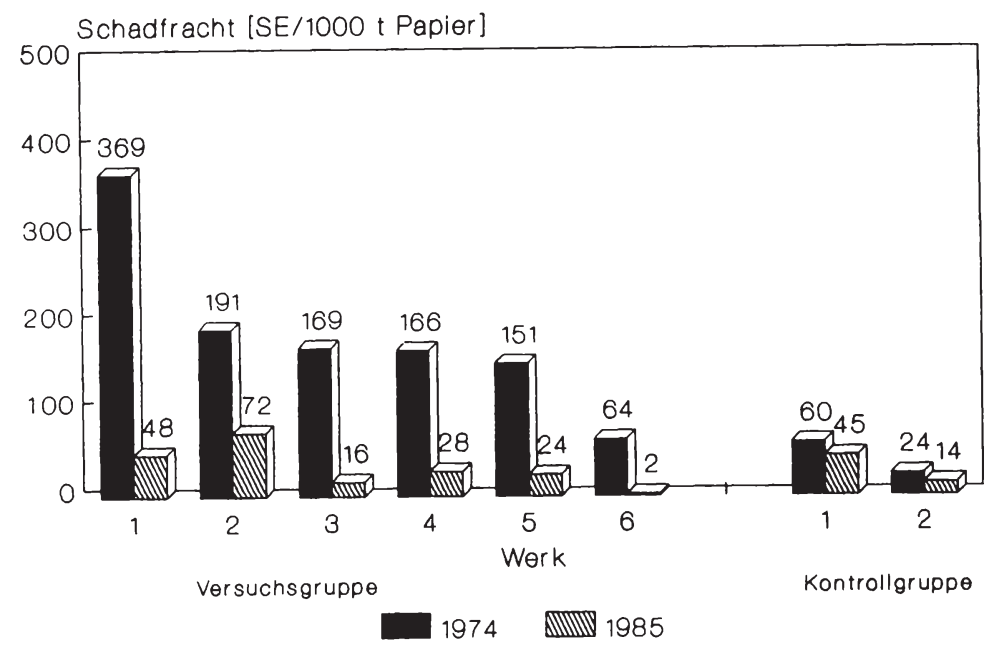

Abb. 11: Emittierte Schadfrachten (produktbezogen) in den Jahren 1974 und 1985

Um feststellen zu können, ob die Verringerung der Abwasserschädlichkeit nur die Einhaltung der Auflagen bedeutete oder über diese hinausging, wurde die Anzahl der 1985 eingeleiteten Schadeinheiten denjenigen Schadmengen gegenübergestellt, die gemäß den Auflagen hätten eingeleitet werden dürfen. Diese Betrachtung wurde bei 17 deutschen Papierfabriken durchgeführt, weil bei ihnen Uberwachungswerte für die Absetzbaren stoffe und den CSB vorlagen ${ }^{1}$. Da die schweizerischen Werke keine CSB-Auflagen haben, konnten sie $\mathrm{zu}$ einem Vergleich nicht herangezogen werden. Abb. 12 zeigt in einer Häufigkeitsverteilung die im Jahr 1985 eingeleiteten Schadeinheiten als prozentsatz der jeweils bescheidlich erlaubten Schadmenge. 35 \% der Werke erfüllten 1985 gerade die Auflagen, d.h. die eingeleiteten Schadeinheiten betrugen zwischen 80 und $100 \%$ der zugelassenen Schadmenge. Bei diesen Einleitern hat die Abwasserabgabe also höchstens die

1 Es wurden auch Papierfabriken einbezogen, bei denen die Bescheide noch nicht umgestellt worden waren, uberwachungswerte aber bereits vorlagen. 


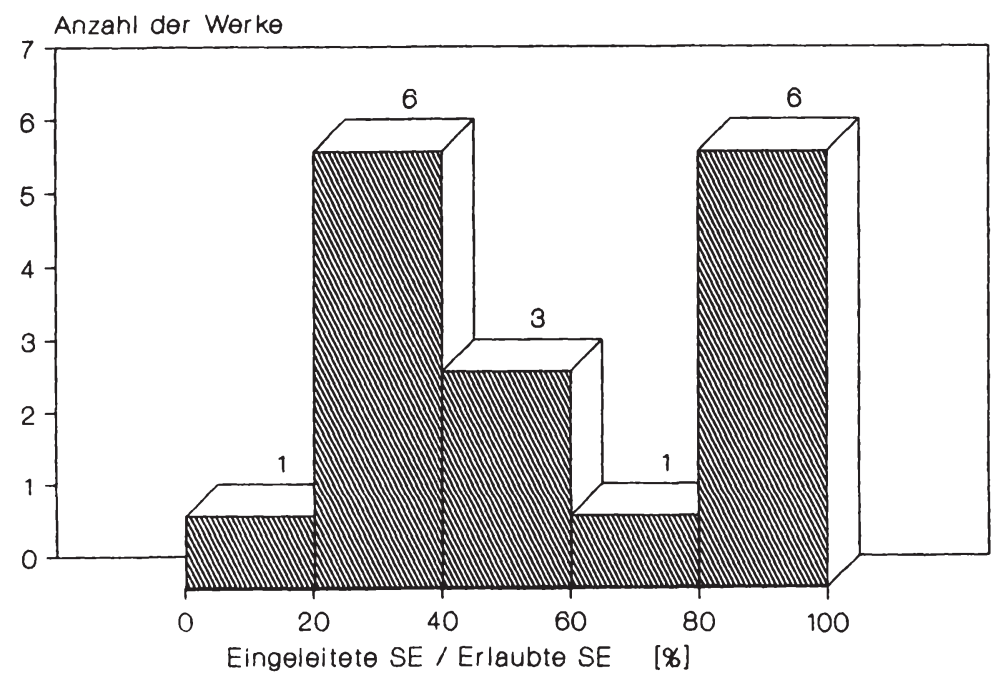

Abb. 12: Das Verhältnis von eingeleiteten zu erlaubten Schadeinheiten bei den deutschen Werken (1985)

Einhaltung der Auflagen bewirkt, nicht jedoch eine darüber hinausgehende Reinigung.

Auf der Suche nach Bestimmungsgründen des Emissionsverhaltens insbesondere bei der Reinigung über die Auflagen hinaus wurde nun untersucht, welche Einleiter Finanzierungshilfen und Subventionen in Anspruch genommen hatten. Mit Ausnahme eines Werkes hatten alle 17 Papierfabriken, also auch diejenigen, die gerade die Auflagen einhielten, von steuerlichen Vergünstigungen (elf Werke) und/oder sonstigen Hilfen wie z.B. ERP-Darlehen, Investitionszulagen und kommunalen Unterstützungen (neun Werke) Gebrauch gemacht1. Mittel aus dem Abgabenaufkommen wie auch aus dem Rhein-Bodensee-Programm waren dagegen keiner der Untersuchungseinheiten zugeflossen².

1 Hingegen hatte nur eines der schweizerischen Werke finanzielle Hilfe - in Form eines zinsvergünstigten Darlehens - erhalten.

2 Auch die anderen, hier nicht berücksichtigten Untersuchungseinheiten hatten keine Unterstützung aus dem Rhein-Bodensee-Programm bekommen, und nur ein Werk hatte Mittel aus dem Abgabenaufkommen erhalten. 
Auch war keinem Werk die Abgabe gänzlich erlassen worden, wohingegen 9 Einleiter in den Genuß einer Abgabenverminderung gemäß § 10 Abs. 3 AbwAG gekommen waren. Sämtliche Untersuchungseinheiten hatten also finanzielle Förderungen wahrgenommen, weshalb ein Zusammenhang zwischen deren Inanspruchnahme und prozentualer Unterschreitung der Auflagen nicht festgestellt werden konnte.

Aus der Vielzahl weiterer Ursache-Wirkungs-Zusammenhänge wurden ferner die folgenden Kausalitäten überprüft:

Die prozentuale Abwelchung der eingeleiteten von der erlaubten Schadmenge ist bei den Einleitern um so größer,

- je niedriger die Abwasserreinigungskosten bezogen auf den Umsatz des Werkes sind,

- je größer das Werk und damit die Abwasserreinigungsanlage ist',

- je höher der Wirkungsgrad der Abwasserreinigungsanlage.

Keine dieser Hypothesen konnte jedoch bei einer Analyse der entsprechenden werksindividuellen Gegebenheiten bestätigt werden. Dagegen zeichnete sich ein Zusammenhang $a b$, der folgendermaßen umschrieben werden kann:

Die Einleiter reinigen soweit, wie es die vorhandenen Reinigungsstufen und der allgemeine stand des Reinigungswissens erlauben.

In $\mathrm{Abb} .13$ wurden jeweils diejenigen Werke gruppiert, die ähnliche oder gleiche Papiersorten bei entsprechender Ubereinstimmung der Einsatzstoffe produzierten, und deren Abwasserbeschaffenheit deshalb vergleichbar war. Gruppe $C$ ließ wegen der größeren Anzahl an Werken am deutlichsten erkennen, daß die eingeleiteten Produktfrachten recht eng zusammenlagen, während die erlaubten Schadmengen in hohem

1 Bei größeren Reinigungsanlagen könnten economics of scale emissionsmindernd wirken. 


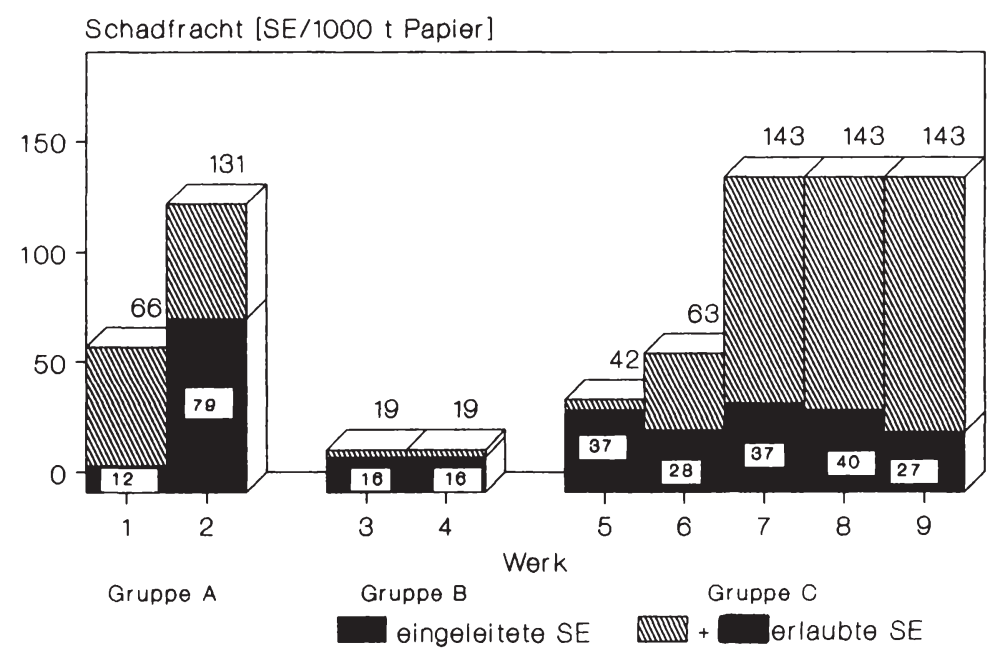

Abb. 13: Eingeleitete und erlaubte schadfrachten (produktbezogen) bei vergleichbaren deutschen Werken (1985)

Maße differierten. Gruppe A zeigte dagegen auch bei den eingeleiteten Produktfrachten deutliche Unterschiede. Diese ließen sich teilweise auf werksindividuelle Gegebenheiten zurückführen: Man hatte beim Bau des Werkes 1 die Schädlichkeit des $z u$ reinigenden Produktionswassers nicht hinreichend genau abschätzen können und deshalb die Reinigungsanlage zu groß ausgelegt.

Die aufgestellte Hypothese, die Emissionen bewegten sich in einer bestimmten Bandbreite ungeachtet der erlaubten Emission, wurde weiterhin durch einen Vergleich zwischen den deutschen Versuchs- und den schweizerischen Kontrolleinheiten überprüft. Dieser mußte durch eine Gegenüberstellung der BSBs-Frachten erfolgen, weil bei den schweizerischen Papierfabriken für den CSB keine Auflagen bestehen. Der BSBs ist dagegen sowohl in der Schweiz als auch in der Bundesrepublik als Grenzwert festgelegt.

Aus der schweizerischen Kontrollgruppe entsprachen zwei Werke sowohl hinsichtlich des Produktionsprogramms als auch der Einsatzstoffe in hohem Maße jeweils einer deutschen 


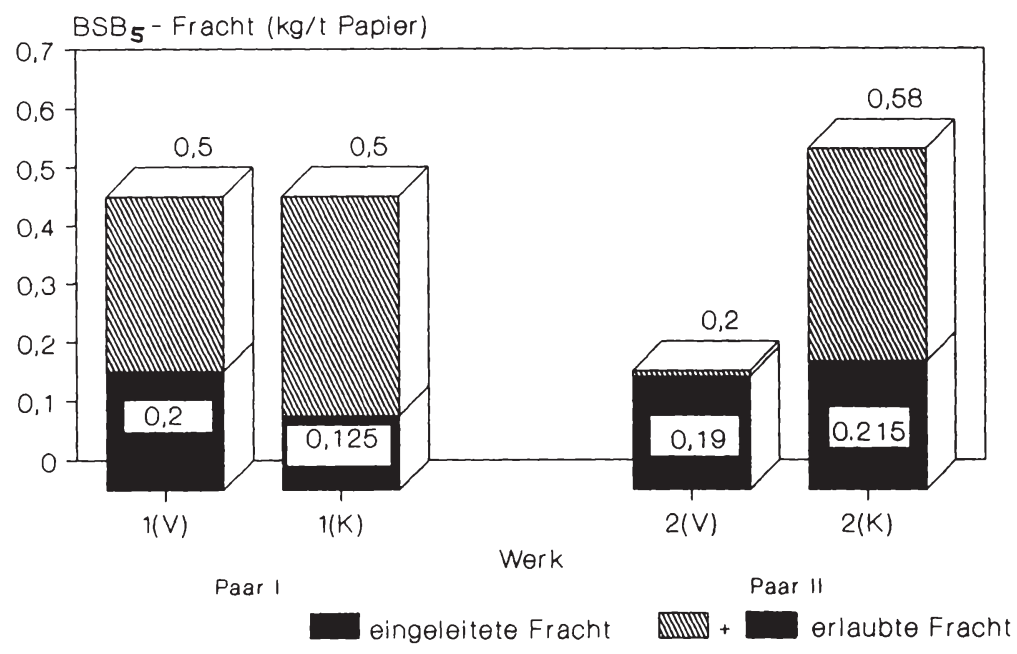

$(V)=$ Versuchsgruppe. $(K)=$ Kontrollgruppe

Abb. 14: Paarvergleich eingeleiteter und erlaubter BSBsFrachten (1985)

Untersuchungseinheit. Abb. 14 zeigt für beide "Paare" die eingeleiteten und erlaubten BSBs-Frachten. Die deutschen Untersuchungseinheiten ( $1(\mathrm{~V}), 2(\mathrm{~V})$ ) sind Papierfabriken, die in die obige Gegenüberstellung emittierter und erlaubter schadeinheiten nicht einbezogen werden konnten.

Bei beiden Paaren lieB sich ein recht einheitliches Emissionsniveau konstatieren. Während die behördlich erlaubten Produktfrachten beim erstaufgeführten Paar identisch waren und das Mehrfache der eingeleiteten Produktfrachten betrugen, waren sie beim zweiten Paar sehr unterschiedlich. Gleichwohl nutzte die schweizerische Kontrolleinheit ihre gegenüber dem deutschen Einleiter um ein Dreifaches höhere Emissionsmöglichkeit nicht aus, sondern bewegte sich auf dem gleichen Emissionsniveau wie das deutsche werk.

Sowohl die Untersuchung der Schadfrachten wie auch die der BSBs-Emissionen sprechen dafür, daß verhältnismäßig weitbemessene Auflagen vom Einleiter nicht ausgenutzt werden, wenn die Auflagen ihn andererseits zum Bau einer Reinigungs- 
stufe zwingen, mit der er eine bessere als die behördlich geforderte Reinigung erreichen kann¹.

Um den Einfluß der Abwasserabgabe auf das Emissionsverhalten eingrenzen zu können, wurden die deutschen Untersuchungseinheiten zunächst gefragt, ob sie der Meinung seien, wesentlich über die Auflagen hinaus zu reinigen. Von sämtlichen 23 deutschen Papierfabriken, die mit offenem Wasserkreislauf produzierten, bejahten insgesamt 12 Einleiter diese Frage. Sie gaben anschließend durchweg an, daß sie ihren Reinigungsstand auch ohne Abwasserabgabe verwirklicht hätten, und begründeten dies überwiegend mit reinigungstechnischen wie auch mit umweltorientierten Argumenten. Erstere verdeutlichten, daß sich die Anlagen innerhalb einer bestimmten Bandbreite hoher Reinigungsleistungen am besten, d.h. weniger störanfällig fahren lassen. Nicht zuletzt deshalb sind die für die Vermeidungsmaßnahmen Verantwortlichen in der Regel daran interessiert, möglichst hohe Wirkungsgrade zu erzielen. Dieser "Ehrgeiz" wird auch durch einen hohen Informationsaustausch innerhalb der Branche gefördert.

Weiterhin wurde vereinzelt von Einleitern, deren Bescheide noch nicht umgestellt worden waren, auf die zukünftig schärferen Auflagen verwiesen, auf die man sich mit entsprechenden Vermeidungsmaßnahmen bereits eingestellt hatte. Ebenso wurde das Argument, man wolle "auf der sicheren seite" sein, genannt.

Hingegen erklärten acht von den elf Einleitern, die nach eigener Einschätzung nicht wesentlich die Auflagen unterschritten, sie hätten ihren Reinigunsstand auch realisiert, wenn sie zwar eine Abwasserabgabe entrichten, jedoch keine Auflagen erfüllen müBten. Sie begründeten dies allerdings nicht durchweg mit den Abgabezahlungen, sondern auch mit den sonst auftretenden Verschmutzungen der Vorfluter sowie den

1 Nur eines der in Abb. 13 aufgeführten Werke, bei dem der Bescheld zudem noch nicht umgestellt worden war, hätte die Uberwachungswerte auch ohne den Bau einer biologischen Reinigungsstufe (gerade) einhalten können. 
einhergehenden Beschwerden des sozialen Umfelds. An anderer Stelle wurde von dreien dieser Einleiter auch die Schadenshaftung hervorgehoben. Drei Werke hätten dagegen ihren damaligen Reinigungsstand ohne Auflagen nicht verwirklicht.

Von den acht Werken, die 1985 mit geschlossenem Wasserkreislauf produzierten, hätte die Hälfte diese Maßnahme auch ergriffen, wenn die Abwasserabgabe nicht erhoben worden wäre. Für sie standen die Höhe der Investitionen, die zur Einhaltung der Auflagen notwendig gewesen wären, sowie räumliche Probleme beim Ausbau der Reinigungsanlagen im Vordergrund.

Abschließend kann festgehalten werden, daß während des Untersuchungszeitraums sowohl die absolute als auch die produktbezogene Emission in erheblichen Maße gesenkt wurde. Die Auflagen wurden von mehreren Papierfabriken gerade eingehalten und von anderen weit unterschritten. Gemäß den Aussagen der Einleiter dürten die Wirkungen der Abwasserabgabe im Bereich der Restverschmutzung als gering einzustufen zu sein. Die grundsätzliche Reinigungsbereitschaft schien allerdings durch die Abgabezahlungen sowie die in Aussicht gestellte Abgabenhalbierung erhöht. Wegen des Einflusses weiterer unabhängiger Variable und nicht zuletzt wegen der mannigfaltigen Bestimmungsgrößen der uberwachungswerte läBt sich der Einfluß des AbwAG auf das Emissionsverhalten hier nicht abschließend beurteilen. Die nachfolgende Untersuchung zu den abgaberechtlichen Teilzielen soll über Wirkungen des AbwAG mehr Aufschluß geben.

\subsection{Verwirklichung der Teilziele}

\subsubsection{Bau von Abwasserreinigungsanlagen}

Durch den Bau von Abwasserreinigungsanlagen kann eine wesentliche Verminderung der Emissionen erreicht werden. Abb. 15 veranschaulicht für die 23 deutschen 


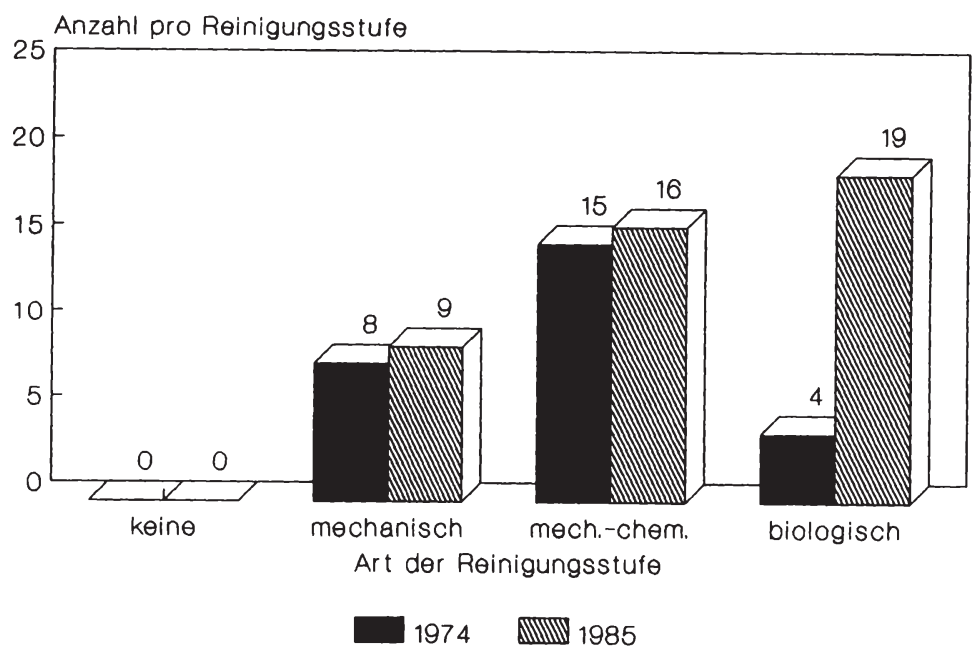

Abb. 15: Angewandte Reinigungsverfahren bei den deutschen
Werken

Untersuchungseinheiten mit offenem Wasserkreislauf Unterschiede, die zwischen der 1974 und der 1985 praktizierten Abwasserbehandlung bestanden. Während bereits 1974 sämtliche (damals 21) Werke über eine mechanische oder -in der Regel alternativ - mechanisch-chemische Reinigung verfügten, behandelten nur vier Einleiter ihre Abwässer biologisch. Die Anzahl letzterer erhöhte sich jedoch bis 1985 auf 19 Papierfabriken, sie stieg also von 19 auf $83 \%$. Ein Blick auf die angewandten Verfahren der biologischen Abwasserreinigung zeigt, daß die einstufige Fahrweise dominiert (siehe Abb. 16).

Vier Papierfabriken reinigten ihre Abwässer auch 1985 noch nicht biologisch. Bei einem Werk stand der AnschluB an die kommunale Kläranlage bevor, ein anderes hatte mit dem Bau einer Tropfkörperanlage bereits begonnen und bei zwei Einleitern gab die produktbedingte Abwasserqualität auch für die Zukunft keinen AnlaB zur biologischen Reinigung, wohl aber waren die Erweiterungen der mechanisch-chemischen stufen geplant. 


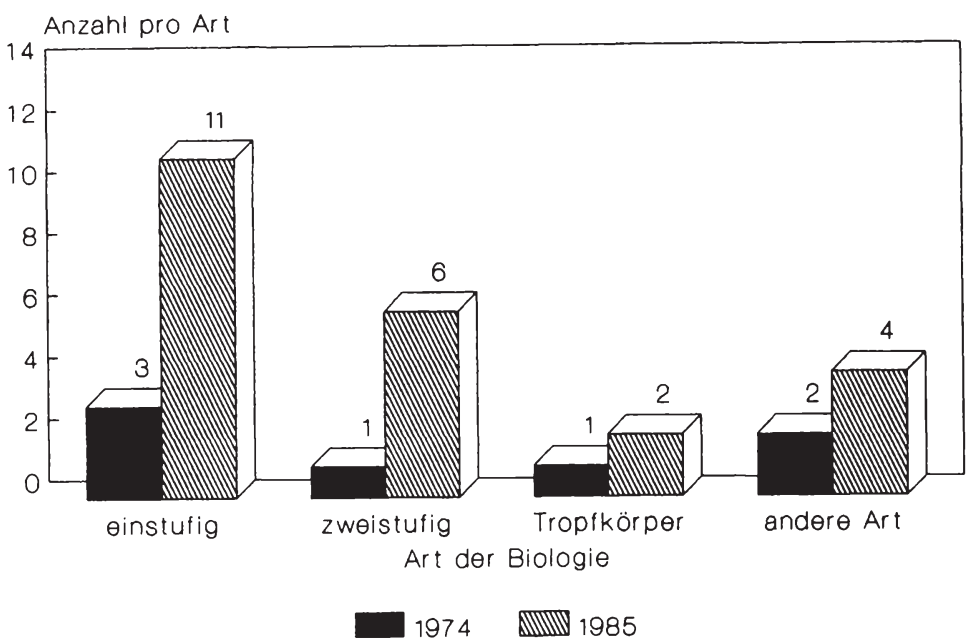

Abb. 16: Angewandte Arten der biologischen Reinigung bei den deutschen Werken

Ergänzend sei hinzugefügt, daß zwei Papierfabriken während des Untersuchungszeitraums die Anzahl der bereits vorhandenen bioligischen Reinigungseinheiten erhöhten und fünf Werke ihre mechanisch-chemischen Anlagen ausbauten.

Insgesamt investierten 17 Papierfabriken während des Untersuchungszeitraums in Reinigungsanlagen ${ }^{2}$. Der Prozentsatz der Werke, der während des Untersuchungszeitraums die biologische Reinigung einführte, ist allerdings nicht repräsentativ für die Grundgesamtheit. Dies ergibt ein Vergleich mit den Umfrageergebnissen des Verbandes Deutscher Papierfabriken, der feststellte, daß sich der Anteil der biologisch reinigenden Werke unter seinen Mitgliedsfirmen von 14 auf 56 \& während des gleichen Untersuchungszeitraums veränderte ${ }^{2}$.

Die nach 1974 getätigten Investitionen wurden nach den

1 Nicht mitgezählt sind die beiden Papierfabriken, die erst nach 1974 die Produktion aufnahmen.

2 Vgl. Verband Deutscher Papierfabriken (Hrsg.): PapierReport, a.a.0., s. 4 . 
Angaben der im Rahmen dieser Arbeit befragten Einleiter durchgeführt bei (Mehrfachnennungen waren möglich)

7 Werken wegen höherer Papierproduktion und damit verbundenem höherem Abwasseranfall,

10 Werken, um überhaupt nach $\$ 7$ a WHG die a.a.R.d.T. zu erreichen,

5 Werken, um über die Mindestanforderungen hinausgehende Auflagen zu erfüllen,

8 Werken, um gemäB $\$ 9$ Abs. 5 AbwaG durch Unterschreitung der Mindestanforderungen den Abgabesatz zu halbieren,

4 Werken aus sonstigen Gründen, nämlich

einmal aus Umweltschutzgründen,

einmal aus Umweltschutzgründen, zur Image-

festigung im sozialen Umfeld und mit dem Ziel, auf dem neuesten technischen stand der Frischwasser- und Abwasseraufbereitung zu arbeiten,

zweimal im Rahmen des Aufbaus des gesamten Werkes.

Die Abgabenhalbierung wurde als Begründung nur einmal nicht in Kombination mit der Erfüllung der Mindestanforderungen bzw. darüber hinausgehender Auflagen genannt.

Vergleicht man die Abwasserbehandlung der deutschen Untersuchungseinheiten mit der der sechs schweizerischen Werke, so zeigen letztere ein ganz anderes und insgesamt inhomogeneres Bild der angewandten Reinigungsstufen (siehe Abb. 17). Während einerseits 1974 noch zwei und selbst 1985 noch eine Papierfabrik ihr Abwasser ungeklärt emittierten, verfügten andererseits bereits 1974 vier Werke über eine zweistufige Biologie. Bis $1985 \mathrm{kam}$ eine weitere einstufige hinzu, außerdem baute eine Papierfabrik die bereits vorhandene mechanische Reinigungsstufe aus und zwei Untersuchungseinheiten erweiterten die biologische Reinigung.

Sämtliche schweizerischen Werke gaben an, die Investitionen im Kläranlagenbereich getätigt zu haben, um die Auflagen 


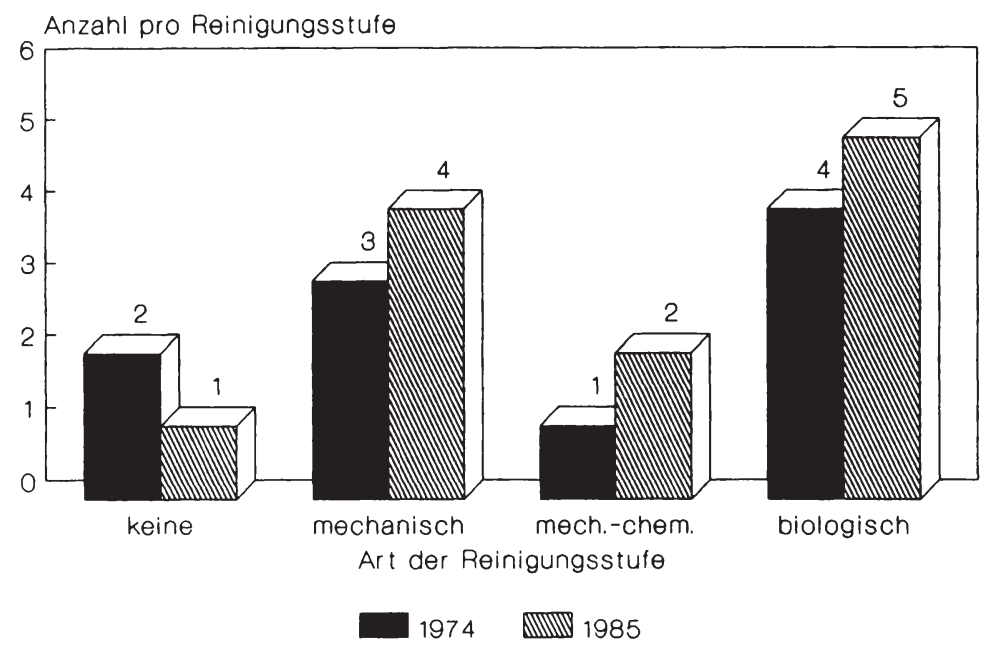

Abb. 17: Angewandte Reinigungsverfahren bei den schweizerischen Werken

erfüllen zu können. Dies galt auch für die Biologien, die bereits vor 1974 gebaut worden waren. Bei zwei Einleitern waren zudem eine höhere Papierproduktion, bei einem weiteren Qualitätsumstellungen im Produktbereich maßgeblich.

Zusammenfassend kann festgestellt werden, daß 15 der 17 deutschen Untersuchungseinheiten, die während des Untersuchungszeitraums externe Reinigungsmaßnahmen ergriffen, diese durchführten, um die a.a.R.d.T. oder strengere Auflagen zu erfüllen. Wenngleich Auflagen, wie aus den Antworten der schweizerischen Kontrolleinheiten ersichtlich, das Investitionsverhalten maßgeblich beeinflussen, gab die Hälfte der deutschen Werke, die Abwasserreinigungsanlagen baute oder erweiterte, auch die Halbierung des Abgabesatzes und damit die Abgabe schlechthin als Begründung ihres Handelns an. Dieses Ergebnis zeigt einen die Auflagen unterstützenden EinfluB der Abwasserabgabe beim Bau von Abwasserreinigungsanlagen an. Daß auf der anderen seite 15 werke erst einmal "Basismaßnahmen" zur Erreichung des Auflagenniveaus durchführen muBten, verdeutlicht, daß das AbwAG aufgrund dieses 
großen Nachholbedarfs eine alleinige Wirkung von vornherein nur schwerlich zeigen konnte.

\subsubsection{Verbesserung der Abwasserreinigungstechnik}

Die Verbesserung der Abwasserreinigungstechnik wurde durch die Veränderung des CSB- und des BSBs-Abbaus in den einzelnen Reinigungsstufen während des Untersuchungszeitraums gemessen. Mit der Umfrage konnte zunächst festgestellt werden, daß die Untersuchungseinheiten - es waren die 23 deutschen Papierfabriken mit offenem Wasserkreislauf - die Messung der Schadstoffkonzentrationen, aus denen sich die oben genannten Abbauraten berechnen, zumeist nicht für jedes einzelne stadium der Abwasserbehandlung vornehmen: Einige Werke erfaßten nur die Zulauf- und Ablaufwerte der gesamten Reinigungsanlage, andere auch die Konzentrationen, mit denen das Abwasser eine stufe verläßt und in die nächste eintritt, und wieder andere beschränkten sich auf die Zulauf- und Ablaufwerte der Biologie als der letzten Reinigungsstufe. Am seltensten gemessen wurde die Verminderung der Schadstoffkonzentrationen in der mechanischen bzw. mechanisch-chemischen Reinigung, so daß für diese stufe wegen zu geringen Umfangs des Datenmaterials auch keine hinreichend repräsentativen Wirkungsgrade berechnet werden konnten.

Den before-and-after-Vergleich erschwerend kam hinzu, daß die wenigsten Einleiter Werte aus dem Jahr 1974 vorlegen konnten. Die einzige Möglichkeit eines Zeitvergleichs zeigte sich deshalb in einer Gegenüberstellung von VDP-Daten des Jahres 1974 und den im Rahmen dieser Arbeit erhobenen Daten aus dem Jahr $1985^{1}$. In der VDP-Umfrage hatte man zum einen die durchschnittlichen wirkungsgrade mechanischer und mechanischchemischer Reinigungsstufen, zum anderen die Wirkungsgrade

1 Der VDP veröffentlichte Wirkungsgrade nur für das Jahr 1974 und nicht für das Jahr 1985, so daß ein Vergleich auf "reiner" VDP-Datenbasis nicht möglich war. 
von Reinigungsanlagen einschließlich biologischer Restabwasserklärung (Gesamtwirkungsgrade) ermittelt ${ }^{1}$. Ein Vergleich letzterer Wirkungsgrade mit den im Rahmen dieser Arbeit erhobenen Werten aus dem Jahr 1985 ergab im gewichteten Mittel eine Erhöhung des BSBs-Wirkungsgrades von 80 auf 96 \% und eine steigerung des CSB-Wirkungsgrades von 55 auf $82 \%$. Der BSBs-Abbau wurde somit um 20 und der CSB-Wirkungsgrad um rund 50 \% während des Untersuchungszeitraums verbessert. Der Gesamtwirkungsgrad im Jahr 1974 errechnete sich dabei aus den Abbauleistungen von neun Werken, derjenige im Jahr 1985 resultierte aus den schadstoffverminderungen von acht Papierfabriken.

Die maßgebliche Abbauarbeit leistet die biologische Reinigungsstufe: So unterschieden sich deren Wirkungsgrade 1985 bei vielen Papierfabriken nur um 1 bis 2 \% von den Gesamtwirkungsgraden. Die BSBs-Abbauraten zeigten dabei ein erstaunliches Gleichmaß auf. Wie Abb. 18 veranschaulicht, bewegten sie sich bei den 16 Werken, für die sie ermittelt werden konnten, fast durchweg zwischen 92 und 99 \%. Dieser Befund spricht für eine allgemeine Kenntnis und Anwendung des zum Untersuchungszeitpunkt verfügbaren Verfahrens-Know-How.

Weniger nivelliert zeigten sich 1985 die Abbauraten des abgaberechtlichen Schadparameters CSB (siehe Abb. 19); sie schwankten 1985 bei denselben Untersuchungseinheiten zwischen 71 und $96 \%$. Die Spannen innerhalb der einzelnen Produktgruppen waren jedoch weitaus geringer, was auf produktbedingte Restriktionen bei der CSB-Reduzierung hindeutet.

Insgesamt kann eine erhebliche Verbesserung des Verfahrensprozesses - insbesondere in Hinblick auf den CSBAbbau - sowie ein bei allen Untersuchungseinheiten gleichartiger stand der ProzeBoptimierung konstatiert werden. Inwieweit dieser abgabenbedingt ist, bleibt allerdings offen.

1 Vgl. Dalpke, H.-L., Göttsching, L.: Uber den spezifischen Abwasseranfall .... a.a.0.: S. 725. Es handelt sich hier um gewichtete Mittelwerte der produktspezifischen $\mathrm{BSB}_{3}-$ und CSB-Frachtverminderungen. 


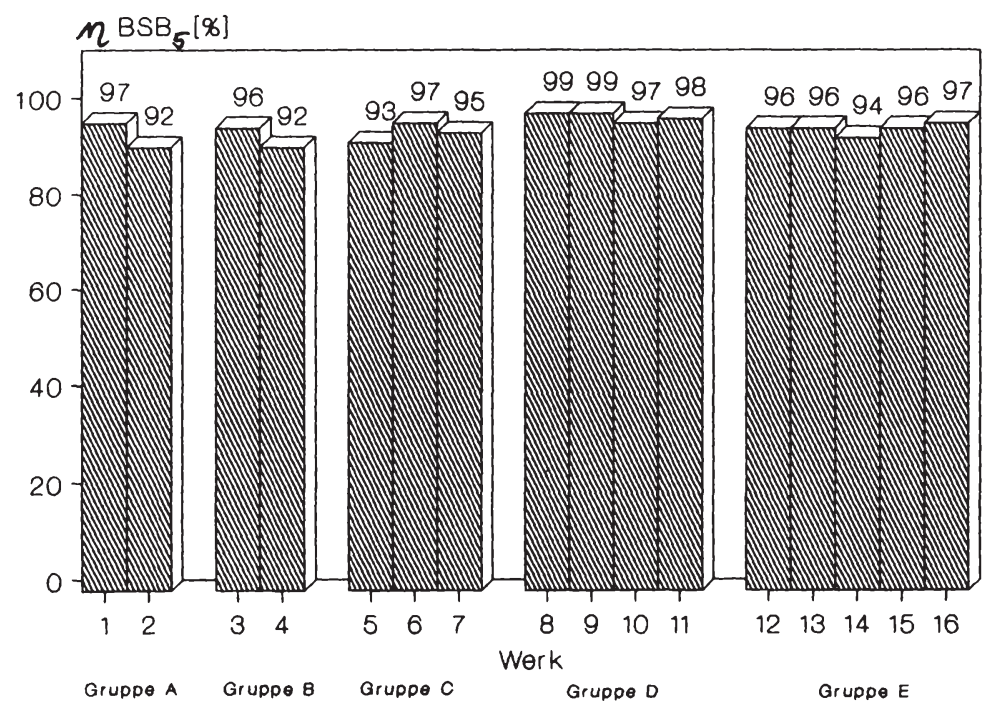

Abb. 18: BSBs-Abbau von biologischen Reingungsanlagen
deutscher Werke (1985)

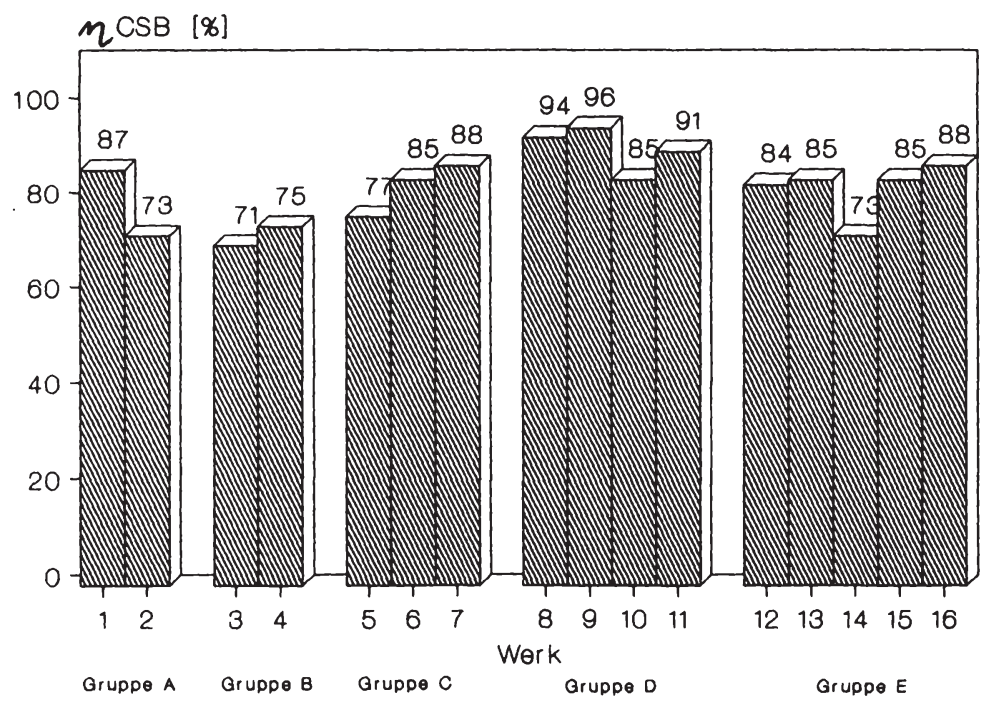

Abb. 19: CSB-Abbau von biologischen Reinigungsanlagen deutscher Werke (1985) 


\subsubsection{Einsatz abwasserarmer/-loser Produktionsverfahren}

Die Schädlichkeit des Abwassers läßt sich bei der Papierherstellung - wie auch bei anderen Produktionszweigen - nicht nur durch die Abwasserreinigung als "end-of-the-pipetechnolgy", sondern auch durch innerbetriebliche Vermeidungsmaßnahmen verringern. Unter letzteren versteht man Veränderungen des stoffeinsatzes (Faser- und Hilfsstoffe) und der Verfahrenstechnik als "vorbeugende" Maßnahmen sowie z.B. die innerbetriebliche stoffrūckgewinnung als "nachträgliche" Vermeidungsmaßnahme1 . Das Ergebnis sind abwasserärmere Produktionsverfahren und zum Teil sogar die abwasserlose Fahrweise, die durch das Schließen des Wasserkreislaufs erreicht wird.

In der engeren Auslegung hat "als Papierfabrik mit Geschlossenem Kreislauf ... eine solche zu gelten, bei der kein Abwasser das Werk verläBt."2 In der weiteren - und geläufigeren - Auslegung versteht man unter der Papierherstellung mit geschlossenem Kreislauf eine Produktionsweise, bei der im laufenden ProduktionsprozeB kein Abwasser emittiert wird. Unter Berücksichtigung seltener störfälle, "die zum Ausstoß geringer Mengen Abwasser führen können, ... [darf] ein geschlossener Wasserkreislauf langfristig gesehen eine spezifische Abwassermenge von maximal 0,1 l/kg erzeugten Produktes aufweisen."3

Legt man letztere Definition zugrunde, so stieg bei den deutschen Untersuchungseinheiten die Zahl der mit geschlossenem Wasserkreislauf produzierenden Werke während des

1 Vgl. Göttsching, L.: Innerbetriebliche Vermeidungsmaßnahmen .... a.a.0., s. 361 .

2 Brecht, W., Dalpke, H. -L.: Wasser, Abwasser, Abwasserreinigung in allgemeiner sicht und in der sicht der Papier- und Zellstoffindustrie, Biberach/RiB 1980, S. 250.

3 Möbius, C.H.: Die Abwassersituation der Zellstoff- und Papierindustrie in der Bundesrepublik Deutschland, in: Wochenblatt für Papierfabrikation, 107. Jg. (1979), Heft 19 , s. 767 . 
Untersuchungszeitraums von eins auf acht1. Diese Papierfabriken produzierten durchweg Sorten innerhalb der Produktgruppen "Papier für Verpackungszwecke" oder "Karton/Pappe für Verpackungszwecke", und eines der Werke stellte neben Verpackungspapieren auch graphische Papiere auf Altpapierbasis her. Die Kreislaufschließung wurde durchgeführt bei (Mehrfachnennungen waren möglich)

2 Werken wegen höherer Papierproduktion und damit verbundenem höheren Abwasseranfall,

4 Werken, um überhaupt nach $\$ 7$ a WHG die "allgemein anerkannten Regeln der Technik" zu erreichen,

1 Werk, um über die Mindestanforderungen hinausgehende Auflagen zu erfüllen,

0 Werken als Resultat allgemeiner Wirtschaftlichkeits-, Rationalisierungs- oder Kostenüberlegungen und bei

6 Werken aus sonstigen Gründen:

- Abwasserabgabe, Ausbau der Kläranlage zu teuer,

- Abwasserabgabe, Ausbau der Kläranlage zu teuer, kommunale Reinigung wäre bei Einleitung überlastet,

- Abwasserabgabe, Voraussetzungen für Schließung waren bereits gegeben,

- Ausbau der Kläranlage zu teuer,

- Ausbau der Kläranlage zu teuer, Unabhängigkeit von kommunaler Reinigung.

- kein Raum für den Ausbau der Kläranlage vorhanden.

Auch die Papierfabrik, die bereits vor 1974 den Wasserkreislauf geschlossen hatte, begründete die Umstellung mit dem

1 Die geschlossenen Kreisläufe sind in der stichprobe stärker repräsentiert als in der Grundgesamtheit. Der Verband Deutscher Papierfabriken zählte 1985 bei seinen Mitgliedsfirmen neben 70 Direkt- und 47 Indirekteinleitern insgesamt 13 geschlossene Kreisläufe. Vgl. Verband Deutscher Papierfabriken (Hrsg.): Papier-Report, a.a.0., S. 4 . 
fehlenden Raum für eine Abwasserreinigungsanlage, welche den gestellten Auflagen gerecht geworden wäre.

Die vier Papierfabriken, die unter den "sonstigen Gründen" die Abwasserabgabe nicht nannten, gaben an, sie hätten den Kreislauf auch dann geschlossen, wenn sie keine Abwasserabgabe zahlen müßten.

Bereits aus der Tatsache, daß die Kreislaufschließung nur in bestimmten Produktgruppen zu beobachten ist, wird deutlich, daß sie derzeit nur für einige Papiersorten, nämlich für diejenigen, bei denen an das Fabrikationswasser verhältnismäBig geringe Anforderungen gestellt werden, in Frage kommt. Dagegen ist die Kreislaufeinengung eine emissionsvermeidende Maßnahme grundsätzlicher Art ${ }^{1}$. So gaben auch 20 der insgesamt 23 Untersuchungseinheiten, die $1985 \mathrm{mit}$ offenem Wasserkreislauf produzierten, an, Investitionen zur Kreislaufeinengung durchgeführt $\mathrm{zu}$ haben. Es handelte sich beispielsweise um den Einsatz von stoffängern, um innerbetriebliche Maßnahmen der Wasserrückführung und um den Ersatz korrodierbarer Anlagenteile durch Teile aus korrosionsfesten Werkstoffen. Diese Maßnahmen vollzogen sich zumeist kontinuierlich über mehrere Jahre oder sogar über den gesamten Untersuchungszeitraum. Sie wurden vorgenommen bei (Mehrfachnennungen waren möglich)

4 Werken, um überhaupt die Mindestanforderungen nach \$ 7 a WHG zu erfüllen,

5 Werken, um über die Mindestanforderungen hinausgehende Auflagen zu erfüllen,

6 Werken, um gemäB $\$ 9$ Abs. 5 AbwAG durch Unterschreitung der Mindestanforderungen den Abgabesatz zu halbieren,

1 Die mit der Kreislaufeinengung verbundene Senkung der spezifischen Abwassermenge führt zwar zu einer Erhöhung der Konzentrationswerte des Abwassers, insgesamt wird jedoch die Schadfracht und damit die Emission reduziert. Vgl. Göttsching, L., Lüttgen, W.: Organische Hilfsstoffe als eine Quelle der Wasserbelastung bei der Papierherstellung, in: Das Papier, 32. Jg. (1978), Heft 10 A, S. V 47 . 
2 Werken, um über die bereits erreichte Halbierung hinaus die Abwasserwerte zu verbessern und damit die Regel- bzw. Bezugswerte weiter zu senken,

15 Werken als Resultat allgemeiner Wirtschaftlichkeits-, Rationalisierungs- oder Kostenüberlegungen und bei

4 Werken aus sonstigen Gründen:

zweimal aus abwassertechnischen Gründen, zweimal, weil Frischwassereinsparungen erforderlich waren.

Die Abgabenhalbierung wurde dabei nie als einzige Begründung, sondern immer in Verbindung mit der Erfüllung der Mindestanforderungen bzw. darüber hinausgehender Auflagen angegeben. Die Tatsache, daß nur zwei Einleiter die Maßnahmen durchführten, um über die Auflagen hinaus zu reinigen und die Abgabe dadurch entsprechend zu senken, unterstützt die Annahme, daB die Wirkung des AbwaG im Bereich der Restverschmutzung als gering zu erachten ist. Sie erhärtet sich vor dem Hintergrund, daß gerade innerbetrieblich marginale und damit weniger kostenträchtige und grundsätzliche Maßnahmen zu realisieren sind. Weitergehende Anstrengungen zur Senkung der Abwasserabgabe wären deshalb hier besonders $\mathrm{zu}$ erwarten gewesen.

Bedeutsamste Ursache für die auf breiter Ebene vorgenommene Kreislaufeinengung sind allgemeine wirtschaftlichkeits-, Rationalisierungs- oder Kostenüberlegungen. Diese Begründung ist naheliegend, weil es im ureigenen Interesse der Papierfabriken liegt, bis zu einem gewissen Grad die Kreisläufe zu schließen, um Verlusten der Einsatzstoffe entgegenzuwirken'

1 Dieser stoffrŭckgewinnung stehen allerdings mit zunehmendem Einengungsgrad insbesondere die Nachteile der verminderten Produktqualität, der Schleim- und Geruchsbildung, der Korrosion und der zu starken Erhöhung der Abwassertemperatur entgegen. Sie begrenzen dann auch die Kreislaufelnengung. Vgl. u.a. Göttsching, L.: Innerbetriebliche Vermeidungsmaßnahmen .... a.a.0., s. 362 f.; Baumgarten, H.L., Welcker, U.: Zur Technologie des Wassergebrauches in Papierfabriken, in: Das Papier, 40. Jg. (1986), Heft $10 \mathrm{~A}, \mathrm{~S} . \mathrm{V} 184 \mathrm{ff}$. 
und Energie einzusparen. DaB die Kreislaufeinengung in vielen Fällen nicht nur ein ökologisches Muß, sondern auch ein technischer und wirtschaftlicher Vorteil sein kann, belegt die Entwicklung des durchschnittlichen spezifischen Abwasseranfalls bzw. Frischwasserbedarfs ${ }^{1}$ über mehrere Jahrzehnte. Während der Frischwasserbedarf zur Herstellung von Papier um die Jahrhundertwende immerhin bei 600 bis $800 \mathrm{~m}^{3} / \mathrm{t}$ Papier $\mathrm{lag}$, hatte man ihn 1930 bereits auf 100 bis $300 \mathrm{~m}^{3} /$ gesenkt $^{2}$. Für 1960 wurde der Frischwasserbedarf mit $60 \mathrm{~m}^{3} / \mathrm{t}$ im Mittel angegeben. Die VDP-Umfragen ermittelten für 1974 einen spezifischen Abwasseranfall von durchschnittlich $49 \mathrm{~m}^{3} / \mathrm{t}$ und für 1985 von $23 \mathrm{~m}^{3} / \mathrm{t}$ Papier ${ }^{3}$. Hingegen betrugen die gewichteten Mittel, die im Rahmen dieser Arbeit für die deutschen Untersuchungseinheiten mit offenem Wasserkreislauf festgestellt wurden, $40 \mathrm{~m}^{3} / \mathrm{t}$ im Jahr 1974 und $15 \mathrm{~m}^{3} / \mathrm{t}$ Papier im Jahr 1985. Weniger als die absoluten Zahlen weichen jedoch die prozentualen Veränderungen über den Untersuchungszeitraum voneinander ab: Gemäß den Ergebnissen des VDP reduzierte sich der spezifische Abwasseranfall um $53 \%$, und bei der Umfrage dieser Arbeit verringerte er sich um $62 \%$.

Abb. 20 gibt die Häufigkeitsverteilung für die prozentuale Senkung des spezifischen Abwasseranfalls von 1974 bis 1985 in der deutschen stichprobe wieder. Insgesamt konnten 25 Papierfabriken die produktbezogenen Abwassermengen für beide

$1 \quad$ Zu einer Erfassung der spezifischen Abwassermengen ging man erst in den siebziger Jahren über; vormals wurden in den Papierfabriken lediglich die Frischwasserverbräuche festgestellt. Letztere überschreiten den Abwasseranfall um diejenige Wassermenge, die im Papier, in den Produktionsabfällen, als verdampftes und als verdunstetes wasser aus dem System abgeführt wird. Man veranschlagt sie mit 1 bis $2 \mathrm{~m}_{3} / \mathrm{t}$ produziertem Papier. Vgl. Göttsching, L., Dalpke, H.-L.: Chancen und Risiken der Wasserkreislaufschließung in Papierfabriken, in: Das Papier, 30 . Jg. (1976), Heft 10 A, S. V 128.

2 Vgl. Möbius, D.: Die Abwassersituation ...., a.a.0., s. 765 .

3 Vgl. Verband Deutscher Papierfabriken (Hrsg.): PapierReport, a.a.0., s. 4 . 


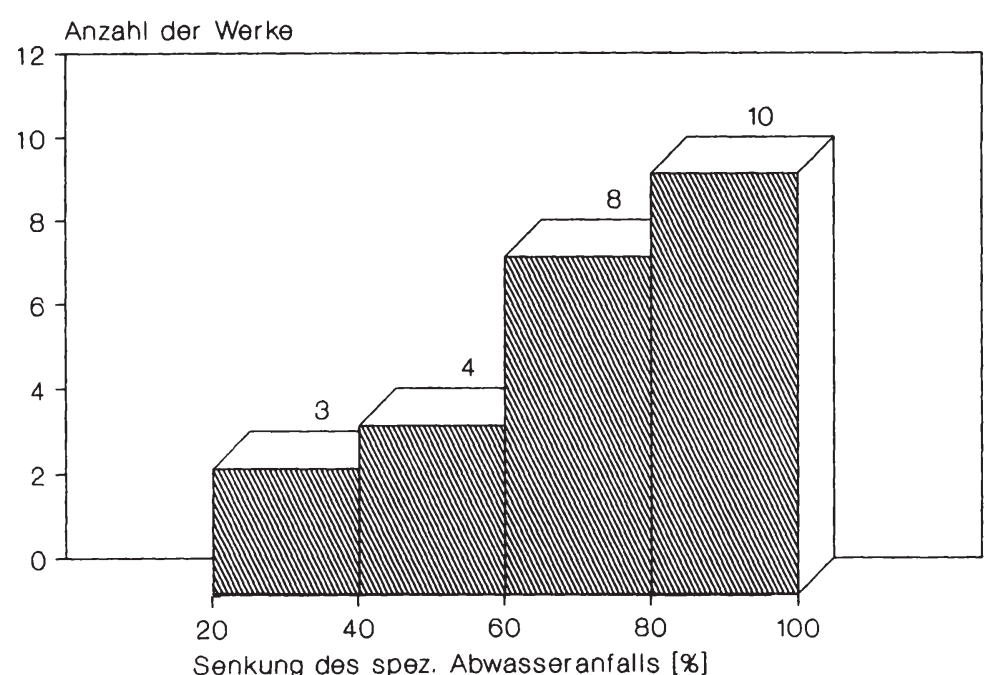

Abb. 20: Prozentuale Senkung des spezifischen Abwasseranfalls von 1974 bis 1985 bei den deutschen Werken

Untersuchungsjahre angeben. Unter den Werken, die den spezifischen Abwasseranfall um 80 bis 100 \% verringerten, sind auch die sieben Papierfabriken aufgeführt, die den Wasserkreislauf während des Untersuchungszeitraums schlossen.

Der spezifische Abwasseranfall wurde gleichermaßen bei den schweizerischen Papierfabriken erfaBt. Als gewichtetes Mittel betrug er $197446 \mathrm{~m}^{3} / \mathrm{t}$ und $198533 \mathrm{~m}^{3} / \mathrm{t}$ Papier ${ }^{1}$. Diese Zahlen sind insofern nicht mit denen der deutschen Einleiter vergleichbar, als die schweizerische Kontrollgruppe mehrere Papierfabriken enthielt, die produktbedingt hohe Abwassermengen benötigten, welche die Durchschnittswerte der insgesamt kleinen Gruppe entsprechend beeinflußten. Vergleichbarer sind dagegen die prozentualen Veränderungen von 1974 bis 1985; sie betrugen in der schweizerischen

1 Eine Abwasserumfrage des Verbandes der Schweizerischen Zellstoff-, Papier- und Kartonindustrie, die die Abwassermengen nicht nur der Direkt-, sondern auch der Indirekteinleiter berücksichtigte, errechnete für die papiererzeugenden Werke $47 \mathrm{~m}^{3} / \mathrm{t}$ Papier im Jahr 1973 und $34 \mathrm{~m}^{3} / \mathrm{t}$ im Jahr 1981. Vgl. Verband der Schweizerischen Zellstoff-, Papier- und Kartonindustrie (Hrsg.): Auswertung der Abwasser-Umfrage 1980/81, Zürich 1983, S. 1 f. 
Kontrollgruppe mit 28 \& nur etwa die Hälfte der Verminderung, die die deutschen Papierfabriken mit offenem Wasserkreislauf aufwiesen. Wie bereits in Abschnitt D.2.2 angemerkt, liegen von einer Ausnahme abgesehen bei den schweizerischen Papierfabriken keine Mengenbeschränkungen für das Abwasser vor, so daß dort gemessene Veränderungen des spezifischen Abwasseranfalls weniger auf wasserrechtliche Regelungen als auf exogene Faktoren wie den technischen Fortschritt in der Kreislaufeinengung zurückzuführen sind. So hatten zwar sämtliche Werke Maßnahmen der Kreislaufeinengung ergriffen, jedoch begründete nur ein Einleiter diese mit der Erfüllung der Auflagen. Dagegen wurden Wirtschaftlichkeits-, Rationalisierungs- und Kostenüberlegungen von allen Papierfabriken angegeben ${ }^{1}$. Die Differenz zwischen deutscher und schweizerischer Veränderung des spezifischen Abwasseranfalls dürfte zum einen als wirkung der bundesdeutschen wasserrechtlichen Regelungen auszulegen sein. Zum anderen muß jedoch auch hier die in Versuchs- und Kontrollgruppe unterschiedliche Produktionsstruktur berücksichtigt werden; Werke, die auf Altpapierbasis produzieren - und diese waren mit offenem Kreislauf nur in der deutschen stichprobe vertreten -, haben vergleichsweise bessere Möglichkeiten, den Wasserkreislauf einzuengen und mithin den Abwasseranfall zu senken.

Abschließend sei vermerkt, daß 12 und damit über die Hälfte der 23 deutschen Papierfabriken mit of fenem Wasserkreislauf aufgrund der abgaberechtlichen Bestimmungen Veränderungen des Stoffeinsatzes (Faser- und Hilfsstoffe) vorgenommen hatten und somit durch "vorbeugende" Maßnahmen auf eine Emissionsverminderung hingewirkt haben. Weiterhin hatten sechs Werke, die Leim und stärke als Hilfsstoff verwendeten, deren Einsatz vom - abwasserbelastenden - Masseeinsatz zum Auftrag über die sogenannte Leimpresse verlagert. Diese Maßnahme ist jedoch auch mit Verbesserungen der Papierqualität begründet.

1 Das Werk, welches den Wasserkreislauf nicht nur eingeengt, sondern geschlossen hatte, begründetete dies mit "Umweltbewußtsein". 
Resümmierend kann festgestellt werden, daß sich die Produktionsverfahren 1985 wesentlich abwasserärmer gestalteten als im Jahr 1974. Der spezifische Abwasseranfall wurde bei den deutschen Untersuchungseinheiten mit offenem wasserkreislauf um über die Hälfte reduziert. Die prozentualen Verminderungen waren dabei doppelt so hoch wie bei den schweizerischen Einleitern. Aus der Reduzierung des spezifischen Abwasseranfalls bei letzteren geht das grundsätzliche, nicht durch abgaberechtliche Regelungen geprägte Interesse an der Kreislaufeinengung hervor. Die Differenz zwischen deutscher und schweizerischer Reduzierung des Abwasseranfalls läBt sich dagegen auch oder insbesondere als wirkung der bundesdeutschen wasserrechtlichen Regelungen deuten. Hier kommen als wirkungsursache sowohl das WHG als auch das AbwAG in Betracht. Gemäß den Antworten der Einleiter muß der Einfluß des AbWAG auf die Emissionsvermeidung, die über die Auflagen hinausging, allerdings als gering angenommen werden.

\subsubsection{Sparsamere Verwendung abwasserintensiver Güter}

Die sparsamere Verwendung abwasserintensiver Güter wurde bei denjenigen Papierfabriken untersucht, die 1974 und/oder 1985 mehrere Papiersorten bzw. mehrere Qualitäten einer Papiersorte fertigten. Es waren dies 28 der 31 deutschen Untersuchungseinheiten.

Die Analyse ergab, daB

16 Werke über den unterschiedlichen Abwasseranfall und

19 Werke über die unterschiedliche Abwasserbelastung

der von ihnen hergestellten Papierqualitäten informiert waren.

Aufgrund ihres Uberblicks hatten

6 Werke das Sortenprogramm verändert (z.B. Elimination einer Papiersortel und 
3 Werke mengenmäßige Verschiebungen zwischen den Sorten vorgenommen.

1 Werk hatte sich für beide Maßnahmen entschieden. Keines der Werke hatte Verschiebungen zu einem "papierfremden" Produktbereich vorgenommen, und 2 Werke hatten die Produktion bestimmter Sorten an einen anderen standort verlagert.

14 Werke, also mehr als die Hälfte der Untersuchungseinheiten, hatte das Produktionsprogramm weder qualitativ noch quantitativ verändert:

8 von ihnen, obwohl die Untersuchungen einen unterschiedlichen Abwasseranfall und/oder eine unterschiedliche Abwasserbelastung bei den verschiedenen Papierqualitäten ergeben hatte, und

6 von ihnen, weil sich herausgestellt hatte, das sich die Papiersorten bzgl. des Abwassers nicht wesentlich unterschieden.

Fünf Papierfabriken hatten keine Untersuchungen zum "Abwasserverhalten" ihrer einzelnen Papiersorten angestellt.

Für die gesonderte Erfassung abwasserbedingter Kosten hatten 22 der 31 deutschen Werke eine Kostenstelle eingerichtet. Selbst die Hälfte der acht mit geschlossenem Wasserkreislauf arbeitenden Papierfabriken verfügte über eine entsprechende Kostenstelle. Hier ist anzumerken, daB auch diese Werke das gebrauchte wasser durch mechanische und/oder mechanischchemische Reinigungsanlagen schickten, bevor sie es wieder im ProduktionsprozeB einsetzten.

12 der 23 mit offenem Kreislauf produzierenden Werke gaben darüber hinaus an, die Abwasserabgabe in der Preiskalkulation zu berücksichtigen'.

Zusammenfassend kann gesagt werden, das zum Zeitpunkt der Untersuchung etwa 80 \% der Papierfabriken, die als Mehr-

1 Siehe dazu allerdings die Anmerkung in Fußnote 2, S. 138. 
produktbetrieb zu qualifizieren waren, das "Abwasserverhalten" ihrer unterschiedlichen Produkte kannten. Eliminiert man diejenigen, deren Sorten ein annähernd homogenes Verhalten zeigten, so haben von den verbleibenden Werken die Hälfte Anderungen des Produktionsprogramms aus Abwassergründen vorgenommen. Dieses Resultat sowie die Tatsache, daß 71 aller Untersuchungseinheiten eine Kostenstelle für Abwasser eingerichtet hatte, verdeutlichen, daß das "Nebenprodukt" Abwasser integraler Bestandteil betriebswirtschaftlicher Entscheidungen geworden ist. Wenn einerseits eine sparsamere produktion abwasserintensiver Güter konstatiert werden kann, bleibt andererseits allerdings offen, ob die Verbraucher ihr Kaufverhalten verändert haben.

\subsubsection{Beschleunigte Anwendung der allgemein anerkannten Regeln der Technik}

Die beschleunigte Anwendung der a.a.R.d.T. wurde zum einen durch die zeitliche Vorverlegung, zum anderen durch die sachliche Veränderung bereits geplanter Abwasserreinigungsmaßnahmen gemessen. In die Auswertung wurden nicht nur die Papierfabriken mit offenem Wasserkreislauf, sondern auch die abwasserfrei produzierenden Werke einbezogen, weil die dort vorgenommene Kreislaufschließung u.U. auf den 8 a wHG zurückzuführen ist'. Der geschlossene Kreislauf stellt allerdings eine Maßnahme dar, die über die a.a.R.d.T. im Rahmen der Produktionsverfahren hinausgeht.

Bei den 17 Papierfabriken mit offenem Kreislauf, die zwischen 1974 und 1985 externe Maßnahmen ergriffen hatten², wurde die

1 Diesen Werken wurden die im Fragebogen unter 2.5 und 2.6 aufgeführten Fragen im Hinblick auf die Kreislaufschließung gestellt.

2 Die zwei während des Unterguchungszeitraums erbauten Werke sind von der Betrachtung ausgeschlossen. 
Durchführung dieser Maßnahmen beschleunigt bei (Mehrfachnennungen waren möglich)

4 Werken durch die Mindestanforderungen nach \& 7a wHG,

4 Werken durch über die Mindestanforderungen hinausgehende Auflagen und bei

3 Werken durch die Abwasserabgabe.

8 Werke beschleunigten die Maßnahmen nach ihren Angaben nicht.

Die Abwasserabgabe wurde einmal als alleinige Begründung angegeben.

Bereits bestehende Planungen wurden im Zeitraum von 1974 bis 1985 sachlich verändert bei (Mehrfachnennungen waren möglich)

3 Werken durch die Mindestanforderungen nach \$7a wHG,

1 Werk durch über die Mindestanforderungen hinausgehende Auflagen und bei

2 Werken durch die Abwasserabgabe.

13 Werke veränderten die geplanten Maßnahmen nicht.

Die Abwasserabgabe wurde einmal in Verbindung mit den Mindestanforderungen und einmal in Kombination mit darüber hinausgehenden Auflagen angegeben.

Bei den sieben Untersuchungseinheiten, die zwischen 1974 und 1985 den Wasserkreislauf geschlossen hatten, waren die durchgeführten Maßnahmen beschleunigt worden bei (Mehrfachnennungen waren möglich)

2 Werken durch die Mindestanforderungen nach \$ 7a WHG,

1 Werk durch über die Mindestanforderungen hinausgehende Auflagen und bei

3 Werken durch die Abwasserabgabe.

2 Werke beschleunigten die Maßnahmen nicht. 
Bereits bestehende Planungen wurden verändert bei

3 Werken durch die Mindestanforderungen nach $\$ 7$ a WHG,

0 Werken durch über die Mindestanforderungen hinausgehende Auflagen und bei

1 Werk durch die Abwasserabgabe.

3 Werke veränderten ihre Planungen nicht.

Fazit: 53 \% der Papierfabriken, die mit offenem Kreislauf produzierten und zwischen 1974 und 1985 Investitionen im Bereich der Abwasserreinigung tätigten, hatten diese aufgrund der neuen gewässergütewirtschaftlichen Regelwerke vorverlegt und rund 24 \% hatten bereits geplante Maßnahmen sachlich verändert1. Fünf der sieben Papierfabriken, die im selben Zeitraum die Kreislaufschließung vornahmen, beschleunigten diese und vier Werke entschlossen sich überhaupt erst $z u$ dieser Maßnahme aufgrund der neuen Regelwerke. Der große Einflus des 5 a WHG und des AbwAG insbesondere auf den Bau von Biologien kommt auch in einer Meinungsumfrage des Verbandes Deutscher Papierfabriken zum Ausdruck, die Ende 1973, also vor Erlas der Gesetze durchgeführt wurde. Damals hielten 170 von 213 befragten (allerdings auch indirekt einleitenden) Werken den Bau einer biologischen Reinigungsstufe für nicht erforderlich!

Gemäß den Angaben der Untersuchungseinheiten fiel die Abwasserabgabe als Wirkungsursache hauptsächlich bei der Vorverlegung der Kreislaufschließung ins Gewicht ${ }^{3}$. Daß der EinfluB der Abwasserabgabe sonst eher zweitrangig war, wird

1 Siehe dazu auch die auf s. 95 ff. beschriebenen Ergebnisse früherer Untersuchungen.

2 Vgl. Verband Deutscher Papierfabriken (Hrsg.): Umweltbilanz .... a.a.0., Anlage 1 .

3 Der festgestellte Einflus der Abwasserabgabe auf die Kreislaufschließung harmoniert auch mit der AuBerung von Möbius, daß der größte Vorteil des völlig geschlossenen Wasserkreislaufs in einer Papierfabrik wohl der Wegfall der Abwasserabgabe sein dürfte. Vgl. Möbius, C.H.: Die Abwassersituation .... a.a.0., s. 768 . 
dadurch bestätigt, daß von den 17 biologischen Reinigungsstufen, die zwischen 1974 und 1985 erstmals eingesetzt oder erweitert wurden, 10 erst nach Beginn der Abgabepflicht in Betrieb genommen wurden. Ebenso ging die Hälfte der im gleichen Zeitraum erbauten mechanischen und mechanischchemischen Reinigungsstufen erst nach 1981 in Betrieb. Hier stellt sich die Frage, ob die Abgabestaffelung und die gesetzlich fixierte Abgabenverminderung vor Inbetriebnahme einer neuen Reinigungsanlage die möglichen Wirkungen der Abwasserabgabe nicht gedrosselt haben. Andererseits wurden die Mindestanforderungen an Papierabwässer erst Anfang 1982 herausgegeben. Legt man die Erfahrungen mit dem Vollzug reiner Auflagenlösungen zugrunde, wären Vermeidungsmaßnahmen ohne den Anreiz der Abwasserabgabe noch später erfolgt.

\subsubsection{Einhaltung der Auflagen}

Inwieweit die einzelnen Papierfabriken die wasserrechtlichen Uberwachungswerte für die abgaberechtlichen Schadparameter im Zeitraum von 1981 bis 1985 eingehalten haben, ließ sich daran ablesen, ob ihnen in diesen Jahren die Halbierung des Abgabesatzes für die Restemission gewährt wurde.

Die Untersuchung zeigte ein recht eindeutiges Ergebnis: Die 23 mit offenem Wasserkreislauf produzierenden Werke haben insgesamt $112 \mathrm{Mal}^{1}$ eine Abwasserabgabe entrichtet, wobei 23 Mal Ausnahmen von der Abgabepflicht bestanden, die nicht in die Analyse eingingen. Bei den verbleibenden 89 "Abgabejahren" wurde 79 Mal die Abgabe halbiert, 10 Mal gewährte die zuständige Wasserbehörde die Abgabenhalbierung also nicht. Hierbei handelt es sich offensichtlich nicht um ein gezieltes Nichteinhalten der Auflagen seitens bestimmter Einleiter,

1 Erfast wurden fünf Abgabejahre, wobei 21 Werke während des gesamten Zeitraums die Abwasserabgabe zahlten, ein Einleiter im Jahr 1981 nicht veranlagt wurde und ein Werk, das die Produktion 1982 aufnahm, erst ab 1983 die Abgabe zu entrichten hatte. 
denn die 10 nicht bewilligten Halbierungen verteilten sich auf sieben Untersuchungseinheiten. Auch läßt sich keine Anhäufung der nicht gewährten Halbierungen in bestimmten (z.B. abgabeniedrigen) Jahren beobachten; vielmehr lag die oberschreitung der Auflagen zumeist entweder vor der Inbetriebnahme einer neuen oder erweiterten Reinigungsstufe oder nach einer Produktionsumstellung bzw. -erweiterung.

Es kann also resümmiert werden, daß in 89 \% derjenigen Veranlagungsfälle, in denen keine Ausnahmen der Abgabepflicht bestanden, die Auflagen von den Behörden als eingehalten erachtet und deshalb die Abgabenhalbierungen vorgenommen wurden. Inwieweit hier ein Einfluß der Abwasserabgabe geltend gemacht werden kann, läßt sich allerdings nicht feststellen. Es kann lediglich darauf hingewiesen werden, daß die Auflagen unterschiedlich weit bemessen waren', so daB die zur Einhaltung erforderliche Anstrengung und damit auch die Anreizwirkung der Abgabenhalbierung entsprechend variierte.

1 Siehe dazu Abb. 13. 


\subsection{Die Emissionsentwicklung während der Abgabejahre}

Die in Abschnitt C.2.2.2 aufgestellte Hypothese, die Abgabestaffelung habe den Anreizeffekt der Abwasserabgabe in den Jahren 1981 bis 1985 reduziert, sollte anhand der jährlichen Veränderungen der produktbezogenen schadfrachten, für die die Einleiter die Abgabe zu entrichten hatten, überprüft werden. Tab. 13 zeigt für Papierfabriken, bei denen keine Ausnahmen von der Abgabepflicht bestanden, die Anzahl der Schadeinheiten pro 1000 t Papier, für die die Einleiter Abgabe zahlten. Die für den Zeitraum von 1981 bis 1985 errechneten prozentualen Veränderungen dieser schadfrachten waren bei acht Werken negativ und bei vier Werken positiv. Sie nahmen Werte von -72 bis $+46 \%$ an. Dieser Befund

\begin{tabular}{|c|c|c|c|c|c|c|c|c|}
\hline Werk & \multicolumn{5}{|c|}{$\begin{array}{l}\text { Entgoltene Schadfrachten } \\
\text { (SE/1000 t Papier) }\end{array}$} & \multicolumn{3}{|c|}{$\begin{array}{l}1981 \text { bis } 1985 \\
\text { Veränderung der }\end{array}$} \\
\hline 1 & 308,5 & 178,9 & 160,6 & 148,7 & 145,7 & $-52,8 \%$ & $+33,79$ & \\
\hline 2 & 2,6 & 2,6 & 2,4 & 2,1 & 2,1 & $-19,28$ & $+27,49$ & \\
\hline 3 & 173,4 & 246,8 & 133,7 & 119,8 & 101,4 & $-41,5 \%$ & $+57,69$ & $\%$ \\
\hline 4 & 12,4 & 13,9 & 11,1 & 13,2 & 14,5 & $+16,6 \%$ & $+34,39$ & $\%$ \\
\hline 5 & 4,2 & 6,9 & 8,9 & 8,6 & 6,1 & $+45,7 \%$ & $+49,49$ & $\%$ \\
\hline 6 & 15,2 & 28,8 & 9,0 & 8,4 & 8,2 & $-45,9 \%$ & $+44,3$ & \% \\
\hline 7 & 35,3 & 29,6 & 26.0 & 23,5 & 23,2 & $-34,2 \%$ & $+52,1$ & $q_{6}$ \\
\hline 8 & 79,3 & 51,0 & 29,0 & 22,5 & 22,2 & $-72,0 \%$ & $+117,0$ & \% \\
\hline 9 & 23,5 & 23,5 & 21,1 & 18,7 & 16,0 & $-32,0 \%$ & $+29,89$ & $\%$ \\
\hline 10 & 27,5 & 24,5 & 21,2 & 21,4 & 14.7 & $-46,6 \%$ & $+65,2$ & \% \\
\hline 11 & 18,6 & 18,6 & 18,6 & 18,6 & 19,3 & $+3,7 \%$ & $+36,0$ & \% \\
\hline 12 & 19,1 & 19,3 & 23,5 & 28,9 & 27,4 & $+43,5 \%$ & $+5,39$ & $\%$ \\
\hline
\end{tabular}

Tab. 13: Entwicklung der entgoltenen schadfrachten (und der Jahresproduktionen) von 1981 bis 1985 bei den deutschen Werken 
spricht gegen einen allgemeingültigen Zusammenhang zwischen Höhe des Abgabesatzes und Anzahl der emittierten Schadeinheiten. Die Aussage kann allerdings nur für diejenigen Werke gemacht werden, die während der Abgabejahre nicht in Reinigungsanlagen investierten.

Aus der Beobachtung, daß die Bescheidwerte, also die Uberwachungswerte, die Regel- und Höchstwerte wie auch die Jahresschmutzwassermengen trotz zum Teil erheblicher Produktionssteigerungen bei den meisten Werken während der Abgabejahre konstant geblieben waren, resultierte die Uberlegung, daB die Zunahme der Produktion zu einer Abnahme der produktbezogenen Frachten hatte führen müssen. Abb. 21 gibt für die einzelnen Werke die prozentualen Veränderungen der Schadfrachten und der Jahresproduktionen wieder. Die Veränderungen beziehen sich in der Regel auf den Zeitabschnitt 1981 bis 1985. Die in Tab. 13 aufgeführten Einleiter wurden um solche ergänzt, bei denen keine Ausnahmen von der Abgabepflicht in den Jahren 1981 und 1985 bzw. 1982 und 1985

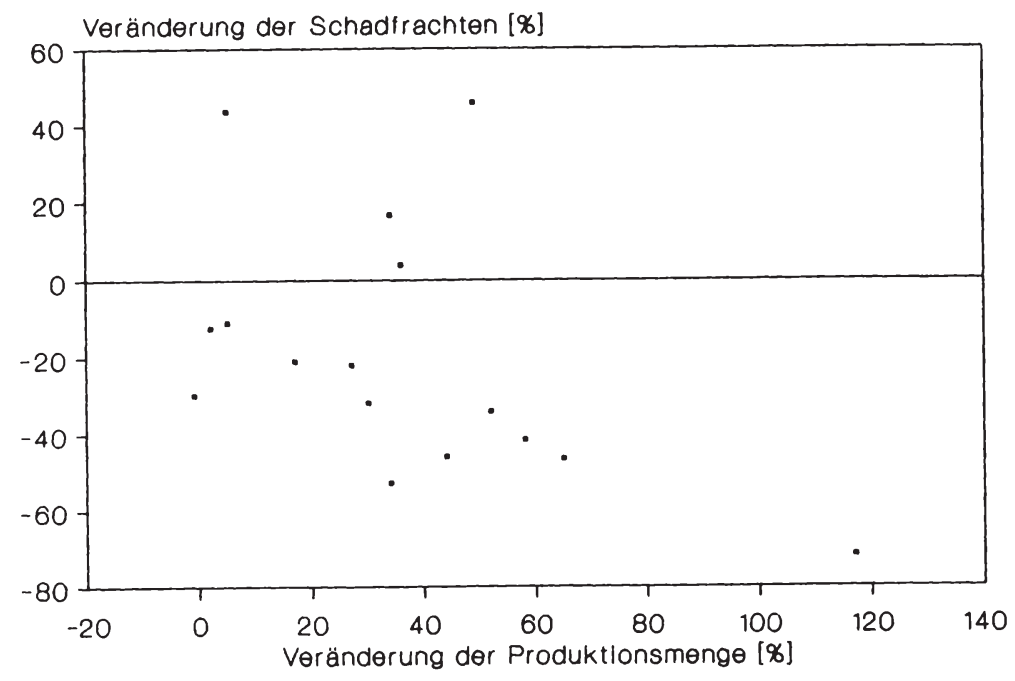

Abb. 21: Prozentuale Veränderung der Produktionsmenge und der produktbezogenen Schadfrachten (SE gemäB Abgabenerhebung) über die Abgabejahre bei den deutschen Werken 
bestanden. Außerdem konnten zwei Papierfabriken einbezogen werden, die ab 1982 bzw. 1983 ohne Ausnahmeregelung die Abwasserabgabe entrichtet hatten ${ }^{1}$.

Aus Abb. 21 wird ersichtlich, daß sich die Werke zu zwei Gruppen zusammenfassen lassen. Die eine besteht aus den Werken, die sowohl die Produktion als auch die Emission pro Produkteinheit erhöhten, so daß die Gesamtemission - trotz Verdreifachung des Abgabesatzes - überproportional zur Produktionserhöhung stieg. Die andere Gruppe läBt die Tendenz erkennen, die Produktfrachten in Abhängigkeit der Produktionssteigerung $\mathrm{zu}$ senken. Letzterer Zusammenhang wurde statistisch überprüft und in $\mathrm{Abb} .22$ isoliert dargestellt. Die durchgeführte Regressionsanalyse wies einen Korrelationskoeffizienten von 86 \% auf, und $74 \%$ der Werte wurden durch die Regression erklärt. Ein positiver Zusammenhang zwischen Verminderung der Schadfrachten und Erhöhung der Produktion wurde damit bestätigt.

Noch nicht erfaßt sind damit die Faktoren, die zu dieser beobachteten Abhängigkeit führten. Zunächst kommt die Aufiagenpraxis als Einflußgröße in Betracht. Wie in Abschnitt D.2.1 beschrieben, werden die in der 19. Verwaltungsvorschrift festgelegten Produktfrachten für Papierabwässer in der Regel nicht als solche in die wasserrechtlichen Bescheide übernommen, sondern in Konzentrationen umgeformt. Im Zusammenspiel mit der ebenfalls festgeschriebenen Jahresschmutzwassermenge stellen sie dann jahres- und nicht produktbezogene Begrenzungen dar. Sofern die Bescheide also nicht an Produktionsveränderungen angepaßt werden oder

1 Folgende Wertekombinationen kommen $\mathrm{zu}$ den in Tab. 14 aufgeführten hinzu:

\begin{tabular}{|c|c|c|}
\hline Werk & $\begin{array}{l}\text { Veränderung der Schad- } \\
\text { frachten }\end{array}$ & $\begin{array}{l}\text { Veränderung der Pro- } \\
\text { duktion }\end{array}$ \\
\hline 12 & $-21,0 \%$ & $+17,1 \%$ \\
13 & $-11,0 \%$ & $+4,8 \%$ \\
14 & $-30,0 \%$ & $-1,0 \%$ \\
15 & $-12,5 \%$ & $+2,3 \%$ \\
\hline
\end{tabular}




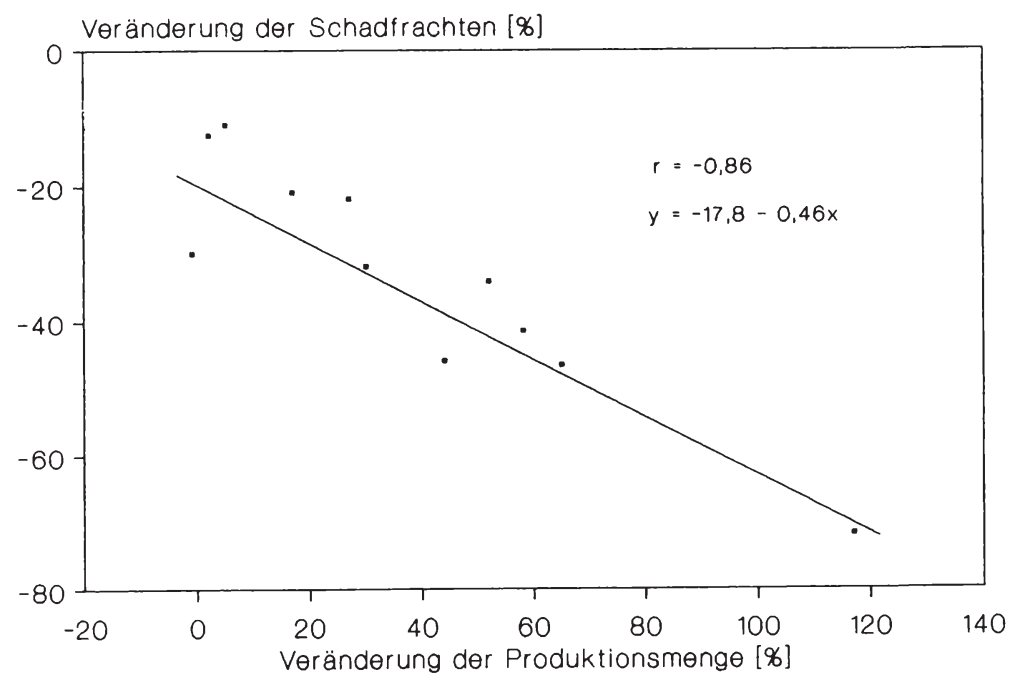

Abb. 22: Zusammenhang zwischen der prozentualen Veränderung von Produktionsmenge und produktbezogenen Schadfrachten (SE gemäß Abgabenerhebung) bei deutschen Werken

bereits auf Produktionssteigerungen ausgelegt sind, erfordert die Erhöhung der Produktion die Senkung der Produktfrachten. Diese Erklärung erscheint für mehrere der aufgeführten Werke plausibel und hat vielleicht auch grundsätzlich das Denken der Einleiter geprägt. Sie kann jedoch nicht für sämtliche Papierfabriken zutreffen, weil einige Werke durchaus "Spielraum" zwischen eingeleiteter und erlaubter Jahresemission hatten und diesen bei Produktionserhöhungen nicht ausgenutzt haben. Hier scheint eher das Bemühen, ein einmal erreichtes Reinigungsniveau nicht wieder zu unterschreiten, im Vordergrund zu stehen ${ }^{1}$. Für diese Haltung seitens der Einleiter sprechen auch die Ergebnisse einer Regressionsanalyse, der Schadfrachten zugrundeliegen, in deren Berechnung durchweg die eingeleiteten und nicht die abgaberechtlich

1 Als weitere Erklärung für das beobachtete Verhalten kommt ferner in Betracht, daß die - limitierten - Frischwassermengen ausgeschöpft waren und deshalb bei Produktionssteigerungen die Wasserkreisläufe weiter eingeengt werden mußten. So begründeten jedenfalls zwei Werke u.a. die von ihnen durchgeführten innerbetrieblichen Vermeidungsmaßnahmen. 
erlaubten Jahresschmutzwassermengen eingegangen sind' ${ }^{\text {. Wie }}$ aus Abb. 23 ersichtlich, werden die Korrelation (90 \&) und der Anteil der erklärten streuung an der Gesamtstreuung (81 \%) dann noch größer.

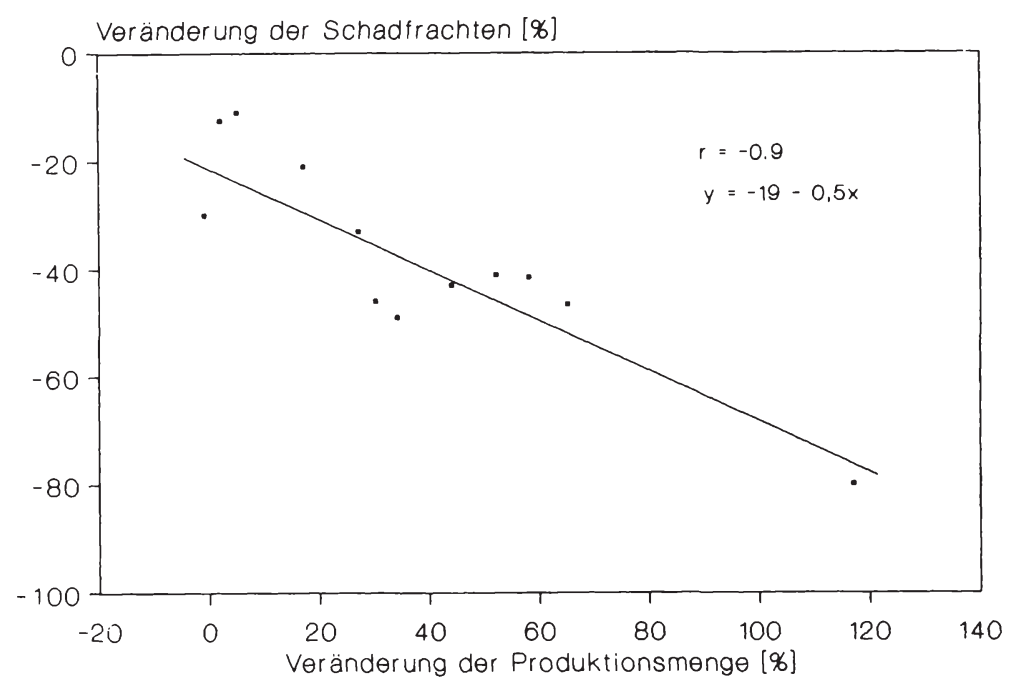

Abb. 23: Zusammenhang zwischen der prozentualen Veränderung von Produktionsmenge und produktbezogenen Schadfrachten (SE bei eingeleiteter Jahresschmutzwassermenge) bei deutschen Werken

Neben dem Zusammenhang zwischen Produktionssteigerung und Frachtverminderung verdeutlichen die Regressionsgleichungen weiterhin, daß der Emissionsabbau zu einem Teil unabhängig von der Produktionsveränderung vorgenommen wurde. Addiert man die Anzahl der emittierten Schadeinheiten und die Produktion über sämtliche Werke, die in Abb. 22 berücksichtigt wurden, so stand einer Produktionserhöhung von 25 \% eine Verminderung der Emissionen um 53 \& gegenüber. Letztere entwickelte sich

1 Die Berechnung der Schadeinheiten, für die die Werke Abwasserabgabe $\mathrm{zu}$ entrichten haben, erfolgt von seiten der Behörden insofern nicht einheitlich, als z.B. bei Einleitern, deren Bescheid noch nicht umgestellt worden ist, die tatsächliche und nicht die abgabenrechtlich festgelegte Jahresschmutzwassermenge in die Abgabenberechnung eingeht. 
also $\mathrm{zu}$ ersterer überproportional, was auf eine Reihe exogener Einflußgrößen, wie z.B. den umwelttechnischen Fortschritt zurückzuführen sein dürfte. Dieser könnte auch den oben regressionsanalytisch festgestellten Zusammenhang mitbewirkt haben. Denn Produktionssteigerungen bedingen in der Regel Veränderungen der Produktionsanlagen, bei denen verstärkt neuere technische Entwicklungen Berücksichtigung finden, welche dann zu einer Verminderung der Produktfrachten führen.

Einer eingehenderen Betrachtung bedurften auch die Werke, bei denen die Schadfrachten über die Zeit erhöht wurden. Bei zwei Einleitern dieser Gruppe handelte es sich um Papierfabriken, die als "Vorreiter" der Abwasserreinigung qualifiziert werden konnten, weil sie zu den ersten zählten, die biologisch reinigten und deshalb früher als die anderen Werke über eine entsprechende Abwasserqualität verfügten. Sie wiesen, wie auch die beiden anderen Einleiter dieser Gruppe, selbst noch 1985 Abwasserwerte auf, die auf dem Reinigungsniveau vergleichbarer Werke lagen. Bei drei Einleitern hatte - gleichermaßen wie bei mehreren Werken der anderen Gruppe eine Umstellung der Bescheide noch nicht stattgefunden.

Um das Verhalten der deutschen Einleiter relativieren $\mathbf{z u}$ können, wurde auch die Entwicklung der Emissionen von den schweizerischen Werken untersucht. Sie wurde über die BSB。 Produktfrachten in den Jahren 1981 und 1985 erfaBt, weil der BSBo der meistuntersuchte schadparameter in der schweizerischen Kontrollgruppe war. Die erforderlichen Daten lagen für fünf der sechs Werke mit offenem Wasserkreislauf vor. Wie Abb. 24 veranschaulicht, streuten die Veränderungen der Produktfrachten zwischen -65 und $+117 \%$.

Zusammenfassend ist festzuhalten, daß keine Ursache-WirkungsBeziehung zwischen der Höhe des Abgabesatzes und dem Emissionsverhalten bei Einleitern, die während der Abgabejahre nicht in neue Abwasserreinigungsanlagen investierten, 


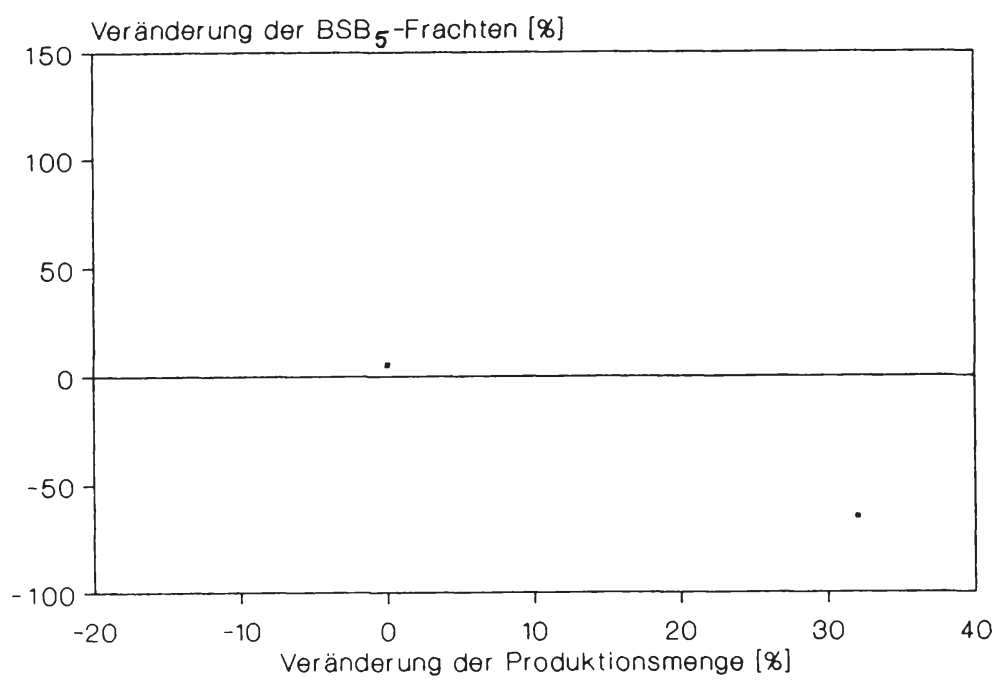

Abb. 24: Prozentuale Veränderung der Produktionsmenge und der eingeleiteten $\mathrm{BSB}_{3}$-Frachten (produktbezogen) bei schweizerischen Werken von 1981 bis 1985

hergestellt werden konnte. Die Hypothese, die Abgabestaffelung habe den Anreizeffekt der Abgabe in den Jahren 1981 bis 1985 um den jeweiligen Betrag reduziert, lieB sich wegen der von Einleiter zu Einleiter sehr unterschiedlichen Entwicklung der Emission nicht bestätigen. Für das Emissionsverhalten waren offensichtlich eine Vielzahl von Variablen sowie ihr einleiterindividuelles Zusammenspiel verantwortlich. Sie führten bei vielen Werken dazu, daß die Produktfrachten in Abhängigkeit der Produktionssteigerung gesenkt wurden. Nicht zuletzt die Beobachtung, das die schweizerische Kontrollgruppe ein mit den deutschen Untersuchungseinheiten vergleichbares Verhalten aufzeigte, läBt auf eine untergeordnete Rolle des AbwAG bei der Entwicklung der Emissionen während der Abgabejahre schließen. 


\subsection{Exkurs: Anfall und Verbleib der Rückstände aus der Abwasserbehandlung}

Aus der Abwasserreinigung resultiert einerseits gesäubertes Wasser, andererseits wird aber auch Schlamm in Form von Sedimenten der einzelnen Reinigungsstufen produziert. Aufgrund der Feststoffverluste bei der Blattbildung, die durch die unvollständige Rückhaltung der Faser- und Hilfsstoffe im Faservlies bedingt ist, entstehen bei der Papierherstellung Schlammengen, wie sie in ihrem produktbezogenem Umfang in fast keiner anderen Industrie anfallen². Die Behandlung und Entsorgung dieser Schlämme spielt sowohl verfahrens- als auch kostenmäßig eine der Abwasserreinigung durchaus ebenbürtige Rolle $e^{2}$.

Als Möglichkeiten der Beseitigung oder Verwertung der entwässerten und zum Teil auch getrockneten Schlämme kommen insbesondere die Deponie, die Verbrennung (mit anschließendem Deponieren oder Verwerten) sowie verschiedene Verwertungsmöglichkeiten in Betracht. Zu letzteren zählen der Einsatz des Schlamms als Rohstoff anderer Erzeugnisse sowie seine biologische bzw. agrartechnische Verwendung. Auch können die Schlämme bei einigen Papiersorten in den ProduktionsprozeB zurückgeführt werden. Dabei muß jedoch mit Produktionseinbußen gerechnet werden, wenn biologische Schlämme zu einem wesentlichen Anteil im Schlammgemisch enthalten sind ${ }^{3}$.

Ausgehend von der Ubberlegung, daß nicht nur Veränderungen des Produktionsumfangs, sondern auch die neuen wasserrechtlichen Regelungen Einfluß auf den Schlammanfall nehmen können, wurde im Rahmen der vorliegenden Arbeit das Augenmerk auch auf die

1 Vgl. Brecht, W., Dalpke, H. -L.: Wasser ..., a.a.O., s. 461 .

2 Vgl. ebenda: Wasser .... a.a.O., s. 461; Wenze1, L.: Schlamm: Entwässerung, Verwertung, Beseitigung - brauchbare andere Reststoffe eingeschlossen, in: Allgemeine Papierrundschau, 110. Jg. (1986), Heft 44, S. 1538 .

3 Vgl. ebenda, S. 1540 . 
Entwicklung der Menge sowie des Verbleibs der Schlämme gerichtet.

Abb. 25 und Abb. 26 illustrieren die von den deutschen Untersuchungseinheiten gewählten Arten der Beseitigung und Verwertung ihrer Rückstände aus der Abwasserreinigung. Es lassen sich zwei wesentliche Entwicklungen während des Untersuchungszeitraums verzeichnen:

1. Während 1974 keines der Werke die Möglichkeit der "externen" Verwertung nutzte, wurden 1985 immerhin in neun Fällen mechanische/mechanisch-chemische schlämme und in drei Fällen biologische Überschußschlämme außerbetrieblich wiederverwertet. Fünf Werke lieferten ihre Rückstände aus der Abwasserreinigung Ziegeleien, die anderen Werke führten sie der Pappenfertigung, der Kompostierung oder Begrünungszwecken zu. Ein Werk gab die bei der Verbrennung enstandene Asche an Zementhersteller weiter.

2. Der biologische Uberschußschlamm wurde in erster Linie an Deponien abgegeben.

Im Gegensatz zu den deutschen Untersuchungseinheiten nutzten drei schweizerische Werke bereits 1974 Möglichkeiten der auBerbetrieblichen, insbesondere die der landwirtschaftlichen Verwertung. 1985 wurden $89 \%$ der Rückstände, die nicht innerbetrieblich verarbeitet wurden, anderen Verwertungen zugeführt.

Während die deutschen Werke die Produktionsmenge von 1974 bis 1985 insgesamt um 72 \% steigerten, kam es im gleichen Zeitraum etwa zu einer Verdoppelung derjenigen Rückstände, die nicht im eigenen Werk zurückgeführt wurden. Die Entsorgung über das Abwasser ist also wenigstens teilweise zu anderen Bereichen verlagert worden. Von einigem Interesse aber hier nicht zu beantworten - ist dabei die Frage, wie diese Entwicklung, die als Nebenwirkung der neuen wasserrechtlichen Regelungen qualifiziert werden dürfte, aus gesamtökologischer sicht $z u$ bewerten ist. 


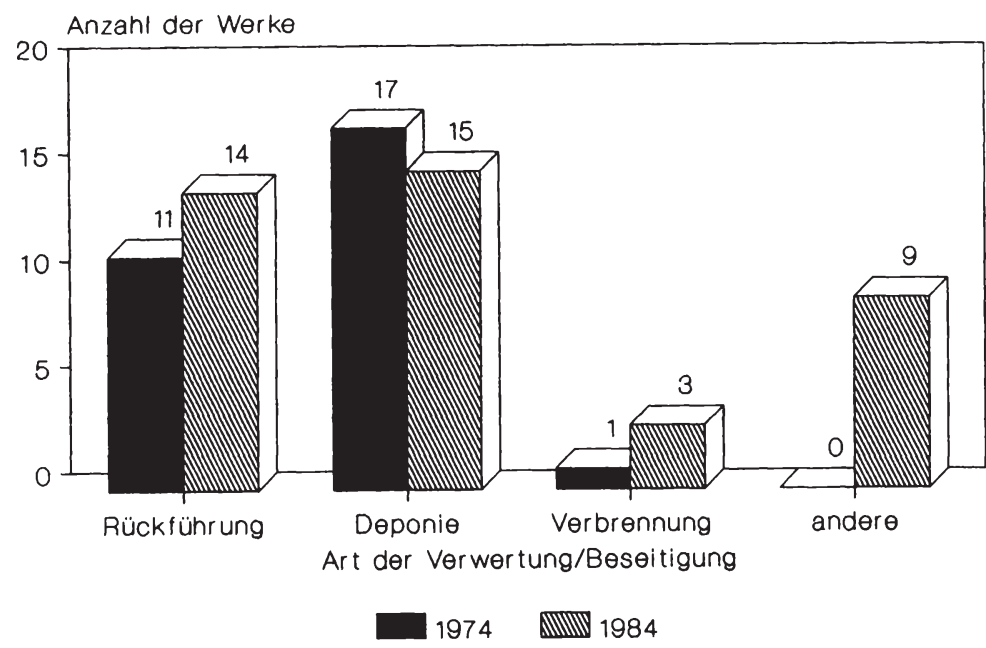

Abb. 25: Verbleib der mechanischen/mechanisch-chemischen Faserschlämme bei den deutschen Werken

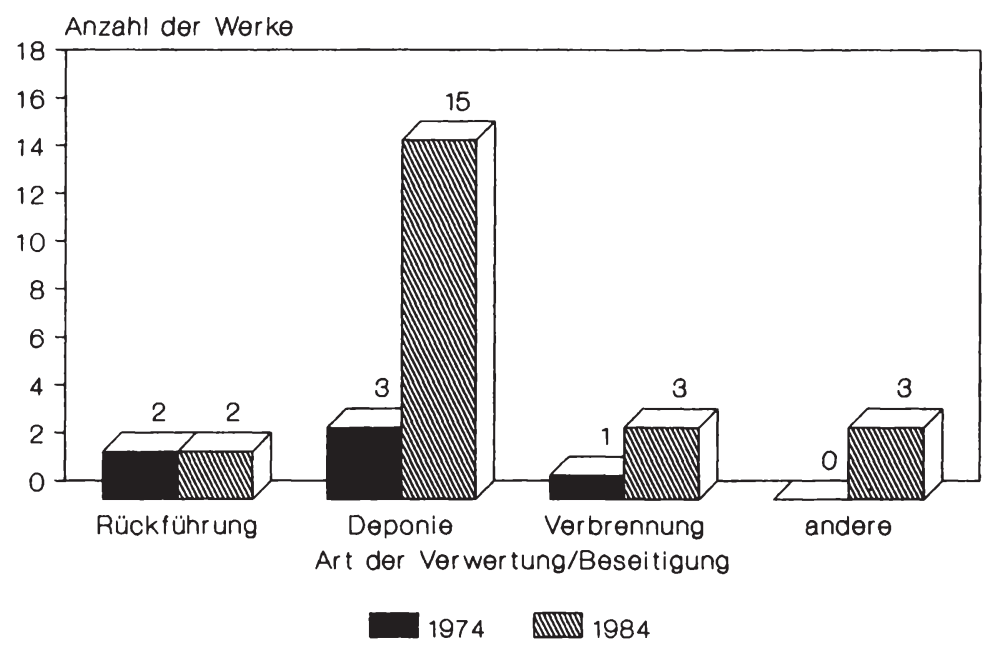

Abb. 26: Verbleib des biologischen Uberschußschlamms bei den deutschen Werken 


\section{Okonomische Wirkungen}

\subsection{Allokative Effekte}

4.1.1 Gültigkeit der abgabentheoretischen Wirkungshypothese

Die Wirkungsweise, die einer Emissionsabgabe allgemein unterstellt wird, baut auf der Annahme auf, der Emittent führe Reinigungsmaßnahmen bis zu dem Umfang durch, bei dem die Grenzkosten der Vermeidungsmaßnahmen die Höhe des Abgabesatzes erreichen. Bei der Ausgestaltung des AbwAG nahm deshalb die Diskussion um die Höhe des Abgabesatzes, mit dem ein bestimmter Wirkungsgrad der Kläranlagen herbeigeführt werden sollte, eine zentrale stellung ein. Im Rahmen dieser Arbeit soll mehr Klarheit über die Kosten der Vermeidungsmaßnahmen auf der einen und über das daraus resultierende Verhalten der Emittenten auf der anderen seite gewonnen werden. Damit wird intendiert, die allokativen Effekte der Abwasserabgabe besser einschätzen zu können.

Die Einleiter der deutschen stichprobe wurden nach den Abwasserreinigungskosten befragt, die bei ihnen für die Vermeidung einer schadeinheit anfielen. Wie erwartet, konnten die einzelnen Werke die Kosten der letzten vermiedenen Schadeinheit (geschweige denn die Grenzkostenfunktion ihrer externen Vermeidungsmaßnahmen) nicht angeben. Es war jedoch bei 14 Papierfabriken möglich, die durchschnittlichen Kosten pro vermiedener Schadeinheit zu ermitteln. Sechs Werke konnten sie allerdings nicht für die biologische, sondern nur für die gesamte Reinigungsanlage (mechanische bzw. chemischmechanische und biologische stufe) beziffern, weil eine Kostenunterteilung nach Reinigungsstufen nicht durchführbar war. Bei drei Werken, bei denen die durchschnittlichen Kosten für die gesamten externen Vermeidungsmaßnahmen 120, 136 und 360 DM ergaben, bestanden Unsicherheiten bzgl. der Anzahl der vermiedenen Schadeinheiten, weshalb sie in die weiteren Analysen nicht eingingen. 
Zunächst wurde ein zwischenbetrieblicher Vergleich der durchschnittlichen Kosten vorgenommen. Dafür erfolgte insofern eine Homogenisierung der Abwasserreinigungskosten über alle Einleiter, als die Anschaffungskosten der Reinigungsanlagen linear über zehn Jahre abgeschrieben und nach der Durchschnittswertmethode mit 7 \& verzinst wurden. Neben den Betriebskosten war also ein einheitlich berechneter Kapitaldienst Grundlage der weiteren Betrachtungen.

In Tab. 14 sind die so ermittelten durchschnittlichen Kosten pro vermiedener schadeinheit zusammen mit den Wirkungsgraden der Anlagen aufgelistet und in Abb. 27 graphisch dargestellt. Die Werke sind in der Tabelle nach ihrer Zugehörigkeit zu bestimmten Produktgruppen, wie sie die Mindestanforderungen definieren, zusammengefaßt.

\begin{tabular}{|c|c|c|c|c|}
\hline Gruppe & Werk & $\begin{array}{l}\text { Durch- } \\
\text { schnittliche } \\
\text { Kosten pro } \\
\text { vermiedener } \\
\text { Schadeinheit } \\
\quad(\mathrm{DM} / \mathrm{SE})\end{array}$ & $\begin{array}{l}\text { Realisierter } \\
\text { Wirkungs- } \\
\text { grad, } n_{\text {sE }} \\
\qquad(8)\end{array}$ & $\begin{array}{l}\text { Reinigungs- } \\
\text { anlage }\end{array}$ \\
\hline A & $\begin{array}{l}1 \\
2 \\
3 \\
4\end{array}$ & $\begin{array}{l}31,- \\
25,- \\
53,- \\
47,-\end{array}$ & $\begin{array}{l}82 \\
91 \\
88 \\
91\end{array}$ & $\begin{array}{l}\text { Biologie } \\
\text { Biologie } \\
\text { Biologie } \\
\text { Gesamte Anl. }\end{array}$ \\
\hline B & $\begin{array}{l}5 \\
6 \\
7\end{array}$ & $\begin{array}{l}64,- \\
21,- \\
19,-\end{array}$ & $\begin{array}{l}87 \\
95 \\
92\end{array}$ & $\begin{array}{l}\text { Biologie } \\
\text { Biologie } \\
\text { Biologie }\end{array}$ \\
\hline C & $\begin{array}{l}8 \\
9\end{array}$ & $\begin{array}{l}64,- \\
24,-\end{array}$ & $\begin{array}{l}79 \\
92\end{array}$ & $\begin{array}{l}\text { Biologie } \\
\text { Biologie }\end{array}$ \\
\hline D & $\begin{array}{l}10 \\
11\end{array}$ & $\begin{array}{l}41,- \\
58,-\end{array}$ & $\begin{array}{l}91 \\
83\end{array}$ & $\begin{array}{l}\text { Gesamte Anl. } \\
\text { Gesamte Anl. }\end{array}$ \\
\hline
\end{tabular}

Tab. 14: Homogenisierte durchschnittliche Kosten pro vermiedener Schadeinheit und realisierte Wirkungsgrade von Reinigungsanlagen deutscher Werke (1985) 


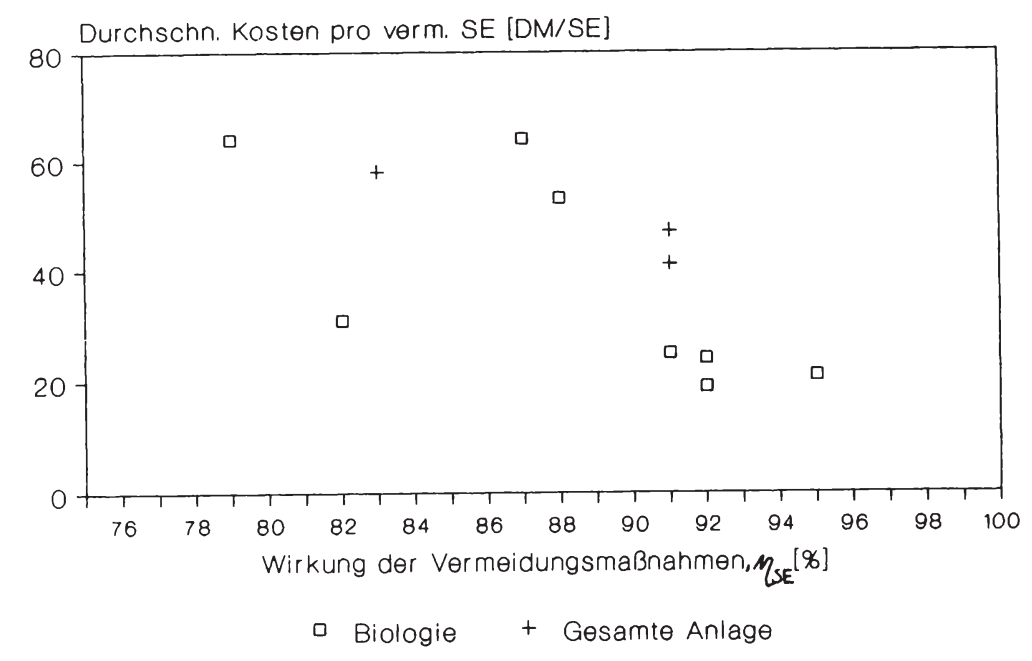

Abb. 27: Durchschnittliche Kosten pro vermiedener Schadeinheit bei den deutschen Werken (1985)

Es konnte zunächst festgestellt werden, daß die durchschnittlichen Kosten 1985 Werte von 19 bis 64 DM annahmen und die wirkungsgrade von $n_{\mathrm{SE}}=79$ bis 95 \% reichten. Die große Bandbreite der finanziellen Belastungen - gelbst innerhalb der Produktgruppen zeigten die Kosten erhebliche Schwankungen - dürfte die Ursache dafür sein, daß ein Ansteigen der durchschnittlichen Kosten - und damit der Grenzkosten - bei zunehmendem Wirkungsgrad nicht zu erkennen war. Gleichermaßen konnten, wie Abb. 28 veranschaulicht, ecommoics of scale nicht bestätigt werden.

Das große streuen der durchschnittlichen Kosten dürfte zum einen an der Vielfalt der möglichen Vermeidungsmaßnahmen, die selbst innerhalb einer Reinigungsstufe erheblich variieren und sich in unterschiedlich hohen Anschaffungs- und Betriebskosten niederschlagen, gelegen haben ${ }^{1}$. In diesem Zusammenhang

1 Auch die Kosten für die Schlammbehandlung und -entsorgung fielen zum Teil sehr unterschiedlich aus. 


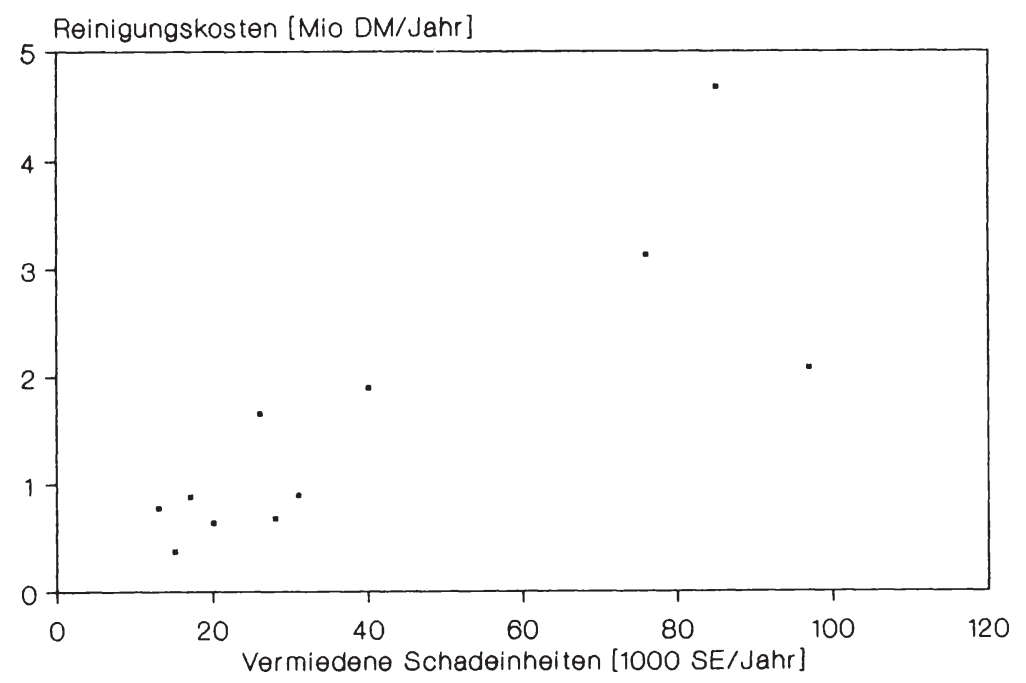

Abb. 28: Homogenisierte Abwasserreinigungskosten und Anzahl der vermiedenen Schadeinheiten bei den deutschen Werken (1985)

kann auch die verschiedenartige Beschaffenheit der Abwässer, die unterschiedliche Vermeidungsmaßnahmen erfordert, nicht außer acht gelassen werden. Zum anderen waren einige Reinigungsanlagen auf produktionserweiterungen ausgelegt und verursachten mithin einen entsprechend höheren Kapitaldienst.

Die homogenisierten durchschnittlichen Kosten lagen bei fünf Werken unter und bei sechs Werken über dem Abgabesatz, der $198536 \mathrm{DM} / \mathrm{SE}$ betrug und sich seit 1986 auf $40 \mathrm{DM} / \mathrm{SE}$ beläuft. Im gewichteten Mittel konnten die durchschnittlichen Kosten für die biologischen Reinigungsstufen in Höhe von 39 DM und für die gesamten Abwasserreinigungsanlagen in Höhe von 45 DM festgestellt werden. Unterstellt man steigende Grenzkosten, hätten die Kosten für die biologische Reinigung an sich höher als die der gesamten Abwasserreinigung liegen mũssen ${ }^{1}$. Die

1 Der Unterschied dürfte jedoch unwesentlich sein, weil bis zu Wirkungsgraden von etwa 90 bis 95 \%ur ein schwach progressiver Grenzkostenverlauf unterstellt wird. Vgl. Rincke, G., Göttsching, L., Irmer, H., Dalpke, H.-L.: 
entgegengesetzte Beobachtung im Rahmen dieser Arbeit dürfte auf die verhältnismäßig kleine Anzahl der Untersuchungseinheiten zurückzuführen sein.

Der mittlere realisierte Wirkungsgrad betrug bei den Biologien $\eta_{B E}=88$ und bei den gesamten Reinigungsanlagen $90 \%$. Im "Gutachten über die einzel- und volkswirtschaftlichen Auswirkungen des geplanten Abwasserabgabengesetzes auf die Papier- und Zellstoffindustrie" von Rincke/Göttsching/ Irmer/Dalpke war man zu dem Ergebnis gekommen, daß auf der Kostenbasis des Jahres 1974 die Anreizwirkung der Abwasserabgabe bei einem Abgabesatz von $40 \mathrm{DM} / \mathrm{SE}$ bis zu einem Wirkungsgrad von $\eta_{5 E}=96 \%$ und bei einem Abgabesatz von $25 \mathrm{DM} / \mathrm{SE}$ bis $\mathrm{zu}$ einem Wirkungsgrad von $\mathrm{n}_{\mathrm{E}} \mathrm{E}=95 \% \mathrm{im}$ Branchenmittel gereicht hätte. Zieht man diese Daten hier $z u$ einem Vergleich herbei, muß u.a. berücksichtigt werden, das die Anzahl der vermiedenen Schadeinheiten damals noch nach der Formel des Gesetzentwurfes vom 18.6.1974 berechnet wurde $^{1}$, welche von der heute gültigen Formel abweicht. Des weiteren war damals von einem Abschreibungszeitraum von 15 Jahren und einem kalkulatorischen Zinsfuß von 9 \% ausgegangen worden ${ }^{2}$.

Einen steigenden Grenzkostenverlauf vorausgesetzt, lag bei wenigstens sechs der untersuchten Einleiter, nämlich bei all denjenigen, deren durchschnittliche Kosten größer als der Abgabesatz waren, der Schnittpunkt von Grenzkosten und Abgabesatz bei einem niedrigeren als dem jeweils realisierten Wirkungsgrad und damit unter dem für 1974 ermittelten Wirkungsgrad von $\eta_{\mathrm{BE}}=96 \%$ bzw. $95 \%$. Bei den Werken, deren durchschnittliche Kosten niedriger als der Abgabesatz waren,

Gutachten ..., a.a.0., s. 120 .

1 Vgl. Deutscher Bundestag 7. Wahlperiode: Drucksache 7/2272 vom 18.6.1974, S. 15 .

2 Vgl. Rincke, G., Göttsching, L., Irmer, H., Dalpke, H.-L.: Gutachten .... a.a.0., s. 97. 
kann eine derartige "Lagebestimmung" des Schnittpunktes nicht gemacht werden.

Das Reinigungsverhalten der Einleiter wurde anhand deren nicht homogenisierten Kosten beurteilt. Aus Tab. 15 geht hervor, daß auch diese bei vier Werken über dem damals gültigen Abgabesatz lagen. Uber die Anreizwirkung der Abwasserabgabe hinaus haben jedoch sämtliche Werke gereinigt, denn sie kamen durchweg in den Genuß der Abgabenhalbierung, so daß der Abgabesatz also nur $18 \mathrm{DM} / \mathrm{SE}$ betrug. Um feststellen zu können, ob dieses Reinigungsverhalten "freiwillig" oder zur Einhaltung der Auflagen notwendig war, wurden in

\begin{tabular}{|c|c|c|c|c|}
\hline Gruppe & Werk & $\begin{array}{l}\text { Durch- } \\
\text { schnittliche } \\
\text { Kosten pro } \\
\text { vermiedener } \\
\text { Schadeinheit } \\
\quad \text { (DM/SE) }\end{array}$ & $\begin{array}{l}\text { Realisierter } \\
\text { Wirkungs_ } \\
\text { grad, } n_{\text {SE }} \\
\text { (8) }\end{array}$ & $\begin{array}{l}\text { Reinigungs- } \\
\text { anlage }\end{array}$ \\
\hline A & $\begin{array}{l}1 \\
2 \\
3 \\
4\end{array}$ & $\begin{array}{l}25,- \\
27,- \\
45,- \\
34,-\end{array}$ & $\begin{array}{l}82 \\
91 \\
88 \\
91\end{array}$ & $\begin{array}{l}\text { Biologie } \\
\text { Biologie } \\
\text { Biologie } \\
\text { Gesamte Anl. }\end{array}$ \\
\hline B & $\begin{array}{l}5 \\
6 \\
7\end{array}$ & $\begin{array}{l}59,- \\
21,- \\
31,-\end{array}$ & $\begin{array}{l}87 \\
95 \\
92\end{array}$ & $\begin{array}{l}\text { Biologie } \\
\text { Biologie } \\
\text { Biologie }\end{array}$ \\
\hline C & $\begin{array}{l}8 \\
9\end{array}$ & $\begin{array}{l}67,- \\
24,-\end{array}$ & $\begin{array}{l}79 \\
92\end{array}$ & $\begin{array}{l}\text { Biologie } \\
\text { Biologie }\end{array}$ \\
\hline D & $\begin{array}{l}10 \\
11\end{array}$ & $\begin{array}{l}38,- \\
52,-\end{array}$ & $\begin{array}{l}91 \\
83\end{array}$ & $\begin{array}{l}\text { Gesamte Anl. } \\
\text { Gesamte Anl. }\end{array}$ \\
\hline
\end{tabular}

Tab. 15: Nicht homogenisierte durchschnittliche Kosten pro vermiedener Schadeinheit und realisierte Wirkungsgrade von Reinigungsanlagen deutscher Werke (1985) 
Tab. 16 die realisierten Wirkungsgrade denjenigen Wirkungsgraden gegenübergestellt, die als erforderlich erachtet wurden, um die Überwachungswerte bei den behördlichen Kontrollen nicht zu überschreiten. Die durchschnittlich emittierten schadkonzentrationen sollten dafür höchstens $80 \%$ der jeweiligen Uberwachungswerte betragen.

Es sei angemerkt, daß bei den Werken 1, 2, 10 und 11 die Bescheide bis 1985 noch nicht umgestellt worden waren, die beiden letztgenannten Werke hatten zudem keine Uberwachungswerte zu erfüllen.

\begin{tabular}{|c|c|c|c|c|}
\hline Werk & $\begin{array}{l}\text { Realisierter } \\
\text { Wirkungs- } \\
\text { grad, } \text { n SE } \\
\text { (\%) }\end{array}$ & $\begin{array}{l}\text { Erforder- } \\
\text { licher Wir- } \\
\text { kungsgrad, } \\
\mathrm{n}_{\text {sE }} \\
\qquad(\&)\end{array}$ & $\begin{array}{l}\text { Differenz } \\
\text { der Wir- } \\
\text { kungsgrade } \\
\text { (Anzahl der } \\
\text { Prozent- } \\
\text { punkte) }\end{array}$ & Bescheid \\
\hline 1 & 82 & 75 & -7 & "alt" \\
\hline 2 & 91 & 63 & -28 & "alt" \\
\hline 3 & 88 & 86 & -2 & "neu" \\
\hline 4 & 91 & 78 & -13 & "neu" \\
\hline 5 & 87 & 88 & +1 & "neu" \\
\hline 6 & 95 & 89 & -6 & "neu" \\
\hline 7 & 92 & 93 & +1 & "neu" \\
\hline 8 & 79 & 72 & -7 & "neu" \\
\hline 9 & 92 & 75 & -17 & "neu" \\
\hline 10 & 91 & -- & & "alt" \\
\hline 11 & 83 & -- & & "alt" \\
\hline
\end{tabular}

Tab. 16: Realisierte und zur Einhaltung der Überwachungswerte erforderliche Wirkungsgrade von Reinigungsanlagen deutscher Werke (1985) 
Vergleicht man die realisierten und die zur Einhaltung der Auflagen erforderlichen Wirkungsgrade' ${ }^{1}$, so kann konstatiert werden, daß die Werke 5 und 7 keine geringere als die erbrachte Reinigungsleistung hätten aufweisen dürfen, beabsichtigten sie, die ihnen gestellten Auflagen einzuhalten. In einer annähernd gleichen situation befand sich das Werk 3. Die anderen werke reinigten zwischen 7 und 28 Prozentpunkten über den erforderlichen Wirkungsgrad hinaus und befanden sich damit im eigenständigen Wirkungsbereich der Abwasserabgabe. Ursächlich für dieses bereits in Abschnitt D.3.1 beschriebene Reinigungsverhalten dürften jedoch in erster Linie die dort gegebenen technischen, umwelt- und motivationsorientierten Erklärungen sein; denn die Gegenüberstellung von halbiertem Abgabesatz und nicht homogenisierten durchschnittlichen Kosten pro vermiedener schadeinheit zeigt, daß die Minimierung der Abwasserkosten bei diesen Einleitern kaum handlungsbestimmend gewesen sein kann.

Hervorgehoben werden muß in diesem Zusammenhang jedoch auch, daß bei allen untersuchten Werken die biologische Reinigung unerläBlich für die Einhaltung bereits oder in naher zukunft gestellter Auflagen war, so daß der Kapitaldienst sowie ein Teil der Betriebskosten festgeschrieben war. Okonomische Opportunität setzte insofern bei der Optimierung der Reinigungsstufen an, deren Kosten in obiger Betrachtung jedoch nicht gesondert zum Ausdruck kommen.

Resümmierend sei festgehalten, daß die Bandbreite der durchschnittlichen Kosten pro vermiedener Schadeinheit bei den untersuchten Einleitern so groß war, daß weder ein Zusammenhang zwischen Höhe der besagten Kosten und Wirkungsgrad noch Größe der Reinigungsanlage hergestellt werden konnte. Dies ist umso bemerkenswerter, als die untersuchten Werke aufgrund der verhältnismäBig ähnlichen Beschaffenheit ihrer Abwässer - legt man die bundesdeutsche Grundgesamtheit

1 Die zur Einhaltung der Auflagen erforderlichen Wirkungsgrade lagen zwischen zwei und sechs prozentpunkten über den aus den Uberwachungswerten errechneten Wirkungsgraden. Bei Werk 2 betrug der Unterschied sogar zehn Prozentpunkte. 
der Abwasseremittenten zugrunde - eine homogene Gruppe bildeten.

Es konnte weiterhin beobachtet werden, daß die Minimierung der Abwasserkosten bei weitem nicht die Bedeutung hatte, die ihr in der Abgabentheorie zugesprochen wird. Der Vergleich von Grenzkosten und Abgabesatz schien wenig verbreitet, und die gesamten Kosten der betrachteten Reinigungsstufe zugrundegelegt, handelte keines der untersuchten Werke gemäß der abgabentheoretischen Wirkungshypothese. Daß die Einleiter so gesehen durchweg über die Anreizwirkung der Abwasserabgabe hinaus reinigten - und deshalb etwa der angestrebte Reinigungsgrad von $\eta_{S E}=90 \%$ erreicht wurde, der laut den Berechnungen des Sachverständigenrats nur mit einem $\mathrm{Ab}-$ gabesatz von $80 \mathrm{DM} / \mathrm{SE}$ zu erzielen gewesen wäre - läBt auf eine Reihe weiterer Bestimmungsgründe der Emissionsvermeidung schließen ${ }^{1}$. Eine ganz wesentliche Ursache sind zweifellos die einzuhaltenden Auflagen, die im folgenden unter dem Gesichtspunki statischer Allokationswirkungen der Abwasserabgabe nochmals betrachtet werden.

1 Siehe dazu auch die Ausführungen in D.3.1.1. 


\subsubsection{Statische Allokationswirkungen}

In Abschnitt A.1.3 wurde beschrieben, daß es die (reine) Abgabenlösung ist, mit der - im Gegensatz zur (reinen) Auflagenlösung - eine "gesamtwirtschaftlich möglichst günstige Mittelverwendung" realisiert werden kann. Eine Voraussetzung für die statische Allokationseffizienz der Abgabe ist jedoch, daß die Emittenten nicht gleichzeitig Auflagen $z u$ erfüllen haben, die von ihren Reinigungsanlagen (umfassender: Vermeidungsmaßnahmen) Wirkungsgrade erfordern, welche sich auf dem Niveau der abgaberechtlichen Anreizwirkung bewegen.

Im Rahmen der Untersuchung dieser Arbeit konnte nicht abschließend festgestellt werden, ob bei den Untersuchungseinheiten das Eingriffsniveau von AbwAG und $\$ 7$ a WHG weitgehend identisch und mithin die statische Allokationseffizienz der Abwasserabgabe aufgehoben war. Da bei den Einleitern die Wirkungsgrade, die der Anreizwirkung der Abwasserabgabe entsprachen, nicht zu ermitteln waren, konnten die für die Einhaltung der Uberwachungswerte berechneten Wirkungsgrade nur den realisierten Wirkungsgraden gegenübergestellt werden.

In Tab. 17 sind die homogenisierten durchschnittlichen Kosten pro vermiedener schadeinheit sowie die angesprochenen Wirkungsgrade derjenigen Werke nochmals aufgeführt, deren Bescheide 1985 schon den neuen wasserrechtlichen Regelungen entsprachen. Werke 3 und 5 reinigten einerseits eindeutig über die Anreizwirkung des AbwAG hinaus, waren andererseits aber auch zu diesem Verhalten durch die ihnen gestellten Auflagen verpflichtet. Die Voraussetzungen für statische Allokationseffekte der Abwasserabgabe waren hier also nicht gegeben. Werk 7 kann aufrund seiner verhältnismäßig niedrigen Kosten diesbezüglich kaum beurteilt werden. 


\begin{tabular}{|c|c|c|c|c|}
\hline Werk & $\begin{array}{l}\text { Durch- } \\
\text { schnittliche } \\
\text { Kosten pro } \\
\text { vermiedener } \\
\text { Schadeinheit } \\
(\text { DM/SE)* }\end{array}$ & $\begin{array}{l}\text { Realisierter } \\
\text { Wirkungs- } \\
\text { grad, }\end{array}$ & $\begin{array}{l}\text { Erforder- } \\
\text { licher Wir- } \\
\text { kungsgrad, } \\
n_{\text {sE }}\end{array}$ & $\begin{array}{l}\text { Diffe- } \\
\text { renz } \\
\text { der } \\
\text { Wir- } \\
\text { kungs- } \\
\text { grade }\end{array}$ \\
\hline 3 & $\begin{array}{c}(8) \\
43,-\end{array}$ & 88 & 86 & -2 \\
5 & $34,-$ & 91 & 78 & -13 \\
6 & $64,-$ & 87 & 88 & +1 \\
7 & $21,-$ & 95 & 93 & -6 \\
8 & $19,-$ & 94 & 72 & -1 \\
9 & $24,-$ & 92 & 75 & -17 \\
\hline
\end{tabular}

* homogenisierte Kosten

Tab. 17: Realisierte und zur Einhaltung der Uberwachungswerte erforderliche Wirkungsgrade bei Einleitern, deren Bescheide 1985 bereits umgestellt waren

Die anderen Werke reinigten 6 bis 17 Prozentpunkte über den ernannten "Sicherheitsbereich" hinaus. Geht man vom halbierten Abgabesatz aus, weil die Auflagen eingehalten wurden, so waren auch bei diesen Werken die Wirkungsgrade, die der Anreizwirkung der Abwasserabgabe entsprachen, niedriger als die realisierten Wirkungsgrade. Mithin war auch der für die allokativen Effekte notwendige Handlungsspielraum der Einleiter geringer als die ermittelten Differenzen. Legte man hingegen den vollen Abgabesatz zugrunde, kann eine derartige Aussage nur für Werk 8 gemacht werden.

Die - allerdings unzureichenden - Beobachtungen sprechen dafür, daß das Eingriffsniveau von AbwAG und $\S 7$ a WHG bei mehreren der untersuchten Werke in der Tat weitgehend identisch war, so daB die Voraussetzungen für statische Allokationseffekte der Abwasserabgabe nur teilweise vorlagen. Anhand der durchschnittlichen Kosten pro vermiedener Schadeinheit wurde jedoch auch in diesem Abschnitt wieder deutlich, daß nicht nur ökonomische opportunität das 
Emissionsverhalten der Einleiter bestimmte. Nicht zuletzt auch dieser Befund stellt die ökonomische Effizienz der Abwasserabgabe in Frage. 


\subsection{Distributive Effekte}

\subsubsection{Gerechtere Verteilung der Kostenlast}

Um feststellen zu können, ob das AbwAG zu einer gerechteren Verteilung der Kostenlast bei der Vermeidung, der Beseitigung und dem Ausgleich von Gewässerbelastungen geführt hat, sollten zunächst im Rahmen der Zielerreichungskontrolle die auf den Umsatz bezogenen Gesamtkosten der Abwasservermeidung derjenigen Werke verglichen werden, die auf der Produktseite miteinander im wettbewerb standen. Es stellte sich jedoch heraus, daB ein Vergleich auf Basis der Gesamtkosten der Abwasservermeidung nicht durchführbar war. Denn 19 Papierfabriken konnten diese selbst für das Jahr 1985 nicht angeben, weil die Kosten der innerbetrieblichen Vermeidungsmaßnahmen nicht gesondert in der Kostenrechnung erfast wurden. Deshalb mußte der Kostenvergleich ohne Berücksichtigung der innerbetrieblichen Maßnahmen erfolgen.

Demgemäß wurden die schweizerischen Werke von vornherein nur nach den Kosten der externen Maßnahmen befragt. Da jedoch vier Werke keine Angaben über ihre Umsätze machten und deshalb eine umsatzbezogene Relativierung der Kosten nicht möglich war, darüber hinaus ein weiteres Werk nicht die Höhe seiner Abwasserkosten für 1974 angab, konnte ein Vergleich zwischen deutscher und schweizerischer Kostensituation nur sehr eingeschränkt vorgenommen werden.

Auch der before-and-after-Vergleich innerhalb der deutschen stichprobe war nicht durchführbar, weil nur zehn Werke, von denen die meisten nicht miteinander im Wettbewerb standen, die Abwasserkosten des Jahres 1974 zur Verfügung stellen konnten ${ }^{1}$.

1 Zumindest sei aber darauf hingewiesen, daß bei sechs dieser zehn Papierfabriken die auf den Umsatz bezogenen Abwasserkosten während des Untersuchungszeitraums zwischen 80 und 130 stiegen. Bei den anderen Werken betrugen die prozentualen Veränderungen $+42,+12,-16$ und $-23 \%$. Die beiden schweizerischen Werke wiesen Veränderungen von +12 und -25 isf. 
Die Untersuchung der Kostensituation beschränkte sich mithin auf das Jahr 1985. Abb. 29 legt für konkurrierende Werke, die jeweils zu Gruppen zusammengefaßt sind, die auf den Umsatz bezogenen homogenisierten Abwasserkosten dar ${ }^{1}$. Da bei Werken mit geschlossenem Kreislauf der schwerpunkt der Vermeidungsmaßnahmen zumeist innerbetrieblich liegt, wurden bei diesen, soweit vorhanden, sämtliche Kosten der Abwasservermeidung berücksichtigt. Bei den anderen Werken dürften die Gesamtkosten der Abwasservermeidung bis zu 40 \% höher als die Abwasserkosten liegen ${ }^{2}$.

Ob die Kosten durch die neuen Regelungen gerechter verteilt und mithin, wie gleichermaßen vom AbwAG intendiert, die Wettbewerbsverzerrungen zwischen den Werken gemindert werden, hätte sich nur mit einem before-and-after-Vergleich beurteilen lassen. Es kann deshalb nur konstatiert werden, daB 1985 die auf den Umsatz bezogenen Abwasserkosten innerhalb der einzelnen Gruppen sehr stark differierten. Das zuletzt aufgeführte Werk hatte häufig das Mehrfache der Kosten des jeweils zuerst aufgeführten Werkes einer Gruppe zu tragen.

In die gebildeten Gruppen konnten auch zwei der schweizerischen Papierfabriken eingegliedert werden. Bei dem einen Werk, das Gruppe 3 zuzuordnen ist, betrugen die auf den Umsatz bezogenen Abwasserkosten (hier ohne Abwasserabgabe) $0,8 \%$, bei dem anderen Werk, daß Gruppe 4 angehörte, 1,2 $\%$. Beide Papierfabriken bewegten sich also in mittleren Kostenbereichen ihres deutschen Wettbewerbs.

Im zweiten Schritt, der Wirkungskontrolle, sollte versucht werden, die Auswirkungen speziell der Abwasserabgabe auf die Kostenverteilung zu ermitteln. Dafür sollten die Abwasserreinigungskosten derjenigen konkurrierenden Werke miteinander

1 Die Anschaffungskosten der externen Vermeidungsmaßnahmen wurden über zehn Jahre linear abgeschrieben und nach der Durchschnittswertmethode mit 7 verzinst.

2 Prozentuale Unterschiede bis zu dieser Höhe wiesen diejenigen Werke auf, die die Kosten für die innerbetrieblichen Vermeidungsmaßnahmen beziffern konnten. 
Abwasserkosten in \% vom Umsatz

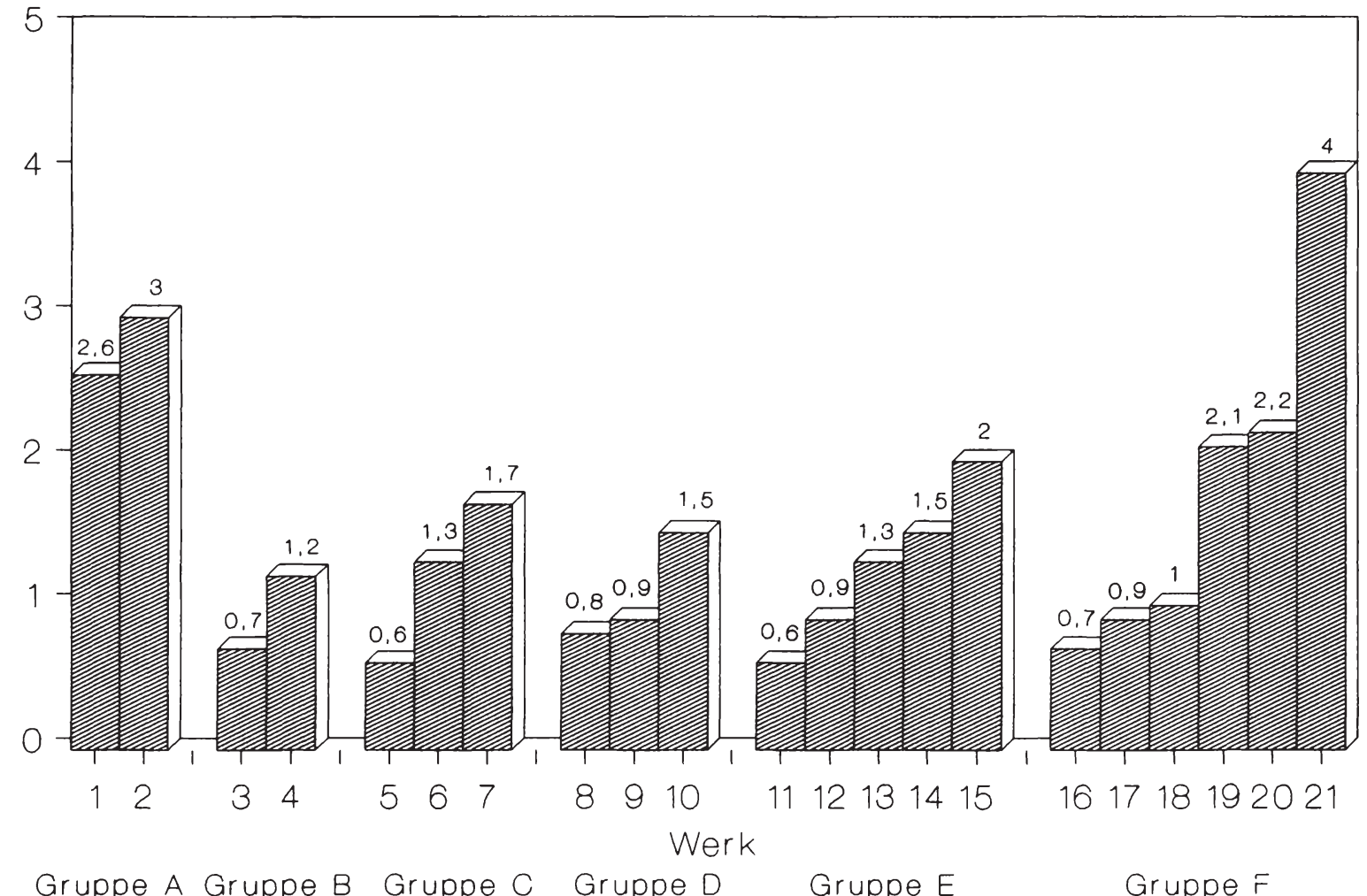

Abb. 29: Auf den Umsatz bezogene Abwasserkosten von Werken, die auf der Produktseite im Wettbewerb stehen 
verglichen werden, die gerade die Auflagen erfüllten und bei denen deshalb als abgabebedingte Kosten nur die Abwasserabgabe anfiel. Jedoch mußte auch diese Untersuchung ausscheiden, weil die Papierfabriken, die lediglich die Auflagen erfüllten, nicht einer bestimmten Gruppe konkurrierender Werke angehörten, sondern sich auf alle Gruppen verteilten oder auch von vornherein keine Mitanbieter in der stichprobe hatten. Die erforderlichen Vergleichsmöglichkeiten waren deshalb nicht gegeben.

Was also die mit dem AbwAG intendierte gerechtere Verteilung der Kostenlast und damit verknüpft die Minderung der Wettbewerbsverzerrungen betrifft, so kann im Rahmen dieser Arbeit nur festgestellt werden, daß die auf den Umsatz bezogenen Abwasserkosten nach Einführung des AbwAG in erheblichen Maße voneinander abweichen. Dabei muß auch darauf hingewiesen werden, daB das AbwAG Kostenverzerrungen insofern geradezu induziert, als die Abgabenhalbierung nicht an die a.a.R.d.T., sondern an die höchst unterschiedlich bemessenen Uberwachungswerte anknüpft.

Abschließend sei vermerkt, daß vier der deutschen Untersuchungseinheiten angaben, aufgrund des AbwAG an nationaler Wettbewerbsfähigkeit gewonnen zu haben. Sechs Werke sahen ihre Wettbewerbsfähigkeit verschlechtert und 20 Werke waren der Meinung, ihre Position im Markt sei unverändert. Demnach haben sich bei einem Drittel der Papierfabriken Wettbewerbsverschiebungen durch die Einführung des AbwAG ergeben. 


\subsubsection{Exkurs: Internationale Wettbewerbswirkungen}

1985 wurden $32 \%$ der deutschen Papierproduktion im Ausland verkauft, und 41 \% des heimischen Bedarfs wurde durch Einfuhren gedeckt ${ }^{\prime}$ Zu den größten Abnehmern zählten Frankreich, die Niederlande, Großbritannien, Belgien/Luxemburg und Italien; als "Lieferant" stand Schweden an erster stelle, gefolgt von Finnland, Frankreich, Osterreich und den Niederlanden. In einigen der genannten und in der Mehrzahl der weiteren Handelsländer wurden damals wie heute keine Abwasserabgaben erhoben ${ }^{2}$.

Vor diesem Hintergrund wurden die deutschen Untersuchungseinheiten gefragt, ob sie durch das Institut der Abwasserabgabe an internationaler Wettbewerbsfähigkeit verloren hätten oder ob sie ihre Position unverändert sähen. Auf diese "weiche" Frage wurde 11 Mal geantwortet, das AbwAG hätte keinen Einfluß auf die internationale Wettbewerbsfähigkeit genommen. Ein Einleiter sah die Position des Werkes aufgrund der technischen Veränderungen, die wegen der neuen wasserund abgaberechtlichen Regelungen vorgenommen worden waren, sogar gestärkt. Dagegen empfanden 16 Untersuchungseinheiten ihre Konkurrenzfähigkeit durch das AbwAG und - so wurde mehrfach betont - durch die Auflagenregelungen beeinträchtigt. Einen Rückgang des Exportanteils während des Untersuchungszeitraums hatte jedoch keines der Werke zu verzeichnen; bei drei Werken war die Exportquote allerdings unverändert geblieben.

Insgesamt stieg der Exportanteil in der stichprobe während des Untersuchungszeitraums von 19 auf $30 \%$. Inwieweit diese Entwicklung ohne das AbwAG bzw. ohne seine möglichen

1 Vgl. Verband Deutscher Papierfabriken (Hrsg.): Papier ' 86 ..., a.a.0., s. $24 \mathrm{ff}$.

2 Einen Uberblick über Abwasserabgaben in anderen Ländern geben Ewringmann/Schafhausen. Vgl. Ewringmann, D., Schafhausen, F.: Abgaben ...., a.a.0., s. $99 \mathrm{ff}$.; vgl. auch Honert, S.: Erhebung und Verwendung von Abwasserabgaben in ausländischen Staaten, Berlin 1973; Salzwede1, J.: Studien zur Erhebung von Abwassergebühren, Berlin 1972. 
Nebenwirkungen einen anderen Verlauf genommen hätte, bleibt offen.

\subsubsection{Vermeidung sprunghafter Nachfrage nach Abwasser- reinigungsanlagen}

Es ist ein Ziel des AbWAG, negative distributive Wirkungen, die aus einer diskontinuierlichen Kapazitätsauslastung der Anlagenbauer resultierten, zu vermeiden. Um den Einfluß des AbwAG auf die Nachfrage nach Abwasserreinigungsanlagen beurteilen zu können, war es zunächst erforderlich, die gesamte und nicht nur die auf die Einführung des AbwAG zurückzuführende Nachfrage nach Reinigungsanlagen in der deutschen stichprobe zu erfassen. In Tab. 18 sind deshalb für die Bauten und Ausbauten von mechanischen, chemisch-mechanischen und biologischen Reinigungsstufen die Jahre der Planungen, des Baubeginns und der Inbetriebnahmen zusammengestellt. Da die Jahresangaben für Planungen und Baubeginn lückenhaft sind, orientieren sich die nachfolgenden Ausführungen in erster Linie an den Inbetriebnahmen.

Wie aus Tab. 18 ersichtlich, wurden die meisten Reinigungsanlagen während des letztaufgeführten Zeitabschnitts, also in den Jahren 1981 bis 1985 in Betrieb genommen, so daß auch die Nachfrage nach ihnen in diesen und in den voranliegenden Jahren am gröBten war. Ein sprunghafter Anstieg der Nachfrage kann hier also beobachtet werden. Bemerkenswert ist, daB über 60 aller Anlagen, die nach dem Erlaß des WHG und des AbwAG im Jahr 1976 gebaut wurden, erst ihre Reinigungsarbeit aufnahmen, als die Abwasserabgabe bereits erhoben wurde. Zehn von insgesamt 15 erstmalig eingesetzten biologischen Reinigungsstufen wurden erst nach 1980 in Betrieb genommen. Hier stellt sich einerseits die bereits in Abschnitt D.3.2.5 aufgeworfene Frage, ob die Abgabestaffelung und die gesetzlich fixierte Verminderung der Abgabezahlung vor Inbetriebnahme einer neuen Reinigungsanlage zu einer 


\begin{tabular}{|c|c|c|c|c|c|c|}
\hline Jahr & Planung & & Baubegin & & Inbet & bnahme \\
\hline $\begin{array}{l}1938 \\
1950 \\
1954 \\
1955\end{array}$ & 1 & & 1 & & $\begin{array}{l}1 \\
1 \\
1\end{array}$ & \\
\hline $\begin{array}{l}1956 \\
1957 \\
1958 \\
1959 \\
1960\end{array}$ & $\begin{array}{l}1 \\
1\end{array}$ & 2 & $\begin{array}{l}1 \\
1\end{array}$ & 2 & $\begin{array}{l}1 \\
1 \\
1 \\
2\end{array}$ & 5 \\
\hline $\begin{array}{l}1961 \\
1962 \\
1963 \\
1964 \\
1965\end{array}$ & 1 & 1 & 1 & 1 & $\begin{array}{l}3 \\
1 \\
1 \\
3\end{array}$ & 8 \\
\hline $\begin{array}{l}1966 \\
1967 \\
1968 \\
1969 \\
1970\end{array}$ & $\begin{array}{l}5 \\
1 \\
2 \\
2\end{array}$ & 10 & $\begin{array}{l}6 \\
2\end{array}$ & 8 & $\begin{array}{l}2 \\
3 \\
3 \\
3\end{array}$ & 11 \\
\hline $\begin{array}{l}1971 \\
1972 \\
1973 \\
1974 \\
1975\end{array}$ & $\begin{array}{l}1 \\
2 \\
1 \\
1 \\
2\end{array}$ & 7 & $\begin{array}{l}1 \\
1 \\
1 \\
3 \\
2\end{array}$ & 8 & $\begin{array}{l}3 \\
1 \\
2 \\
2 \\
2\end{array}$ & 10 \\
\hline $\begin{array}{l}1976 \\
1977 \\
1978 \\
1979 \\
1980\end{array}$ & $\begin{array}{l}2 \\
4 \\
1 \\
6 \\
1\end{array}$ & 14 & $\begin{array}{l}1 \\
2 \\
5 \\
3 \\
3\end{array}$ & 14 & $\begin{array}{l}2 \\
1 \\
3 \\
2\end{array}$ & 8 \\
\hline $\begin{array}{l}1981 \\
1982 \\
1983 \\
1984 \\
1985\end{array}$ & $\begin{array}{l}4 \\
1 \\
2 \\
1\end{array}$ & 8 & $\begin{array}{l}3 \\
4 \\
2 \\
1 \\
1\end{array}$ & 11 & $\begin{array}{l}4 \\
3 \\
4 \\
2 \\
1\end{array}$ & 14 \\
\hline Summe & 43 & & 45 & & 59 & \\
\hline
\end{tabular}

b. 18: Jahre der Planung, des Baubeginns und der Inbetriebnahme von Reinigungsstufen bei den deutschen Werken 
Drosselung der Abgabewirkung geführt haben'1. Andererseits war es gerade das vom Gesetzgeber erklärte Ziel, eine gleichmäßige Nachfrage nach Reinigungsanlagen dadurch zu bewirken, daß die "Tarifstruktur" der Abwasserabgabe erst die Einleiter mit relativ niedrigen und dann die Einleiter mit relativ hohen spezifischen Vermeidungskosten zum Bau von Reinigungsanlagen veranlassen sollte $e^{2}$.

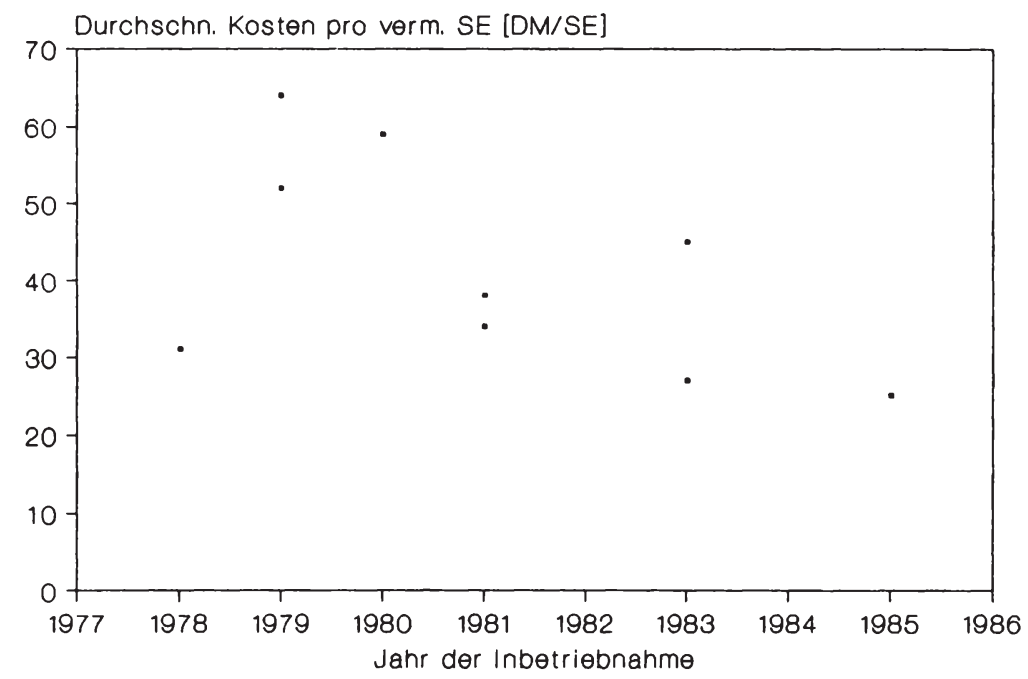

Abb. 30: Jahre der Inbetriebnahme neuer Anlagen und (nicht homogenisierte) Kosten pro vermiedener Schadeinheit

Abb. 30 zeigt für die Papierfabriken, bei denen die durchschnittlichen Kosten pro vermiedener schadeinheit ermittelt werden konnten, das Jahr der Inbetriebnahme der zuletzt errichteten Reinigungsanlage. Ein Zusammenhang zwischen den

1 Berücksichtigt werden muß in diesem Zusammenhang jedoch auch, daß die Allgemeine Verwaltungsvorschrift für das Einleiten von Papierabwässern in Gewässer erst Anfang 1982 erlassen wurde. Die Unsicherheit, die bis dahin über die Höhe der Mindestanforderungen bestand, kann ebenfalls die Vermeidungsmaßnahmen verzögert haben.

2 Auch entspricht die Abgabestaffelung "den Grundvorstellungen eines dynamischen Modells zur Abdeckung des Nachholbedarfs." Rat von Sachverständigen für Umweltfragen: Die Abwasserabgabe ...., a.a.0., s. 32 (Hervorhebungen vom Sachverständigenrat). 
- nicht homogenisierten - Kosten und den Jahren der Inbetriebnahmen läßt sich nicht erkennen. Auch im Rahmen dieser letzten Teilzielprüfung wird also deutlich, das das Handeln der untersuchten Werke nicht allein durch die Höhe des Abgabesatzes bestimmt wurde. 
Ergebnisse, Konsequenzen und Ausblick

Im Rahmen der vorliegenden Arbeit wurde eine Erfolgskontrolle des AbwAG entwickelt und auf die Papierindustrie als einer Adressatengruppe des Gesetzes angewendet. Die Untersuchung war als before-and-after-Vergleich für die Jahre 1974 und 1985 und zugleich auch als with-and-without-Vergleich angelegt. Die Kontrollgruppe setzte sich aus schweizerischen Papierfabriken zusammen.

Zunächst wird ein Uberblick darüber gegeben, inwieweit die vom AbWAG angestrebten ökologischen und ökonomischen Ziele bei den deutschen Papierfabriken erreicht werden konnten. Soweit nicht anders vermerkt, handelt es sich um die Untersuchungsergebnisse der Primärerhebung. Im Anschluß wird auf Ursache-Wirkungs-Beziehungen eingegangen.

Wie von den neuen wasserrechtlichen Regelwerken intendiert, wurden biologische Reinigungsstufen in beachtlichem Umfang gebaut. So verzeichnete der Verband Deutscher Papierfabriken bei seinen direkteinleitenden Mitgliedsfirmen während des Untersuchungszeitraums einen Anstieg der biologisch reinigenden Werke von 14 auf $56 \%$. In der vorliegenden stichprobe waren die biologisch reinigenden werke stärker vertreten.

Doch nicht nur der Einsatz biologischer Anlagen, sondern auch deren Reinigungsleistung steigerte sich von 1974 bis 1985 beträchtlich. So wurde der $\mathrm{BSB}_{5}-\mathrm{Abbau}$ im gewichteten Mittel von 80 auf 96 erhöht, und der CSB-Abbau verbesserte sich von 55 auf 82 \%. Dabei konnte für 1985 ein über alle Untersuchungseinheiten gleiches Niveau der Abbauraten konstatiert werden.

Der spezifische Abwasseranfall reduzierte sich gemäB den Untersuchungsergebnissen der VDP-Umfrage um 53 \%, während die direkteinleitenden Werke, die im Rahmen der vorliegenden Arbeit befragt wurden, den spezifischen Abwasseranfall um 62 * senkten. Mit Ausnahme von drei Werken hatten sämtliche befragten Papierfabriken innerbetriebliche Maßnahmen zur 
Kreislaufeinengung bis hin zur Kreislaufschließung - sofern dies die hergestellten Papiersorten zuließen - vorgenommen. 52 \& aller deutschen Untersuchungseinheiten gaben darüber hinaus an, Veränderungen des stoffeinsatzes (Faser- und Hilfsstoffe) speziell aufgrund der abgaberechtlichen Regelungen vorgenommen $\mathrm{zu}$ haben.

80 \% der Papierfabriken kannten die spezifischen Abwassermengen und/oder Abwasserbelastungen der unterschiedlichen von ihnen hergestellten Papierqualitäten. Bei der Hälfte der Werke, die qualitätsbedingte Unterschiede festgestellt hatten, waren daraufhin Veränderungen des Produktionsprogramms vorgenommen worden. Auch die Tatsache, daB bei 70 \% aller Werke eine Kostenstelle für Abwasser bestand, verdeutlicht, daB das "Nebenprodukt" Abwasser integraler Bestandteil unternehmerischer Entscheidungen geworden ist.

Was die ebenfalls mit dem AbwAG intendierte beschleunigte Anwendung der a.a.R.d.T. betrifft, so hatten $53 \%$ der mit offenem Kreislauf produzierenden Werke geplante externe Vermeidungsmaßnahmen vorverlegt und 24 \% hatten sachliche Veränderungen an diesen Maßnahmen vorgenommen. Fünf von sieben Papierfabriken, die den Wasserkreislauf während des Untersuchungszeitraums schlossen, beschleunigten diese Maßnahme, und vier Werke entschlossen sich aufgrund der neuen Auflagen- und Abgabenregelungen überhaupt erst zu diesem Schritt ${ }^{1}$.

Die Abgabenhalbierung wurde in 89 \% derjenigen Veranlagungsfälle, in denen keine Ausnahmen von der Abgabepflicht bestanden, von den Behörden gewährt. Das heiBt, daß die Behörden in diesen Fällen die a.a.R.d.T. als eingehalten erachteten.

1 Große Beschleunigungs- und Veränderungseffekte bzgl. der VermeidungsmaBnahmen vor allem in der Papierindustrie waren auch in einer Evaluationsstudie während der Signalwirkungsphase festgestellt worden. Vgl. Ewringmann, D., Kibat, K. -D., Schafhausen, F.J.: Die Abwasserabgabe .... a.a.O., S. 72; vgl. außerdem Hoffmann, V., Ewringmann, D.: Auswirkungen .... a.a.0., s. $138 \mathrm{ff}$. 
Insgesamt führten all die genannten Maßnahmen und Entwicklungen zu einer erheblichen Emissionsverminderung während des Untersuchungszeitraums. Bei sechs Werken, die mit offenem Kreislauf produzierten und die Daten zur Ermittlung der emittierten Schadeinheiten beider Untersuchungsjahre zur Verfügung stellen konnten, sank die absolute Emission von 1974 bis 1985 im gewichteten Mittel um $71 \%$, obwohl die Produktion gleichzeitig um $57 \%$ gesteigert werden konnte. Die produktbezogenen Emissionen wurden bei einem dieser Einleiter um $62 \%$, bei den anderen Papierfabriken zwischen 83 und $97 \%$ abgebaut.

Inwieweit die Kostenlast nach der Reformierung des Wasserrechts gerechter auf die Werke verteilt war als zuvor, konnte wegen unzureichend vorhandener Kostendaten des Jahres 1974 nicht ermittelt werden. Jedoch unterschieden sich die auf den Umsatz bezogenen Abwasserkosten bei Werken, die auf den Produktseite konkurrierten, im Jahr 1985 um das Zwei- bis Dreifache.

Was den Verlauf der Nachfrage nach Abwasserreinigungsanlagen betrifft, so konnte in den sechziger und siebziger Jahren eine gleichbleibende Nachfrage verzeichnet werden. Von 1981 bis 1985 wurden dagegen fast doppelt so viele Reinigungsanlagen wie von 1976 bis 1980 in Betrieb genommen.

Soweit die ökologischen und ökonomischen zielerreichungen auf ihre Wirkungsursachen, also auf das AbwAG, die Auflagen oder andere Einflußgrößen zurückgeführt werden konnten, wird dies im folgenden beschrieben.

Der instrumentelle Verbund von Wasserhaushalts- und Abwasserabgabengesetz erfordert es, den abgaberechtlichen Wirkungsradius in den durch Auflagen kontrollierten Bereich und den nachfolgenden Bereich der Restverschmutzung zu untergliedern. So hatten 88 \% der Papierfabriken, die während des Untersuchungszeitraums in Abwasserreinigungsanlagen investierten, mit diesen Maßnahmen zunächst einmal die a.a.R.d.T. bzw. darüber hinausgehende Auflagen zu erfüllen. Immerhin gab aber die Hälfte der Werke, die Reinigungsanlagen gebaut 
hatte, als Motivation ihres Handelns auch die mit der Einhaltung der Auflagen einhergehende Halbierung der Abwasserabgabe an.

DaB die Abwasserabgabe den Bau von Abwassereinigungsanlagen und damit die Anwendung der a.a.R.d.T. beschleunigt hat, wurde - im Gegensatz zu einer früheren Studie ${ }^{1}$ - nur vereinzelt von den Einleitern bestätigt. Gegen einen spürbaren Einfluß des AbwAG auf die Vorverlegung von Vermeidungsmaßnahmen spricht auch, daß von 17 biologischen Reinigungsstufen, die zwischen 1974 und 1985 gebaut bzw. ausgebaut wurden, 10 erst nach Beginn der Abgabepflicht in Betrieb genommen wurden. Dieser Befund wirft die Frage auf, ob mit der Abgabestaffelung und der gesetzlich fixierten Abgabenverminderung vor Inbetriebnahme einer neuen Reinigungsanlage Wirkungspotentiale der Abwasserabgabe verschenkt worden sind. Andererseits muß aber auch berücksichtigt werden, daß die Mindestanforderungen für das Einleiten von Papierabwässern in Gewässer erst Anfang 1982 erlassen wurden; möglicherweise hätten die Werke die Vermeidungsmaßnahmen ohne den Anreiz der - wie auch immer gestalteten - Abwasserabgabe noch später durchgeführt.

52 * der Papierfabriken mit offenem Wasserkreislauf reinigten nach eigener Einschätzung wesentlich über die Auflagen hinaus. Sie gaben jedoch durchweg an, daß sie diesen Reinigungsstand auch ohne die Abwasserabgabe verwirklicht hätten. Entsprechend waren auch nur bei zwei Werken $(8 \%)$ Umstellungen des Produktionsprozesses vorgenommen worden, um die Abwasserabgabe über die Abgabenhalbierung hinaus zu senken. Daß dennoch weit über die Hälfte der Einleiter die Auflagen wenigstens um 20 \% unterschritten, läBt sich auf eine Fülle von Beweggründen sowie deren einleiterindividuelles Zusammenspiel zurückführen. Die wichtigsten gewässergütewirtschaftlichen und exogenen Einflußgrößen seien im folgenden aufgezeigt.

1 Vgl. Hoffmann, V., Ewringmann, D.: Auswirkungen .... a.a.0., S. $138 \mathrm{ff}$. 
Wenngleich der Bereich der Restverschmutzung gemeinhin als der "eigenständige" Wirkungsbereich des AbwAG gilt, ließ sich auch hier ein Einfluß der Auflagen ausmachen. So hatten einige Werke bereits für schärfere Auflagen gerüstet - die Bescheidumstellung war bei $35 \%$ der Einleiter bis 1985 noch nicht erfolgt - oder reinigten über die Einhaltung der Auflagen hinaus, um "auf der sicheren seite zu sein". Hier konnte also ein "offensives" Vermeidungsverhalten der Emittenten beobachtet werden ${ }^{1}$.

Aus dem Spektrum des gewässergütepolitischen Instrumentariums dürften weiterhin Finanzierungshilfen und subventionen (z.B. in Form von Sonderabschreibungen nach $\$ 7$ a EStG, Investitionszulagen und ERP-Darlehen) die Vermeidung von Emissionen begünstigt haben, denn sie wurden von $87 \%$ aller Untersuchungseinheiten in Anspruch genommen. Zur Einhaltung der Auflagen animierte bei mehreren Einleitern auch die Schadenshaftung.

Aus dem Katalog exogener Einflußgrößen auf das Emissionsverhalten sind neben Produktionserweiterungen zunächst die Bedingungen der Abwasserreinigungstechnik $\mathrm{zu}$ nennen. Es war offensichtlich, daß es das allgemeine Bestreben war, die vorhandenen Reinigungsstufen optimal, d.h. mit möglichst hohen Wirkungsgraden zu fahren, nicht zuletzt weil die Störanfälligkeit und mithin Schwankungen der Reinigungsleistung dann in der Regel abnehmen. Da die Einhaltung der Mindestanforderungen zumeist das Betreiben einer biologischen Reinigung erforderte, konnte mehrfach bei Werken, die gleiche oder ähnliche Papiersorten produzierten, ein einheitliches Emissionsniveau trotz höchst unterschiedlich weit bemessener Auflagen festgestellt werden. Auch zwei Paarvergleiche mit schweizerischen Werken unterstützen die These, daß die Reinigungsleistung der Einleiter mehr von den vorhandenen

1 Zum offensiven Umweltschutzmanagement vgl. Wicke, L.: Plädoyer für ein offensives Umweltmanagement, in: Pieroth, E. , Wicke, L. (Hrsg.), Chancen der Betriebe durch Umweltschutz: Plädoyer für ein offensives Umweltschutzmanagement, Freiburg i.Br. 1988, s. 11 ff. 
Reinigungsstufen und dem allgemeinen stand des VerfahrensKnow-How als von der konkreten Ausgestaltung der Auflagenwerte abhängen.

Die auf breiter Ebene vorgenommenen (innerbetrieblichen) Maßnahmen der Kreislaufeinengung galten sowohl bei den deutschen als auch bei den schweizerischen werken in hohem Maße der Rückgewinnung von Einsatzstoffen. Bemerkenswert ist allerdings, daB die schweizerischen Papierfabriken den spezifischen Abwasseranfall nur halb so stark reduzierten wie die deutschen Werke; hier kommt das grundsätzliche, nicht durch die Abgaberegelungen geprägte Interesse an der Kreislaufeinengung zum Ausdruck. In der doppelt hohen Senkung des Abwasseranfalls bei den deutschen Untersuchungseinheiten spiegelt sich auch wider, daß die Abwassermengen in den deutschen Bescheiden limitiert werden.

Der EinfluB der Abwasserreinigungskosten auf das Emissionsverhalten wurde bei denjenigen Werken sichtbar, die sich während des Untersuchungszeitraums zur Kreislaufschließung entschlossen. Vier von sieben Werken wäre der Ausbau der Kläranlagen, der sonst hätte vorgenommen werden müssen, zu kostenintensiv gewesen. Allerdings gaben drei werke auch die Abwasserabgabe auf die Restverschmutzung als Motivation der Kreislaufschließung an.

Nicht zuletzt sei vermerkt, daß das Umweltbewußtsein in den Unternehmen zweifellos zugenommen und offensichtlich auch durch das auf Umweltverunreinigungen sensibler gewordene soziale Umfeld einen spürbaren Anstoß erhalten hat. Die zum Teil weit über die Einhaltung der Auflagen hinausgehende Reinigungsleistung der Werke wurde mehrfach auch mit der andernfalls zu hohen Verschmutzung - häufig sehr kleiner Vorfluter - begründet.

Abschließend ist darauf hinzuweisen, daß ein Zusammenhang zwischen Abgabestaffelung und Höhe der Emission, soweit keine Ausnahmen von der Abgabepflicht bestanden, nicht hergestellt werden konnte. Es konnte zwar bei 12 von 17 Werken eine Emissionsverminderung während der Abgabejahre 
festgestellt werden, ohne daB in der Regel ein Ausbau der Reinigungsanlagen im gleichen Zeitraum erfolgt war. Bei diesen Einleitern wurden jedoch die Produktfrachten in Abhängigkeit der Produktionssteigerung und darüber hinaus gesenkt, gleichwohl die Auflagen wenigstens teilweise eine Emissionserhöhung erlaubt hätten. Bei einigen Werken war es offensichtlich das eigene, möglicherweise auch durch die Abwasserabgabe bewirkte Bestreben, bei anderen Einleitern die ordnungsrechtlich bedingte Notwendigkeit, ein einmal erreichtes Emissionsvermeidungsniveau nicht wieder zu überschreiten.

Aus den beschriebenen Beobachtungen kann gefolgert werden, daB die Abwasserabgabe als anreizpolitisches Instrument in der Tat die Erfüllung der Auflagen beschleunigt und ihre Einhaltung nachhaltig unterstützt hat, im Bereich der Restverschmutzung als Ursache für Emissionsverminderungen jedoch in den Hintergrund tritt. Letzteres steht im Gegensatz zu den Ergebnissen früherer studien, nach denen die Abwasserabgabe bereits in der signalwirkungsphase in hohem Maße eigenständige Wirkungen entwickelte ${ }^{1}$.

Die oben skizzierte Fülle von Einflußgrößen auf das Emissionsverhalten der Einleiter erklärt auch, warum viele Einleiter über den Anreizpunkt der Abwasserabgabe hinaus reinigten und der angestrebte Wirkungsgrad von $\eta_{B} E=90 \%$ auch ohne einen Abgabesatz von $80 \mathrm{DM} / \mathrm{SE}$ erreicht wurde. Wenn man die durchschnittlichen Kosten pro vermiedener Schadeinheit zugrundelegt, vermieden sämtliche 12 Werke, für welche die Untersuchung durchgeführt wurde, Schadeinheiten über die Anreizwirkung des halbierten Abgabesatzes hinaus, und etwa die Hälfte der Einleiter wies Kosten auf, die über dem "ganzen" Abgabesatz (36 DM/SE) lagen. Bei den durchschnittlichen Kosten pro vermiedener schadeinheit schlägt allerdings in hohem Maße der Kapitaldienst zu Buche, und gerade dieser ist im wesentlichen durch die Auflagen

1 Vgl. Hoffmann, V., Ewringmann, D.: Augwirkungen .... a.a.O., S. 145 ff.; Ewringmann, D., Kibat, K.-D., Schafhausen, F.J.: Die Abwasgerabgabe .... a.a.O., s. 75 und $79 \mathrm{f}$. 
festgeschrieben. Doch auch das Denken in Grenzkosten schien wenig verbreitet1, so daß die abgabentheoretische Wirkungshypothese, der Emittent reinige bis zu dem Vermeidungsgrad, bei dem die Grenzkosten der Vermeidungsmaßnahmen gleich dem Abgabesatz sind - sofern die Auflagen keinen höheren Abbau der Schadeinheiten verlangen -, nicht bestätigt werden konnte. Diese Ergebnisse geben AnlaB zu der Vermutung, daB die mit dem AbwAG intendierte "gesamtwirtschaftlich möglichst günstige Mittelverwendung" nicht nur durch die Zangenwirkung von Auflagen- und Abgabengesetz, sondern auch durch eine kostenintensive "vbererfüllung" der gewässergütepolitischen Ziele nicht erreicht wird. Wenngleich auf der einen seite unverkennbar ist, daB die Abwasserabgabe Impulse zur Vermeidung von Emissionen gegeben hat, ist auf der anderen Seite fraglich, ob mit der Abwasserabgabe im besonderen und der Emissionsabgabe im allgemeinen die steuerung der Vermeidungsaktivitäten, wie sie in der umweltökonomischen Theorie beschrieben ist, erreicht werden kann. Okologische und ökonomische Effizienz sind damit wenigstens teilweise in Frage gestellt. Die Kombination von Auflagen- und Abgabenlösungen ist zumindest aus Sicht des Umweltschutzes zu befürworten.

Ein Instrumentenset ist jedoch auch unter dem Gesichtspunkt, daß die Emissionsabgabe gerade dann an ökologischer Effizienz verliert, wenn die ökonomische Effizienz besonders groß ist, zu empfehlen. Betrachtet man es als umweltpolitisches ziel, die Umweltbelastungen an ihrem Entstehungsort zu vermeiden, bedeutet dies im engeren Sinne die Vermeidung der Schadstoffe bereits im ProduktionsprozeB und im weiteren sinne die nachgeschaltete Vermeidung entweder durch den Emittenten selbst oder eine "durch ihn beauftragte stelle", bevor das Umweltgut wieder in seinen "natürlichen Bereich" entlassen

1 Ahnlich stellten Ewringmann/Kibat/Schafhausen vor Beginn der Abgabepflicht fest, daB "die 'Angst' vor der zumeist sehr ungewissen Abgabenhöhe insgesamt ein wichtigerer 'Incentive' für Anpassungsüberlegungen und -reaktionen darstellt als der 'rationale' Abgabensatz-GrenzkostenVergleich." Ewringmann, D., Kibat, K.-D., Schafhausen, F.J.: Die Abwasserabgabe ..., a.a.0., s. 78 . 
wird. Entscheiden sich nun große Emittenten für die Zahlung der Abgabe, weil dies für sie ökonomisch vorteilhafter als die Emissionsvermeidung ist, werden sie in der Regel entsprechend hohe lokale Umweltbelastungen auslösen, denn es dürfte dem staat nicht möglich sein, an allen bedeutsamen Emissionsquellen Vermeidungsinvestitionen vorzunehmen - unabhängig davon, in welchem Maße das Abgabenaufkommen zur Deckung des Verwaltungsaufwandes genutzt wird. Das "Modell Emscher" hingegen kann weder Vorbild für sämtliche Gewässer noch für die allgemeine Nutzung anderer Umweltbereiche sein.

Was die Ausgestaltung von Emissionsabgaben betrifft, so ist zunächst auf die Festlegung des Abgabesatzes einzugehen. In der umweltökonomischen Theorie wird die Grenzkostenfunktion aus den gesamten Kosten der Vermeidungsaktivitäten ermittelt. Wenngleich man regelmäßig Hinweise auf die Existenz sprungfixer Kosten findet, wird diesem Aspekt nicht ausreichend Rechnung getragen. Gerade wenn Abgaben mit Auflagen kombiniert Anwendung finden und der Bau einer bestimmten Reinigungsstufe durch letztere vorgegeben ist, stehen bei der Uberlegung, Abgabe zu zahlen oder zu reinigen, marginale Veränderungen der Reinigungsleistung im Vordergrund. Insofern stellt sich die Frage, ob bzw. inwieweit insbesondere der Kapitaldienst in die Berechnung der Grenzkosten und mithin in die Bestimmung des Abgabesatzes einzugehen hat. Ist die Abgabe allerdings in erster Linie als Unterstützung des Auflagenvollzugs gedacht, sind sämtliche Vermeidungskosten in die Betrachtung einzubeziehen.

Werden in abgaberechtliche Regelungen ökonomische Anreize durch Abgabenverminderungen, die an den Bau von Vermeidungsmaßnahmen knüpfen, eingearbeitet, sollten sie nicht auf mehrere Jahre vor Inbetriebnahme dieser Maßnahmen fixiert sein, sondern frühestens ab dem Zeitpunkt einsetzen, zu dem die Aufwendungen entstehen. Dadurch wird verhindert, daß es zu zeitlichen Verzögerungen der Abgabewirkungen kommt.

"Incentives" für die Einhaltung bestimmter Emissionswerte, wie im AbwaG durch die Abgabenhalbierung praktiziert, sind 
nicht nur vor dem Hintergrund verteilungs- und gesamtwirtschaftlicher Ziele zu bewerten, sondern sollten bei der Ausgestaltung einer Emissionsabgabe auch deswegen diskutiert werden, weil sie als "spielerisches Element" den Ehrgeiz der Emittenten anregen, bestimmte Emissionsgrenzen nicht zu überschreiten. Hervorzuheben ist, daß es zur Festlegung dieser Emissiongrenzen keiner Auflagenwerte bedarf. Die Grenzwerte sollten allerdings nicht, wie es das untersuchte AbWAG zuläßt, "individuell" bestimmt werden; ungleiche Verteilungen der Kostenlast sind dann vorprogrammiert. Werden Abgabenverminderungen bei Einhaltung bestimmter Emissionswerte gewährt, ist zu überprüfen, ob eine Emissionsvermeidung über diese hinaus erforderlich ist und auch dafür genügend Anreize geschaffen wurden.

Mit dem Ziel, die Anreizfunktion der Abwasserabgabe für weitere Reinigungsmaßnahmen $z$ u erhöhen und den Verwaltungsaufwand durch Vereinfachung des Gesetzesvollzugs zu senken, hat der Gesetzgeber eine Neugestaltung des AbWAG vorgenommen ${ }^{1}$, die in wesentlichen Punkten am 1. Januar 1989 in Kraft getreten ist. Eine weitere Novellierung, nämlich den Entwurf eines Dritten Gesetzes zur Anderung des Abwasserabgabengesetzes, hat der Bundestag am 17. Februar 1989 beschlossen. Diese Fassung soll bereits am 1. Januar 1991 in Kraft treten. Der Experimentiercharakter des AbwAG als dem deutschen Paradebeispiel einer Emissionsabgabe bleibt also auch weiterhin unverkennbar ${ }^{2}$.

Die Anderungsgesetze sehen u.a. die Aufnahme weiterer Schadparameter, die überproportionale Erfassung von vber- und Unterschreitungen der in $\$ 7$ a WHG gestellten Anforderungen und die Erhöhung des Abgabesatzes von 40 auf 60 DM vor. Inwieweit diese Regelungen die ökologische Effizienz der Abwasserabgabe in der Tat verbessern werden, wird in hohem

1 Bekanntmachung der Neufassung des Abwasserabgabengesetzes vom 5. März 1987, BGBl. I S. 880 .

2 Die schnelle Abfolge der Novellierungen ist insofern negativ zu beurteilen, als der Gesetzgeber für die Emittenten nicht mehr kalkulierbar erscheint. 
Maße von der Ausgestaltung der neuen Mindestanforderungen abhängen. Denn mehr als zuvor sind Wasserhaushalts- und Abwasserabgabengesetz ineinander verzahnt und entscheiden die Auflagen über die Höhe des Abgabesatzes und damit über den finanziellen Anreiz, der auf die Entwicklung und den Einsatz von Vermeidungsmaßnahmen ausgeübt wird. Eine Erfolgskontrolle, die auf einem Soll-Ist-Vergleich aufbaut, wird auch bei den Novellierungen nicht möglich sein: uber die ziele der Neugestaltungen macht der Gesetzgeber wiederum nur Tendenzaussagen. 


\section{LITERATURVERZEICHNIS}

\section{Allgemeine Literatur}

Aderhold, D.: Kybernetische Regierungstechnik in der Demokratie, Planung und Erfolgskontrolle, Deutsches Handbuch der Politik, Bd. 7, München, Wien 1973

Albach, H.: Gutachten über "Methodische Probleme der Ermittlung von betriebs-und volkswirtschaftlichen Auswirkungen des geplanten Abwasserabgabengesetzes auf die Papier- und Zellstoffindustrie", Bonn 1976

Atteslander, P.: Methoden der empirischen Sozialforschung, Berlin 1969

Bälder. K. -H.: Recht der Abfallwirtschaft, Bielefeld 1979

BASF: BASF Umweltschutz - Denken Planen Handeln, 0.0. 1981

Baumgarten, H.L., Welcker, U.: Zur Technologie des Wassergebrauches in Papierfabriken, in: Das Papier, 40. Jg. (1986), Heft 10 A, S. V $181-$ V 192

Baumol, W.J., Oates, W.E.: Die Anwendung von standards und Preisen zum Schutz der Umwelt, in: Siebert, H. (Hrsg.), Umwelt und wirtschaftliche Entwicklung, Darmstadt 1979, S. $169-188$

Bea, F.X.: Die Verteilung der Lasten des Umweltschutzes nach dem Verursacherprinzip, in: Wirtschaftswissenschaftliches studium, 2. Jg. (1973), S. $453-457$

Bender, D.: Makroökonomik des Umweltschutzes, Göttingen 1976

Berendes, K., Winters, K.P.: Das neue Abwasserabgabengesetz. Eine systematische Darstellung der wasser- und abgaberechtlichen Bestimmungen des ab 1.1.1981 geltenden Abwasserabgabengesetzes mit Wiedergabe der wichtigsten Rechtsvorschriften, München 1981

Berendes, $K$. : Was bedeutet die Neufassung der wassergesetze für die Industrie?, in: Verband Deutscher Papierfabriken (Hrsg.), VDP-Frühjahrstagung 186 , Teil I, Nr. 58 der Schriftenreihe, Bonn 1986, S. $8-15$

Boehm, V.: Abwasserabgabe und Gewässerschutz, in: Institut für gewerbliche Wasserwirtschaft und Luftreinhaltung e.V., Köln (Hrsg.), Abwasser-Abgaben-Gesetz, IWL-Forum 74/II, Köln 1974, S. 1 - 13 
Börner, F., Dalpke, H.-L., Geller, A., Göttsching, L.: Ermittlung von Abwasserparametern zur Festlegung von Mindestanforderungen gem. \$ 7 a WHG bei sulfitzellstoffabriken und bei Papier- und Pappenfabriken, Darmstadt 1979

Bohley, P.: Gebühren und Beiträge, in: Handbuch der Finanzwissenschaft, Bd. 2, 3., gänzl. neubearb. Aufl., Tübingen 1980 , S. $915-947$

Bonus, H.: Instrumente einer ökolgieverträglichen wirtschaftspolitik, in: Binswanger, H.-Ch., Bonus, H., Timmermann, M.: Wirtschaft und Umwelt - Möglichkeiten einer ökologieverträglichen Wirtschaftspolitik, stuttgart, Berlin, Köln, Mainz 1981, S. $84-163$

Bonus, H.: Marktwirtschaftliche Instrumente im Umweltschutz, in: Wirtschaftsdienst, 64. Jg. (1984), Heft 4, s. $169-172$

Bonus, H.: Marktwirtschaftliche Konzepte im Umweltschutz, Stuttgart 1984

Bonus, H.: Eine Lanze für den "Wasserpfennig". Wider die Vulgärform des Verursacherprinzips, in: Wirtschaftsdienst, 66. Jg. (1986), Heft 9, S. $451-455$

Bonus, H.: Don Quichotte, Sancho Pansa und der Wasserpfennig, in: Wirtschaftsdienst, 66. Jg. (1986), Heft 12, s. $625-629$

Bortz, J.: Lehrbuch der empirischen Forschung: für Sozialwissenschaftler, Berlin, Heidelberg, New York, Tokyo 1984

Brandt, E.: Rechtliche Fragen beim Einsatz von Lenkungsabgaben als Instrumente der Umweltpolitik - unter besonderer Berücksichtigung der Abwasserabgabe, in: Jarre, J. (Hrsg.), Umweltrecht in der Bundesrepublik Deutschland. Erfolge, Probleme, Perspektiven, Loccumer Protokolle, Bd. 18., Rehburg-Loccum 1984, S. $76-83$

Brecht, W., Dalpke, H.-L.: Wasser, Abwasser, Abwasserreinigung in allgemeiner sicht und in der sicht der Papierund Zellstoffindustrie, Biberach/Riß 1980

Brümmerhoff, D., Wolff, H.: Aufgabe und Möglichkeit einer Erfolgskontrolle der staatlichen Aktivität, in: Zeitschrift für die gesamte staatswissenschaft, 130. Bd. (1974), s. $477-493$

Brunowsky, R. -D., Wicke, L.: Der Okoplan. Durch Umweltschutz zum neuen Wirtschaftswunder, München, Zürich 1984

Bullinger, $M_{.}:$Rechtsfragen des Verursacherprinzips beim Umweltschutz, in: Bullinger, M., Rincke, G., Oberhauser, A., Schmidt, . $_{-}$. B., Das Verursacherprinzip und seine Elemente, Berlin 1974, S. $69-108$ 
Bundesminister des Innern (Hrsg.): Das Verursacherprinzip, Möglichkeiten und Empfehlungen zur Durchsetzung, Umweltbrief Nr. 1, Bonn 1973

Bundesminister des Innern (Hrsg.): Erfahrungsbericht zum Abwasserabgabengesetz, Bonn 1983

Burrows, P.: Pigouvian Taxes, Polluter Subsidies, Regulation, and the size of a Polluting Industry, in: Canadian Journal of Economics, Vol. 12 (1979), S. 494 - 501

Caesar, R.: "Pfennigabgaben" - fiskalisch motivierte Steuertarnung und Rückfall in die Fondswirtschaft? - Eine finanzwissenschaftliche Analyse -, in: Finanzarchiv Neue Folge Bd. $38(1980)$, S. $385-415$

Cansier, D.: Okonomische Grundprobleme der Umweltpolitik, Berlin 1975

Cansier, D.: Förderung des umweltfreundlichen technischen Fortschritts, in: Wirtschaftgdienst, 58. Jg. (1978), Heft 9. S. $456-460$

Cansier, D.: Steuer und Umwelt: Zur Effizienz der Emissionsabgabe, in: Hansmeyer, K.H. (Hrsg.), staatsfinanzierung im Wandel, Schriften des Vereins für Socialpolitik, Gesellschaft für Wirtschafts- und Sozialwissenschaften, Neue Folge Bd. 134, Berlin 1983, S. $765-782$

Cansier, D.: Offentliche Finanzen im Dienst der Umweltpolitik. Neuere theoretische Ansätze, in: Schmidt, $K$. (Hrsg.), offentliche Finanzen und Umweltpolitik I, Schriften des Vereins für Socialpolitik, Gesellschaft für Wirtschafts- und Sozialwissenschaften, Neue Folge Bd. 176/I, Berlin 1988, S. $11-50$

Caro, F.G.: Evaluation Research. An Overwiew, in: ders. (ed.), Readings in Evaluation Research, New York 1977

Coase, R.H.: The Problem of Social Cost, Journal of Law and Economics, Vol. 3, 1960, S. $1-44$

Cronbach, L.J.: Beyond the Two Disciplines of Scientific Psycholgy, in: American Psychologist, Vol. 30 (1975), S. $116-127$

Dahme, H.: Abwasserabgabengesetz, Kissing 1976

Dalpke, H.-L., Göttsching, L.: Uber den spezifischen Abwasseranfall und die spezifische Schmutzfracht von Papierfabriken, in: Wochenblatt für Papierfabrikation, 102. Jg. (1974), Heft 19, S. $721-730$

Das Umweltprogramm der Bundesregierung (ohne Hrsg.), 3. Aufl., stuttgart, Köln, Berlin, Mainz 1973 
Deniston, O.L., Rosenstock, I.M., Welch, W., Getting, V.A.: Evaluation of Program Effectiveness and Program Efficiency, in: Lyden, F.J., Miller, E.G. (eds.), Planning, Programming, Budgeting. A systems Approach to Management, 2nd ed., Chicago 1972 , s. $141-170$

Derlien, H. $-U .:$ Die Erfolgskontrolle staatlicher Planung. Eine empirische Untersuchung über Organisation, Methode und Politik der Programmevaluation, Schriften zur öffentlichen Verwaltung und öffentlichen Wirtschaft, Bd. 17, Baden-Baden 1976

Deutscher Bundestag 6. Wahlperiode: Drucksache 6/1298 vom 20.10 .1974

Deutscher Bundestag 7. Wahlperiode: Drucksache 7/2272 vom 18.6 .1974

Deutscher Bundestag 7. Wahlperiode: Drucksache 7/4546 vom 6.1 .1976

Deutscher Bundestag 7. Wahlperiode: Drucksache $7 / 5183$ vom 13.5 .1976

Deutscher Bundestag 8. Wahlperiode, Drucksache $8 / 4311$ vom 25.6 .1980

Deutscher Bundestag 10. Wahlperiode: Drucksache 10/2977 vom 7.3.1985

Deutscher Bundestag 10. Wahlperiode: Drucksache $10 / 5533$ vom 22.5.1986

Dickertmann, D.: Maßnahmen für den Umweltschutz im Rahmen des bestehenden steuersystems, in: Schmidt, $K$. (Hrsg.), offentliche Finanzen und Umweltpolitik I, Schriften des Vereins für Socialpolitik, Gesellschaft für Wirtschafts- und Sozialwissenschaften, Neue Folge Bd. 176/I, Berlin 1988, S. 91 - 227

Diederichsen, $U .:$ Die Verantwortlichkeit für Altlasten im Zivilrecht, in: Breuer, R., Kloepfer, M., Marburger, P., Schröder, M. (Hrsg.), Altlasten und Umweltrecht. Trierer Kolloquium zum Umwelt- und Technikrecht vom $20-22$. November 1985, Düsseldorf 1986 , s. $117-138$

Eekhoff, J., u.a.: Methoden und Möglichkeiten der Erfolgskontrolle städtischer Entwicklungsmaßnahmen, Schriftenreihe "Städtebauliche Forschung" des Bundesministers für Raumordnung, Bauwesen und städtebau 03.060, Bonn-Bad Godesberg 1977

Eekhoff, J., Werth, G.: Einige Grundprobleme der Erfolgskontrolle staatlicher Maßnahmen, in: Gesellschaft für Regionalforschung (Hrsg.), Jahrbuch für Regionalwissenschaft, 2. Jg. $(1981)$, s. $5-35$ 
Eekhoff, J.: Ansatzpunkte für die Beurteilung öffentlicher Maßnahmen. Erfolgskontrolle von strukturprogrammen, in: Eichhorn, P., Kortzfleisch, G. V.(Hrsg.), Erfolgskontrolle bei der Verausgabung öffentlicher Mittel, Baden-Baden 1986. S. $59-80$

Ellermann, R.: Anregungen zur Konzeptualisierung einer Effektivitätsforschung rechtlicher Regelungen, in: Hellstern, G. -M. Wollmann, H. (Hrsg.), Experimentelle Politik Reformstrohfeuer oder Lernstrategie, Opladen 1983, S. $130-146$

Endres, A.: Umwelt- und Ressourcenökonomie, Darmstadt 1985

Ewringmann, D., Kibat, K. -D., Schafhausen, F.J.: Die Abwasserabgabe als Investitionsanreiz. Auswirkungen des $\$ 7$ a WHG und des Abwasserabgabengesetzes auf Investitionsplanung und -abwicklung industrieller und kommunaler Direkteinleiter, Berlin 1981

Ewringmann, D., Hansmeyer, K.-H., Hoffmann, V., Kibat, K.-D.: Auswirkungen des Abwasserabgabengesetzes auf industrielle Indirekteinleiter, Berlin 1981

Ewringmann, D.: Wirtschaftliche Auswirkungen der Abwasserabgabe - theoretische und praktische oberlegungen, in: Universität Dortmund, Institut für Umweltschutz (Hrsg.): Umweltschutz der achtziger Jahre. Eine standortbestimmung ökologischer und ökonomischer Anforderungen, Reihe B, Bd. B 14, Berlin 1981, S. 111 - 117

Ewringmann, D., Schafhausen, F.: Abgaben als ökonomischer Hebel in der Umweltpolitik - Ein Vergleich von 75 praktizierten oder erwogenen Abgabenlösungen im In- und Ausland, Berlin 1985

Fischer, H.P.: Die Finanzierung des Umweltschutzes im Rahmen einer rationalen Umweltpolitik, Frankfurt, Bern, Las Vegas 1978

Fox, K. - P.: Erfolgskontrolle der regionalen wirtschaftsförderung, in: Eichhorn, P., Kortzfleisch, G. V. (Hrsg.), Erfolgskontrolle bei der Verausgabung öffentlicher Mittel, Baden-Baden 1986, S. $35-58$

Frey, B.S.: Umweltökonomie, Göttingen 1972

Friauf, K.H.: Zur Zulässigkeit von außersteuerlichen Sonderabgaben, in: Festschrift für w. Haubrichs, Der Bürger als Objekt der staatlichen Finanzpolitik, 2. Aufl., Bad Wörrishofen 1977, S. $103-125$

Friedrich, H.: Staatliche Verwaltung und Wissenschaft, Frankfurt 1970 
Friedrichs, J.: Methoden empirischer Sozialforschung, 9. Aufl., Opladen 1981

Genscher, H.D.: Umweltpolitik in der Bundesrepublik Deutschland, in: Das Umweltprogramm der Bundesregierung (ohne Hrsg.), 3. Auf1., stuttgart, Köln, Berlin, Mainz 1973, S. $6-12$

Gieseke, P., Wiedemann, W., Czychowski, M.: Wasserhaushaltsgesetz unter Berücksichtigung der Landeswassergesetze und des Wasserstrafrechts. Kommentar, 4., neubearb. Aufl., München 1985

Görres, P.A.: Der Zusatznutzen einer Umweltsteuer, in: Zeitschrift für Umweltpolitik und Umweltrecht, 7. Jg. (1985), S. $45-68$

Göttsching, L., Dalpke, H.-L.: Chancen und Risiken der Wasserkreislaufschließung in Papierfabriken, in: Das Papier, 30. Jg. (1976), Heft 10 A, S. V 128 - V 137

Göttsching, L., Lüttgen, W.: Organische Hilfsstoffe als eine Quelle der Wasserbelastung bei der Papierherstellung, in: Das Papier, 32. Jg. (1978), Heft 10 A, S. V $46-$ V 53

Göttsching, L.: Innerbetriebliche Vermeidungsmaßnahmen und Abwasserreinigung in der Papierindustrie, in: Wochenblatt für Papierfabrikation, 107. Jg. (1979), Heft 10, S. $359-364$

Göttsching, L., Hamm, U., Putz, H.-J.: Altpapier-Studie über Marktanalyse und Schadstoff-Pfade, Darmstadt 1986

Hansmeyer, K.H., Fürst, D.: Die Gebühren, stuttgart, Berlin, Köln, Mainz 1968

Hansmeyer, K.H.: Die Abwasserabgabe als Versuch einer Anwendung des Verursacherprinzips, in: Issing, $O$. (Hrsg.), Okonomische Probleme der Umweltschutzpolitik, Berlin 1976, S. $65-97$

Hansmeyer, K.H., mit Caesar, R., Koths, D., Siedenberg, A.: Steuern auf spezielle Güter, in: Handbuch der Finanzwissenschaft, Bd. 2, 3., gänzl. neubearb. Aufl., Tübingen 1980, S. $709-885$

Hansmeyer, K.H.: Abgaben und steuerliche Instrumente der Umweltpolitik - Wirkungsweise, Erfahrungen, Möglichkeiten, in: Zeitschrift für Umweltpolitik \& Umweltrecht, 9. Jg. (1987), Heft 3, S. $251-266$

Hansmeyer, K.H.: Das AbwAG und seine Bedeutung im Rahmen der Bemühungen um eine Sanierung der Gewässer, in: gwf-wasser/abwasser, 119. Jg. (1987), Heft 11, S. $539-534$

Hartkopf, G., Bohne, E.: Umweltpolitik, Bd. 1, Opladen 1983 
Hauff, V.: Umweltpolitische Konzeptionen aus politischer Sicht, in: Wirtschaftsdienst, 64. Jg. (1984), Heft 4, S. $163-166$

Heinen, E.: Das Zielsystem der Unternehmung, Wiesbaden 1966

Hellstern, G.-M., Wollmann, H.: Wirkungsanalysen: Eine neue Variante wissenschaftlicher Politikberatung, in: Transfer 4, Planung in öffentlicher Hand, Opladen 1977, S. $157-168$

Hellstern, G.-M., Wollmann, H.: Evaluierungsforschung Ansätze und Methoden. Dargestellt am Beispiel des Städtebaus, Basel, Boston, stuttgart 1983

Hellstern, G.-M., Wollmann, H.: Evaluierung und Evaluierungsforschung - ein Entwicklungsbericht, in: dies. (Hrsg.), Handbuch zur Evaluierungsforschung, Bd. 1, Opladen 1984, S. $17-93$

Hembach, K.: Der stellenwert von Wirkungsanalysen für die Regionalpolitik. Eine systematisierung der Problematik am Beispiel der regionalen Wirtschaftspolitik, Frankfurt, Bern, Circencester/U.K. 1980

Henseler, P. : Begriffsmerkmale und Legitimation von Sonderabgaben, Baden-Baden 1984

Hoffmann, V., Ewringmann, D.: Auswirkungen des Abwasserabgabengesetzes auf Investitionsplanung und -abwicklung in Unternehmen, Gemeinden und Abwasserverbänden, Köln 1977

Institut Fresenius GmbH Taunusstein-Neuhof W. Fresenius und W. Schneider, Forschungsinstitut für Wassertechnologie an der RWTH Aachen (FiW) B. Böhnke, und K. Pöppinghaus (Hrsg.): Abwassertechnologie. Entstehung, Ableitung, Behandlung, Analytik der Abwässer, Berlin, Heidelberg, New York, Tokyo 1984

Isensee, J.: Nichtsteuerliche Abgaben - ein weiBer Fleck in der Finanzverfassung, in: Hansmeyer, K.H. (Hrsg.), Staatsfinanzierung im Wandel, Schriften des Vereins für Socialpolitik, Gesellschaft für Wirtschafts- und Sozialwissenschaften, Neue Folge Bd. 134, Berlin 1982, S. $437-461$

Jacobs, G.: Wasser und Abwasser in der Papierindustrie. Umweltorientierte Anforderungen, Leistungen und Probleme, in: Verband Deutscher Papierfabriken (Hrsg.), Umweltschutz in der Papierindustrie, Schriftenreihe Nr. 5/P, 1981, S. $16-32$

Jürgensen, H.: Das Verursacherprinzip im Umweltschutz, in: Volkswirtschaftliche Korrespondenz der Adolf-Weber-stiftung, 11. Jg. (1972), Nr. 6, 0.S.

Kabelitz, K.R., Köhler, A.: Abgaben als Instrument der Umweltschutzpolitik, Köln 1977 
Kabelitz, K.R., Köhler, A.: Auflagen als Instrument der Umweltpolitik, Köln 1978

Kade, G.: Okonomische und gesellschaftspolitische Aspekte des Umweltschutzes, in: Glagow, M. (Hrsg.), Umweltgefährdung und Gesellschaftssystem, München 1972, S. $124-141$

Katalyse-Umweltgruppe (Hrsg.): Umweltlexikon, Köln 1985

Kibat, $K_{.}-D_{.}:$Okonomische Aspekte der Wirkungen wasserwirtschaftlicher Regelwerke (AbwAG/WHG) auf Abwasserverbände und deren Mitglieder, Berlin 1982

Kibat, K. $-D$. : Begleitende Untersuchung der angewandten Gebührenmodelle der Abwälzung der Abwasserabgabe auf Indirekteinleiter in ausgewählten Kommunen, Köln 1983, unveröffentlicht

Kibat, K. -D.: Verursacherbezogene Entwässerungsgebühren und Abwasserabgabe, in: Korrespondenz Abwasser, 31. Jg. (1984), Heft 8, s. $708-713$

Kibat, K.-D.: Wasserverbände als Träger der Gewässergütepolitik, München 1988

Kirchhof, P.: Verfassungsrechtliche Beurteilung der Abwasserabgabe des Bundes. Die Grundkonzeption des Abwasserabgabengesetzes des Bundes im verfassungsrechtlichen system der öffentlichen Abgaben, Berlin 1983

Kiresuk T.J., Larsen, N.E., Lund, S.H.: Wissenstransfer als Strategie in Programm-Management und Evaluierung, in:

Hellstern, G.-M., Wollmann, H. (Hrgg.), Handbuch zur Evaluierungsforschung, Bd. 1, Opladen 1984, S. $196-218$

Kloepfer, M.: Umweltschutz durch Abgaben, in: Die öffentliche Verwaltung, 28. Jg. (1975), Heft 17, S. $593-597$

Koch, E.R., Vahrenholt, F.: Die Lage der Nation, UmweltAtlas der Bundesrepublik, Hamburg 1983

Koch, H.-J.: Altlasten - Eine umweltpolitische Herausforderung, in: Brandt, E. (Hrsg.), Altlasten: Untersuchung, Sanierung, Finanzierung, Taunusstein 1988

König, H.: Dynamische Verwaltung. Bürokratie zwischen Politik und Kosten, 2. Auf1., stuttgart 1977

Länderarbeitsgemeinschaft Wasser (LAWA) (Hrsg.): Die Gewässergütekarte der Bundesrepublik Deutschland, stuttgart 1974

Länderarbeitsgemeinschaft Wasser (LAWA) (Hrsg.): Die Gewässergütekarte der Bundesrepublik Deutschland, stuttgart 1980 
Länderarbeitsgemeinschaft Wasser (LAWA) (Hrsg.): Die Gewässergütekarte der Bundesrepublik Deutschland, München 1985

Lauschmann, E.: Grundlagen einer Theorie der Regionalpolitik, 3. Aufl., Hannover 1976

Lersner, $H_{.} v_{.}$, als Teilnehmer in der Podiumsdiskussion: Rechtspolitische Lösungen des Altlastenproblems, in: Breuer, R., Kloepfer, M., Marburger, P., Schröder, M. (Hrsg.), Altlasten und Umweltrecht. Trierer Kolloquium zum Umwelt- und Technikrecht vom $20-22$. November 1985, Düsseldorf 1986 , S. $183-211$

Lijphart, A.: Comparative Politics and the Comparative Method. American Political Science Review, 1971

Maas, Ch.: Einfluß des Abwasserabgabengesetzes auf Emissionen und Innovationen, in: Zeitschrift für Umweltpolitik und Umweltrecht, 9. Jg. (1987), Heft 1, S. $65-85$

Maier-Rigaud, G.: Umweltpolitik in der Marktwirtschaft, in: Wirtschaftsdienst, 60. Jg. (1980), Heft 7, s. $431-345$

Maier-Rigaud, G.: Umweltpolitik in der offenen Gesellschaft, Opladen 1988

Maloney, M.T., McCormick, R.E.: A Positive Theory of Environmental Quality Regulation, in: Journal of Law and Economics, Vol. 25 (1982), S. $99-123$

Mayntz, R., Bohne, E., Derlien, H.-U., Hesse, B., Hucke, J., Müller, A.: Vollzugsprobleme der Umweltpolitik. Empirische Untersuchung der Implementation von Gesetzen im Bereich der Luftreinhaltung und des Gewässerschutzes, stuttgart 1978

Mayntz, R.: Die Implementation politischer Programme: Theoret1sche Uberlegungen $\mathrm{zu}$ einem neuen Forschungsgebiet, in: dies. (Hrsg.): Implementation politischer Programme, Bd. 1, Königstein/Ts. 1980, S. $236-249$

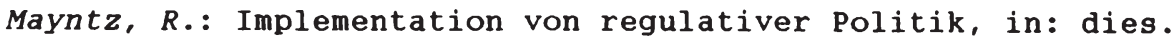
(Hrsg.), Implementation politischer Programme, Bd. 2: Ansätze zur Theoriebildung, Opladen 1983, S. $50-74$

Merck, P.: Verteilungswirkungen einer effizienten Umweltpolitik, Berlin 1988

Meßerschmidt, $K_{.}$: Umweltabgaben als Rechtsproblem, Berlin 1986

Möbius, C.H.: Die Abwassersituation der Zellstoff- und Papierindustrie in der Bundesrepublik Deutschland, in: Wochenblatt für Papierfabrikation, 107. Jg. (1979), Heft 19, S. $765-777$ 
Mußgnug, $R_{\text {.: }}$ Die zweckgebundene öffentliche Abgabe, in: Festschrift für E. Forsthoff, München 1972, S. $259-304$

Nichols, A.L.: Targeting Economic Incentives for Environmental Protection, Cambridge/Mass., London 1984

Nowotny, E.: Wirtschaftspolitik und Umweltschutz, Freiburg i.Br. 1974

Oberhauser, A.: Abgrenzung des Verursacherprinzips und seine Einordnung in die Umweltpolitik, in: Bullinger, M., Rincke, G., Oberhauser, A., Schmidt, R.-B., Das Verursacherprinzip und seine Instrumente, Berlin 1974, S. $27-49$

Oberhauser, A.: Gesamtwirtschaftliche Wirkungen der Anwendung des Verursacherprinzips, in: Bullinger, M., Rincke, G., Oberhauser, A., Schmidt, R.-B., Das Verursacherprinzip und seine Instrumente, Berlin 1974, S. $51-68$

O.V.: Schlag ins Abwasser, in: Wirtschaftswoche, 40 . Jg. (1986), Nr. 26 vom 20.6.1986, S. $20-22$

Osterkamp, R.: Emissionsstandards und Emissionssteuern als alternative Instrumente der Umweltschutzpolitik. Ein theoretischer Vergleich, München 1984

Patzig, W.: Steuern - Gebühren - Beiträge und "Sonderabgaben", in: Die öffentliche Verwaltung, 34. Jg. (1981), Heft 19 , s. $729-747$

Pethig, R.: Umweltökonomische Allokation und Emissionssteuern, Tübingen 1979

Pigou, A.C.: The Economics of Welfare, Reprint der 4. Auflage von 1932, London 1952

Praml, R.: Emissionsabgaben als Instrument des Umweltrechts, in: Jarre, J. (Hrsg.), Umweltrecht in der Bundesrepublik Deutschland. Erfolge, Probleme, Perspektiven, Loccumer Protokolle, Bd. 18, Rehburg-Loccum 1984, s. 84 - 107

Praml, R.: Abgaben als Instrument des Umweltschutzes, in: Hauff, V., Müller, M. (Hrsg.), Umweltpolitik am Scheideweg. Die Industriegesellschaft zwischen Selbstzerstörung und Aussteigermentalität, München 1985, S. $116-121$

Rat von Sachverständigen für Umweltfragen: Umweltgutachten 1974, stuttgart, Mainz 1974

Rat von Sachverständigen für Umweltfragen: Die Abwasserabgabe: wassergütewirtschaftliche und gesamtökonomische Wirkungen, 2. Sondergutachten, stuttgart, Mainz 1974

Rat von Sachverständigen für Umweltfragen: Umweltgutachten 1978, Stuttgart, Mainz 1978 
Rat von Sachverständigen für Umweltfragen: Umweltgutachten 1987, stuttgart, Mainz 1987

Reding, $K$. : Die Effizienz staatlicher Aktivitäten: Probleme ihrer Messung und Kontrolle, Baden-Baden 1981

Rehbinder, E.: Politische und rechtliche Probleme des Verursacherprinzips, Berlin 1973

Rehbinder, E.: Allgemeines Umweltrecht, in: Salzhedel, J. (Hrsg.), Grundzüge des Umweltrechts, Berlin 1982, S. $81-115$

Reinermann, H.: Erfolgskontrolle im öffentlichen Sektor. Beiträge des Rechnungsweseng als Brücke zwischen NutzenKosten-Untersuchung und Evaluierung, in: Die Betriebswirtschaft, 37. Jg. (1977), Heft 3, s. $399-416$

Rincke, G., Göttsching, L., Irmer, H., Dalpke, H.-L.: Gutachten über einzel- und volkswirtschaftliche Auswirkungen des geplanten Abwasserabgabengesetzes auf die Papier- und Zellstoffindustrie, Darmstadt 1974

Rincke, G.: Anwendbarkeit des Verursacherprinzips am Beispiel der Wassergütewirtschaft, in: Bullinger, M., Rincke, G., Oberhauser, A., Schmidt, $R_{.}-B .$, Das Verursacherprinzip und seine Instrumente, Berlin 1974, S. 109 - 154

Roth, H. (Hrsg.): Wasserhaushaltsgesetz. Abwasserabgabengesetz. Textausgabe mit Einführung, schriftlichen Berichten des Innenausschusses des Deutschen Bundestages und Sachregister, Berlin 1977

Salzwedel, J.: Studien zur Erhebung von Abwassergebühren, Berlin 1972

Scheele, M., Schmitt, G.: Der "Wasserpfennig": Richtungsweisender Ansatz oder Donquichoterie?, in: Wirtschaftsdienst, 66. Jg. (1986), Heft 11, S. $570-574$

Schemmel, L.: Quasi-Steuern - Gegen den Wildwuchs steuerähnlicher Sonderabgaben, hrsg. vom Karl-Breuer-Institut des Bundes der Steuerzahler, Heft 46, Wiesbaden 1980

Schendel, F.A.: Die Vielfalt der wasserrechtlichen werte und ihre Bedeutung insbesondere im Gewässerstrafrecht, in:

Korrespondenz Abwasser, 32. Jg. (1985), Heft 9, S. 752 - 757

Schottelius, D.J.: Das Verursacherprinzip. Irrungen, Wirrungen, in: Privatautonomie, Eigentum und Verantwortung. Festgabe für Hermann Weitnauer zum 70. Geburtstag, Berlin 1980 , S. $397-410$

Siebert, H.: Analyse der Instrumente der Umweltpolitik, Göttingen 1976 
Siebert, H.: Neuere Entwicklungen in der ökonomischen Analyse des Umweltschutzes, in: Möller, H., Osterkamp, R., Schneider, W. (Hrsg.), Umweltökonomik. Beiträge zur Theorie und Politik, Königstein/Ts., 1982, S. $267-283$

Siebert, H.: Instrumente der Umweltpolitik. Die ökonomische Perspektive, in: Möller, H., Osterkamp, R., Schneider, $W$. (Hrsg.), Umweltökonomik. Beiträge zur Theorie und Politik, Königstein/Ts. 1982, S. $284-294$

Siebert, $H_{.:}$Umweltschäden als Problem der Unsicherheitsbewältigung: Prävention und Risikoallokation, Konstanz 1986

Siebert, H.: Die Umwelt in der ökonomischen Theorie, Konstanz 1987

Sprenger, R.-U.: Kriterien zur Beurteilung umweltpolitischer Instrumente aus der sicht wissenschaftlicher Politikberatung, in: Schneider, G., Sprenger, R. $-U$. (Hrsg.), Mehr Umweltschutz für weniger Geld - Einsatzmöglichkeiten und Erfolgschancen ökonomischer Anreizsysteme in der Umweltpolitik, München 1984 , S. $41-73$

Statistisches Bundesamt Wiesbaden (Hrsg.): Wasserversorgung und Abwasserbeseitigung im Bergbau und Verarbeitenden Gewerbe und bei Wärmekraftwerken für die öffentliche Versorgung, Fachserie 19, Reihe 2.2, stuttgart, Mainz

Steger, U.: Umweltmanagement. Erfahrungen und Instrumente einer umweltorientierten Unternehmensstrategie, Frankfurt 1988

Terhardt, K.: Die Befolgung von Umweltschutzauflagen als betriebswirtschaftliches Entscheidungsproblem, Berlin 1986

Töpfer, $K .:$ Umweltschutz im Spannungsfeld zur Wirtschaftspolitik, in: Duwendag, D., Siebert, H. (Hrsg.), Politik und Markt, stuttgart 1980 , S. $433-449$

Töpfer, K.: Anwendungsbedingungen und -restriktionen "neuer" ökonomischer Instrumente, in: Deutsche stiftung für Umweltpolitik (Hrsg.), Umweltpolitisches Gespräch: Okonomische Instrumente der Umweltpolitik - Neuer Weg oder Sackgasse?, Beiträge zur Umweltgestaltung, Bd. A 93, Berlin 1984, S. $23-34$

Umweltbericht '76. Fortschreibung des Umweltprogramms der Bundesregierung vom 14. Juli 1976. Mit einer Einführung von Werner Maihofer (ohne Hrsg.), Stuttgart, Berlin, Köln, Mainz 1976

Umweltbundesamt (Hrsg.): Daten zur Umwelt 1984, Berlin 1984

Umweltbundesamt (Hrsg.): Daten zur Umwelt 1986/87, Berlin 1986 
Veh, G.M., Hulsch, J., Edom, E.: Vorschriften der Europäischen Gemeinschaften auf dem Gebiet des Wassers - systematische Darstellung und Textsammlung, Köln 1984

Verband der Chemischen Industrie (Hrsg.): Mehr Wachstum mehr Umweltschutz. Eine Bilanz der chemischen Industrie, 0.0 . und $0 . \mathrm{J} .$.

Verband der Schweizerischen Zellstoff-, Papier- und Kartonindustrie (Hrsg.): Auswertung der Abwasserumfrage 1980/81, Zürich 1983

Verband Deutscher Papierfabriken (Hrsg.): Umweltbilanz der deutschen Zellstoff- und Papierindustrie, Bonn 1974

Verband Deutscher Papierfabriken (Hrsg.): Papier' 86. Ein Leistungsbericht der deutschen Zellstoff- und Papierindustrie, Bonn 1986

Verband Deutscher Papierfabriken (Hrsg.): Papier-Report, Bonn, Juni 1988

Volz, J.: Erfolgskontrolle kommunaler Planung. Eine Untersuchung über Möglichkeiten und Grenzen der Erfolgskontrolle kommunaler Planungen, Köln, Berlin, Bonn, München 1980

Voss, G.: Erfolgskontrolle regionaler Strukturpolitik, Diss. Köln 1973

Weihe, U.: Evaluationsforschung als Politikersatz? in: Hellstern, G.-M., Wollmann, H. (Hrsg.), Experimentelle Politik - Reformstrohfeuer oder Lernstrategie, Opladen 1983, S. $269-273$

Weiss, C.H.: Evaluation Research in the Political Context, in: Struening, E.L., Guttentag, M. (Eds.), Handbook of Evaluation Research, Bd. 1, Beverly Hills 1975

Wenzel, L.: Schlamm: Entwässerung, Verwertung, Beseitigung brauchbare andere Reststoffe eingeschlossen, in: Allgemeine Papierrundschau, 110. Jg. (1986), Heft 44, S. 1538 - 1548

Wicke, L.: Umweltökonomie. Eine praxisorientierte Einführung, München 1982

Wicke, L.: Plädoyer für ein offensives Umweltmanagement, in: Pieroth, E., Wicke, L. (Hrsg.), Chancen der Betriebe durch Umweltschutz: Plädoyer für ein offensives Umweltschutzmanagement, Freiburg i.Br. 1988, s. $11-33$

Wittkämper, G.: Analyse und Planung in Verwaltung und Wirtschaft, stuttgart 1972

Wolff, H.: Erfolgskontrolle in der Regionalpolitik, Basel 1975 
Wulf, J., d'Orville, H.: Entwurf eines Systems der Erfolgskontrolle für die regionale Wirtschaftsförderung, Koblenz 1975

Zangemeister, $C .:$ Nutzwertanalyse in der systemtechnik. Eine Methodik zur multidimensionalen Bewertung und Auswahl von Projektalternativen, 3. Aufl., München 1973

Zavelberg, H.G.: Staatliche Rechnungsprüfung und Erfolgskontrolle - Möglichkeiten und Grenzen, in: Eichhorn, P., Kortzfleisch, G. V. (Hrsg.), Erfolgskontrolle bei der Verausgabung öffentlicher Mittel, Baden-Baden 1986, S. $103-119$

Zeitel, G.: Gebühren und Beiträge, in: Handwörterbuch der wirtschaftswissenschaft, Bd. 3, stuttgart, New York 1981, S. $347-355$

Zimmermann, H.: Typen ökonomischer Anreizinstrumente in der Umweltpolitik, in: Schneider, G., Sprenger, R.-U. (Hrsg.), Mehr Umweltschutz für weniger Geld - Einsatzmöglichkeiten und Erfolgschancen ökonomischer Anreizsysteme in der Umweltpolitik, München 1984, S. $225-246$

Zimmermann, H., Henke, K.-D.: Finanzwissenschaft. Eine Einführung in die Lehre von der öffentlichen Finanzwirtschaft, 4., überarbeitete und ergänzte Auflage, München 1985

Zitzelsberger, W. (Bearb.): Das neue Wasserrecht für die betriebliche Praxis: Recht und Technik der Abwasserbeseitigung, der Wasserversorgung, der Lagerung und des Transports wassergefährdender Stoffe; mit dem neuen Abwasserabgabengesetz, den neuen Mindestanforderungen für Abwassereinleitungen und sämtlichen praxisrelevanten Vorschriften, Losebl.-Ausg., Kissing, Zürich, Paris, Mailand, Amsterdam, Wien, London, Rechtsstand Januar 1981 - 1988 


\section{Gesetze und gesetzesähnliche Werke}

Bekanntmachung der Neufassung des Abwasserabgabengesetzes vom 5. März 1987, BGBl. I S. 880

Bekanntmachung der Neufassung des Gesetzes zur Ordnung des Wasserhaushalts (Wasserhaushaltsgesetz - WHG) vom 16. Oktober 1976, BGBl. I S. 3017

Bundesgesetz über den Schutz der Gewässer gegen Verunreinigung (Gewässerschutzgesetz) vom 8. Oktober 1971 (stand am 1. April 1985), 814.20 (Schweizerisches Gesetzeswerk)

Gesetz über Abgaben für das Einleiten von Abwasser in Gewässer (Abwasserabgabengesetz - AbwAG) vom 13. September 1976, BGBl. I S. 2721

Ministerialblatt des Bundesministers der Finanzen und des Bundesministers für Wirtschaft, Nr. 13/1973 v. 11.7.1973

Neunzehnte Allgemeine Verwaltungsvorschrift über Mindestanforderungen an das Einleiten von Abwasser in Gewässer (Zellstofferzeugung, Herstellung von Papier und Pappe) - 19. AbwasserVwV vom 15. Januar 1982, GMBI. S. 59

Richtlinie des Rates der Europäischen Gemeinschaften vom 4. Mai 1976, betreffend die Verschmutzung infolge der Ableitung bestimmter gefährlicher stoffe in die Gewässer der Gemeinschaft, in: Amtsblatt der Europäischen Gemeinschaften vom 26. Januar $1980, \mathrm{Nr} .20 / 43$

Verordnung über Abwassereinleitungen vom 8. Dezember 1975 (Stand am 1. April 1985), 814.225.21 (Schweizerische Verordnung)

Wasserhaushaltsgesetz in der Fassung der Bekanntmachung vom 23. September 1986, BGBI. I S. 1529 
ANHANG

ANHANG 1: Gesetz über Abgaben für das Einleiten von Abwasser in Gewässer (Abwasserabgabengesetz - AbwAG) vom 13. September 1976, BGBI. I S. 2721

ANHANG 2: Neunzehnte Allgemeine Verwaltungsvorschrift über Mindestanforderungen an das Einleiten von Abwasser in Gewässer (Zellstofferzeugung, Herstellung von Papier und Pappel - 19. AbwasserVwV vom 15. Januar 1982, GMBI. S. 59

ANHANG 3: Fragebogen für die deutschen Papierfabriken ANHANG 4: Fragebogen für die schweizerischen Papierfabriken 
ANHANG 1

Marietta Jass-Teichmann - 978-3-631-75034-6 Downloaded from PubFactory at 01/11/2019 09:02:57AM via free access 
Marietta Jass-Teichmann - 978-3-631-75034-6 Downloaded from PubFactory at 01/11/2019 09:02:57AM via free access 


\section{Bundesgesetzblatt ${ }^{m x}$}

Teil I

Z1997 A

\begin{tabular}{l|l|l|}
\hline 1976 & Ausgegeben zu Bonn am 15. September 1976 & Nr.118 \\
\hline
\end{tabular}

\section{Gesetz \\ über Abgaben für das Einleiten von Abwasser in Gewässer \\ (Abwasserabgabengesetz - AbwAG)}

Vom 13. September 1976

Der Bundestag hat das folgende Gesetz beschlos. sen:

\section{Erster Abschnitt$$
\S 1
$$ \\ Grundsatz}

Allgemeine Vorschriften

Für das Einlejten von Abwasser in ein Gewässer im Sinne des $\$ 1$ Abs. 1 des Wasserhaushaltsgesetzes vom 27. Juli 1957 (Bundesgesetzbl. I S. 1110), zuletzt geändert durch das Vierte Gesetz zur Änderung des Wasserhaushaltsgesetzes vom 26. April 1976 (Bundesgesetzbl. I S. 1109), ist eine Abgabe zu entrichten (Abwasserabgabe). Sie wird durch die Länder erhoben.

\section{2}

\section{Begriflsbestimmungen}

(1) Abwasser im Sinne dieses Gesetzes sind das durch häuslichen, gewerblichen, landwirtschaftlichen oder sonstigen Gebrauch in seinen Eigenschaften veränderte und das bei Trockenwetter damit zusammen abfließende Wasser (Schmulzwasser) sowje das von Niederschlägen aus dem Bereich von bebauten oder befestigten Flächen abflieBende Wasser (Niederschlagswasser).

(2) Einleiten im Sinne dieses Gesetzes ist das unmittelbare Verbringen des Abwassers in ein Gewässer; das Verbringen in den Untergrund gilt als Einleiten in ein Gewässer, ausgenommen hier. von ist das Verbringen im Rahmen landbaulicher Bodenbehandlung.

(3) Abwasserbehandlungsanlage im Sinne dieses Gesetzes ist eine Einrichtung, die dazu dient, die Schädlichkeit des Abwassers zu vermindern oder zu beseitigen; ihr steht eine Einrichtung gleich, die dazu dient, die Entstehung von Abwasser ganz oder teilweise zu verhindern.

\section{3}

Bewertungsgrundlage

(1) Die Abwasserabgabe richtet sich nach der Schädlichkeit des Abwassers, die unter Zugrundelegung der Abwassermenge, der absetzbaren Stoffe. der oxydierbaren Stoffe und der Giftigkeit des Abwassers in Schadeinheiten nach der Anlage zu diesern Gesetz bestimmt wird. 
(2) In den Fällen Jes $\$ 9$ Abs. 3 (Flußkläranlagen) richlet sich die Abgabe nach der Zahl der Schadein. heiten im Gewässer unterhalb der Flußkläranlage.

(3) Die Länder können bestimmen, daB die Schäd. lichkeit des Abwassers insoweit außer Ansatz bleibt, als sie in Nachklärteichen, die einer Abwas. serbehandlungsanlage klärtechnisch unmittelbar zugeordnet sind, beseitigt wird.

(4) Die Länder können bestimmen, daß auf Antrag des Abgabepflichtigen die Schädlichkeit absetzbarer Stoffe nach ihrem Gewicht bestimmt wird, wenn die Zahl der Kubikmeter Jahresmenge mehr als fünfmal so groB ist wie die Zahl der Tonnen der Trockensubstanz im Jahr.

(5) Die Bundesregierung wird ermächtigt, durch Rechtsverordnung mit Zustimmung des Bundesrates die in der Anlage Teil B festgelegten Vorschriften über die Verfahren zur Bestimmung der Schädlichkeit dem jeweiligen Stand der Wissenschaft und Technik anzupassen, um die Verfahren zu verfeinern oder um den für die Bestimmung der Schädlichkeit erforderlichen persönlichen oder sachlichen Aufwand $\mathrm{zu}$ vermindern, wenn dadurch die Bewertung der Schädlichkeit nicht wesentlich verändert wird.

\section{Zweiter Abschnitt Ermiltlung der Schädlichkelt}

\section{4}

\section{Ermittlung aui Grund des Bescheides}

(1) Die Werte für die Ermittlung der Zahl der Schadeinheiten sind auBer bei Niederschlagswasser (\$7) und bei Kleineinleitungen (\$ 8) dem die Abwassereinleitung zulassenden Bescheid zu entnehmen. Der Bescheid hat mindestens Angaben über die Jahresschmutzwassermenge sowie über die absetzbaren Stoffe, die oxydierbaren Stoffe und die Giftigkeit nach 3 Abs. 1, unterschieden nach im Mittel einzuhaltenden Werten (Regelwerte) und Werten, die in keinem Fall überschritten werden dürfen (Höchstwerte), zu enthalten. Bei der Ermittlung der Zahl der Schadeinheiten sind die Regelwerte, mindestens die halben Werte der Höchstwerte, zugrunde zu legen (Bezugswerte). Sind absetzbare Stoffe, oxydierbare Stoffe oder eine Giftigkeit nach \$ 3 Abs. 1 im Abwasser nicht zu erwarten oder sind im Abwasser weniger als ein Kilogramm Quecksilber im Jahr oder weniger als zehn Kilogramm Cadmium im Jahr zu erwarten, so kann insoweit auf die Festsetzung von Werten im Bescheid verzichtet werden; enthält der Bescheid gleichwohl Werte für Quecksilber oder Cadmium. so bleiben sie bei der Ermittlung der Schädlichkeit auBer Ansatz.

(2) In den Fällen des $\$ 9$ Abs. 3 (FluBkläranlagen) gilt Absatz 1 entsprechend.

(3) Weist das aus einem Gewässer unmittelbar entnommene Wasser vor seinem Gebrauch bereits eine Schädlichkeit nach $\$ 3$ Abs. 1 (Vorbelastung) all, so ist auf Anirag des Abgabepflichligen die Vorbelastung zu schälzen und ihm die geschätzle Vorbelastung nicht zuzurechnen. Die Länder können für Gewässer oder Teile von Gewässern die Vorbelastung einheitlich fostlegen.

(4) Die Einhaltung des Bescheides ist im Rahmen der Gewässerüberwachung nach den wasserrechllichen Vorschriften durch staatliche oder staatlich anerkannte Stellen zu überwachen. Ergibt die Uberwachung, daß einer der im Bescheid festgelegten Höchstwerte mehr als einmal im Jahr überschritten wird, so ist bei der Ermittlung der Zahl der Schadeinheiten insow'eit ein erhöhter Bezugswert zugrunde zu legen; der erhöhte Bezugswert ist die Summe des Bezugswertes des Bescheides und des arithmetischen Mittels der Differenzen, um die die gemessenen Werte den in Bescheid festgelegten Höchstwert überschreiten.

(5) Erklärt der Einleiter gegenüber der Behörde. daß er während éines bestimmten Zeitraums, der nicht kürzer als drei Monate sein darf, eine geringere Abwassermenge einleiten oder geringere Regelwerte einhalten und entsprechend niedrigere Höchstwerte nicht überschreiten wird, so ist die Zahl der Schadeinheiten für diesen Zeitraum nach der geringeren Abwassermenge oder den angegebenen Bezugswerten zu ermitteln. Die Abweichung muB mindestens 25 vom Hundert der Abwassermenge oder der in Betracht kommenden Regelwerte betragen. Die Absätze 3 und 4 gelten entsprechend.

\section{$\$ 5$}

\section{Ermittlung auf Grund von Messungen}

(1) Weist der Abgabepflichtige auf Grund eines von der zuständigen Behörde zugelassenen Meßprogramms durch Vorlage von Meßwerten nach, daß das gewogene Mittel der Meßergebnisse im vorangegangenen Veranlagungszeitraum um mehr als 25 vom Hundert vom Regelwert nach $\$ 4$ Abs. 1 abweicht, ist bei der Ermittlung der Zahl der Schadeinheiten das gewogene Mittel der Meßwerte, mindestens aber die Hälfte des höchsten gemessenen Wertes zugrunde zu legen. Das Meßprogramm muß mindestens neben einer kontinuierlichen Mengenmessung eine Probenahme je Tag zu wechselnden Zeiten vorsehen.

(2) $\$ 4$ Abs. 3 und 4 gilt entsprechend. Ergibt die Uberwachung, daB der höchste nach Absatz 1 Satz 1 vorgelegte MeBwert mehr als einmal im Jahr überschritten wurde, so gilt bei der Ermittlung der Zahl der Schadeinheiten $\$ 4$ Abs. 4 Satz 2 entsprechend; hierbei ist mindestens die Hälfte des im Bescheid festgesetzten Höchstwertes zugrunde zu legen.

\section{$\$ 6$}

\section{Ermittlung In sonstigen Fällen}

(1) Ist ein für die Ermittlung der Zahl der Schadeinheiten nach $\$ 3$ Abs. 1 maßgeblicher Wert nicht in einem Bescheid nach $\$$ Abs. 1 festgelegt und nicht nach $\$ 4$ Abs. 1 Satz 4 entbehrlich, so ist er auf Grund des Ergebnisses einer behördlichen Uberwachung festzusetzen. Liegt kein Ergebnis einer 
behördlichen Uberwachung vor, so hat die zustän. dige Behörde diesen Werl zu schälzen.

(2) 4 Abs. 3 gill entsprechend.

\section{7}

Pauschalierung bel Einleitung von verschmutztem Nlederschlagswasser

(1) Die Zahl der Schadeinhciten von Nlederschlagswasser, das über eine öffentliche Kanalisation eingeleitet wird, beträgt zwöll vom Hundert der Zahl der angeschlossenen Einwohner; die Zahl der angeschlossenen Einwohner kann geschätzl werden.

(2) Die Länder bestimmen, inwieweit sich die Zahl der Schadeinheiten bei Rückhaltung von Niederschlagswasser oder Behandlung in einer Abwas. serbehandlungsanlage ermäBigt; sie können in die. sen Fällen bestimmen, daß die Einleitung abgabefrei bleibt.

\section{$\$ 8$}

Pauschallerung bel Klelnelnleitungen von Schmutzwasser aus Haushaltungen und abnlichem Schmutzwasser

Die Zahl der Schadeinheiten von Schmutzwasser aus Haushaltungen und ähnlichem Schmutzwasser, für das eine Körperschaft des öffentlichen Rechts nach $\$ 9$ Abs. 2 Satz 2 abgabepflichtig ist, beträgt die Hälfte der Zahl der nicht an die Kanalisation angeschlossenen Einwohner, soweit die Länder nichts anderes bestimmen. Ist die Zahl der Einwohner nicht oder nur mit unverhältnismäBigem Aufwand zu ermitteln, kann sie geschätzt werden.

\section{Dritter Abschnitt \\ Abgabepnicht}

\section{$\$ 9$}

\section{Abgabepflicht. Abgabesatz}

(1) Abgabepflichtig ist, wer Abwasser einleitet (Einleiter).

(2) Die Länder können bestimmen, daß an Stelle der Einleiter Körperschaften des öffentlichen Rechts abgabepflichtig sind. An Stelle von Einleitern, die im Jahresdurchschnitt weniger als acht Kubikmeter je Tag Schmutzwasser aus Haushaltungen und ähnliches Schmutzwasser einleiten, sind von den Ländern zu bestimmende Körperschaften des öffentlichen Rechts abgabepflichtig. Die Länder regeln die Abwälzbarkeit der Abgabe.

(3) Wird das Wasser eines Gewässers in einer FluBkläranlage gereinigt, können die Länder bestimmen, daB an Stelle der Einleiter eines festzulegenden Einzugsbereichs der Betreiber der FluBkläranlage abgabepflichtig ist. Absatz 2 Satz 3 gilt entsprechend.

(4) Die Abgabepflicht entsteht bis zum 31. Dezember 1980 nicht. Der Abgabesatz beträgt für jede Schadeinheit

$\begin{array}{ll}\text { ab 1. Januar 1981 } & \text { 12 DM } \\ \text { ab 1. Januar 1982 } & \text { 18 DM } \\ \text { ab 1. Januar 1983 } & 24 \mathrm{DM} \\ \text { ab 1. Januar 1984 } & 30 \mathrm{DM} \\ \text { ab 1. Januar 1985 } & 36 \mathrm{DM} \\ \text { ab 1. Januar 1986 } & 40 \mathrm{DM}\end{array}$

im Jahr.

(5) Der Abgabesalz nach Absalz 4 Satz 2 ermäBigt sich außer bei Niederschlagswasser (\$ 7) oder Kleincinleitungen (\$ 8 ) um die Hälfte für die Schad. einheiten, die nicht vermieden werden, obwohl die Mindestanforderungen nach $\$ 7$ a Abs. 1 Satz 3 des Wasserhaushaltsgeselzes erfüllt werden. Stellt der Bescheid für Werte im Sinne des $\$ 4$ Abs. 1 höhere Anforderungen, so tritt die Ermäßigung nur ein, wenn diese Anforderungen eingehalten werden.

(6) Die Bundesregierung wird ermächtigt, zur Abwehr erheblich, nachteiliger wirtschaftlicher Entwicklungen durch Rechtsverordnung mit Zustimmung des Bundesrates Abgabepflichtige oder regionale oder sektorale Gruppen von Abgabepflichti. gen, die Maßnahmen zur Verringerung der Schäd. lichkeit des Abwassers durchführen oder durchfüh. ren lassen, längstens bis zum 31. Dezember 1989 ganz oder teilweise von der Abgabepflicht freizu. stellen.

$$
\$ 10
$$

\section{Ausnahmen von der Abgabepflicht}

(1) Nicht abgabepflichtig ist das Einleiten von

1. Schmutzwasser, das vor Gebrauch eınem Gewäs. ser entnommen worden ist und über die bei der Entnahme vorhandene Schädlichkeit im Sinne dieses Gesetzes hinaus keine wertere Schadlich. keit im Sinne dieses Gesetzes aufweist.

2. Schmutzwasser in ein beim Abbau von mineralischen Rohstoffen entstandenes oberirdisches Gewässer, sofern das Wasser nur zum Waschen der dort gewonnenen Erzeugnisse gebraucht wird und keine anderen schädlichen Stoffe als die abgebauten enthält und soweit gewahrleistet ist. daß keine schadlichen Stoffe in andere Gerässer gelangen,

3. Schmutzwasser von Wasserfahrzeugen, das auf ihnen anfällt.

4. Niederschlagswasser, wenn es nicht über eine offentliche Kanalisation vorgenommen wird.

(2) Die Länder können bestimmen, daß das Einleiten von Abwasser in Untergrundschichten, in denen das Grundwasser wegen seiner natürlichen Beschaffenheit für eine Trinkwassergewinnung mit den herkömmlichen Aufbereitungsverfahren nicht geeignet ist, nicht abgabepflichtig ist.

(3) Die Abgabepflicht entsteht nicht für die Dauer von drei Jahren vor der vorgesehenen Inbetrieb. nahme einer Abwasserbehandlungsanlage in der Höhe, die der durch den Betrieb der Anlage zu erwartenden Minderung der Schadeinheiten beim Einleiten in das Gewässer entspricht, wenn diese Minderung mindestens 20 vom Hundert beträgt. Sie 
entsteht rückwirkend in voller Höhe, wenn die Anlage nicht in Betrieb genommen wird. Bleibt die tatsächliche Reinigungsleistung hinter der erwarteten Minderung der Schadeinheiten zurück, entsteht insoweit die Abgabepflicht rückwirkend.

\section{Vierter Abschnitt \\ Festsetzung, Erhebung und Verwendung der Abgabe}

\section{$\$ 11$}

Veranlagungszeitraum. Erklärungspflicht

(1) Veranlagungszeitraum ist das Kalenderjahr.

(2) Der Abgabepflichtige hat in den Fällen der $\$ \oint 7$ und 8 die Zahl der Schadeinheiten des Abwassers zu berechnen und die dazugehörigen Unterlagen der zuständigen Behörde vorzulegen. Ist der Abgabepflichtige nicht Einleiter (\$ 9 Abs. 2 und 3), so hat der Einleiter dem Abgabepflichtigen die notwendigen Daten und Unterlagen zu überlassen.

(3) Die Länder können bestimmen, daB der Abgabepflichtige auch in anderen Fällen die Zahl der Schadeinheiten des Abwassers zu berechnen, die für eine Schälzung erforderlichen Angaben zu machen und die dazugehörigen Unterlagen der zuständigen Behörde vorzulegen hat. Absatz 2 Salz 2 gilt entsprechend.

\section{$\$ 12$}

\section{Verletzung der Erklärungspilicht}

(1) Kommt der Abgabepflichtige seinen Verpflichtungen nach $\S 11$ Abs. 2 Satz 1 und den ergänzenden Vorschriften der Länder nicht nach, so kann die Zahl der Schadeinheiten von der zuständigen Behörde geschätzt werden.

(2) Der Einleiter, der nach $\S 9$ Abs. 2 oder 3 nicht abgabepflichtig ist, kann im Wege der Schätzung zur Abgabe herangezogen werden, wenn er seinen Verpflichtungen nach $\$ 11$ Abs. 2 Satz 2 und den ergänzenden Vorschriften der Länder nicht nachkommt. In diesem Fall haften der Abgabepflichtige und der Einleiter als Gesamtschuldner.

\section{3}

\section{Verwendung}

(1) Das Aufkommen der Abwasserabgabe ist für MaBnahmen, die der Erhaltung oder Verbesserung der Gewässergüte dienen, zweckgebunden. Die Länder können bestimmen, daB der durch den Vollzug dieses Gesetzes und der ergänzenden landesrechtlichen Vorschriften entstehende Verwaltungsaufwand aus den Aufkommen der Abwasserabgabe gedeckt wird.

(2) Maßnahmen nach Absatz 1 sind insbesondere:

1. der Bau von Abwasserbehandlungsanlagen,

2. der Bau von Regenrückhaltebecken und Anlagen zur Reinigung des Niederschlagswassers,
3. der Bau von Ring- und Auflangkanälen an Talsperren, Ser- und Mecresufern sowie von Hauptverbindungssammlern, die die Errichlung von Gemeinschaftskläranlagen ermöglichen,

4. der Bau von Anlagen zur Beseitigung des Klärschlamms,

5. Maßnahmen im und am Gewässer zur Beobachtung und Verbesserung det Gewässergüte wie Niedrigwasseraufhöhung oder Sauerstolfanreicherung sowie zur Gewässerunterhaltung,

6. Forschung und Entwicklung von Anlagen oder Verfahren zur Verbesserung der Gewässergüte,

7. Ausbildung und Fortbildung des Betriebspersonals für Abwasserbehandlungsanlagen und andere Anlagen zur Erhaltung und Verbesserung der Gewässergüte.

Funfter Abschnitt

Gemeinsame Vorschriften. Schlußvorschriften

$\S 14$

Anwendung von Straf- und BuBgeldvorschriften der Abgabenordnung

Für die Hinterziehung von Abwasserabgaben gelten die Strafvorschriften des $\S 370$ Abs. 1, 2, 4 und des $\$ 371$ der Abgabenordnung (AO 1977) entsprechend, für die Verkürzung von Abwasserabgaben gilt die Bußgeldvorschrift des $\$ 378$ der Abgabenordnung (AO 1977) entsprechend.

\section{$\S 15$}

\section{Ordnungswidrigkelten}

(1) Ordnungsw'idrig handelt, wer vorsätzlich oder fahrlässig

1. entgegen $\$ 5$ Abs. 1 Satz $1 \mathrm{mit}$ dem Meßprogramn nicht übereinstimmende Meßuerte vorlegt,

2. entgegen $\S 11$ Abs. 2 Satz 1 die Berechnungen oder Unterlagen nicht, nicht richtig oder nicht vollständig vorlegt.

3. entgegen $\$ 11$ Abs. 2 Satz 2 dem Abgabepflichtigen die notwendigen Daten oder Unterlagen nicht, nicht richtig oder nicht vollständig überläBt.

(2) Die Ordnungswidrigkeit kann mit einer Geld. buße bis zu fünftausend Deutsche Mark geahndet werden.

$$
\$ 16
$$

\section{Stadtstaaten-Klausel}

$\$ 1$ findet auch Anwendung, wenn die Länder Berlin und Hamburg selbst abgabepflichtig sind. \$9 Abs. 2 Satz 1 und 2 gilt für die Länder Berlin und Hamburg mit der MaBgabe, daB sie sich auch selbst als abgabepflichtig bestimmen können.

\section{7}

\section{Berlin-Klausel}

Dieses Gesetz gilt nach Maßgabe des $\$ 13$ Abs. 1 des Dritten Ubcrleitungsgesetzes vom 4. Januar 
1952 (Bundesgesetzl,i. I S. 1) auch im Land Berlin Rechlsverordnungen, die auf Grund dieses Gesetzes erlassen werden, gelten im Land Berlin nach $\$ 14$ des Dritten Uberleitungsgesctzes.
$8+18$

nieke 5.3007

Inkrafttreten

Dicses Gesetz tritt am 1. Januar 1978 in Kraft.

Die verlassungsmäBigen Rechle des Bundesrates sind gewahrt.

Das vorstehende Gesetz wird hiermit verkündet.

Bonn, den 13. September 1976

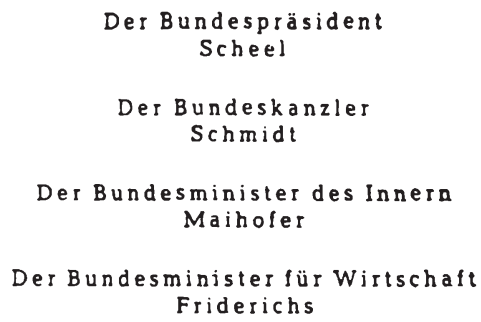




\section{Anlage $2 u \$ 3$}

A.

(1) Bci der Bestimmung der Schädlichkeit des Abwassers sind vorab von den absetzbaren Stoffen 0,1 Milliliter je Liter Abwasser und von den oxydierbaren Stoffen 15 Milligramm je Liter Abwasser abzuziehen; wird die Differenz kleiner als Null, bleibt sie insoweit unberücksichtigt. Die Zahl der Schadeinheiten ergibt sich aus folgender Tabelle:

\begin{tabular}{|c|c|c|}
\hline \multirow{2}{*}{ Bewericte Schadstofle und Schadstoffgruppen } & \multicolumn{2}{|c|}{ Zahl der Schadeinheilen je volle MeBeinheit } \\
\hline & Schadeinheit & MeBeinheil \\
\hline $\begin{array}{l}\text { 1. Alsetzbare Stoffe bei einem organischen Anteil } \\
\text { von mindestens zehn vom Hundert }\end{array}$ & 1 & $\begin{array}{l}\text { Kubikmeter Jahresmenge, im Fall des } \\
\$ 3 \text { Abs. 4. Tonne Jahresmenge }\end{array}$ \\
\hline $\begin{array}{l}\text { 2. Absetzbare Stoffe bei einem organischen Anteil } \\
\text { von weniger als zehn vom Hundert }\end{array}$ & 0,1 & $\begin{array}{l}\text { Kubikmeter Jahresmenge, im Fall des } \\
\text { § } 3 \text { Abs. 4, Tonne Jahresmenge }\end{array}$ \\
\hline $\begin{array}{l}\text { 3. Oxydierbare Stoffe in Chemischem Sauerstoff- } \\
\text { bedarf (CSB) }\end{array}$ & 2,2 & 100 Kilogramm Jahresmenge \\
\hline 4. Quedksilber und seine Verbindungen & 5 & 100 Gramm Quedksilber Jahresmenge \\
\hline 5. Cadmium und seine Verbindungen & 1 & 100 Gramm Cadmium Jahresmenge \\
\hline 6. Giftigkeit gegenüber Fischen & $\left.0,3 \mathrm{G}_{\mathrm{F}}^{*}\right)$ & 1000 Kubikmeter Jahresabwassermenge \\
\hline
\end{tabular}

๑ $G_{F}$ ist det V'erdünnungíaktor, bei dem Abwasser im Fiscriest nicht nehr giftig wirkt. Bei $G_{F}=2$ wird Null eingesetzt.

(2) Wird Abwasser in Küstengewässer eingeleitet, bleibt die Giftigkeit gegenüber Fischen insoweit unberüdksichtigt, als sie auf dem Gehalt an solchen Salzen beruht, die den Hauptbestandteilen des Meerwassers gleichen. Das gleiche gilt für die Einleitung von Abwasser in Mündungsstredken oberirdischer Gewässer in das Meer, die einen ähnlichen natürlichen Salzgehalt wie die Küstengewässer aufweisen.

B.

(1) Das Volumen der absetzbaren Stoffe wird nach zweistündiger Absetzzeit bestimmt.

(2) Der Chemische Sauerstoffbedarf wird nach dem Dichromatverfahren unter Anwendung von Silbersulfat als Katalysator bestimmt.

(3) Quecksilber und Cadmium werden atomabsorptionsspektrometrisch bestimmt.

(4) Die Giftwirkung wird im Fischtest unter Verwendung der Goldorfe (Leuciscus idus melanotus) als Testfisch durch Ansetzen verschiedener Abwasserverdünnungen bestimmt. 
ANHANG 2

Marietta Jass-Teichmann - 978-3-631-75034-6 
Marietta Jass-Teichmann - 978-3-631-75034-6 Downloaded from PubFactory at 01/11/2019 09:02:57AM via free access 


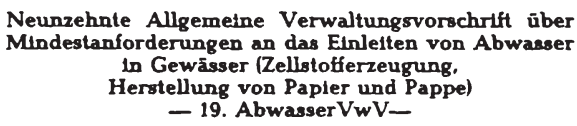

Vom 15. Januar 1982

Nach \& 7a Abs. 1 des Wasserhaushaltsgesetzes in der Fassung der Bekanntmachung vom 16. Oktober 1976 (BGBl. I S. 3017) wird mit Zustimmung des Bundesrates folgende allgemeine Verwaltungsvorschrift erlassen:

\section{Anwendungsberetch}

1.1 Diese allgemeine Verwaltungsvorschrift gilt für in Gewāsser einzuleitendes Abwasser, dessen Schmutzfracht im wesentlichen aus der Erzeugung von Zellstoff sowie aus der Herstellung von Papier und Pappe stammt

1.2 Diese allgemeine Verwaltungsvorschrift gilt nicht für das Einleiten von Abwasser aus Kühlsystemen und aus der Betriebswasseraufbereitung.

2 Mindestanforderungen

21 An das Einleiten des Abwassers aus der Erzeugung von Zellstoff werden folgende Mindestanforderungen gestellt:

21.1 Schmutzwassermenge:

\begin{tabular}{lcccc}
\hline & $\begin{array}{c}\text { Halbzell- } \\
\text { stoti }\end{array}$ & $\begin{array}{c}\text { unge- } \\
\text { bleichter } \\
\text { Zellstoł }\end{array}$ & $\begin{array}{c}\text { gebleich- } \\
\text { Zellstoff }\end{array}$ & $\begin{array}{c}\text { veredelter } \\
\text { Zellstof }\end{array}$ \\
\hline $\begin{array}{l}\text { Schmutz- } \\
\text { wassermenge }\end{array}$ & 100 & 150 & 200 & 230 \\
& & & &
\end{tabular}

wassermenge

in $\mathrm{m}^{3} / \mathrm{t}$

(bezogen auf eine 24-Stunden-Messung bei Trockenwetterabflub)

2.1.2 Abwasserinhaltsstoffe:

\begin{tabular}{|c|c|c|c|c|c|}
\hline & $\begin{array}{c}\text { Absets. } \\
\text { bare } \\
\text { Stotfe } \\
\text { kg/t }\end{array}$ & $\begin{array}{c}\text { Abft- } \\
\text { trierbare } \\
\text { Stotfe }\end{array}$ & $\begin{array}{l}\text { Chemi- } \\
\text { scher } \\
\text { Sauer- } \\
\text { stoffbe- } \\
\text { darf } \\
\text { (CSB) } \\
\mathrm{kg} / \mathrm{t}\end{array}$ & $\begin{array}{l}\text { Bioche- } \\
\text { mischer } \\
\text { Sauer- } \\
\text { stoffoe- } \\
\text { dart in } \\
\text { STagen } \\
\text { (BSBj) } \\
\mathbf{k g} / \mathrm{t}\end{array}$ & $\begin{array}{c}\text { Fiscbgif- } \\
\text { tigkeit } \\
\text { als Ver- } \\
\text { dun- } \\
\text { nunge- } \\
\text { faktor } \\
\text { GF }\end{array}$ \\
\hline \multicolumn{2}{|c|}{ Stichprobe } & \multicolumn{4}{|c|}{ 24-Std.-Mischprobe } \\
\hline $\begin{array}{l}\text { Halbzell- } \\
\text { stoff }\end{array}$ & 3,0 & 5,0 & 80 & 30 & 8 \\
\hline $\begin{array}{l}\text { unge- } \\
\text { bleichter } \\
\text { Zellstoff }\end{array}$ & 45 & 7.5 & 120 & 40 & 8 \\
\hline $\begin{array}{l}\text { gebleichter } \\
\text { Zellstoff }\end{array}$ & 6,0 & 10,0 & 220 & 70 & 8 \\
\hline \multirow[t]{4}{*}{$\begin{array}{l}\text { veredelter } \\
\text { Zellstoff }\end{array}$} & 7.0 & 11.5 & 350 & $\begin{array}{l}\text { aus } \\
\text { Laub- } \\
\text { bolz }\end{array}$ & 8 \\
\hline & & & & 120 & \\
\hline & & & & $\begin{array}{l}\text { sus } \\
\text { Nadel. } \\
\text { bols }\end{array}$ & \\
\hline & & & & 80 & \\
\hline
\end{tabular}

Die produktionsspezifischen Werte $\left(\mathrm{m}^{3} / \mathrm{t} \mathrm{kg} / \mathrm{t}\right)$ beziehen sich auf die dem wasserrechtlichen Bescheid zu. grundeliegende Produktion (Zellstoffertigprodukt luftrocken-lutro-) in 24 Stunden.
2.2 An das Einleiten des Abwassers aus der Herstellung von Papier und Pappe werden folgende Mindestanforderungen gestellt:

\begin{tabular}{|c|c|c|c|c|}
\hline & \multirow{2}{*}{$\begin{array}{c}\text { Abrecz. } \\
\text { bare } \\
\text { Stotle } \\
\mathrm{mll}\end{array}$} & \multirow{2}{*}{$\begin{array}{c}\text { Chemiecher } \\
\text { SauerntoH- } \\
\text { bedart (CSB) } \\
\mathbf{k g} / \mathrm{t} \\
\text { Produkt }\end{array}$} & \multicolumn{2}{|c|}{$\begin{array}{c}\text { Biochemincher Sauer- } \\
\text { rtotbedart in } 5 \text { Tageo } \\
\text { (BSB,) }\end{array}$} \\
\hline & & & $\begin{array}{c}\mathbf{k g} / \mathrm{t} \\
\text { Produkt }\end{array}$ & $m g /$ \\
\hline & $\begin{array}{l}\text { Stich- } \\
\text { probe }\end{array}$ & $\begin{array}{l}\text { 24-Std- } \\
\text { Misch- } \\
\text { probe }\end{array}$ & $\begin{array}{l}\text { 24-Std. } \\
\text { Miecb- } \\
\text { probe }\end{array}$ & $\begin{array}{l}\text { 24-Sid. } \\
\text { Miech- } \\
\text { probe }\end{array}$ \\
\hline $\begin{array}{l}\text { Ungeleimte } \\
\text { holzfreie } \\
\text { Papiere } \\
\text { (max } 5 \% \\
\text { verholzte } \\
\text { Fasern) }\end{array}$ & 0.5 & 6 & 3 & - \\
\hline $\begin{array}{l}\text { Geleimte, } \\
\text { holdreie } \\
\text { Papiere } \\
\text { (max. } 5 \% \\
\text { verholzte } \\
\text { Fasern) }\end{array}$ & 0,5 & 8 & 3 & - \\
\hline $\begin{array}{l}\text { Hochausge- } \\
\text { mablene } \\
\text { Papiere (aus } \\
\text { reinem. } \\
\text { Zellstoff) }\end{array}$ & 0.5 & 15 & 6 & - \\
\hline $\begin{array}{l}\text { Gestrichene } \\
\text { Papiere (über } \\
5 \mathrm{~g} \text { Streich. } \\
\text { masse je m } \mathrm{m}^{2} \\
\text { und Seite) }\end{array}$ & 0,5 & $\left.2(5)^{1}\right)$ & 0,7 & 25 \\
\hline $\begin{array}{l}\text { Holzbaltige } \\
\text { Papiere (über } \\
5 \% \text { verholzte } \\
\text { Fasern, nicht } \\
\text { überwiegend } \\
\text { aus Altpa- } \\
\text { pier) }\end{array}$ & 0,5 & 5 & 0,8 & 25 \\
\hline $\begin{array}{l}\text { Oberwiegend } \\
\text { aus Altpapier } \\
\text { hergestellte } \\
\text { Papiere }\end{array}$ & 0.5 & 6 & 1,2 & - \\
\hline $\begin{array}{l}\text { Echt Perga- } \\
\text { meatpapier }\end{array}$ & 0.5 & 12 & 6 & - \\
\hline
\end{tabular}

Die produktionsspezifischen Werte (kg/t Produkt) beziehen sich auf die dem wasserrechtlichen Bescheid zugrundeliegende Maschinenkapazitãt ausgedrückt in Menge Papier pro 24 Stunden. 
2.3 Den Werten der Nummern 2.1 und 2.2 liegen folgende oder gieichwertige Analysenverfahren zugrunde:

2.3.1 Absetzbare Stoffe als Volumenanteil

DIN $38409 \cdot \mathrm{H} 9 \cdot 2$

als Massenkonzentration:

(Ausgabe Juli 1980)

DIN 38409 - $\mathrm{H} 10$

(Ausgabe Juli 1980)

2.3.2 Abfiltrierbare Stoffe

DIN 38409 - $\mathrm{H} 2 \cdot 2$ -

2.3.3 Chemischer Sauerstoffbedar (CSB) von der abgesetzten Probe:

(Ausgabe Juli 1980)

\author{
DIN 38409 - H 41 \\ (Ausgabe
}

Dezember 1980)

2.3.4 Biochemischer Sauerstoffbedarf in 5 Tagen (BSBs) von der abgesetzten Probe:

DEV H 5 a 2

(8. Lieferung 1979) unter zusătzlicher

Hemmung der Nitrifikation mit $0.5 \mathrm{mg} / \mathrm{l}$

2.3.5 Fischgiftigkeit-als Allylthioharnstoff

Verdünnungsfaktor $\mathrm{G}_{\mathrm{F}}$ von

der nicht abgesetzten Probe: DIN 38412 L 20

(Ausgabe

Dezember 1980)

2.4 Ein in Nummer 2.1 und 2.2 bestimmter Wert ist einzuhalten. Er gilt mit Ausnahme des Wertes für Fischgiftigkeit auch als eingehalten, wenn das arithmetische Mittel der Ergebnisse aus den letzten fünf im Rahmen der staatlichen Gewãsseraúfsicht durchgeführten Untersuchungen diesen Wert nicht überschreitet. Ein in Nummer 2.1 für Fischgiftigkeit bestimmter Wert gilt auch als eingehalten, wenn die Ergebnisse der letzten fünf im Rahmen der staatlichen Gewässeraufsicht durchgefūhrten Untersuchungen diesen Wert in vier Fällen nicht überschreiten. Untersuchungen, die länger als drei Jahre zurückliegen, bleiben unberücksichtigt

Wird in einer Einzelprobe der für die absetzbaren Stoffe in Nummer 2.2 festgelegte Wert überschritten. so kann für die Bildung des arithmetischen Mittels $0.5 \mathrm{ml} / 1$ eingesetzt werden, wenn die Trockenmasse der abfiltrierbaren Stoffe $50 \mathrm{mg} / \mathrm{h}$ nicht übersteigt.

Bonn, den 15. Januar 1982

Der Bundeskanzler

Schmidt

Der Bundesminister des Innern

Baum

GMBI 1982 S. 59 
ANHANG 3

Marietta Jass-Teichmann - 978-3-631-75034-6 Downloaded from PubFactory at 01/11/2019 09:02:57AM via free access 
Marietta Jass-Teichmann - 978-3-631-75034-6 Downloaded from PubFactory at 01/11/2019 09:02:57AM via free access 
FRAGEBOGEN FUR DIE DEUTSCHEN PAPIERFABRIKEN

Sachbearbeiter:

Telefon:

1. Teil: Allgemeine Daten

1.1 Unternehmen:

Werk:

1.2 Bundesland:

1.3 Name des Vorfluters:

1.4 Firmendaten:

\begin{tabular}{|c|c|c|}
\hline & 1974 & 1985 \\
\hline $\begin{array}{l}\text { Umsatz (DM/Jahr) } \\
\text { Unternehmen }\end{array}$ & & \\
\hline Werk & & \\
\hline $\begin{array}{l}\text { Produktion ( } t / J a h r) \\
\text { Unternehmen }\end{array}$ & & \\
\hline Werk & & \\
\hline Exportanteil (Werk, $\%$ ) & & \\
\hline Beschäftigte & & \\
\hline Unternehmen & & \\
\hline Werk & & \\
\hline
\end{tabular}




\subsection{Produktionsprogramm}

(bitte in $\%$ angeben und auf volle $5 \%$ runden)

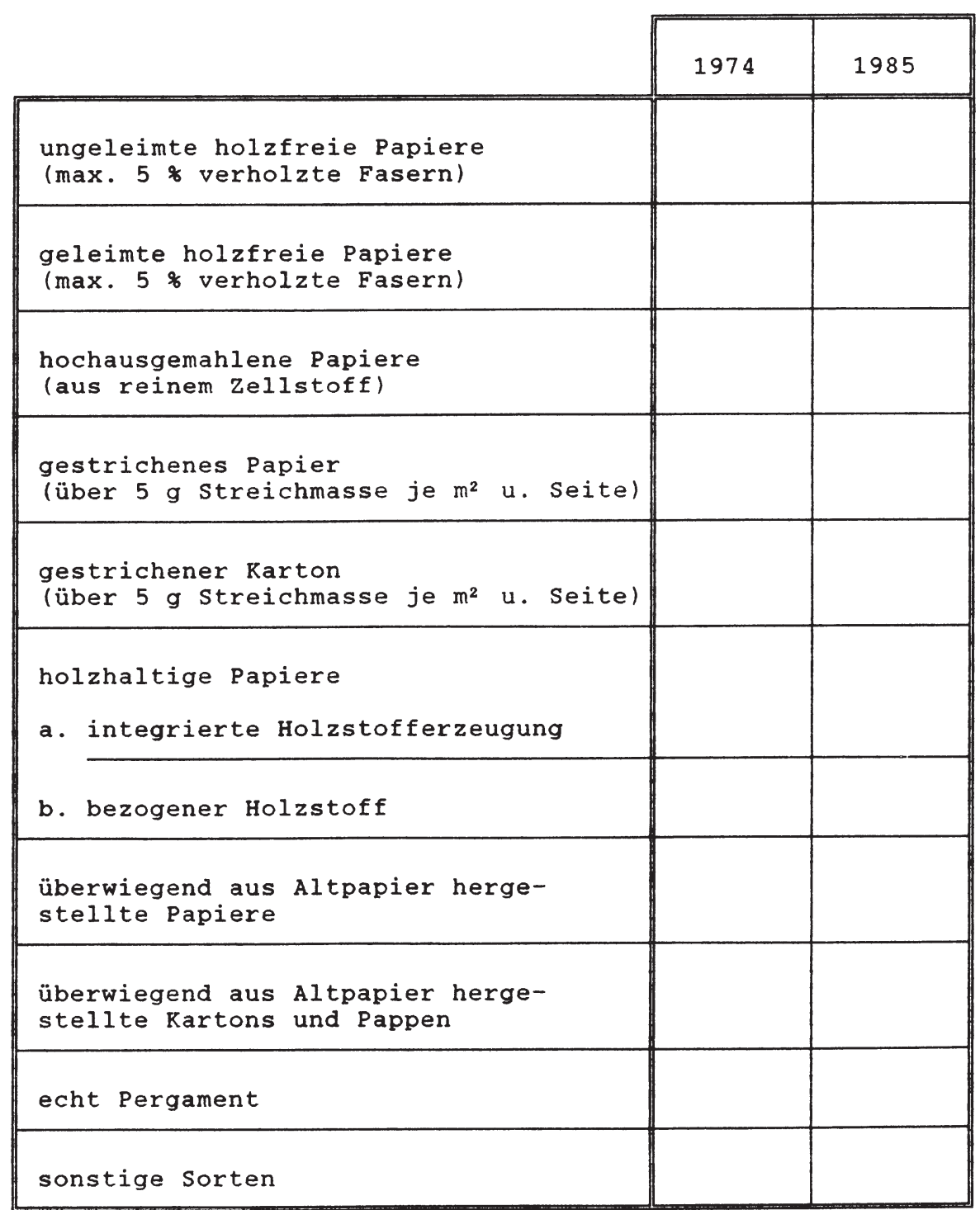




\subsection{Faserstoffeinsatz}

(bitte in $\%$ angeben und auf volle $5 \%$ runden)

\begin{tabular}{|l|l|l|}
\cline { 2 - 3 } \multicolumn{1}{c|}{} & 1974 & 1985 \\
\hline Zellstoff & & \\
\hline Holzstoff & & \\
\hline Altpapier & & \\
\hline sonst. Faserstoffe & & \\
\hline
\end{tabular}




\section{Teil Nachgeschaltete Maßnahmen}

\subsection{Art der Abwasserbehandlung}

\begin{tabular}{|c|c|c|c|c|c|}
\hline & 1974 & 1985 & $\begin{array}{l}\text { Planung } \\
\text { (Jahr) }\end{array}$ & $\begin{array}{l}\text { Bau- } \\
\text { beginn } \\
\text { (Jahr) }\end{array}$ & $\begin{array}{l}\text { Inbe- } \\
\text { trieb- } \\
\text { nahme } \\
\text { (Jahr) }\end{array}$ \\
\hline mechanische Reinigung & & & & & \\
\hline mech.-chem. Reinigung & & & & & \\
\hline biologische Reinigung & & & \multicolumn{3}{|c|}{ siehe unten } \\
\hline sonstige ${ }^{1}$ Reinigung & & & & & \\
\hline keine Reinigung & & & & & \\
\hline $\begin{array}{l}\text { geschlossenener } \\
\text { Kreislauf }\end{array}$ & & & & & \\
\hline
\end{tabular}

\begin{tabular}{|l|l|l|l|l|l|}
\hline Art der Biologie & 1974 & 1985 & Planung & $\begin{array}{l}\text { Bau- } \\
\text { beginn } \\
\text { (Jahr) }\end{array}$ & $\begin{array}{l}\text { Inbe- } \\
\text { trieb- } \\
\text { nahme } \\
\text { (Jahr) }\end{array}$ \\
\hline einstufig & & & & & \\
\hline zweistufig & & & & & \\
\hline Tropfkörper & & & & & \\
\hline andere & & & & & \\
\hline
\end{tabular}

1 z.B. Stähler-Matic, Scheibentropfkörper, Teich-Biologie 2 bitte Art angeben

Wurden 1974 bereits bestehende Reinigungsstufen bis 1985 vergrößert (z.B. Bau eines weiteren mechanischen Rlärbeckens)? Bitte Jahr der Planung, des Baubeginns und der Inbetriebnahme angeben . 
2.2 Für wieviel Einwohnergleichwerte (EGW) waren die Abwasserreinigungsanlagen ausgelegt?

1974

1985

2.3 Warum wurde( $n$ ) diese Investition(en) im Bereich der Kläranlage getätigt? (mehrere Antworten möglich)

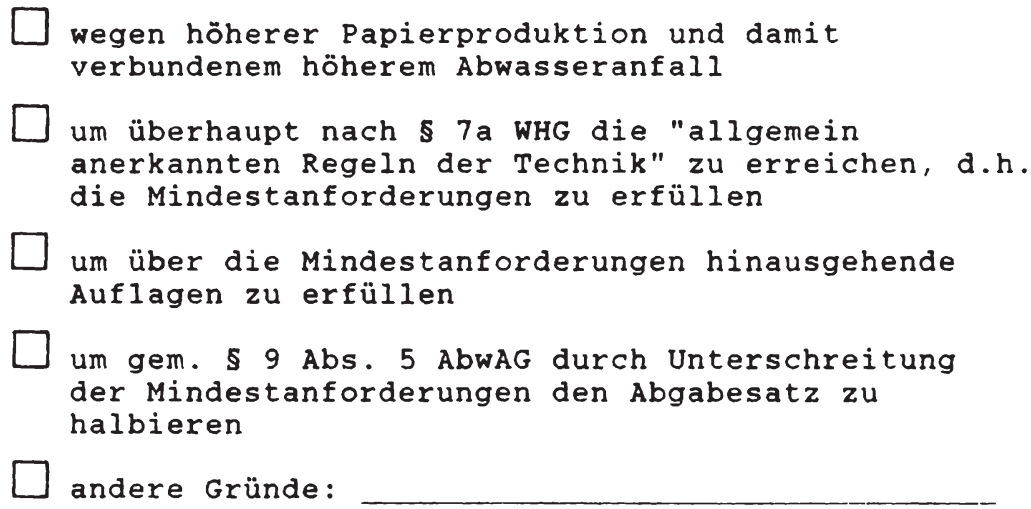

2.4 Geht Ihr Reinigungsstand wesentlich über die Erfüllung der Auflagen hinaus?<smiles>C1CCC1</smiles>

a) Wenn ja, hätten Sie den derzeitigen Reinigungsstand verwirklicht, wenn Sie keine Abwasserabgabe zahlen müßten?

$\square$ ja:

$\square$ nein

b) Wenn nein, hätten Sie den derzeitigen ReinigungsReinigungsstand verwirklicht, wenn sie zwar eine Abwasserabgabe zahlen, jedoch keine Auflagen erfüllen müßten?
$\square$ ja
nein 
2.5 Wurde die Durchführung der Maßnahmen im Zeitraum von 1974 bis 1985 beschleunigt durch (mehrere Antworten möglich)

die Mindestanforderungen nach $\$ 7$ a wHG über die Mindestanforderungen hinausgehende Auflagen

die Abwasserabgabe?

$\square$ Die Durchführung der Maßnahmen wurde nicht beschleunigt.

2.6 Wurden im Zeitraum von 1974 bis 1985 bereits bestehende Planungen verändert durch (mehrere Antworten möglich)

$\square$ die Mindestanforderungen nach $\$ 7$ a WHG

$\square$ über die Mindestanforderungen hinausgehende Auflagen

die Abwasserabgabe?

Die Pläne wurden nicht verändert.

2.7 Haben Sie finanzielle Hilfen wie

$\square$ Abgabenverminderung gemäß $\$ 10$ Abs. 3 AbwAG

$\square$ Erlaß der Abgabe

$\square$ zuwendungen aus dem Abgabeaufkommen (Zuschüsse oder Darlehen)

$\square$ steuerliche Erleichterungen

$\square$ sonstige Hilfen

$\square$ Rhein-Bodensee-Programm

in Anspruch genommen?

2.8 Wie hoch waren die Zuwendungen aus dem Abgabeaufkommen? DM : 


\subsection{Wie hoch waren}

die Investitionsausgaben für die Abwasserreinigungsanlagen (ohne Schlammbehandlung und -entsorgung) zwischen 1974 und 1985?

DM :

\begin{tabular}{|c|c|c|c|}
\hline & & 1974 & 1985 \\
\hline \multirow[t]{5}{*}{ die } & Betriebskosten (DM/Jahr) & & \\
\hline & Personal & & \\
\hline & Chemikalien & & \\
\hline & Energie & & \\
\hline & sonst. & & \\
\hline \multirow[t]{3}{*}{ der } & Kapitaldienst (DM/Jahr) & & \\
\hline & (kalk.) Abschreibungen & & \\
\hline & (kalk.) Zinsen & & \\
\hline
\end{tabular}




\subsection{Rückstände}

\begin{tabular}{|c|c|c|c|c|c|c|c|c|}
\hline & \multicolumn{8}{|c|}{ Verwertung } \\
\hline & \multicolumn{2}{|c|}{ Rückführung } & \multicolumn{2}{|c|}{ Deponie } & \multicolumn{2}{|c|}{ Verbrennung } & \multicolumn{2}{|c|}{ andere ${ }^{1}$} \\
\hline & 1974 & 1985 & 1974 & 1985 & 1974 & 1985 & 1974 & 1985 \\
\hline $\begin{array}{l}\text { Faserschlämme } \\
\text { mech.-chem. }\end{array}$ & & & & & & & & \\
\hline $\begin{array}{l}\text { Bio-Uberschuß- } \\
\text { schlamm }\end{array}$ & & & & & & & & \\
\hline
\end{tabular}

Falls Deponie, bitte Angabe

der Menge

1974:

t otro/Jahr

Falls Verbrennung, bitte Angabe

der Menge

1974 :

t otro/Jahr

1985:

t otro/Jahr

der Asche

1974 :

t otro/Jahr

1985:

t otro/Jahr

1 z.B. Kompostierung, Ziegelei; bitte angeben 1974 : t otro/Jahr

1985: t otro/Jahr 
2.11 Wie hoch waren

die Investitionsausgaben für die Schlammbehandlung und -entsorgung zwischen 1974 und 1985?

DM :

\begin{tabular}{|l|l|l|}
\hline \multicolumn{1}{|l|}{$\begin{array}{l}\text { die Betriebskosten (DM/Jahr, } \\
\text { einschl. Transport- und De- } \\
\text { poniekosten) }\end{array}$} & 1974 & 1985 \\
\hline der Rapitaldienst (DM/Jahr) & & \\
\hline $\begin{array}{l}\text { (kalk.) Abschreibungen } \\
\text { (kalk.) Zinsen }\end{array}$ & & \\
\hline
\end{tabular}

2.12 Wie hoch war der Anteil der Abwasserreinigungskosten (einschl. Schlammbehandlung und -entsorgung) an den gesamten Umweltschutzkosten (in $\%$ V.H.)?

$$
1974:
$$

1985:

2.13 Rönnen Sie die Abwasserreinigungskosten pro vermiedener Schadeinheit angeben?

ja, Betrag (DM/SE):

Jahr : nein

2.14 Wie hoch waren

\begin{tabular}{|l|l|l|}
\hline spez. Frischwasserverbrauch $\left(\mathrm{m}^{3} / \mathrm{t}\right)^{1}$ & & \\
\hline spez. Abwasseranfall $\left(\mathrm{m}^{3} / \mathrm{t}\right)^{1}$ & & \\
\hline Abwassermenge $\left(\mathrm{m}^{3} / \mathrm{Jah}\right)$ & & \\
\hline
\end{tabular}

1 bezogen auf Bruttoproduktion, Jahresdurchschnitt 


\section{Teil: Maßnahmen im Produktionsproze $\beta$}

3.1 Haben sie in der zeit von 1974 bis 1985 Investitionen innerhalb des Produktionsprozesses vorgenommen, um die Abwassermenge und/oder die -belastung zu reduzieren? Bitte Jahr der Planung, des Baubeginns und der Inbetriebnahme angeben.

3.2 Haben Sie diese Maßnahmen ergriffen (mehrere Antworten möglich),

um überhaupt die Mindestanforderungen nach $\$ 7$ a WHG zu erfüllen

$\square$ um über die Mindestanforderungen hinausgehende Auflagen zu erfüllen

$\square$ um gemäß $\$ 9$ Abs. 5 AbwAG durch Unterschreitung der Mindestanforderungen den Abgabesatz zu halbieren

$\square$ um über die bereits erreichte Halbierung hinaus die Abwasserwerte $z$ u verbessern und damit die Regelbzw. Bezugswerte weiter zu senken

als Resultat allgemeiner Wirtschaftlichkeits-, Rationalisierungs- oder Rostenüberlegungen?

$\square$ sonstige Gründe: 
3.3 Wie hoch waren

die Investitionsausgaben der in 3.1 angegebenen Maßnahmen?

DM :

\begin{tabular}{|c|c|c|c|}
\hline & \\
\hline & & 1974 & 1985 \\
\hline \multirow[t]{5}{*}{ die } & Betriebskosten (DM/Jahr) & & \\
\hline & Personal & & \\
\hline & Chemikalien & & \\
\hline & Energie & & \\
\hline & sonst. & & \\
\hline \multirow[t]{3}{*}{ der } & Kapitaldienst (DM/Jahr) & & \\
\hline & Abschreibungen & & \\
\hline & (kalk. Zinsen) & & \\
\hline
\end{tabular}




\section{Teil: Maßnahmen im Produktbereich}

4.1 Bestehen in Ihrem Unternehmen Untersuchungen über den unterschiedlichen spez. Abwasseranfall und/oder

über die unterschiedliche Abwasserbelastung

der von Ihnen hergestellten Papiersorten?

$\square$ Es liegen keine Untersuchungen vor.

4.2 Haben Sie aufgrund dieser Ergebnisse

$\square$ das sortiment verändert (z.B. Elimination einer Papiersortel

$\square$ mengenmäßige Verschiebungen zwischen den sorten vorgenommen

$\square$ die Produktion bestimmter sorten an einen anderen standort verlagert

$\square$ Verschiebungen zu einem "papierfremden" Produktbereich vorgenommen?

$\square$ Es wurden trotz unterschiedlichen Abwasseranfalls und/oder unterschiedlicher Abwasserbelastung keine veränderungen vorgenommen.

$\square$ Es wurden keine Veränderungen vorgenommen, da sich die Papiersorte bzgl. des Abwassers nicht wesentlich unterscheiden.

4.3 Haben Sie die Rezepturen (Faserstoffe, Hilfsstoffe bzgl. Menge und Art) wegen der abgaberechtlichen Bestimmungen verändert?
$\square$ ja
$\square$ nein 


\section{Teil: Wasserrechtliche Rahmenbedingungen und Abgabenerhebung}

5.1 Wird die Abwasserabgabe nach

$\square$ einem Bescheid ( $\$ 4$ AbwAG)

oder

$\square$ einer Erklärung ( 56 AbwAG)

ermittelt?

5.2 Wurde die Bescheidumstellung durchgeführt?

$\square$ ja, Jahr:

$\square$ nein

5.3 Wie häufig wird das Abwasser von Seiten der Behörden untersucht?

Durchschnittliche Anzahl/Jahr:

5.4 Führen Sie Ihre Untersuchungen selbst durch oder geben Sie diese in Auftrag?

Müssen Sie die gemessenen Werte den Behörden vorlegen?

$\square$ nein

5.5 Werden bei Ihnen Teilstrommessungen durchgeführt, die Grundlage für die Abgaberechnung sind?<smiles>C1CCCC1</smiles>

$\square$ nein

5.6 Wird ein Vorwegabzug bei der Abgabeberechnung gewährt, der über dem des Abwasserabgabengesetzes (Anlage zu \$ 3) liegt?

$\square$ ja:

$\square$ nein 
5.7 Wie hoch sind die Grenzwerte und die Jahresschmutzwassermenge im umgestellten Bescheid, und haben sich diese Werte bis 1985 verändert? Wenn die Bescheidumstellung noch nicht erfolgt ist, bitte die Erklärungswerte und, falls vorhanden, die ubbrwachungswerte der Jahre 1981 und 1985 angeben.

\begin{tabular}{|c|c|c|c|c|c|}
\hline & Regelwerte & \multicolumn{2}{|c|}{ Uberwachungswerte } & \multicolumn{2}{|c|}{ Höchstwerte } \\
\hline & $19 \ldots \mid 1985$ & 19. & 1985 & $19 \ldots$ & 1985 \\
\hline absetzbare stoffe $(\mathrm{ml} / \mathrm{l})$ & & & & & \\
\hline CSB， DIN $38 \quad 409 \mathrm{~T}^{1} \quad(\mathrm{mg} / \mathrm{l})$ & & & & & \\
\hline $\mathrm{BSB}_{5}$ DIN $38 \quad 409$ T5 $5^{1} \quad(\mathrm{mg} / \mathrm{l})$ & & & & & \\
\hline Fischgiftigkeit, DIN 38412 T20 & & & & & \\
\hline
\end{tabular}

Jahresschmutzwassermenge 1 t. Bescheid ( $\left.\mathrm{m}^{3} / \mathrm{Jahr}\right)$,

(auch $1 /$ sec. etc.)

Jahresschmutzwassermenge bei der Abgabenerhebung 
5.8 Wie hoch waren die Abwasserabgabe, die Anzahl der Schadeinheiten und die jeweilige Jahresproduktion (brutto)?

\begin{tabular}{|l|l|l|l|}
\cline { 2 - 4 } \multicolumn{1}{c|}{} & $\begin{array}{l}\text { Abwasserabgabe } \\
\text { (DM/Jahr })\end{array}$ & $\begin{array}{l}\text { Schadeinheiten } \\
\text { (SE/Jahr) }\end{array}$ & $\begin{array}{l}\text { Produktion } \\
\text { (t/Jahr) }\end{array}$ \\
\hline 1981 & & & \\
\hline 1982 & & & \\
\hline 1983 & & & \\
\hline 1984 & & & \\
\hline 1985 & & & \\
\hline
\end{tabular}


Abschließende Fragen

1. Haben Sie eine Kostenstelle für Abwasser eingerichtet?<smiles>C1CCC1</smiles>

2. Abwasserabgabe und Preiskalkulation

$\square$ ja $\square$ nein

3. Meinen Sie, daß Sie aufgrund des Abwasserabgabengesetzes

a. an nationaler Wettbewerbsfähigkeit

$\square$ gewonnen

$\square$ verloren

$\square$ Ihre Position nicht verändert

haben?

b. an internationaler Wettbewerbsfähigkeit

verloren

$\square$ Ihre position nicht verändert

haben? 
ANHANG 4

Marietta Jass-Teichmann - 978-3-631-75034-6 Downloaded from PubFactory at 01/11/2019 09:02:57AM via free access 
Marietta Jass-Teichmann - 978-3-631-75034-6 Downloaded from PubFactory at 01/11/2019 09:02:57AM via free access 
FRAGEBOGEN FOR DIE SCHWEIZERISCHEN PAPIERFABRIREN

Sachbearbeiter :

Telefon:

1. Teil: Allgemeine Daten

1.1 Unternehmen:

Werk :

1.2 Kanton:

1.3 Name des Vorfluters:

1.4 Firmendaten (Angaben jeweils bezogen auf die betroffene Produktionsstätte):

\begin{tabular}{|l|l|l|}
\hline \multicolumn{1}{c|}{} & 1974 & 1985 \\
\hline Umsatz (SF/Jahr) & & \\
\hline Produktion (t/Jahr) & & \\
\hline
\end{tabular}


1.5 Produktgruppe

(bitte in $\%$ Angeben und auf volle $5 \%$ runden)

\begin{tabular}{|l|l|l|}
\cline { 2 - 3 } \multicolumn{1}{c|}{} & 1974 & 1985 \\
\hline Graphische Papiere & & \\
\hline Papier für Verpackungszwecke & & \\
\hline Karton/Pappe für Verpackungszwecke & & \\
\hline Hygiene-Papiere & & \\
\hline Technische u. Spezial-Papiere & & \\
\hline Technische und Spezial-Pappen & & \\
\hline
\end{tabular}

1.6 Faserstoffeinsatz

(bitte in $\%$ angeben und auf volle $5 \%$ runden)

\begin{tabular}{|l|l|l|}
\cline { 2 - 3 } \multicolumn{1}{c|}{} & 1974 & 1985 \\
\hline Zellstoff & & \\
\hline Holzstoff & & \\
\hline Altpapier & & \\
\hline sonst. Faserstoffe & & \\
\hline
\end{tabular}




\section{Teil Nachgeschaltete Maßnahmen}

\subsection{Art der Abwasserbehandlung}

\begin{tabular}{|c|c|c|c|c|c|}
\hline & 1974 & 1985 & $\begin{array}{l}\text { Planung } \\
\text { (Jahr) }\end{array}$ & $\begin{array}{l}\text { Bau- } \\
\text { beginn } \\
\text { (Jahr) }\end{array}$ & $\begin{array}{l}\text { Inbe- } \\
\text { trieb- } \\
\text { nahme } \\
\text { (Jahr) }\end{array}$ \\
\hline mechanische Reinigung & & & & & \\
\hline mech.-chem. Reinigung & & & & & \\
\hline biologische Reinigung & & & \multicolumn{3}{|c|}{ siehe unten } \\
\hline sonstige ${ }^{1}$ Reinigung & & & & & \\
\hline keine Reinigung & & & & & \\
\hline $\begin{array}{l}\text { geschlossenener } \\
\text { Kreislauf }\end{array}$ & & & & & \\
\hline
\end{tabular}

\begin{tabular}{|l|l|l|l|l|l|}
\hline Art der Biologie & 1974 & 1985 & Planung & $\begin{array}{l}\text { Bau- } \\
\text { beginn } \\
\text { (Jahr) }\end{array}$ & $\begin{array}{l}\text { Inbe- } \\
\text { trieb- } \\
\text { nahme } \\
\text { (Jahr) }\end{array}$ \\
\hline einstufig & & & & & \\
\hline zweistufig & & & & & \\
\hline Tropfkörper & & & & & \\
\hline andere & & & & & \\
\hline
\end{tabular}

1 z.B. Stähler-Matic, Scheibentropfkörper, Teich-Biologie 2 bitte Art angeben

Wurden 1974 bereits bestehende Reinigungsstufen bis 1985 vergrößert (z.B. Bau eines weiteren mechanischen Klärbeckens)? Bitte Jahr der Planung, des Baubeginns und der Inbetriebnahme angeben. 
2.2 Warum wurde( $n$ ) diese Investition(en) im Bereich der Abwasserreinigiungsanlagen getätigt (mehrere Antworten möglich)?

$\square$ wegen höherer Papierproduktion und damit verbundenem höheren Abwasseranfall

$\square$ die Auflagen zu erfülien

$\square$ andere Gründe:

2.3 Haben Sie finanzielle Hilfen wie

$\square$ steuerliche Erleichterungen

$\square$ Zuschüsse vom Bund/Ranton

$\square$ sonst. Hilfen:

in Anspruch genommen? 
2.4 Wie hoch waren die

Investitionsausgaben für die Abwasserreinigungsanlagen

(incl. Schlammbehandlung und -entsorgung) zwischen 1974 und 1985?

SF :

\begin{tabular}{|c|c|c|}
\hline & 1974 & 1985 \\
\hline \multicolumn{3}{|l|}{ Betriebskosten (SF/Jahr) } \\
\hline \multicolumn{3}{|l|}{ Personal } \\
\hline \multicolumn{3}{|l|}{ Chemikalien } \\
\hline \multicolumn{3}{|l|}{ Energie } \\
\hline \multicolumn{3}{|l|}{ Transport u. Deponie } \\
\hline \multicolumn{3}{|l|}{ sonst. } \\
\hline \multicolumn{3}{|l|}{ Kapitaldienst (SF/Jahr) } \\
\hline (kalk.) Abschreibungen & & \\
\hline (kalk.) Zinsen & & \\
\hline
\end{tabular}




\subsection{Wie hoch waren}

\begin{tabular}{|l|l|l|l|}
\hline \multicolumn{1}{c|}{} & 1974 & 1981 & 1985 \\
\hline spez. Abwasseranfall $\left(\mathrm{m}^{3} / \mathrm{t}\right)^{1}$ & & & \\
\hline Abwassermenge $\left(\mathrm{m}^{3} / \mathrm{Jahr}\right)$ & & & \\
\hline
\end{tabular}

1 bezogen auf die Bruttoproduktion, Jahresdurchschnitt

2.6 Wie hoch waren (bitte Durchschnittswerte angeben)

\begin{tabular}{|l|l|l|l|}
\hline Ablauf, Vorfluter & 1974 & 1981 & 1985 \\
\hline CSB $(\mathrm{mg} / \mathrm{l})$ & & & \\
\hline BSBs $(\mathrm{mg} / \mathrm{l})$ & & & \\
\hline Absetzbare Stoffe $(\mathrm{ml} / \mathrm{l})$ & & & \\
\hline
\end{tabular}




\subsection{Rückstände}

\begin{tabular}{|c|c|c|c|c|c|c|c|c|}
\hline & \multicolumn{8}{|c|}{ Verwertung } \\
\hline & \multicolumn{2}{|c|}{ Rückführung } & \multicolumn{2}{|c|}{ Deponie } & \multicolumn{2}{|c|}{ Verbrennung } & \multicolumn{2}{|c|}{ andere ${ }^{1}$} \\
\hline & 1974 & 1985 & 1974 & 1985 & 1974 & 1985 & 1974 & 1985 \\
\hline $\begin{array}{l}\text { Faserschlämme } \\
\text { mech.-chem. }\end{array}$ & & & & & & & & \\
\hline $\begin{array}{l}\text { Bio-Uberschuß- } \\
\text { schlamm }\end{array}$ & & & & & & & & \\
\hline
\end{tabular}

Falls Deponie, bitte Angabe

der Menge

1974:

t otro/Jahr

1985:

t otro/Jahr

Falls Verbrennung, bitte Angabe

der Menge

1974:

t otro/Jahr

1985:

t otro/Jahr

der Asche

1974:

t otro/Jahr

1985:

t otro/Jahr

1 z.B. Kompostierung, Ziegelei; bitte angeben

$1974:$

t otro/Jahr

1985 :

t otro/Jahr 
3. Teil: Maßnahmen im Produktionsprozeß

3.1 Haben sie in der zeit von 1974 bis 1985 Investitionen innerhalb des Produktionsprozesses vorgenommen, um die Abwassermenge und/oder die -belastung zu reduzieren? Bitte Jahr der Planung und der Inbetriebnahme angeben.

3.2 Haben Sie diese Maßnahmen ergriffen (mehrere Antworten möglich)

um die Auflagen zu erfüllen?

$\square$ als Resultat allgemeiner Wirtschaftlichkeits-, Rationalisierungs- oder Kostenüberlegungen?

$\square$ sonstige Gründe: 


\section{Teil: Wasserrechtliche Rahmenbedingungen}

4.1 Wie häufig wird das Abwasser von Seiten der Behörde untersucht?

Durchschnittliche Anzahl/Jahr:

4.2 Müssen Sie die von Ihnen gemessenen Abwasserwerte den Behörden vorlegen?

ja

nein

4.3 Wie hoch waren die Grenzwerte und, falls vorgegeben, die maximale Jahresschmutzwassermenge 1981 und 1985?

\begin{tabular}{|l|l|l|}
\hline & 1981 & 1985 \\
\hline $\begin{array}{l}\text { Absetzbare Stoffe } \\
\text { (ml/1), Fracht }\end{array}$ & & \\
\hline CSB (mg/l), Fracht & & \\
\hline BSBs (mg/l), Fracht & & \\
\hline $\begin{array}{l}\text { Jahresschmutzwassermenge } \\
\text { (m³/Jahr), (1/sec.) etc. }\end{array}$ & & \\
\hline
\end{tabular}


4.4 Wann wurden diese Grenzwerte festgelegt?

4.5 Wie wurden die Grenzwerte ermittelt (mehrere Antworten möglich)?

$\square$ aus Erfahrungswerten mit der Abwasserreinigungsanlage

$\square$ unter Berücksichtigung zukünftiger Produktionssteigerungen

$\square$ nach den allgemeinen Regeln der Technik sonst. : 


\title{
SOZIALÖKONOMISCHE SCHRIFTEN
}

\author{
Herausgegeben von Prof. Dr. Bert Rürup
}

Band 1 Marietta Jass: Erfolgskontrolle des Abwasserabgabengesetzes. Ein Konzept zur Erfassung der Gesetzeswirkungen verbunden mit einer empirischen Untersuchung in der Papierindustrie. 1990. 


\section{Walter Bückmann / Peter Cebulla / Burkhard Draeger/ Melitta Patzak / Alexander Voegele}

\section{Theoretische Aspekte des Bodenschutzes unter besonderer Berücksichtigung der Bodenschutzkonzeption der Bundesregierung}

Frankfurt/M., Bern, New York, 1986. VI, 268 S.

Europäische Hochschulschriften: Reihe 2, Rechtswissenschaft. Bd. 488

ISBN 3-8204-8517-1

br. sFr. 58.--

Die Probleme des Bodenschutzes sind in den Vordergrund des politischen und theoretischen Interesses gerückt. Die Studie behandelt grundlagen- und fachtheoretische Fragen des Umweltschutzes, die über die Bodenschutzprobleme im engeren Sinne hinausgehen. Sie analysiert das theoretisch/methodische Instrumentarium einiger für den Bodenschutz zuständiger und daher besonders wesentlicher Fachdisziplinen unter dem Aspekt der Brauchbarkeit für den politischen und administrativen Regelungs- und Handlungsbedarf. Die Relevanz der Untersuchung ergibt sich aus mehreren Aspekten, insbesondere etwa daraus, daß Recht und Politik von der Theorie die Benennung der die Bodenbelastungsproblematik kennzeichnenden Umweltstandards - Indikatoren - für rechtliche und planerische Festlegungen oder gar aussagefähige Systemmodelle erwarten, diese jedoch nur dann formuliert werden können, wenn die wesentlichen Fragen von der Wissenschaft hinreichend erforscht sind.

Aus dem Inhalt: Diskussion der Bodenschutzkonzeption der Bundesregierung - Ökologische Aspekte des Bodenschutzes - Ökonomische Aspekte des Bodenschutzes - Juristische Probleme des Bodenschutzes - Umweltschutz in grundlagentheoretischer Sicht.

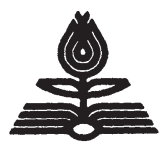

Verlag Peter Lang Frankfurt a.M. Bern - New York · Paris Auslieferung: Verlag Peter Lang AG, Jupiterstr. 15, CH-3000 Bern 15 Telefon (004131) 321122, Telex pela ch 912 651, Telefax (004131) 321131

- Preisänderungen vorbehalten - 


\section{Axel Nawrath}

\section{Die Haftung für Schäden durch Umweltchemikalien \\ Eine Untersuchung über die Strukturen und die Leistungsfähigkeit des bestehenden Schadensrechts}

Frankfurt/M., Bern, 1982.269 S.

Europäische Hochschulschriften: Reihe 2, Rechtswissenschaft Bd. 282

ISBN 3-8204-7000-X br. sFr. 66.--

Der Verfasser stellt sich die Aufgabe, die Strukturen und die Leistungsfähigkeit des bestehenden Schadensrechts bei Schäden durch Umweltchemikalien zu analysieren, nachdem durch das Ende der letzten Legislaturperiode verabschiedete Chemikaliengesetz das Recht der Chemikalien als ein besonderer, die bisherigen medienbezogenen Regelungen überlagernder Rechtsbereich konstituiert worden ist. Nach der Bestimmung der den schadensrechtlich relevanten Bereich der $\mathrm{Ge}-$ fahren durch Umweltchemikalien kennzeichnenden typischen Merkmale und ihrer Abgrenzung zu anderen Chemikaliengefahren untersucht der Verfasser die bestehenden schadensrechtlichen Vorschriften anhand der jeweils miteingeschlossenen stofflichen Gefahren, geschützten Umweltmedien, Verursachungsquellen, Verursachungsund Schadentypen im Hinblick darauf, welche Risiken durch Umweltchemikalien sie aufgreifen, und wie sie die durch Umweltchemikaliengefahren verursachten Schäden dem jeweiligen Verursacher zurechnen.

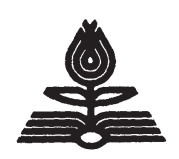

Verlag Peter Lang Frankfurt a.M. B Bern $\cdot$ New York $\cdot$ Paris Auslieferung: Verlag Peter Lang AG, Jupiterstr. 15, CH-3000 Bern 15 Telefon (004131) 321122, Telex pela ch 912 651, Telefax (004131) 321131

- Preisănderungen vorbehalten - 
Johannes M. Meinel

\section{Umweltstrafrecht und Umweltkriminalität in den USA}

Eine Untersuchung zur Bekämpfung illegaler

Umweltbelastungen durch Gewässerverunreinigung und Sonderabfallbeseitigung in den Vereinigten Staaten

Frankfurt/M., Bern, New York, Paris. XX, 341 S.

Europäische Hochschulschriften: Reihe 2, Rechtswissenschaft.

Bd. 688

ISBN 3-8204-9947-4 br./lam. sFr. 70.--

Der Autor zeigt in einer Analyse des U.S.-amerikanischen Umweltstrafrechts mit vielen typischen Fällen aus der Strafrechtspraxis, daß der Einsatz von Kriminalstrafen im wesentlichen auf vorsätzliche Umweltverstöße von Industrie und Gewerbe beschränkt bleibt. Die Verfolgungspolitik der Umweltbehörden, insbesondere die der U.S. Environmental Protection Agency, konzentriert sich zudem auf schwere Umweltverstöße. Seit Beginn der 80er Jahre haben Kriminalstrafen im umweltrechtlichen Vollzug erheblich an Bedeutung gewonnen. Aus der Sicht der Umweltbehörden ist ihr gezielter und selektiver Einsatz wichtiger Bestandteil einer kooperativen Vollzugsstrategie.

Aus dem Inhalt: U.a. Die Sanktionstatbestände des modernen Umweltrechts - Die Durchsetzung von Sanktionen im Umweltrecht Vorgehensweise und Verfolgungspolitik der U.S. Environmental Protection Agency.

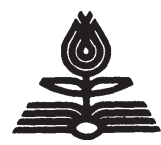

Verlag Peter Lang Frankfurt a.M. $\cdot$ Bern $\cdot$ New York $\cdot$ Paris Auslieferung: Verlag Peter Lang AG, Jupiterstr. 15, CH-3000 Bern 15 Telefon (004131) 321122, Telex pela ch 912 651, Telefax (004131) 321131

- Preisänderungen vorbehalten - 